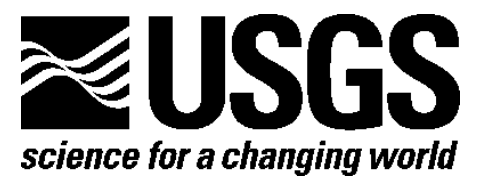

\title{
A Ground-Based Magnetic Survey of Frenchman Flat, Nevada National Security Site and Nevada Test and Training Range, Nevada-Data Release and Preliminary Interpretation
}

By Jeffrey D. Phillips, Bethany L. Burton, Erika Curry-Elrod, and Sigmund Drellack

Open-File Report 2014-1187 


\section{U.S. Department of the Interior \\ SALLY JEWELL, Secretary}

\section{U.S. Geological Survey \\ Suzette M. Kimball, Acting Director}

U.S. Geological Survey, Reston, Virginia: 2014

For more information on the USGS-the Federal source for science about the Earth,

its natural and living resources, natural hazards, and the environment-visit

http://www.usgs.gov or call 1-888-ASK-USGS

For an overview of USGS information products, including maps, imagery, and publications, visit $h$ ttp://www.usgs.gov/pubprod

To order this and other USGS information products, visit $h$ ttp://store.usgs.gov

Suggested citation:

Phillips, J.D., Burton, B.L., Curry-Elrod, Erika, and Drellack, Sigmund, 2014, A ground-based magnetic survey of Frenchman Flat, Nevada National Security Site and Nevada Test and Training Range, Nevada-Data release and preliminary interpretation: U.S. Geological Survey Open-File Report 2014-1187, 144 p., 1 pl., http://dx.doi.org/10.3133/ofr20141187.

ISSN 2331-1258 (online)

Any use of trade, product, or firm names is for descriptive purposes only and does not imply endorsement by the U.S. Government.

Although this information product, for the most part, is in the public domain, it also may contain copyrighted materials as noted in the text. Permission to reproduce copyrighted items must be secured from the copyright owner. 


\section{Contents}

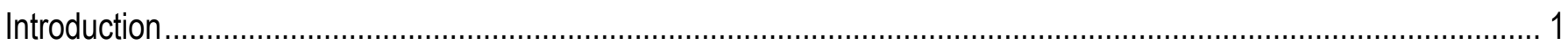

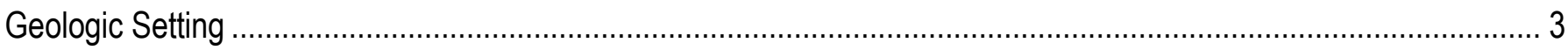

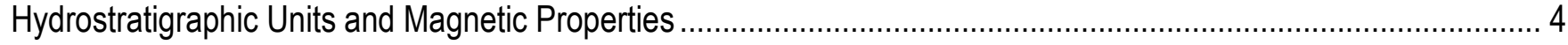

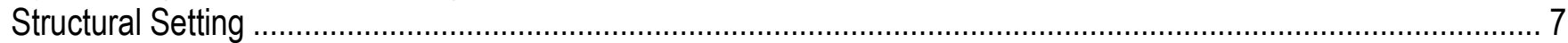

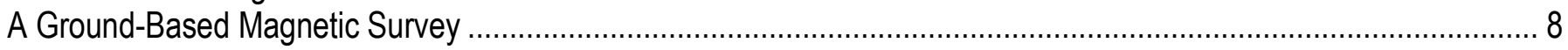

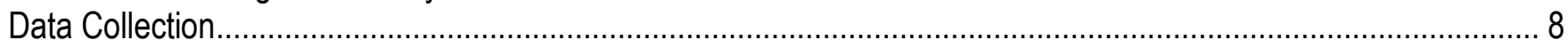

Analysis and Interpretation of the Magnetic-Profile Data ……....................................................................... 9

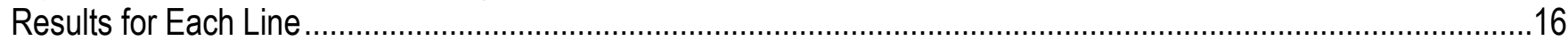

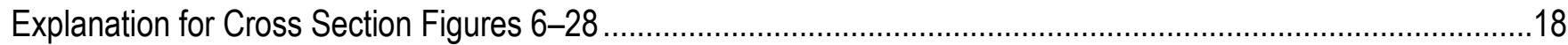

Line A

Line B

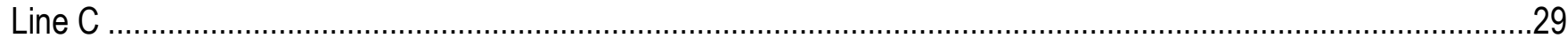

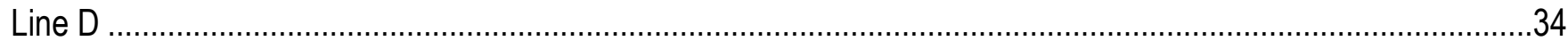

Line E

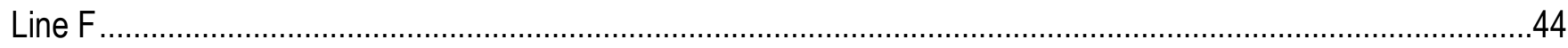

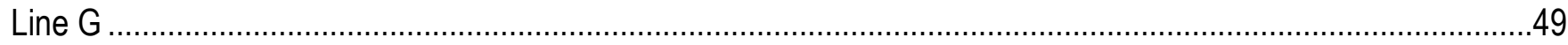

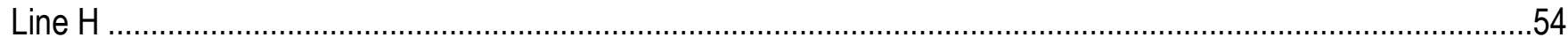

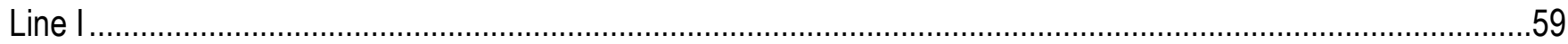

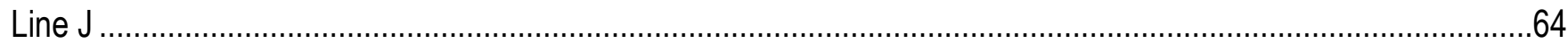

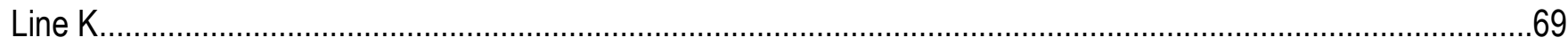

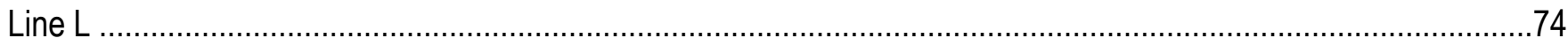

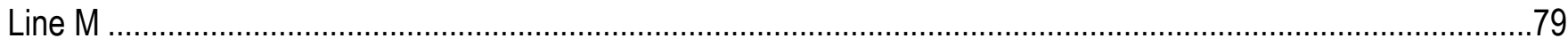

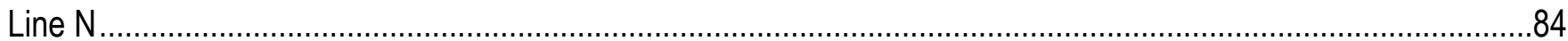

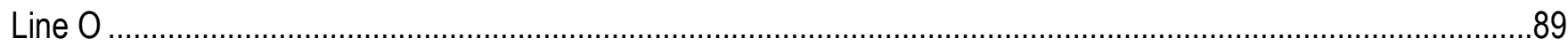

Line P

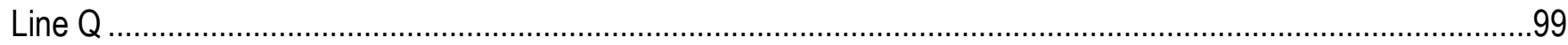

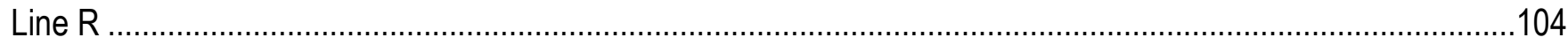

Line S

Line T

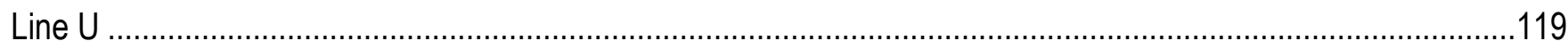

Line V

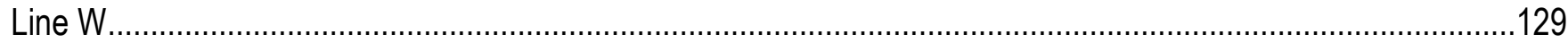

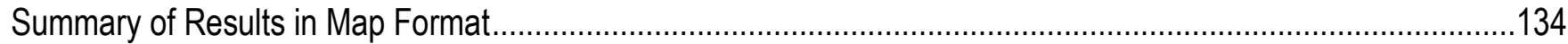

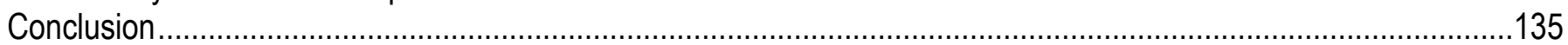

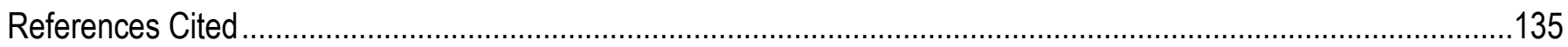

Appendix A. Ground Magnetic Data as Collected....................................................................................137

Appendix B. Ground Magnetic Data Reordered into Lines .........................................................................137

Appendix C. U.S. Geological Survey Procedure for Ground-Based Magnetic Data Collection..................................139

Appendix D. Previous Geophysical Work ……………………............................................................144

Geology of Northern Frenchman Flat, Nevada Test Site_USGS Report-474-216/NTS-188 .................................144 


\section{Plate}

Frenchman Flat ground-based magnetic survey showing unfiltered magnetic profile dataand interpreted faults (black) and edge of basalt (red)

\section{Figures}

1. Index map showing the locations of Frenchman Flat and the study area within the Nevada National Security Site

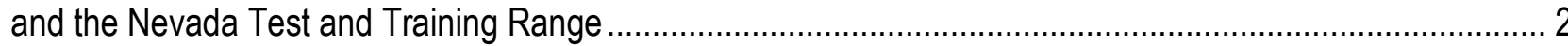

2. Color scale for the three-dimensional EarthVision hydrostratigraphic model with geologic descriptions ................... 5

3. Raw magnetic-profile data after removal of the diurnal field plotted as colored dots on a hydrostratigraphic-unit base map with alluvial units above the basalt removed ........................................................................11

4. Synthetic magnetic profile.

5. Synthetic magnetic profile as in figure 4

6. Line A. A. The hydrostratigraphic cross-section along Line A as predicted by the EarthVision (EV) model. B. Horizontal Gradient (HG) depth solutions for horizontal sheet sources. C. Multiple-source Werner (MSW) depth solutions (gray symbols) for sheet sources from the magnetic field upward continued by $200 \mathrm{ft}$. D. Analytic Signal (AS) depth solutions for contacts (light green "C" symbols with dip lines) and sheet edges (dark green "S" symbols with dip lines) as calculated from the magnetic field upward continued by $200 \mathrm{ft}$

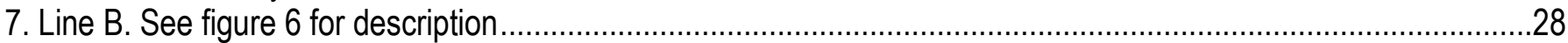

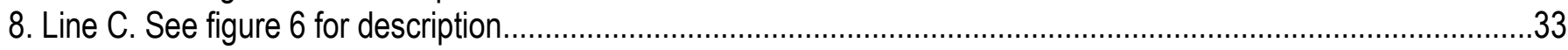

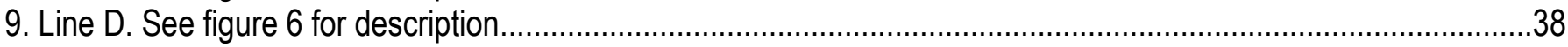

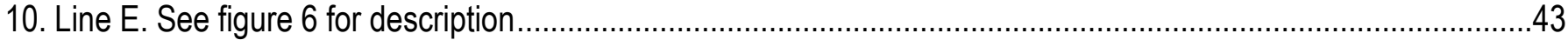

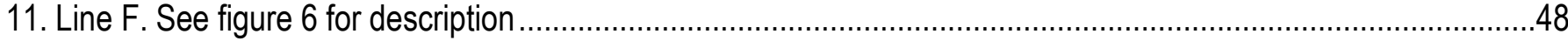

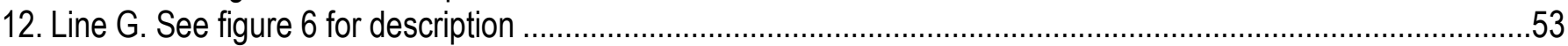

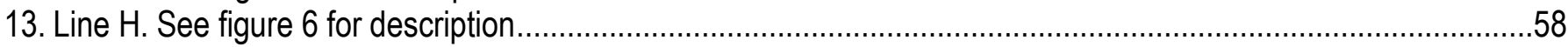

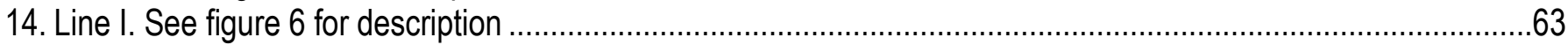

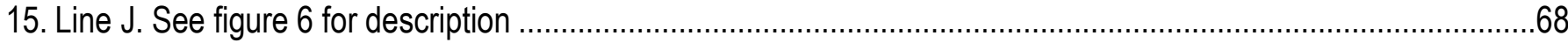

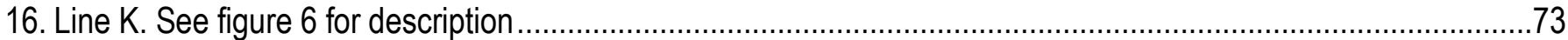

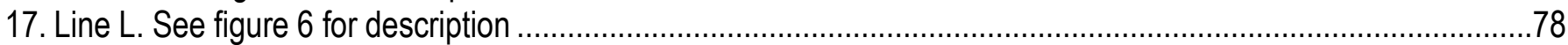

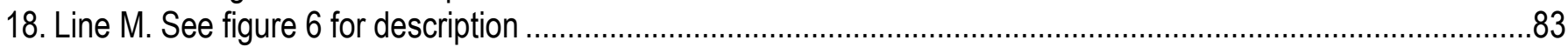

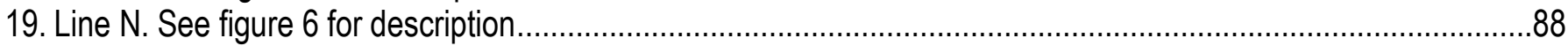

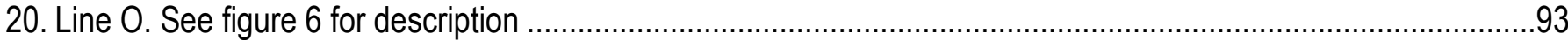

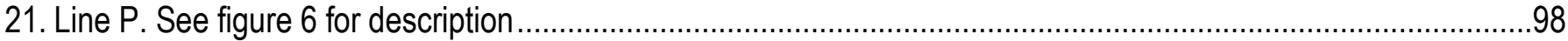

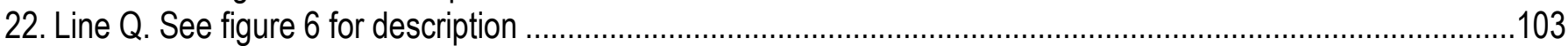

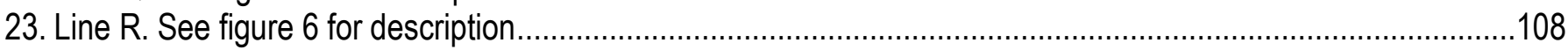

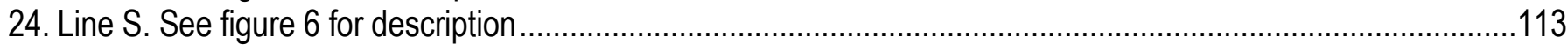

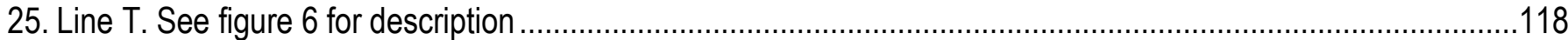

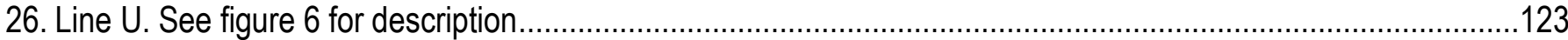

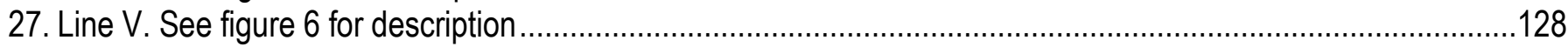

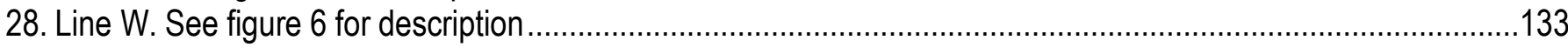




\section{Conversion Factors}

Inch/Pound to SI

\begin{tabular}{lll}
\hline & \multicolumn{1}{c}{ Multiply } & \multicolumn{1}{c}{ To obtain } \\
\hline & Length & \\
\hline foot (ft) & 0.3048 & meter (m) \\
mile (mi) & 1.609 & kilometer $(\mathrm{km})$ \\
\hline
\end{tabular}

SI to Inch/Pound

\begin{tabular}{|c|c|c|}
\hline Multiply & By & To obtain \\
\hline \multicolumn{3}{|c|}{ Length } \\
\hline meter $(\mathrm{m})$ & 3.281 & foot $(\mathrm{ft})$ \\
\hline kilometer (km) & 0.6214 & mile (mi) \\
\hline
\end{tabular}

Vertical coordinate information is referenced to the North American Vertical Datum of 1929 (NGVD 29)

Horizontal coordinate information is referenced to the North American Datum of 1927 (NAD 27)

Altitude, as used in this report, refers to distance above the vertical datum.

\section{Abbreviations}

3-D

AA

$\mathrm{A} / \mathrm{m}$

AS

BLFA

CAU

DOE

EV

GPS

HFM

$\mathrm{HG}$

HSU

IGRF

LCA

$\mathrm{LCCU}$

LTCU

LVTA

MSW

NNSA

NNSS

NSO

nT

NTTR

OAA three-dimentional

alluvial aquifer

ampere per meter

Analytic Signal

Basalt lava flow aquifer

Corrective Action Unit

U.S. Department of Energy

EarthVision

global positioning system

Hydrostratigraphic Framework Model

Horizontal Gradient

hydrostratigraphic unit

International Geomagnetic Reference Field

lower carbonate aquifer

lower clastic confining unit

lower tuff confining unit

lower vitric tuff aquifer

Multiple-Source Werner

National Nuclear Security Administration

Nevada National Security Site

Nevada Site Office

nanotesla

Nevada Test and Training Range

older altered alluvium 
TMWTA Timber Mountain welded-tuff aquifer

TMLVTA Timber Mountain lower vitric-tuff aquifer

TSA Topopah Springs aquifer

UGT underground test

UGTA Underground Test Area

USGS U.S. Geological Survey

VCU volcaniclastic confining unit

WCU Wahmonie confining unit 


\section{A Ground-Based Magnetic Survey of Frenchman Flat, Nevada National Security Site and Nevada Test and Training Range, Nevada-Data Release and Preliminary Interpretation}

By Jeffrey D. Phillips, Bethany L. Burton, Erika Curry-Elrod, and Sigmund Drellack

\section{Introduction}

The Nevada National Security Site (NNSS, formerly the Nevada Test Site) is located in southern Nevada approximately 105 kilometers (km) (65 miles) northwest of Las Vegas. Frenchman Flat is a sedimentary basin located on the eastern edge of NNSS and extending eastward into the adjacent Nevada Test and Training Range (NTTR, fig. 1). 


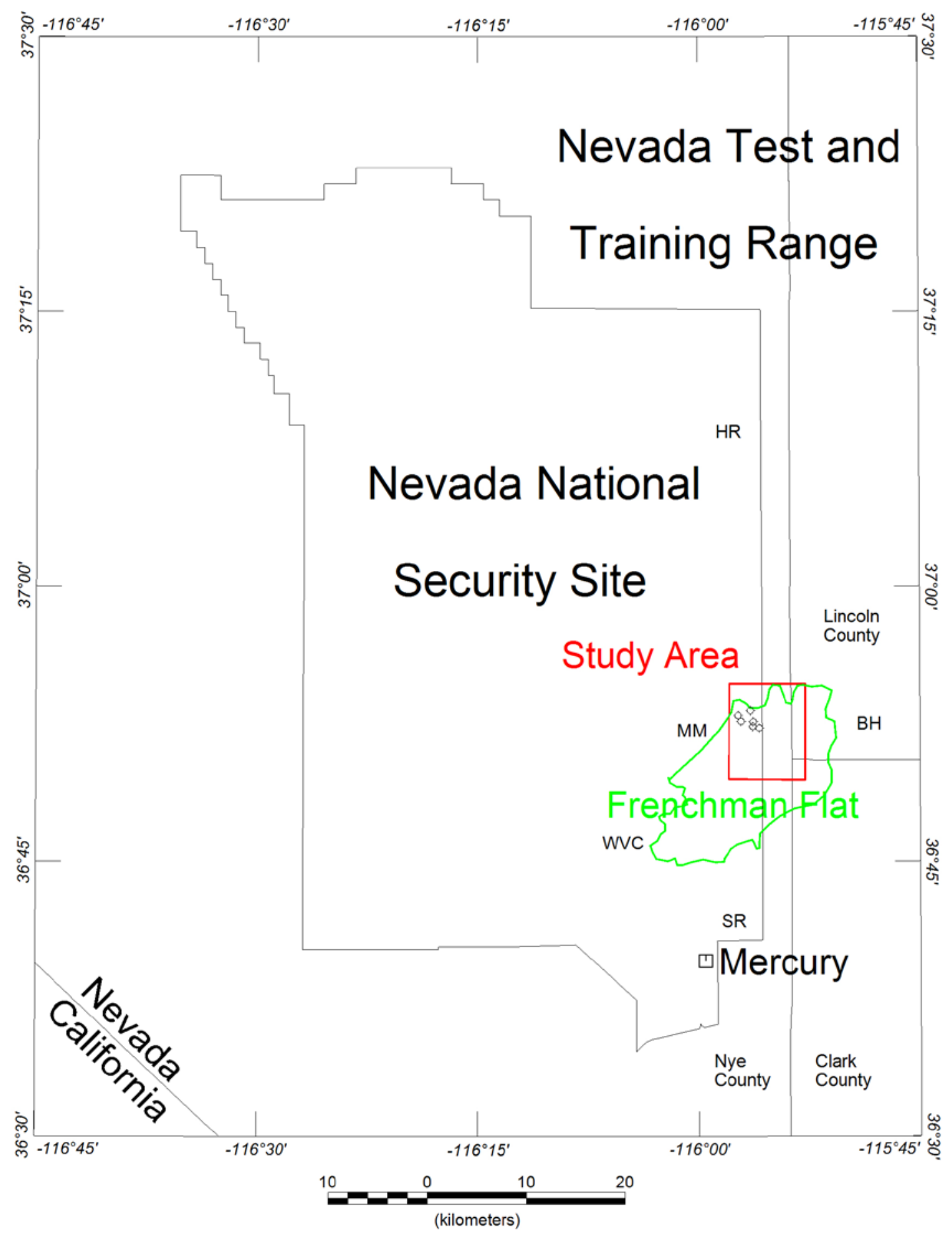

Figure 1. Index map showing the locations of Frenchman Flat and the study area within the Nevada National Security Site and the Nevada Test and Training Range. Abbreviations identify Massachusetts Mountain (MM), the Halfpint Range (HR), the Buried Hills (BH), the Spotted Range (SR), and the Wahmonie volcanic center (WVC). Six boreholes within the study area that are identified on plate 1 are also shown. 
In late September 2010, the U.S. Geological Survey (USGS) conducted a ground-based magnetic survey of the northeast portion of Frenchman Flat within the NNSS and within the adjacent NTTR. The survey was designed to address two questions of importance to the siting of new monitoring wells near (down-gradient of) or within groundwater-contaminant plumes resulting from the Milk Shake and Pin Stripe underground nuclear tests:

Question 1-What is the horizontal extent of the basalt flow (the Basalt lava flow aquifer or BLFA) encountered in three wells (UE5k, UE5i, and ER-5-3) within the alluvial section at depths ranging from 268 to 290 meters (m) (880 to 950 feet [ft]), and having a thickness between 9 and $21 \mathrm{~m} \mathrm{(30} \mathrm{and} 70 \mathrm{ft}$ )? Exploratory Hole UE5k is located near Emplacement Hole U5k, site of the Milk Shake underground nuclear test (U.S. Department of Energy, 2000).

Characterization well ER-5-3 is located approximately $670 \mathrm{~m}(2,200 \mathrm{ft})$ west-northwest of the Milk Shake test.

Question 2-Does basin and range normal faulting observed in the hills north of Frenchman Flat continue southward under alluvium and possibly disrupt the Topopah Spring Tuff of the Paintbrush Group (the Topopah Spring welded tuff aquifer or TSA) east of the Pin Stripe underground nuclear test, which was conducted in Emplacement hole U11b (U.S. Department of Energy, 2000)?

\section{Geologic Setting}

Frenchman Flat is a closed intermontane basin located in the southeastern portion of the NNSS. It is bounded on the north by Massachusetts Mountain and the Halfpint Range, on the east by the Buried Hills, on the south by the Spotted Range, and on the west by the Wahmonie volcanic center. The sparsely vegetated valley floor slopes gently toward a central playa lakebed.

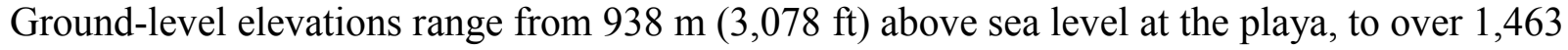
$\mathrm{m}(4,800 \mathrm{ft})$ in the nearby surrounding mountains.

The stratigraphic section for Frenchman Flat consists of (from oldest to youngest) Proterozoic and Paleozoic clastic (silicic) and carbonate rocks, Tertiary sedimentary and tuffaceous sedimentary rocks, Tertiary volcanic rocks, and Tertiary and Quaternary alluvium (Slate and others, 1999). In the northernmost portion of Frenchman Flat, the middle to upper Miocene volcanic rocks that erupted from calderas located to the northwest of Frenchman Flat unconformably overlie Ordovician-age carbonate (O€p on plate 1) and clastic (silicic) rocks. In the southern portion of Frenchman Flat, these volcanic units, including the Ammonia Tanks Tuff and Rainier Mesa Tuff of the Timber Mountain Group (Tmt on plate 1), the Topopah Spring Tuff of the Paintbrush Group (Tpt on plate 1), and Crater Flat Group (not mapped on plate 1), either thin considerably, interfinger with coeval sedimentary rocks, or pinch out together (Bechtel Nevada, 2005). Upper and middle Miocene tuffs, lavas, and debris flows (Tw on plate 1) from the Wahmonie volcanic center located just west of Frenchman Flat dominate the volcanic section beneath the western portion of the valley. To the south and south east, most of the volcanic units are absent, and Oligocene to middle Miocene sedimentary and tuffaceous sedimentary rocks, which unconformably overlie the Paleozoic rocks in the southern portion of Frenchman Flat, dominate the Tertiary section (Prothro and Drellack, 1997). In most of the Frenchman Flat area, upper Miocene to Holocene alluvium (Qc, Qay, and Qayf on plate 1) covers the older sedimentary and volcanic rocks (Slate and others, 1999). Alluvium thicknesses range from a thin veneer along the valley edges to perhaps as much as $1,158 \mathrm{~m}(3,800 \mathrm{ft})$ in north-central Frenchman Flat. 


\section{Hydrostratigraphic Units and Magnetic Properties}

Hydrostratigraphic units (HSUs) for the NNSS volcanic rocks were first defined during the Underground Test Area (UGTA) modeling initiative (IT Corporation, 1996a). HSUs are groupings of contiguous stratigraphic units that have a particular hydrogeologic character, such as an aquifer (a unit through which water moves readily) or a confining unit (a unit that generally is impermeable to water movement). HSUs do not necessarily correspond to any fixed stratigraphic interval. A given stratigraphic interval may correspond to different HSUs in different parts of a study area, depending on the local stratigraphic column. The concept of HSUs is very useful in volcanic terrains where stratigraphic units can vary greatly in hydrologic character both laterally and vertically.

The strata in the Frenchman Flat area have been subdivided (fig. 2) into eight Quaternary and Tertiary alluvium and playa HSUs (AA3, PCU2T, AA2, OAA, PCU1U, AA1, OAA1, and PCU1L), ten Tertiary-age volcanic HSUs (BLFA, TMWTA, TMLVTA, UTCU, TSA, LVTA, LTCU, WCU, LTCU, and VCU), and four pre-Tertiary HSUs (LCA3, UCCU, LCA, LCCU) to serve as layers for the UGTA Frenchman Flat Corrective Action Unit (CAU) groundwater model (Bechtel Nevada, 2005). The dominant units are, from shallowest to deepest, the alluvial aquifers (AA3, AA2, OAA, AA1, and OAA1), the Timber Mountain welded-tuff aquifer (TMWTA), the Timber Mountain lower vitric-tuff aquifer (TMLVTA), the Topopah Spring aquifer (TSA), the Wahmonie confining unit (WCU), the lower tuff confining unit (LTCU), the volcaniclastic confining unit (VCU), the lower carbonate aquifer (LCA), and the lower clastic confining unit (LCCU). 
Color Unit

Scale Code

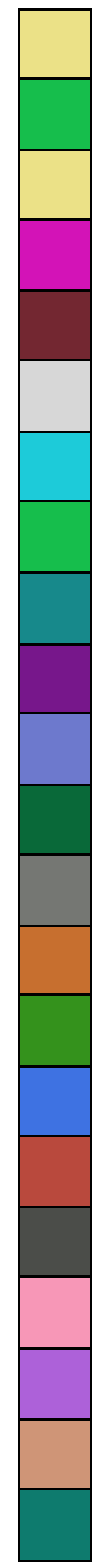

AA3

AA2

OAA

BLFA

AA1

TSA

LVTA

LTCU

WCU

LTCU

VCU

LCA3

LCA

LCCU
Hydrostratigraphic Unit

PCU2T

PCU1U

OAA1

PCU1L

TMWTA

TMLVTA

UTCU

UCCU
Alluvial aquifer 3

Playa confining unit

Alluvial aquifer 2

Older altered alluvial aquifer

Basalt lava-flow aquifer

Older playa confining unit

Alluvial aquifer 1

Older altered alluvial aquifer

Older playa confining unit

Timber Mountain Group welded tuff aquifer

Timber Mountain Group lower vitric tuff aquifer

Upper tuff confining unit

Topopah Spring aquifer

Lower vitric tuff aquifer

Lower tuff confining unit

Wahmonie confining unit

Lower tuff confining unit 1

Volcaniclastic confining unit

Lower carbonate aquifer - thrust plate

Upper clastic confining unit

Lower carbonate aquifer

Lower clastic confining unit
Geologic Description

Younger alluvium (Qay)

Playa, at/near surface

Younger alluvium (Qay)

Older alluvium, above BLFA

Basalt flow

Playa, intermediate subsurface

Younger alluvium

Older alluvium, beneath BLFA

Playa, deep subsurface

Ammonia Tanks and Rainier Mesa

Tuffs (Tmt)

Older (unaltered) tuffs (Tmt)

post-Topopah Spring tuffs (zeolitic)

Topopah Spring Tuff (Tpt)

pre-Topopah Spring tuffs (unaltered)

pre-Topopah Spring tuffs (zeolitic)

Wahmonie Formation (Tw)

zeolitic tuffs beneath the WCU

Older Tertiary sediments

Thrusted LCA

Eleana Formation and Chainman Shale

Middle Cambrian-Devonian (O€p)

Proterozoic-Middle Cambrian

Figure 2. Color scale for the three-dimensional EarthVision hydrostratigraphic model with geologic descriptions. The colors are used in fig. 3 and in the hydrostratigraphic cross-section figures (fig.6A 
through fig. 28A) Geologic unit symbols in parenthesis are taken from Workman and others (2002), and appear on plate 1 .

Because HSUs form the foundation for the three-dimensional (3-D) EarthVision (EV) framework model (and derivative flow and transport models) of Frenchman Flat, these units are used throughout this report. For more information regarding the hydrostratigraphic system used at the NNSS, refer to National Security Technologies (2009) or to Bechtel Nevada (2005) for information specific to Frenchman Flat.

The youngest unaltered alluvial units in Frenchman Flat (alluvial aquifers AA3, AA2, and AA1) consist of poorly indurated tuff debris. This material is magnetic, and it produces a characteristic noise signal in the magnetic profiles with an amplitude of 10 to 20 nanotesla (nT).

In parts of northern Frenchman Flat alluvium units AA2 and AA1 are replaced by altered alluvium OAA and OAA1, respectively. These altered alluvium units can have a combined thickness of more than $1,000 \mathrm{ft}$ and consist locally of either tuff debris or of non-magnetic materials such as chert, limestone, dolomite, and quartzite. The top of the altered alluvium (generally OAA) forms the principal reflector in seismic reflection profiles collected in the 1960s (Carr and others, 1975, which is reproduced in appendix D of this report).

Embedded within the alluvium, either at the base of OAA and just above OAA1, or at the base of AA3 or AA2 and just above AA1, is a discontinuous basalt flow or flows (BLFA). This flow has a thickness of 30 to 70 feet where it is encountered in wells and is discontinuous based on well data and on a previous ground magnetic survey conducted in the 1960s (Carr and others, 1975). The basalt has been dated at 8.4 to $8.6 \mathrm{Ma}$ (Mega-annum [million years]) (Bechtel Nevada, 2005). Where it is present in the subsurface, this basalt flow partially controls the amplitude of the longer wavelength components of the ground magnetic-profile data. As modeled, the basalt flow has normal magnetic polarity and strong magnetization (2.5 ampere per meter $[\mathrm{A} / \mathrm{m}])$. Elsewhere in the southwestern Nevada volcanic field, the younger Tertiary basalts are strongly magnetized $(>1.5 \mathrm{~A} / \mathrm{m})$ and have both normal and reversed magnetic polarity (Grauch and others, 1999).

The alluvial section is locally underlain by a pair of welded ash-flow-tuff units collectively called the Timber Mountain Group (Tmt on plate 1). The younger unit is the Ammonia Tanks Tuff, which has normal magnetic polarity, and the older unit is the Rainier Mesa Tuff, which has reversed magnetic polarity. Both members have moderate to strong magnetization $(1.5 \mathrm{~A} / \mathrm{m})$ (Grauch and others, 1999). The aquifers TMWTA [welded portion], which includes the Ammonia Tanks Tuff and Rainier Mesa Tuff, and TMLVTA [nonwelded] in the EV model are within the Timber Moutain Group. The Timber Mountain Group is the dominant source of magnetic anomalies in the northern part of the study area, where it is either exposed or at shallow depth. Elsewhere it contributes to the long-wavelength magnetic anomalies.

Beneath the Rainier Mesa Tuff is another welded ash-flow tuff, the Topopah Spring Tuff of the Paintbrush Group (Topopah Springs aquifer or TSA in the EV model; Tpt on plate 1), which has normal magnetic polarity and moderate magnetization $(1.0 \mathrm{~A} / \mathrm{m})($ Grauch and others, 1999). Older tuff units include the Wahmonie Formation (Wahmonie confining unit or WCU in the west-central portion of the EV model; Tw on plate 1) and a thick series of mostly bedded zeolitic tuffs (lumped into the lower tuff confining unit or LTCU in the EV model). The LTCU appears to be an important magnetic source in some areas. The contact between the Wahmonie and the LTCU is a simplistic/conceptual boundary representing graditional and interfingering of 
units. Older Tertiary sediments (Volcaniclastic confining unit or VCU in the EV model) underlie the volcanic section in most of the middle and southern portions of Frenchman Flat.

Nonmagnetic carbonate units (O€p on plate 1), which crop out in hills northeast, east, and south of Frenchman Flat, underlie the tuffs and form the base of the EV model.

\section{Structural Setting}

The structural geology of Frenchman Flat is complex. During the late Mesozoic, the region was subjected to compressional deformation, which resulted in folding, thrusting, uplift, and erosion of the pre-Tertiary rocks (Barnes and others, 1982). At approximately $11 \mathrm{Ma}$, the region underwent extensional deformation, during which the present basin-and-range topography was developed, and the Frenchman Flat basin was formed (Ekren and others, 1968; Bechtel Nevada, 2005). A 3-D inversion of gravity data by Phelps and Graham (2002) verified that the Frenchman Flat basin is a northeast-trending, oval-shaped basin with a maximum thickness of $2,400 \mathrm{~m}$. The gravity inversion indicated that no major horst and graben structures were present beneath the basin.

In the immediate vicinity of Frenchman Flat, extensional deformation has produced northeast-trending, left-lateral strike-slip faults and generally north-trending normal faults that displace the Tertiary and pre-Tertiary rocks. Faulting is present within and beneath the alluvial cover in Frenchman Flat, but the locations and trends of many of the buried faults included in the 3-D EV model are poorly constrained. North-trending normal faults consistent with basin-andrange extension are mapped in the hills north of Frenchman Flat. We presume that these faults extend some distance southward beneath the alluvial cover. The ground magnetic and seismic surveys conducted in the 1960s (Carr and others, 1975) were used to estimate fault locations based on steep magnetic gradients and on offsets in the principal seismic reflector. However, these geophysical surveys were conducted along only a few widely spaced, east-west lines in the western part of Frenchman Flat and were not suitable for establishing the strike or continuity of the faults.

A high-resolution 3-D seismic reflection survey was conducted in Frenchman Flat in 2001 as part of a hydrogeologic investigation program for the Department of Energy, National Nuclear Security Administration/Nevada Site Office (DOE NNSA/NSO) UGTA Sub-Project. The purpose of the survey was to better constrain structural interpretations and distributions of hydrostratigraphic units beneath the underground nuclear testing areas in Frenchman Flat. The survey area covered $35.8 \mathrm{~km}^{2}\left(13.8 \mathrm{mi}^{2}\right)$ in the northern and central portions of Frenchman Flat. Additional details regarding the acquisition parameters, processing, and interpretation of the Frenchman Flat 3-D seismic survey are provided in appendix D of Bechtel Nevada (2005).

Results from the 3-D seismic survey provided valuable information on the structure and hydrostratigraphy beneath the northern and central portions of the basin. Three seismic horizons were mapped in detail. These included, from shallowest to deepest, (1) base of the alluvium, which corresponds hydrostratigraphically with the base of the alluvial aquifers and confining units (all units above the Timber Mountain Group [Tmt] in fig. 2); (2) base of the welded volcanic rocks (Topopah Spring Tuff [Tpt] and pre-Topopah Spring tuffs [unaltered] in fig. 2), which generally corresponds to the base of the volcanic aquifers (TSA and LVTA) and top of the volcanic confining units (LTCU, WCU, and VCU); and (3) top of the Paleozoic rocks

(Ordovician carbonates $\left[\mathrm{O} \epsilon_{\mathrm{p}}\right]$ in fig. 2) corresponding to the top of the lower carbonate aquifer (LCA). Important structural information was provided by the seismic data, and recognized faults 
were incorporated directly into the EV model. Of particular importance was the recognition of a previously unknown buried fault zone that strikes northwest beneath the northern portion of Frenchman Flat. This fault zone, referred to as the "detachment fault," offsets the Paleozoic and volcanic rocks as much as $610 \mathrm{~m}(2,000 \mathrm{ft})$ along a series of down-to-the-southwest faults.

Target depths of the seismic survey were from $300 \mathrm{~m}$ to $3,660 \mathrm{~m}(1,000$ to $12,000 \mathrm{ft})$ below ground surface. Unfortunately, the top of the BLFA and older altered alluvium are at or above the depth interval of quality data for this seismic survey.

\section{A Ground-Based Magnetic Survey}

Due to the failure of the 3-D seismic survey to image the BLFA, a decision was made to try a surface magnetometer survey for (1) better definition of the BLFA extent in the vicinity of the Milk Shake underground test (UGT) and (2) detecting the presence of north-south trending faults along the potential groundwater flow path in the vicinity of the Pin Stripe UGT (objective questions 1 and 2 presented in the Introduction of this report).

During the design phase of this survey, it was hoped that steep magnetic gradients in the ground magnetic-profile data would provide an indication of fault locations. However, the noise level in the magnetic profiles turned out to be high enough that steep gradients were present almost everywhere. In the interpretation section, a modern source-location algorithm is used in an attempt to extract fault locations from the noisy magnetic-profile data. However, the recovered sources are always near the top of the section, within the younger alluvium, and they could represent a variety of magnetic sources other than faults.

\section{Data Collection}

The magnetic-survey data were acquired using a Geometrics G-858 self-oscillating splitbeam cesium vapor magnetometer. As configured for this survey, the system consists of a beltmounted display/logging console connected to a single magnetic-field sensor mounted to an allplastic exterior frame backpack. Power was supplied by two 6-volt batteries encased in a waist belt with the batteries located on the back of the operator. A non-magnetic aluminum pole was used to raise the sensor above the operator to separate it from the electronics of the console and global positioning system (GPS) unit. The nominal sensor height was $2.1 \mathrm{~m}$ above the ground.

Field tests were done on-site to determine the optimum sensor orientation relative to the Earth's magnetic field with the given equipment configuration. A vertical orientation provided the highest and most consistent signal level with the sensor.

The survey data were positioned using a Tripod Data Systems (TDS)/Trimble Nomad handheld computer in conjunction with a Kenaz N100 differential GPS antenna, which provided a horizontal accuracy of about $1 \mathrm{~m}$. The Nomad/Kenaz unit was hand carried by the operator and typically held at a height level with the top of the magnetometer console. The clock on the magnetometer console was synchronized to the GPS time on the Nomad, and positional information was recorded separately on the Nomad using Esri's ArcMap software at a sample rate of 1 hertz $(\mathrm{Hz})$. The magnetic and GPS data files were then merged based on the time-stamp information.

A GEM Systems GSM-19 base magnetometer was used during all active survey periods. The base magnetometer system comprises a display/logging console connected to one Overhauser magnetic-field sensor mounted on a non-magnetic tripod and an integrated, single- 
frequency GPS antenna to accurately record time and location. The magnetic sensor is fully sealed and houses a proprietary hydrogen-rich liquid solvent with added free electrons. The console and sensor are powered by a $12-\mathrm{V}$ battery. The data were acquired at a $0.33-\mathrm{Hz}$ sampling rate, which is the fastest rate possible for this unit.

The base station location remained constant throughout the survey. The location was chosen based on its relative distance from obvious cultural features (for example, power lines, metal fences, cables/wire, and heavily travelled roads) that would cause data interference and on a logistically convenient location that could be easily accessed each day without limitations. The tripod, magnetic sensor, and GPS antenna were left in place each evening to minimize variances from day to day that may be caused by a slight change in sensor orientation or placement. Only the console and battery were removed each evening and replaced in the morning prior to the start of the survey.

Ground magnetic profiles were collected along existing trails within Frenchman Flat, and a few profiles were collected off-trail in the hills north of Frenchman Flat. The ground magnetic-profile data as collected are provided in ASCII text file FF_Mag_858.time.xyz, which is described in appendix A of this report. The USGS field procedure for ground-based magnetic data collection is described further in appendix $\mathrm{C}$ of this report.

\section{Analysis and Interpretation of the Magnetic-Profile Data}

The magnetic-profile data were broken into 23 long lines designated as Lines A through W (fig. 3, plate 1) and several shorter connecting lines AA, DD, FF, GG, OO, and RR (plate 1), which were not analyzed. The ground magnetic-profile data as reordered into lines are provided in ASCII text file FF_Mag_858.lines.xyz, which is described in appendix B of this report. Figure 3 shows the raw profile data after removal of the diurnal field, plotted as colored points on a hydrostratigraphic base map. The lines were reordered as necessary so that they started in the south or west and ended in the north or east. Analysis of each line was done using an updated version of program PDEPTH, a magnetic-profile modeling program with built-in source-depth analysis options (Phillips, 1997).

Program PDEPTH includes an option to resample unevenly spaced profile data to a constant sample interval corresponding to the average spacing. Fourier filters can be applied to the resampled data to:

1. Analytically continue the data upward (or downward) a fixed distance. Upward continuation serves as a low-pass filter to reduce short-wavelength noise.

2. Phase filter the total magnetic field so that the profile appears as it would at the north magnetic pole, where the regional field and the induced magnetization are vertical. This "reduction-to-the-pole" operation places the magnetic anomalies directly over their sources.

3. Convert magnetic profiles into pseudo-gravity profiles and gravity profiles into pseudomagnetic profiles by assuming a constant ratio of magnetic susceptibility to density. Both reduction-to-the-pole and pseudogravity filtering require knowledge of the local geomagnetic-field direction. In addition to the direction, magnetic forward modeling requires knowledge of the intensity of the local geomagnetic field. These parameters are calculated using a geomagnetic-field model, such as the International Geomagnetic Reference Field (IGRF). Geomagnetic-field parameters for the study area are provided in appendix B. 
Within PDEPTH, the filtered or resampled profile data can be analyzed, using a variety of methods, to estimate the locations of simple sources contributing to the magnetic (or gravity) field. Simple sources include (1) the tops of vertical or dipping contacts, which separate materials of two different magnetic susceptibilities (or densities) within thick layers (or halfspaces), and (2) the outer edges of thin horizontal or dipping sheets. The contacts and sheet edges are assumed to be two-dimensional and to strike perpendicular to the plane of the section containing the profile.

Due to the high noise levels of the observed magnetic profiles, the PDEPTH sourcelocation analysis was done on profiles that had been analytically continued upward by $200 \mathrm{ft}$ within PDEPTH using Fourier filtering. The 200 - $\mathrm{ft}$ continuation distance provided adequate low-pass filtering to image deeper sources. Contacts and faults digitized from the EV model were used as background linework. 


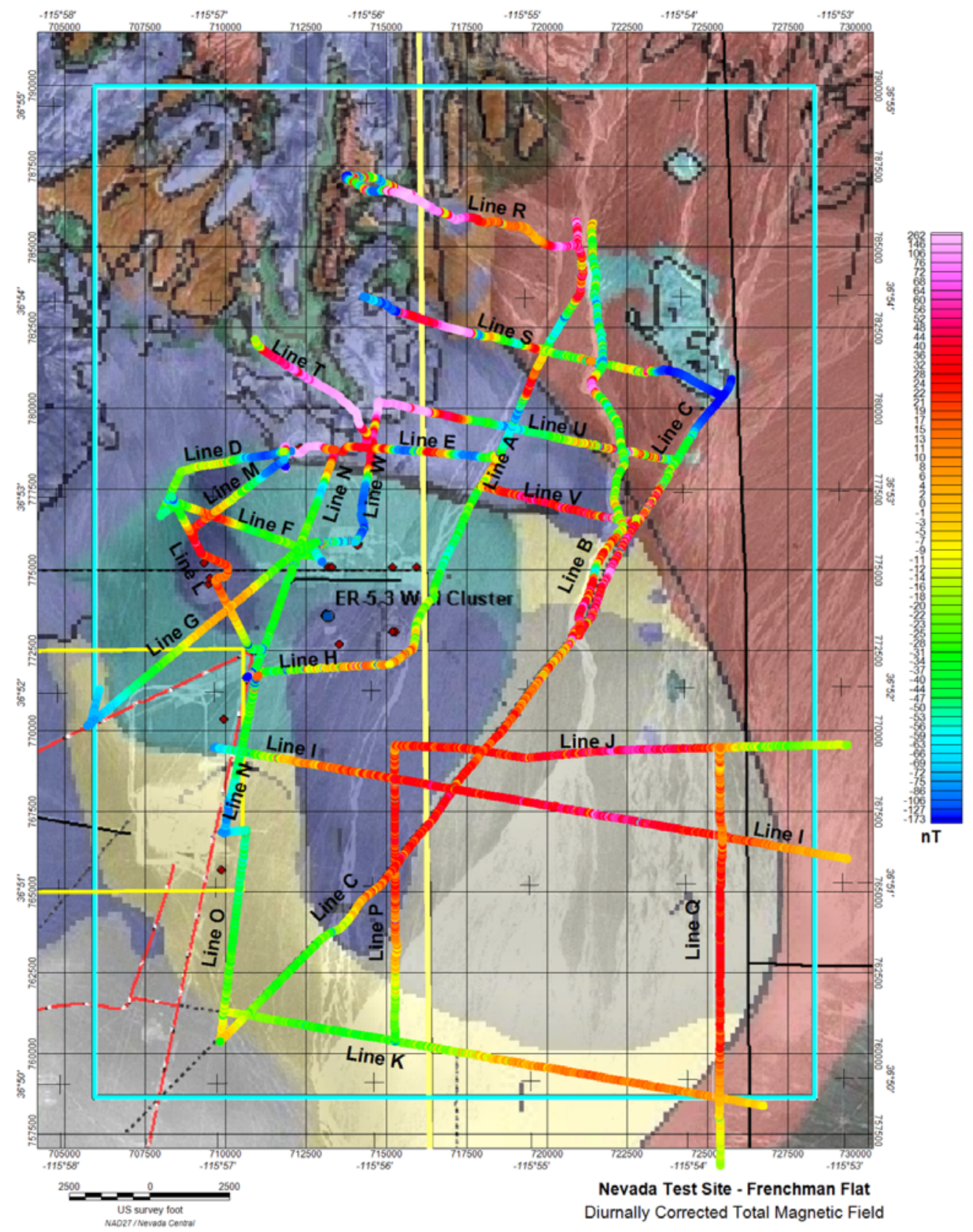

Figure 3. Raw magnetic-profile data after removal of the diurnal field plotted as colored dots on a hydrostratigraphic-unit base map with alluvial units above the basalt removed (Frenchman Flat base Hydrostratigraphic Framework Model [HFM] [Bechtel Nevada, 2005]; see fig. 2 for hydrostratigraphicunit color system). The long lines are labeled by their letter designations. The color scale for the colored dots is in units of nanotesla (nT). Of interest are the red and orange values along lines F, G, H, $\mathrm{L}$, and $\mathrm{M}$, which are known to be due to a discontinuous buried basalt flow encountered in nearby wells (as predicted by the dark bluish gray areas on the hydrostratigraphic map). The red and orange values along lines $\mathrm{C}, \mathrm{I}, \mathrm{J}, \mathrm{K}, \mathrm{P}$, and $\mathrm{Q}$ suggest that the basalt is also present over a large area of the basin to the southeast of the well control (as predicted by the lighter gray areas on the hydrostratigraphic map, which represent the Basalt lava flow aquifer [BLFA] in the Alternative Scenario model of Bechtel Nevada [2005]). 
Because the thin basalt flow was an important target of the investigation, model studies were used to develop a strategy for detecting the presence of a thin basalt at depth. Figure 4 shows PDEPTH results for a synthetic magnetic profile produced by the basalt flow as modeled along Line $\mathrm{C}$. The magnetic profile is noise-free, but it does contain a small amount of shortwavelength signal due to variations in the terrain. The magnetic profile was transformed to a pseudogravity profile using a Fourier filter, then the pseudogravity profile was continued upward by $200 \mathrm{ft}$ using another Fourier filter in order to simulate suppression of geological noise. The Horizontal Gradient (HG) method (Roest and Pilkington, 1993) was used to estimate the locations of horizontal sheet edges from both the pseudogravity profile and the upwardcontinued pseudogravity profile. The results plot close to the true basalt edges. 


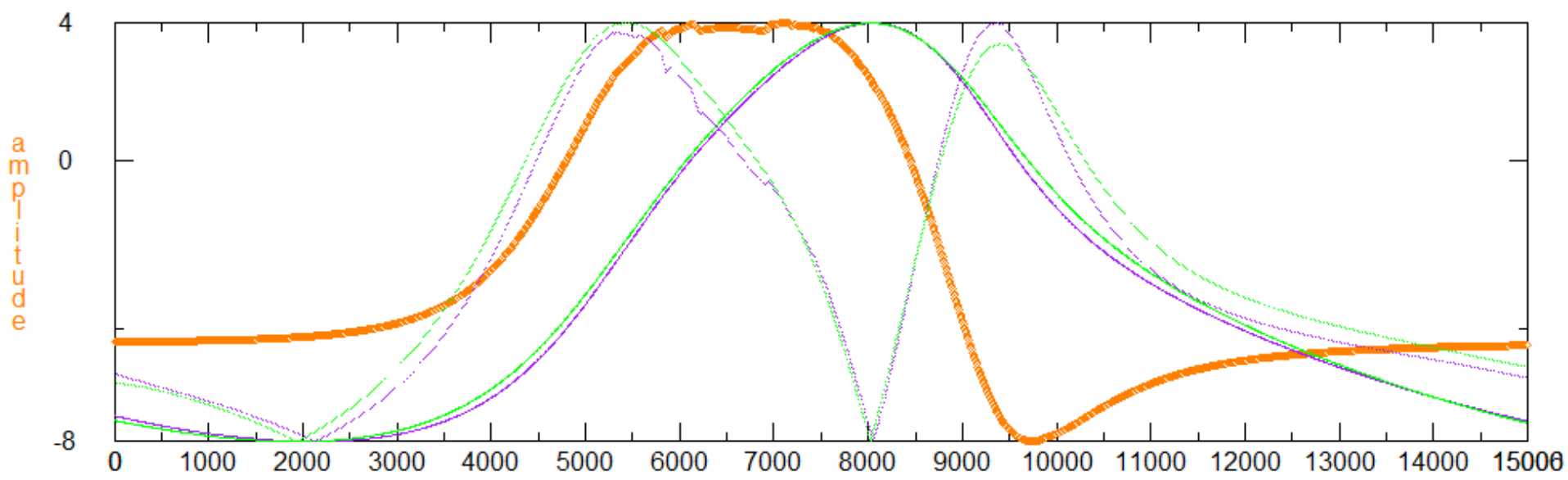

distance

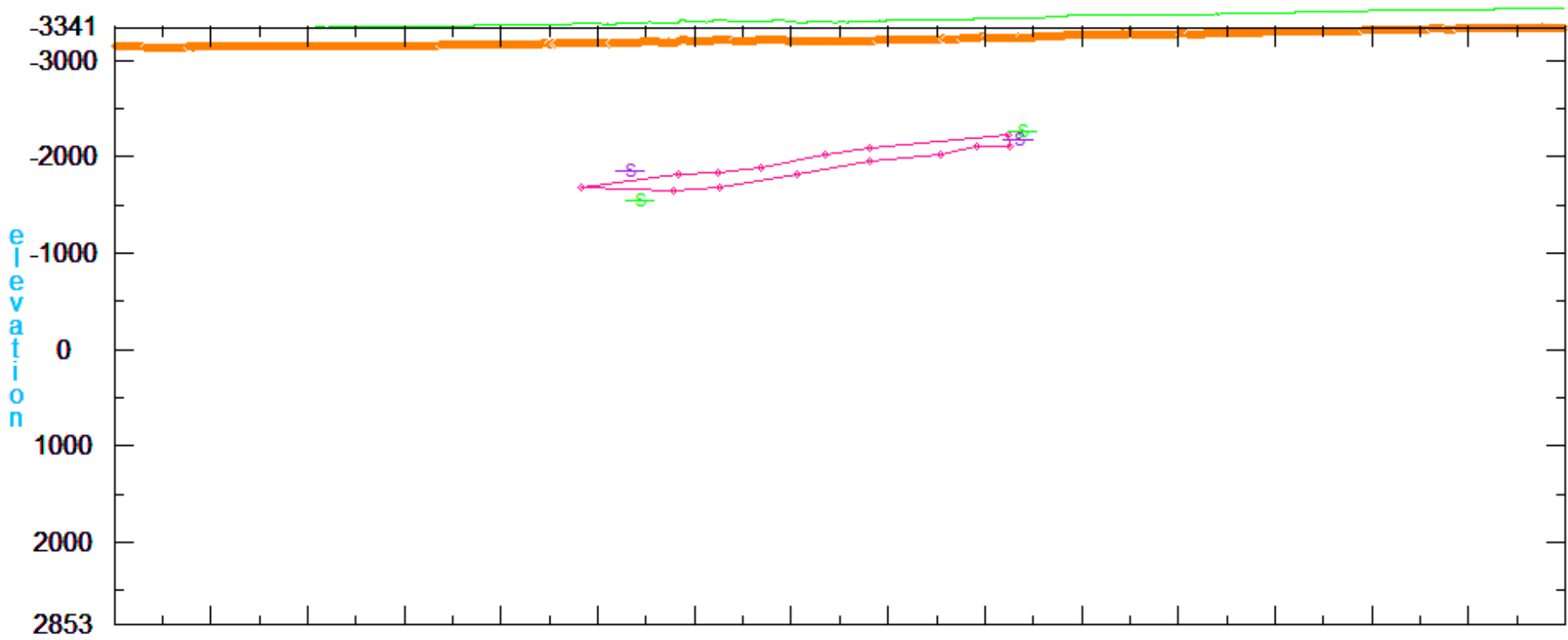

Figure 4. Synthetic magnetic profile (orange symbols in top window) produced by the basalt flow as modeled for Line $C$ (magenta polygon in crosssection window). Induced magnetization and a magnetic susceptibility of 0.001 in dimensionless cgs (centimeter-gram-second) units were 
assumed. Other profile curves, scaled to fit in the window, include the pseudogravity (purple), upwardcontinued pseudogravity (green), and horizontal gradient magnitude curves (dashed purple and dashed green). Horizontal gradient solutions for horizontal sheet sources are shown as "S" symbols with horizontal lines in the cross section, with purple indicating solutions from the pseudogravity and green indicating solutions from 200-ft upward-continued pseudogravity. A 31-point window was used. The horizontal gradient sheet solutions are reliable indicators of basalt edges in this noise-free example.

In another test using the same model (fig. 5), the Multiple-Source Werner (MSW) deconvolution method (Hansen and Simmonds, 1993) was applied to the synthetic magnetic field after it was upward continued by $200 \mathrm{ft}$. Clustered MSW sheet solutions were shown to be reliable indicators of basalt edges in this noise-free example, although the estimated dips are misleading. 


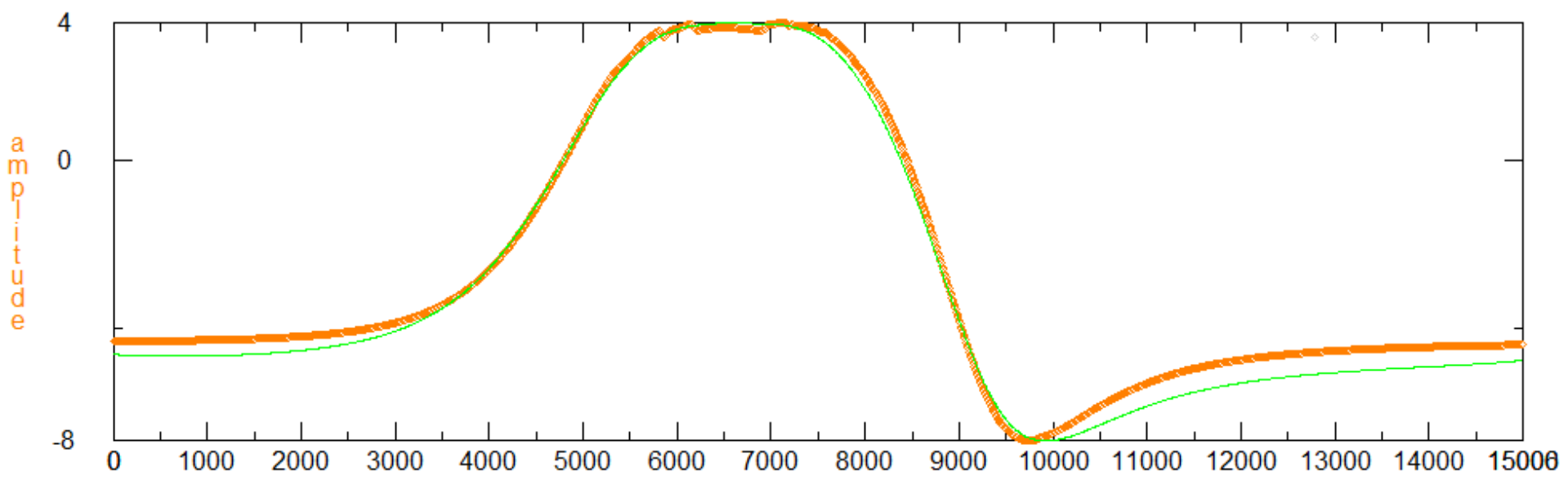

distance

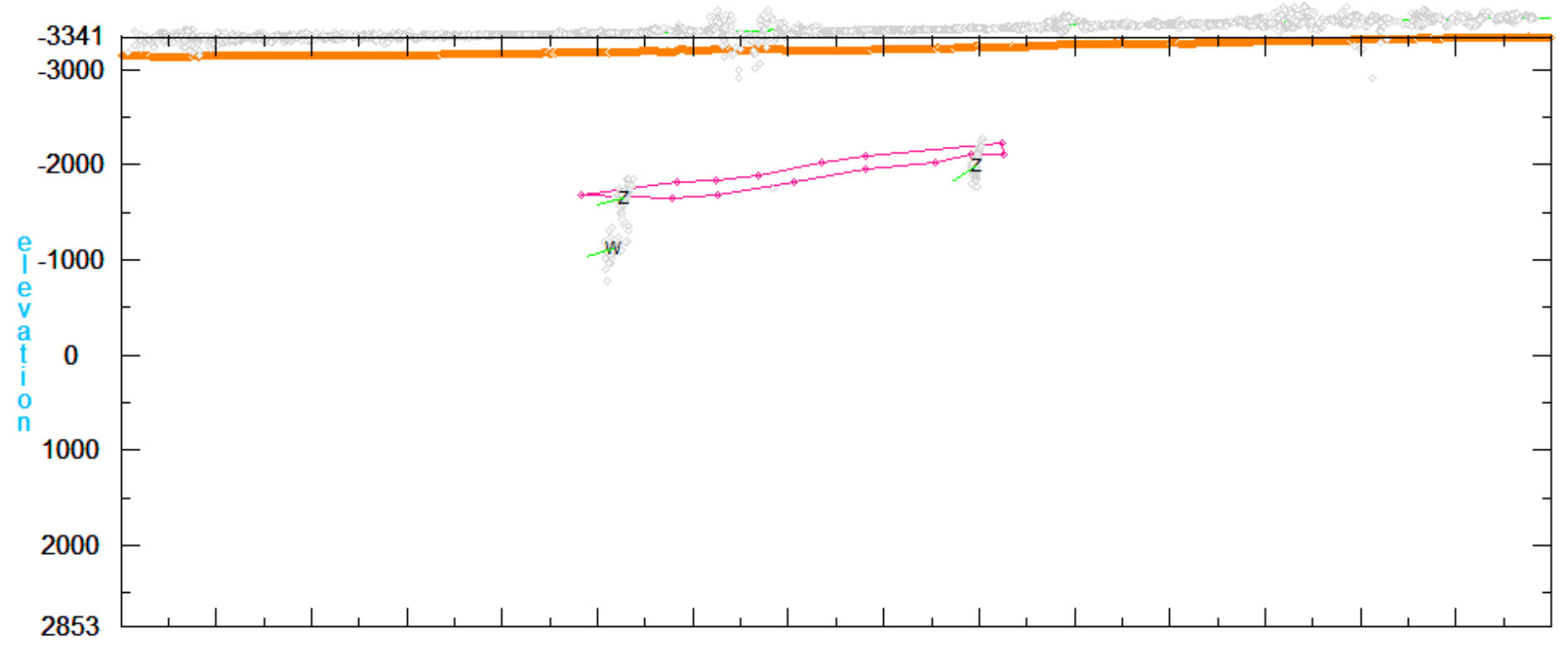

Figure 5. Synthetic magnetic profile as in figure 4. The green profile curve is the magnetic field after upward continuation by 200 feet, scaled to fit in the window. In the lower panel, individual multiple-source Werner solutions for sheet sources, as calculated from the upward-continued field, 
are shown as small gray diamond symbols in the cross section. Clustered solutions are indicated by black number or letter symbols with green dip lines. The number or letter symbols indicate the number of individual solutions in the cluster, with "A" indicating a cluster of 10, "B" indicating a cluster of 11, and so forth. In this figure a "W" indicates a cluster of 32 solutions, and a "Z" indicates a cluster of 35 or more solutions. Most of the clustered solutions are reliable indicators of basalt edges in this noise-free example, although the dips are misleading. Parameters used in this multiple-source Werner analysis include a window length of 175 points, a clustering radius of 15 percent of the depth, a minimum of five solutions in a cluster, and a target of three solutions within the window.

When these edge-detection methods are applied to the real magnetic-profile data, the results are not expected to be as accurate as those in the model studies. The true strikes of the edges are unknown, and they are almost certainly not perpendicular to the planes of the profiles as assumed by the edge-detection methods. These oblique strike directions will result in overestimated depths for two-dimensional edges. Alternatively, the edges may be limited in strike, and the sources may be more three-dimensional than two-dimensional. In this case, the depths of the edges are likely to be underestimated. To allow for errors in the depths, all estimated source locations are compared to the expected depth of the basalt as predicted by the EV model. Only solutions having depths that fall within $250 \mathrm{ft}$ of the expected basalt depth are treated as possible basalt edges.

Magnetic contacts, especially those produced by juxtaposition of geologic units across faults, defined the other important target of the investigation. Unfortunately all source-depth analysis methods available in PDEPTH produced large numbers of contact solutions at very shallow depths, even when the analysis was done on upward-continued data. These solutions could represent a variety of different near-surface magnetic-source types, including faults, contacts, terrain effects, channel fill, and magnetic objects. An ideal magnetic contact is represented by an infinite vertical offset in magnetic properties. Magnetic-contact solutions will tend to underestimate depths to sources represented by finite thickness steps (Phillips, 2000), such as many of the fault offsets of the magnetic tuff units of the Timber Mountain Group appearing in the cross sections from the EV model. Therefore, the shallow nature of the contact solutions does not imply that the EV model is wrong. In fact, any contact solution appearing above a modeled offset in a magnetic unit could serve to validate the model.

In the end, the Analytic Signal (AS) method (Nabighian, 1972) was selected as the most effective analysis method for locating magnetic contacts, largely because it precludes finding many close-together contacts (solutions can only occur under peaks of the analytic-signal amplitude curve), it provides an estimate of the dip of each contact, and the peak amplitude of the analytic signal curve provides a crude estimate of the magnetization contrast across each contact (solutions with lower peaks can be ignored). Contact solutions estimated from the upward-continued, reduced-to-pole magnetic field using the Horizontal Gradient (HG) method were also found to be useful. Although these solutions assume vertical dip and tend to plot downdip of the true contact locations, they can be separated, based on the peak amplitude of the horizontal gradient magnitude curve, into important contacts produced by large apparent magnetization contrasts and minor contacts produced by small apparent magnetization contrasts.

\section{Results for each line}

A multi-part figure is provided for each Line A through W. Each profile is shown with north (or east) on the right. Units on the axes are distance in feet and elevation in feet above sea 
level. Part $(A)$ of each figure shows the hydrostratigraphic cross section as predicted by the EV model (Frenchman Flat base Hydrostratigraphic Framework Model [HFM] [Bechtel Nevada, 2005]). The hydrostratigraphic units are colored as in figure 2. Part (B) of each figure shows the locations of horizontal magnetic-sheet edges and vertical contacts as estimated using the HG method. The locations of horizontal magnetic-sheet edges are estimated from the magnitude of the horizontal gradient of the upward-continued pseudogravity profile using a 31-point window to locate peaks and determine peak curvature. Similarly, the locations of vertical magnetic contacts are estimated from the magnitude of the horizontal gradient of the upward-continued reduced-to-pole magnetic profile using a 31-point window. Part $(C)$ of each figure shows the locations and dips of magnetic-sheet edges, which are estimated from clustered MSW sheet solutions. The upward continued magnetic field within a moving 175-point window is used to locate a set of three sheet solutions. Solutions from all windows are clustered using a radius equal to 15 percent of the depth. Clusters containing five or more solutions are retained. Part $(D)$ of each figure shows the locations and dips of magnetic-sheet edges as estimated from the analytic signal amplitude of the upward contined magnetic profile using a 31-point window to locate peaks and determine peak curvature. Similarly, the locations and dips of magnetic contacts are estimated from the analytic signal amplitude of the horizontal derivative of the upward-continued magnetic profile using a 31-point window.

Part $(A)$ of each figure shows a cross-section through the EV model (Frenchman Flat base HFM [Bechtel Nevada, 2005]), which is the currently accepted best estimate of the location of hydrostratigraphic units in the subsurface of Frenchman Flat. It should be noted that each crosssection may exhibit minor irregularities (for example, inconsistent offset of units across faults); these irregularities are artifacts of model construction.

In parts $(B),(C)$, and $(D)$ of each figure, sheet solutions that are within $250 \mathrm{ft}$ of the predicted depth of the basalt, the OAA-OAA1 contact (bright magenta over bright green on part $[A]$ ) or the AA3-AA1 or AA2-AA1 contact (yellow over cyan on part $[A]$ ) are flagged using blue circles to indicate that the buried basalt flow might be present. Other sheet solutions, mostly at shallower depths within the alluvial section, are flagged using cyan circles. The blue-flagged sheet solutions are then plotted as solid symbols in map view (plate 1) to aid in estimating the horizontal extent of the buried basalt. The cyan-flagged sheet solutions are also plotted in map view but as open symbols. Contact solutions on the cross sections are flagged with red circles where peak amplitudes of the horizontal gradient magnitude or the analytic signal amplitude indicate a significant magnetization contrast across the contact. All analytic signal-contact solutions are plotted as black strike-and-dip symbols in map view; those corresponding to peak analytic signal amplitudes of $0.1 \mathrm{nT} / \mathrm{ft}$ or greater have a green dot superimposed to indicate a significant magnetization contrast. Similarly, all horizontal gradient contact solutions corresponding to peak horizontal gradient magnitudes of $0.1 \mathrm{nT} / \mathrm{ft}$ or greater are plotted as orange strike lines on plate 1 . 


\section{Explanation for Cross Section Figures 6-28}

$A$. Hydrostratigraphic cross section as predicted from the EarthVision model.

See figure 2 for the hydrostatic-unit color scale.

contacts

faults

| bends, line crossings, or ends of the section

Profile common to parts $B, C$, and $D$

$\vec{\nabla} \quad$ observed magnetic field

$B$. Horizontal Gradient profiles

— reduced-to-pole magnetic field

— pseudogravity field

— upward-continued pseudogravity field

horizontal gradient curves for:

a) upward-continued reduced-to-pole field (with peaks over contact solutions)

b) upward-continued pseudogravity field (with peaks over sheet solutions)

C. Multiple-Source Werner profiles

— upward-continued magnetic field

D. Analytic Signal profiles

— upward-continued magnetic field

....... analytic signal amplitude (with peaks over sheet solutions)

analytic signal amplitude (with peaks over contact solutions)

Cross-section lines common to parts $B, C$, and $D$

- upward-continuation surface

$\Delta \forall$ observation surface

- topographic surface and selected contacts and faults from the EarthVision model

stratigraphic horizon containing or potentially containing the basalt

bends, line crossings, or ends of the section (as labeled)

Symbols common to all depth solutions

sheet edges within shallow alluvium

sheet edges near the expected depth of basalt

significant contacts

B. Horizontal Gradient depth solutions

$\S \quad$ horizontal sheet edges

4. vertical contacts

C. Multiple-Source Werner depth solutions

individual sheet edge

Z $\quad$ clustered sheet edge with dip

D. Analytic Signal depth solutions

$\delta \quad$ sheet edge with dip

contact with dip 


\section{Line A}

Line A (fig. 6) extends to the north-northeast from the eastern end of Line $\mathrm{H}$ near drill hole UE5k along a drainage and jeep trail to the northern part of the study area (fig. 3, plate 1). The EV model indicates that the basalt flow seen in drill hole UE5k is present at the southern end of the profile at an approximate depth of $1,000 \mathrm{ft}$ or an elevation of 2,500 ft. The basalt flow is truncated near the 3,000-ft distance marker, but the stratigraphic horizon corresponding to the basalt flow continues north to the 6,000 -ft distance marker where it is truncated by a southwarddipping normal fault. A second southward-dipping normal fault is seen near the $10,500-\mathrm{ft}$ distance marker. The HG solutions indicate one sheet source at the depth of the basalt flow and other possible sheet sources within the alluvium both above and north of the basalt. The MSW sheet solutions indicate several sources at the depth of the basalt flow and other possible sheet sources within the alluvium both above and north of the basalt. The AS method produces no sheet solutions at the depth of the basalt but identifies several solutions at shallower depths. All sheet solutions at the depth of the basalt are to the north of the predicted location of the basalt in the EV model, implying that the basalt extends as far north as distance marker 5,200, and that it may be absent to the south of distance marker 3,700. The southward dipping normal faults do not stand out in the HG and AS contact solutions, although both methods predict an important contact about $700 \mathrm{ft}$ south of the northernmost fault. 


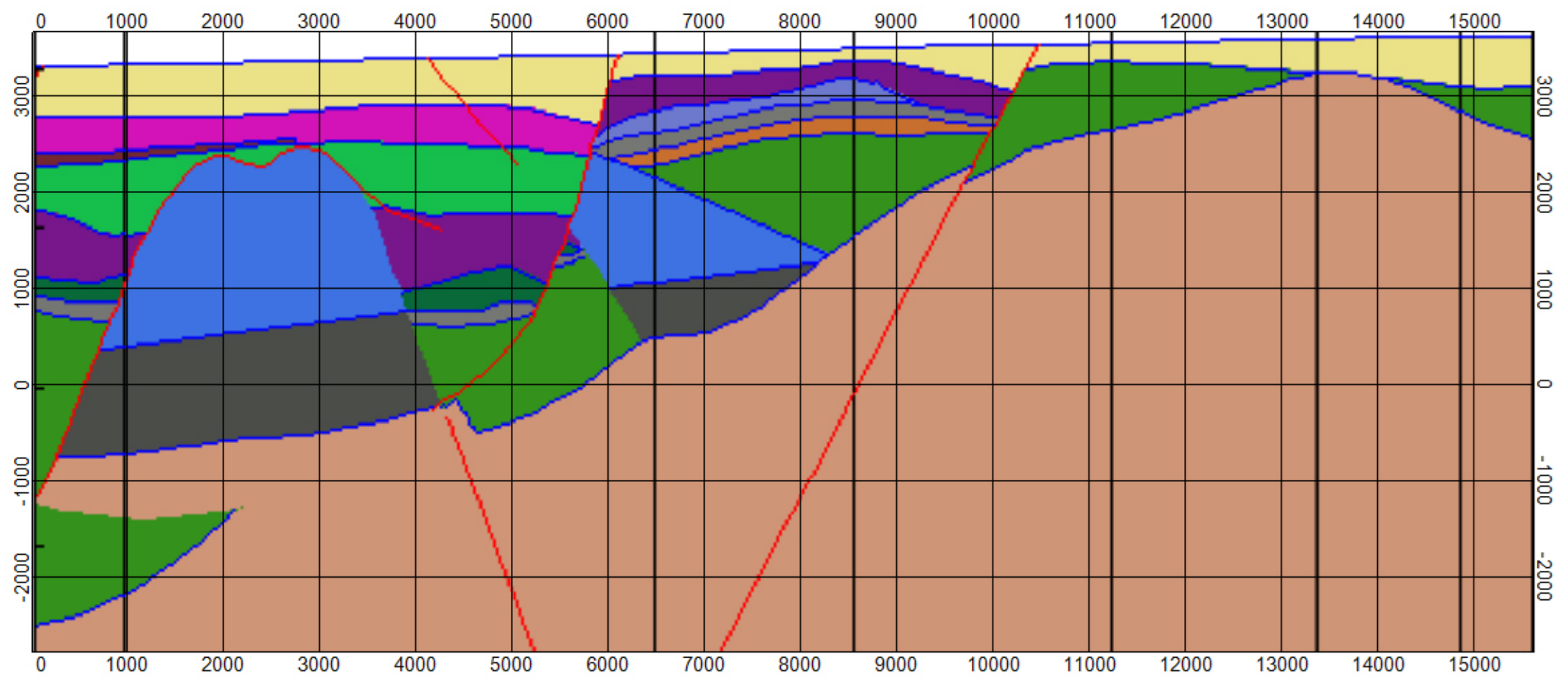

6A. Line A-EarthVision model. 


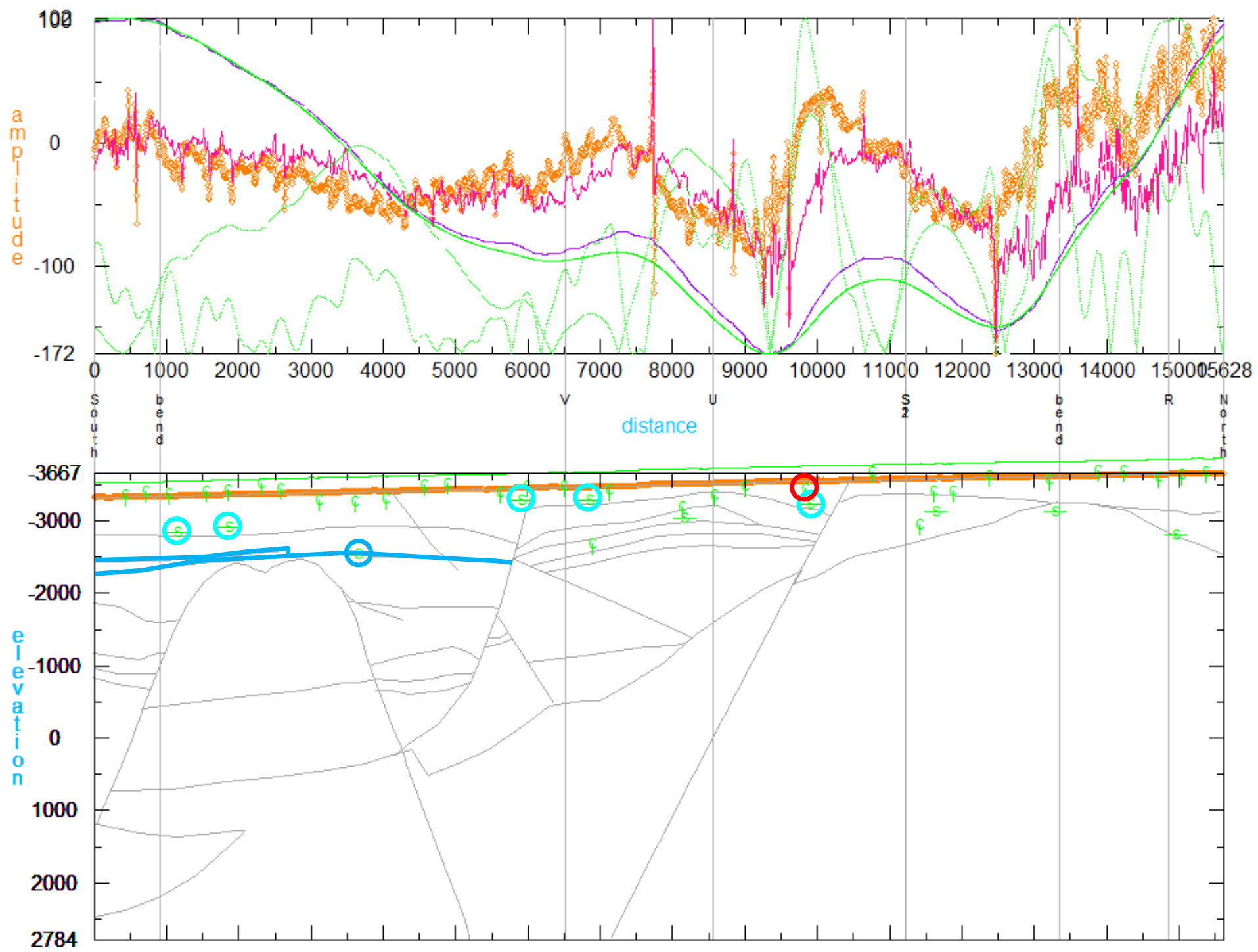

6B. Line A-Horizontal Gradient depth solutions. 


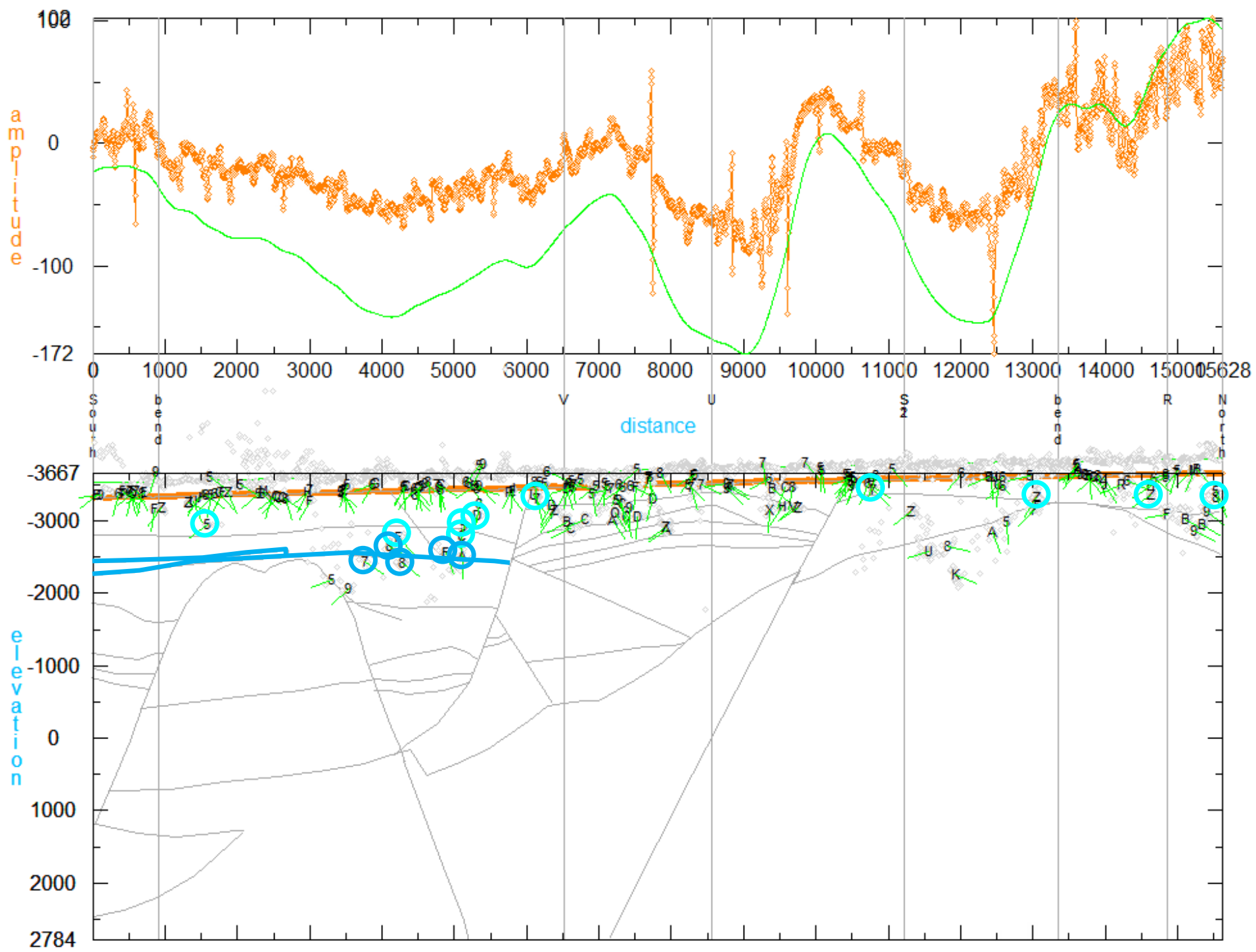

6C. Line A-Multiple-source Werner sheet solutions. 


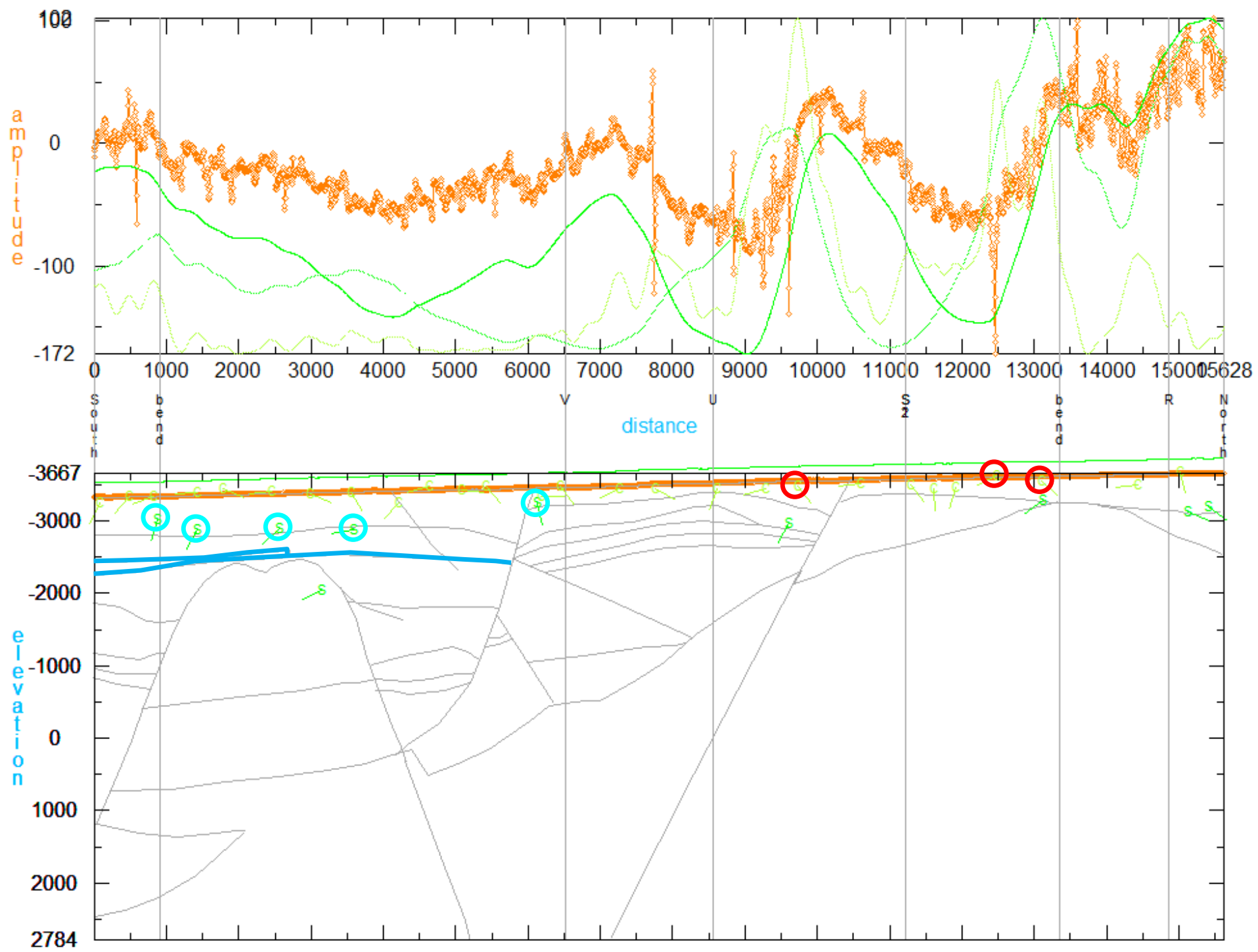

6D. Line A-Analytic Signal depth solutions. 
Figure 6. Line A. A. The hydrostratigraphic cross-section along Line A as predicted by the EarthVision (EV) model (Frenchman Flat base Hydrostratigraphic Framework Model [HFM] [Bechtel Nevada, 2005]). North (or east) is always to the right. The horizontal axis is distance in feet; the vertical axis is elevation in feet. Faults are shown in red. Note that U-shaped or V-shaped faults result from intersection of the two-dimensional section with three-dimensional fault surfaces. The color scale for the units is presented in figure 2. B. Horizontal Gradient (HG) depth solutions for horizontal sheet sources (green "S" symbols with horizontal dip lines) and vertical contact solutions (green "C" symbols with vertical dip lines). Gray lines are contacts from the EV model. Contacts corresponding to the basalt flow or to the stratigraphic position of the basalt flow have been highlighted as blue lines. Labeled vertical lines indicate bends in the section, crossings of other profiles, and compass directions at the ends of the profile. Orange symbols are the locations of the magnetic observations, which are a few feet above the ground surface. Sheet solutions within 250 feet [ft] of the predicted depth of the basalt flow are circled in blue. Other sheet solutions within the alluvial section are circled in cyan. Contact solutions corresponding to peak horizontal gradient magnitudes of 0.1 nanotesla per foot $(\mathrm{nT} / \mathrm{ft})$ or greater are circled in red. Profiles shown above the cross section include the observed magnetic field (orange), reduced-to-pole magnetic field (red), pseudogravity field (purple), upwardcontinued pseudogravity field (green), and horizontal gradient magnitude curves (dashed green) for the upward-continued reduced-to-pole field (used to locate the contact solutions) and the upwardcontinued pseudogravity field (used to locate the sheet solutions). The amplitude scale is correct for the observed magnetic profile; other profiles are scaled to fit within the window. C. Multiple-source Werner (MSW) depth solutions (gray symbols) for sheet sources from the magnetic field upward continued by $200 \mathrm{ft}$ (green curve, top). Black numbers and letters indicate clustered solutions with green dip lines. Solutions above the ground surface (gray line below the orange symbols) should be ignored. Other symbols are as in A above. D. Analytic Signal (AS) depth solutions for contacts (light green "C" symbols with dip lines) and sheet edges (dark green "S" symbols with dip lines) as calculated from the magnetic field upward continued by $200 \mathrm{ft}$. Dashed green profiles are the analytic signal amplitude curves. Contact solutions circled in red have analytic signal peak amplitudes of at least 0.1 $\mathrm{nT} / \mathrm{ft}$. Other symbols are as in $A$ above.

\section{Line B}

Line B (fig. 7) runs east of and subparallel to Line A along another drainage and jeep trail. At its southern end, Line B intersects Line C, and at its northern end Line B is only a few hundred feet east of Line A. The EV model contains one fault along Line B, a south-dipping normal fault near the 6,000-ft distance marker. This same fault appears near the 6,000-ft distance marker in Line A. The stratigraphic horizon corresponding to the basalt flow is present at the southern end of the profile. The HG sheet solutions are all above this stratigraphic interface. The MSW sheet solutions indicate possible basalt flow sources at the southern end of the profile and other sheet sources within the younger alluvium. The AS sheet solutions include one source at the predicted depth of the basalt and many within the younger alluvium. The south-dipping normal fault does not stand out in the HG and AS contact solutions, but both methods predict important contacts near the 1,900- and 8,500-ft distance markers. The contact at the 1,900-ft marker corresponds to a 75-nT negative magnetic anomaly; the one at 8,500 ft corresponds to a 150-nT positive magnetic anomaly. The sources of these anomalies are unknown. 


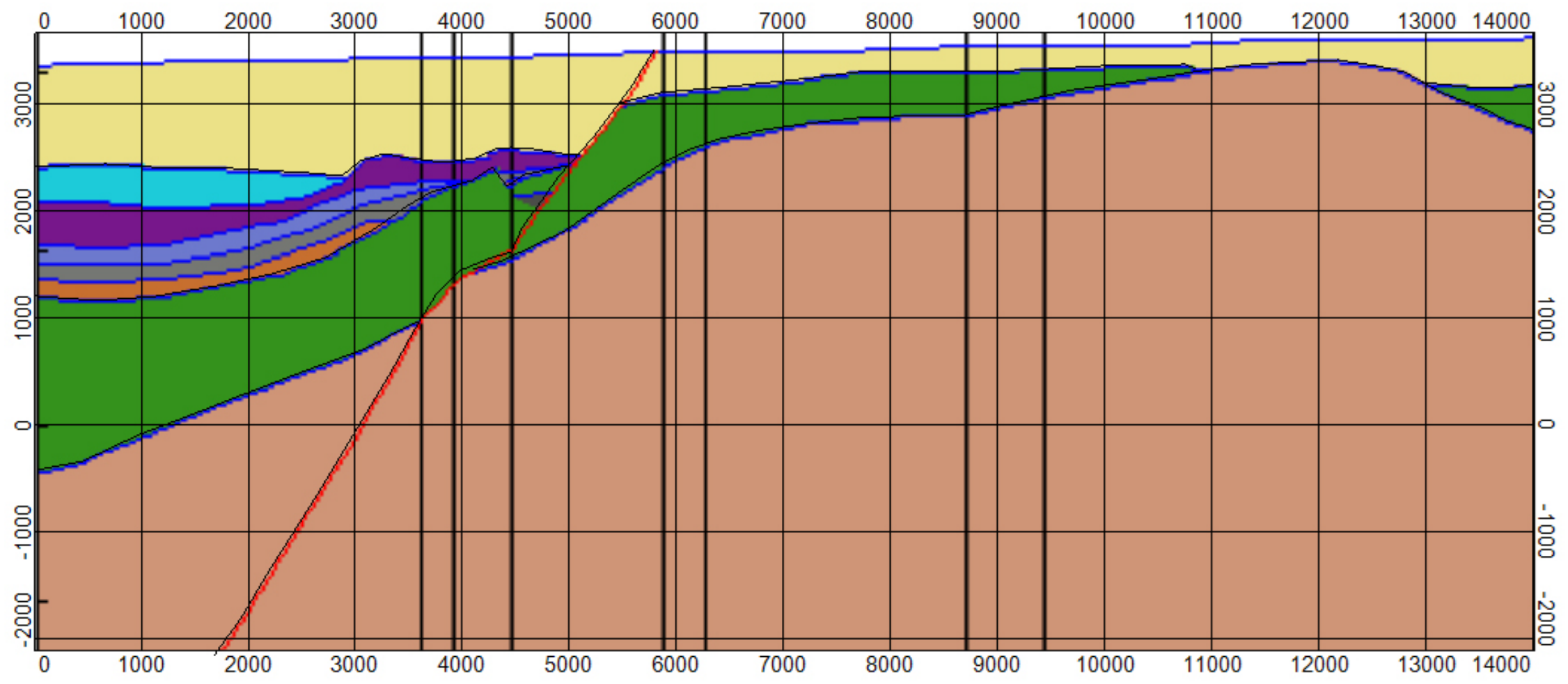

7A. Line B-EarthVision model. 


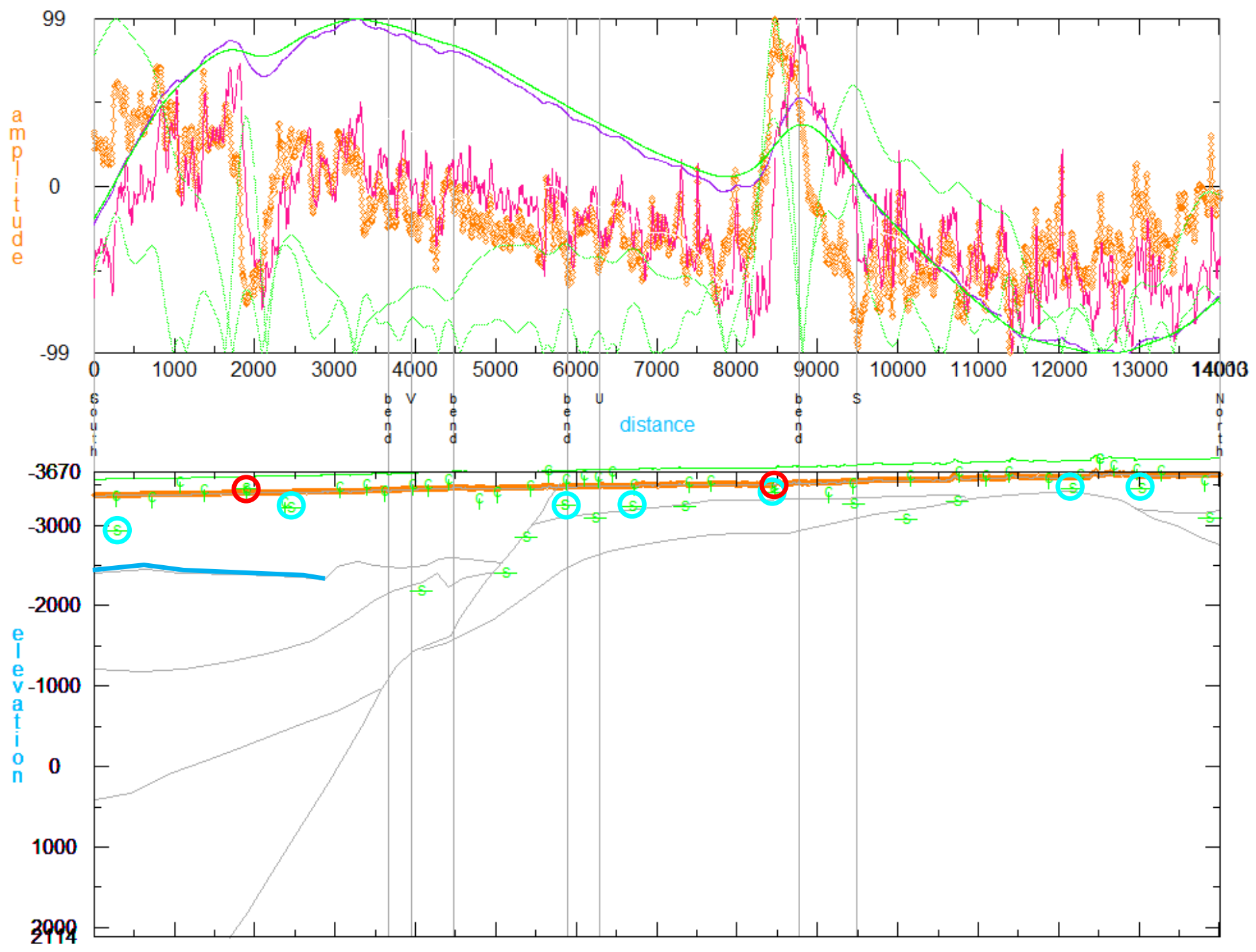

7B. Line B-Horizontal Gradient depth solutions. 


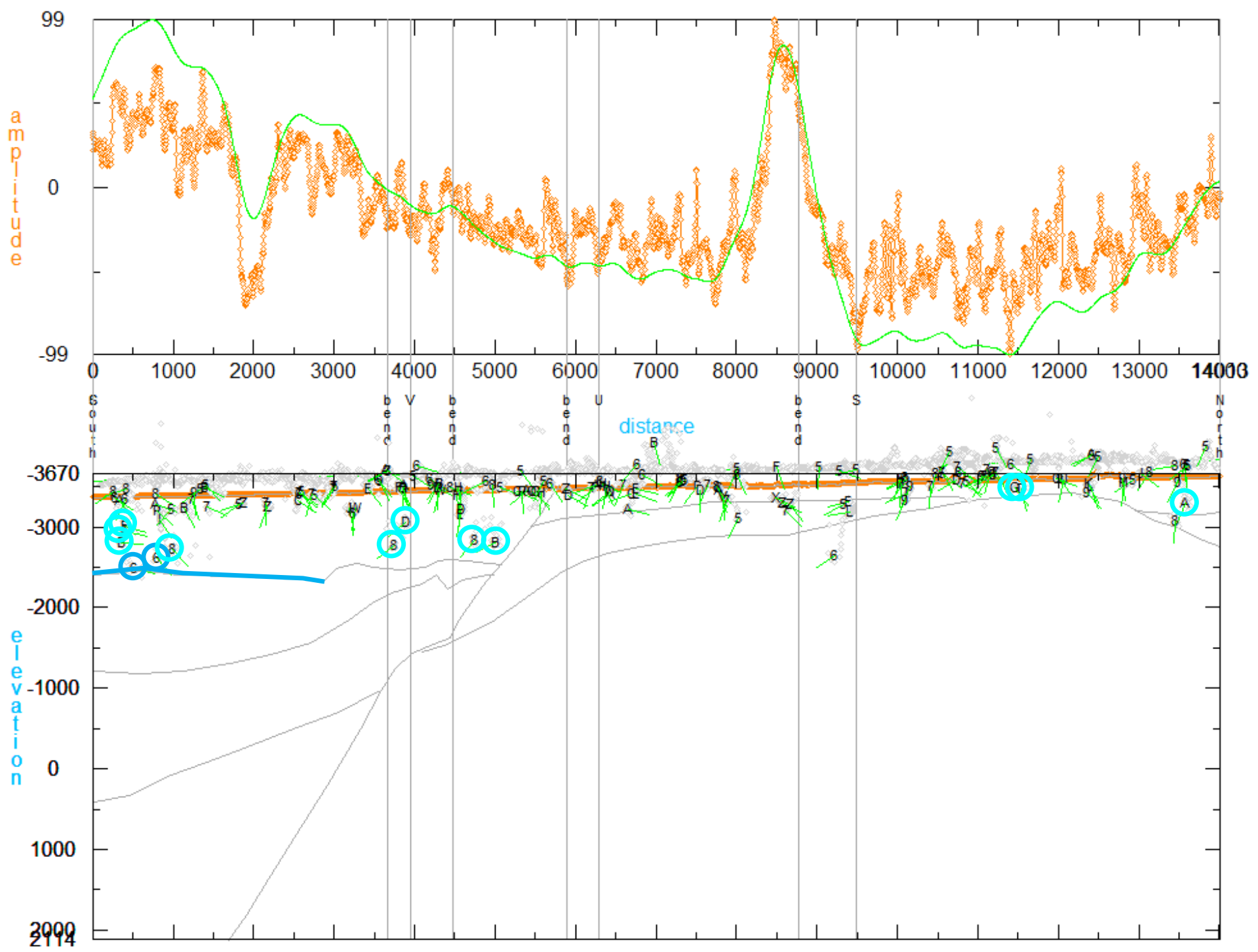

7C. Line B-Multiple-source Werner sheet solutions. 


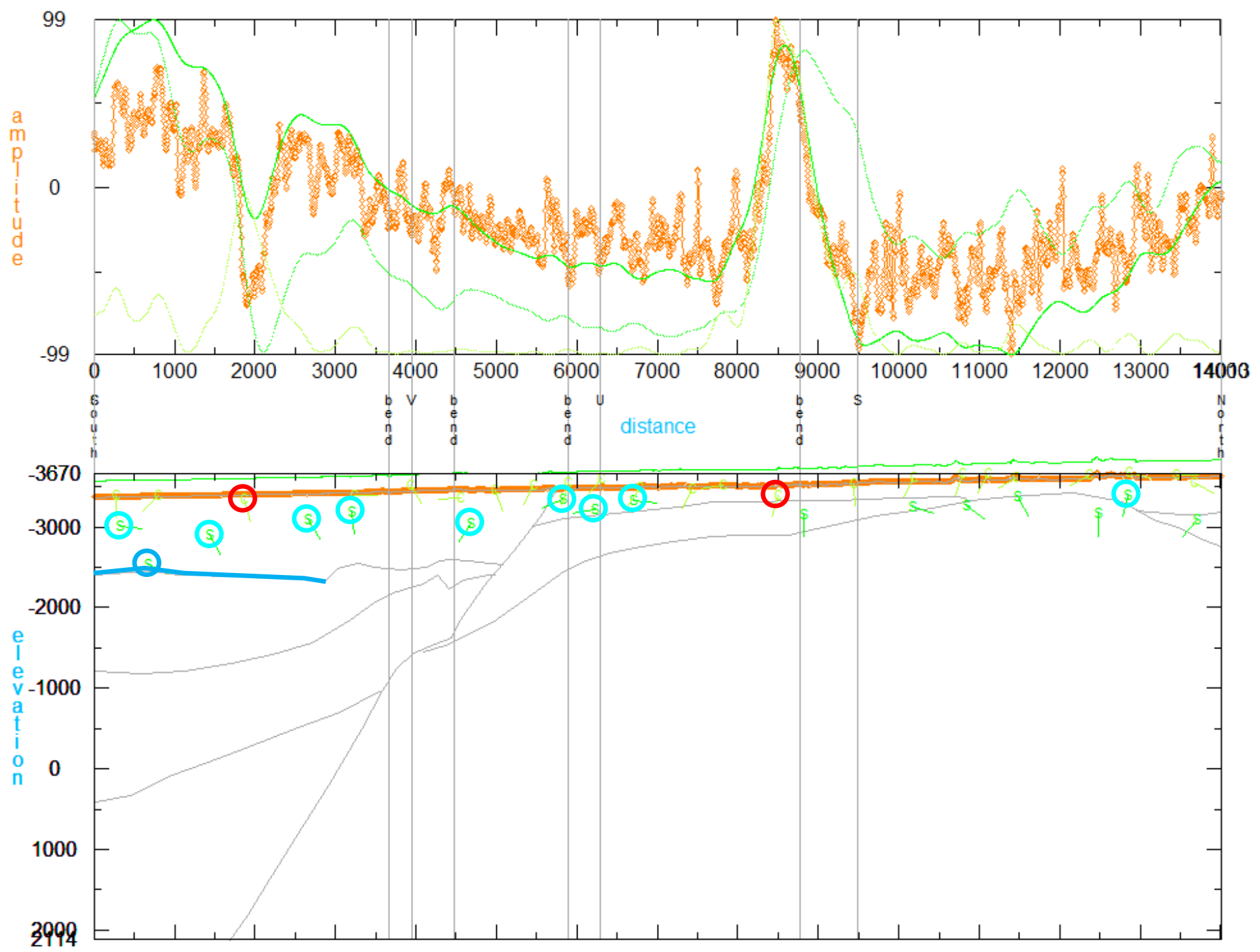

7D. Line B-Analytic Signal depth solutions.

Figure 7. Line B. See figure 6 for description. 


\section{Line C}

Line $\mathrm{C}$ (fig. 8) is a long diagonal profile that extends from the farthest southwestern point of the survey, where it intersects the southern end of Line O, to the farthest northeastern point of the survey, near the eastern end of Line S. The EV model shows several south-dipping faults, but none of them have significant shallow offset. The basalt flow is shown as present between the 5,000-ft and the 9,000-ft distance markers, but the stratigraphic horizon containing the basalt extends from the southwestern end of the profile, northeast to the 20,000-ft distance marker. The HG sheet solutions suggest that basalt is present near where it is modeled (distance markers 7,000 to 10,000 ) and also near the center of the profile (distance marker 13,000). The MSW sheet solutions suggest basalt flow sources over a range extending even farther to the southwest and northeast (distance markers 3,000 to 19,000). Only one AS sheet solution is identified as basalt (at distance marker 8,500). No sheet solutions occur at basalt depths between distance markers 13,000 and 17,000. This could indicate an area of missing basalt (plate 1). An important HG and AS contact solution seen near the 21,500-ft distance marker (near the eastern end of Line $\mathrm{V}$ in plate 1) may represent one of the major south-dipping normal faults in the EV model. Other important contact solutions near the northeastern end of the profile correspond to a negative magnetic anomaly produced by a non-magnetic linestone unit (OEp on Plate 1), that crops out nearby. 


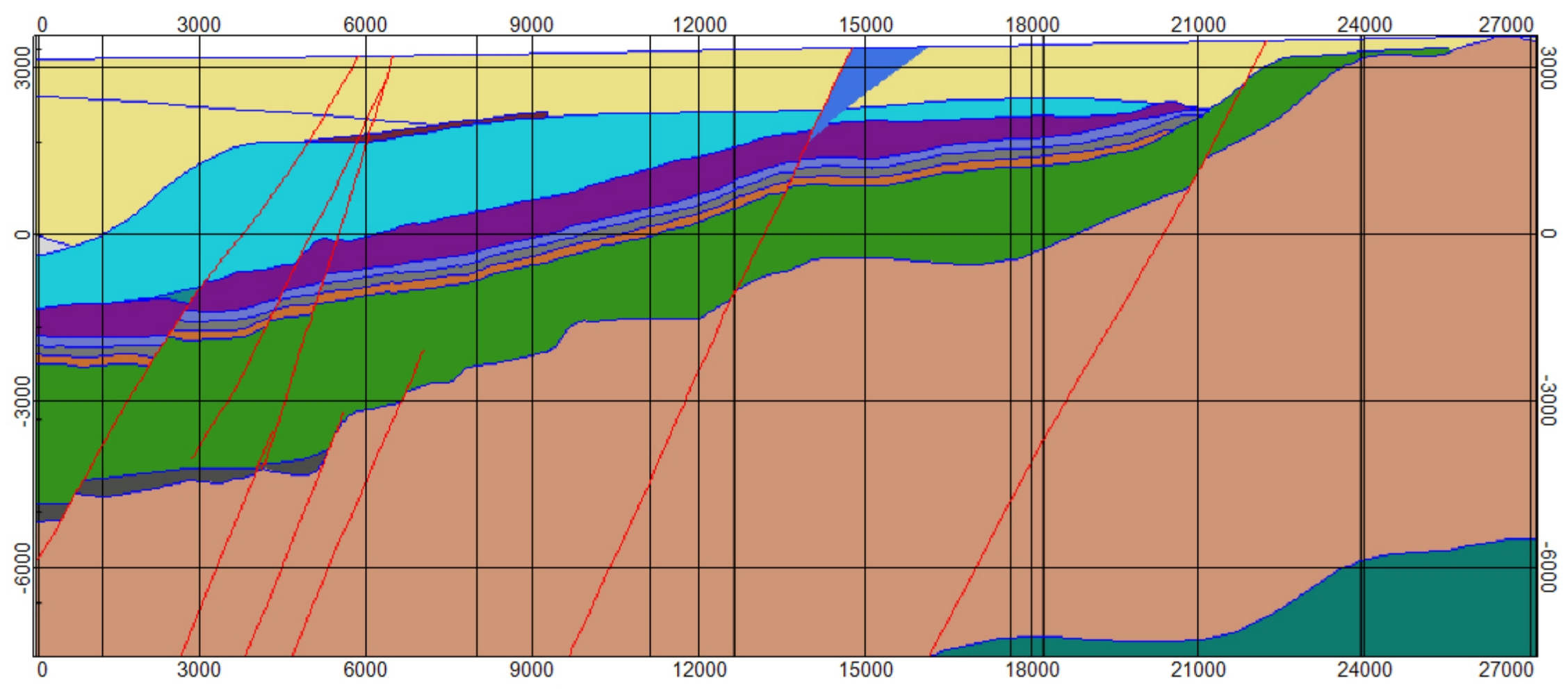

8A. Line C-EarthVision model. 


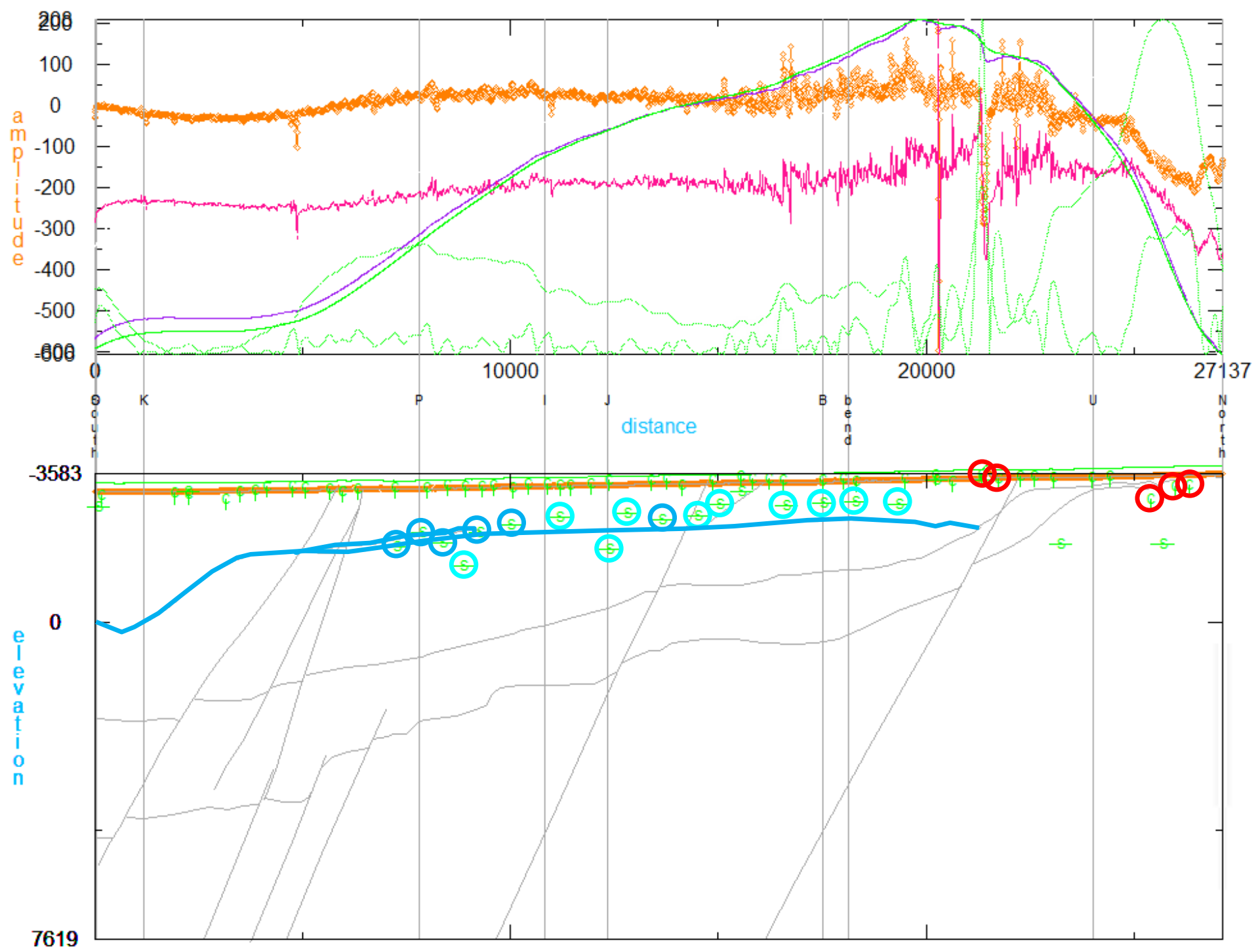

8B. Line C-Horizontal Gradient depth solutions. 


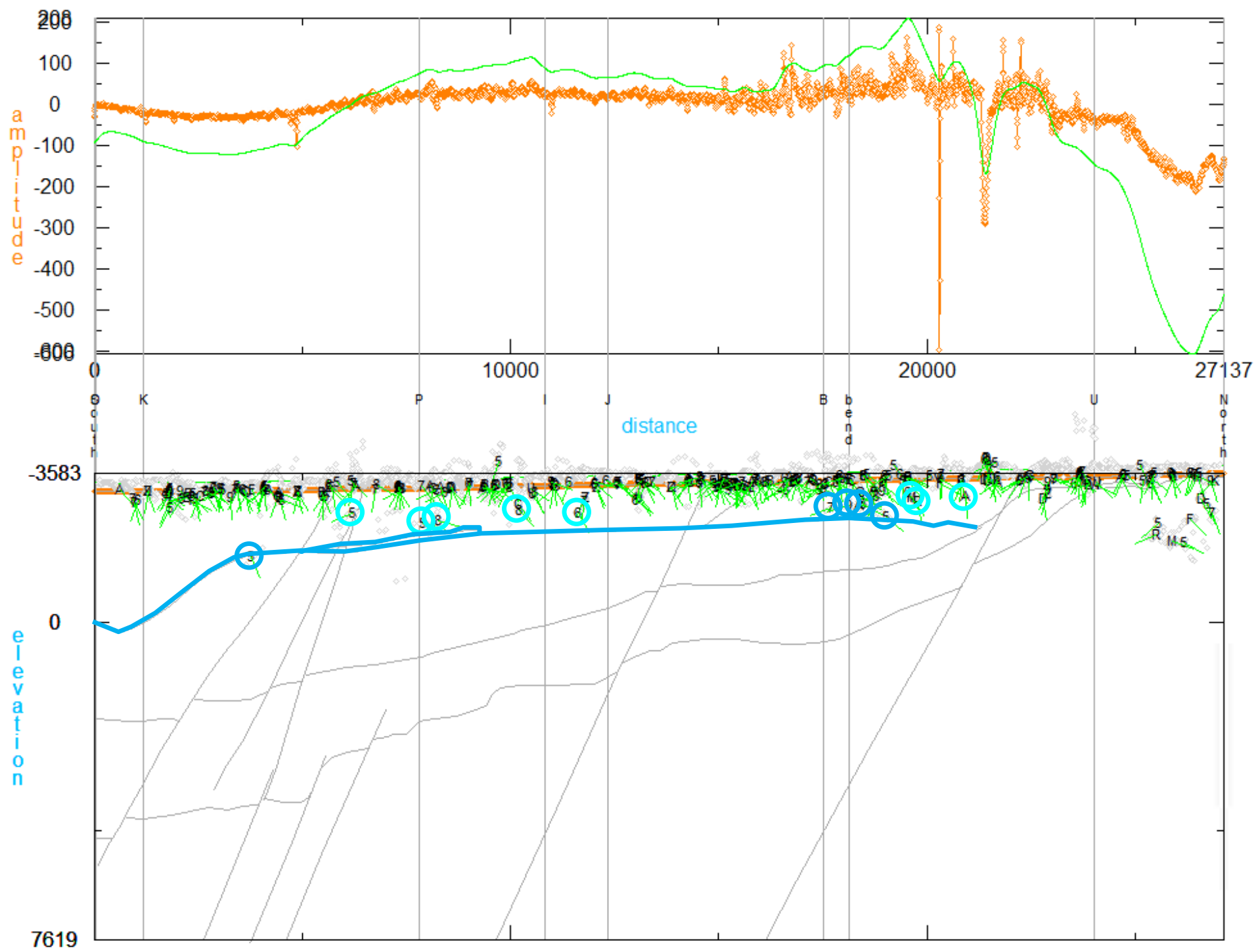

8C. Line C-Multiple-source Werner sheet solutions. 


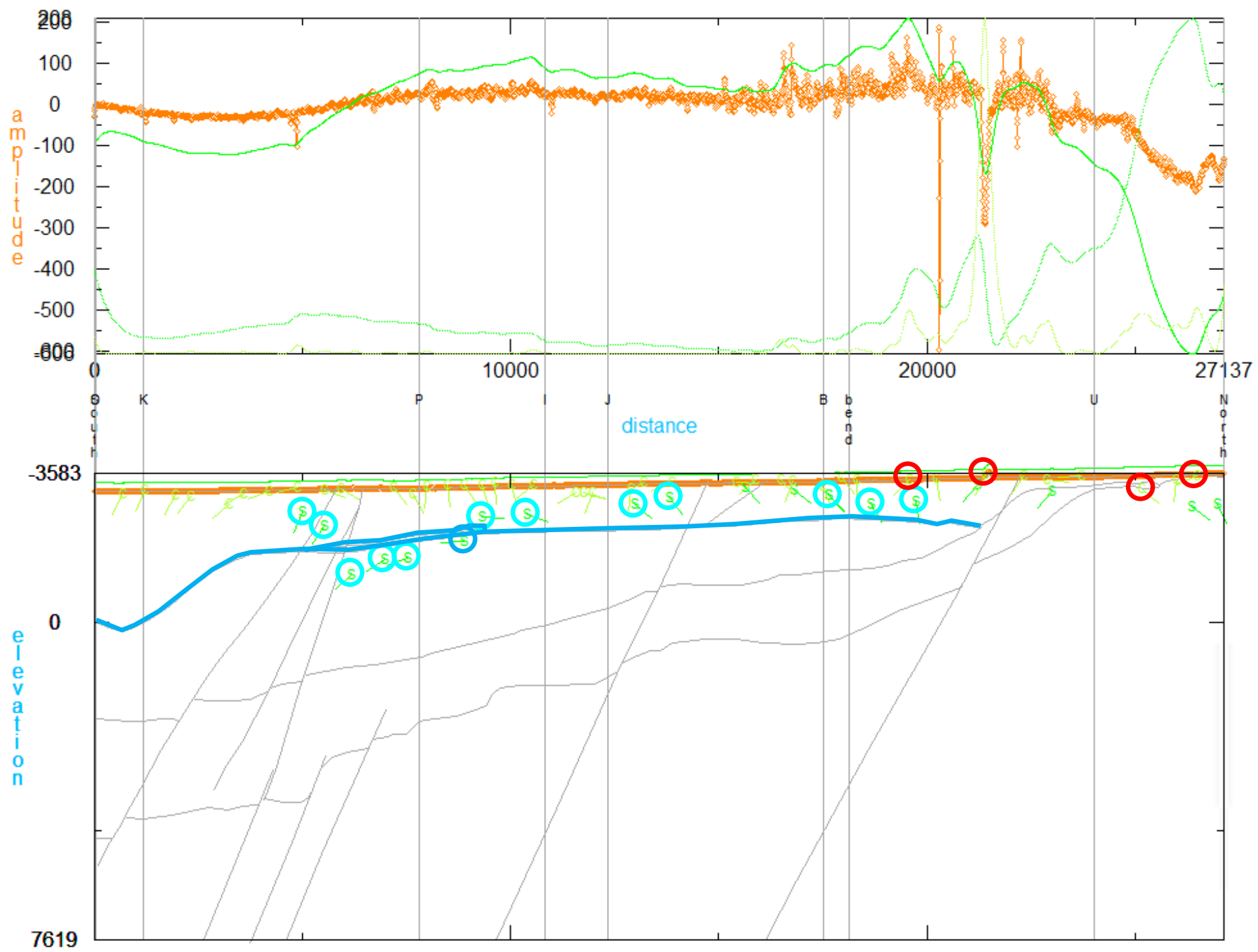

$8 D$. Line C-Analytic Signal depth solutions.

Figure 8. Line C. See figure 6 for description. 


\section{Line D}

Line D (fig. 9) extends east from north of drill hole UE11a, past drill hole UE11b, to an intersection with the northern end of line $\mathrm{N}$ (plate 1). The EV model shows a major westdipping normal fault near the 4,000-ft distance marker that brings Timber Mountain Group (Tmt, plate 1) near the surface on the east side. A short section of basalt is present around the 1,000-ft distance marker, just above the buried Timber Mountain Group. The HG sheet solutions include one source that is near the predicted basalt flow horizon. The sheet solutions from the MSW and AS methods are all at shallow depths. Three significant HG contact solutions occur in the vicinity of the predicted fault. Model studies (Grauch and Hudson, 2007) suggest that the solution at distance marker 3,750 is the best estimate of the fault trace, whereas the adjacent solutions are likely artifacts produced by side-lobes. There is a large negative spike and offset of unknown origin in the observed magnetic field near the predicted fault location. The upward continuation filtering is effective in removing this apparent artifact from the analysis. One significant AS contact solution occurs at the predicted fault location. Another, near the 5,100-ft distance marker, is interpreted as a northeast-trending normal fault in plate 1. 


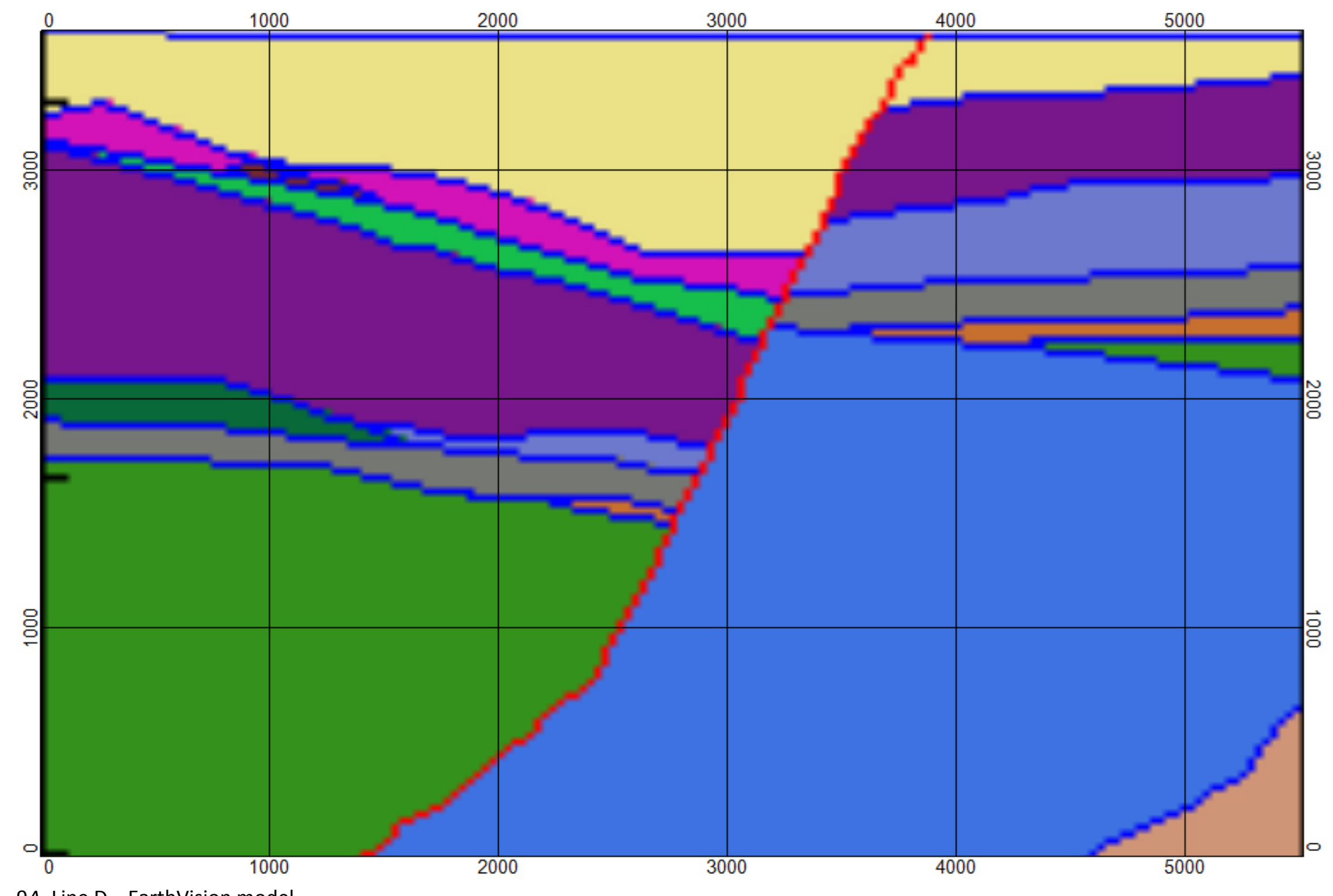

9A. Line D-EarthVision model. 


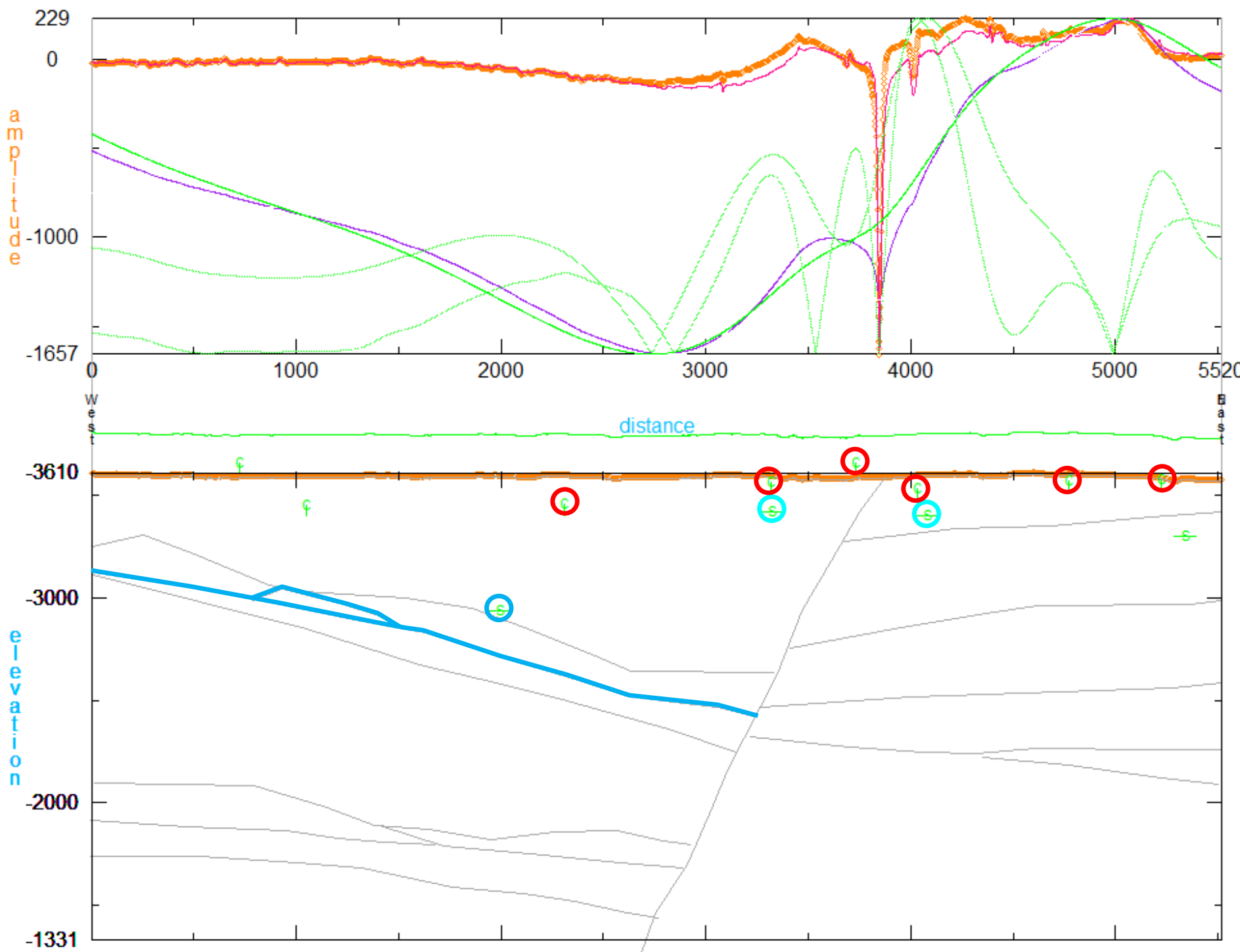

$9 B$. Line D-Horizontal Gradient depth solutions. 


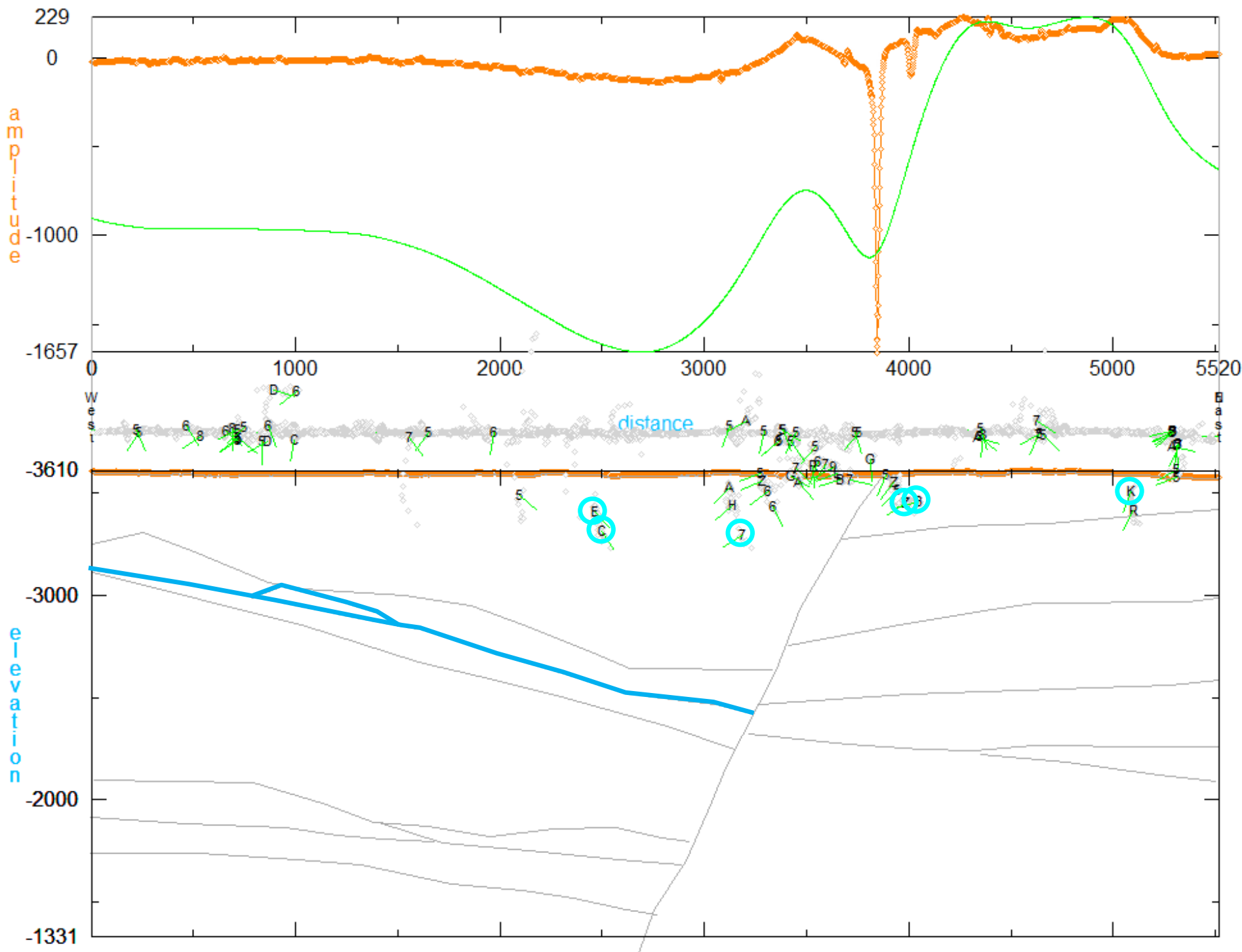

9C. Line D-Multiple-source Werner sheet solutions. 


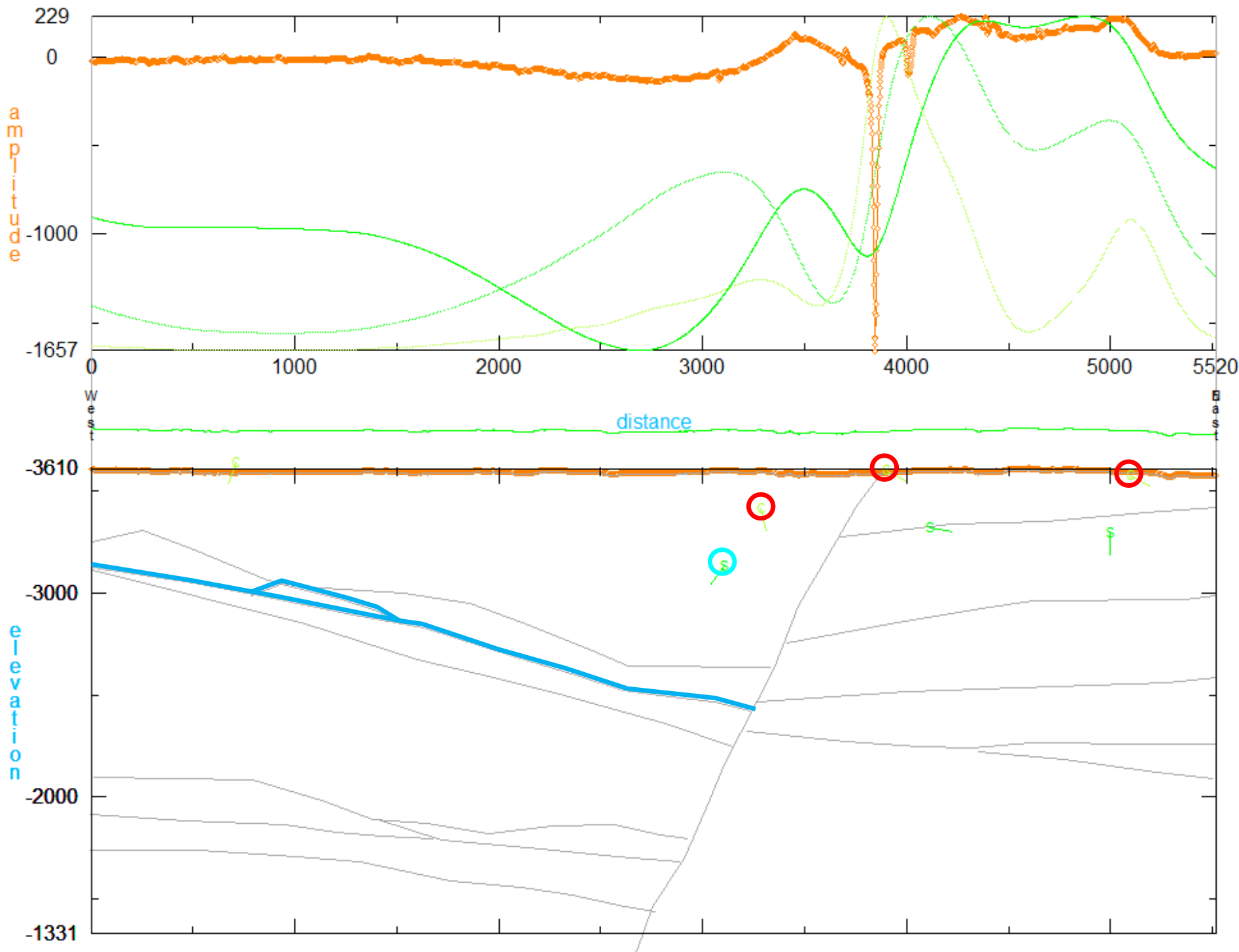

$9 D$. Line D-Analytic Signal depth solutions.

Figure 9. Line D. See figure 6 for description. 


\section{Line $\mathbf{E}$}

Line $\mathrm{E}$ (fig. 10) extends east from near the eastern end of Line $\mathrm{D}$ to an intersection with Line A. The EV model shows shallow Timber Mountain Group and no faults. Most sheet solutions are below the alluvium within the Timber Mountain Group, although some MSW sheet solutions fall within the deeper alluvium. A deep significant AS contact solution near the 3,700$\mathrm{ft}$ distance marker is interpreted as a north-striking, down-to-the-west normal fault in plate 1 . 



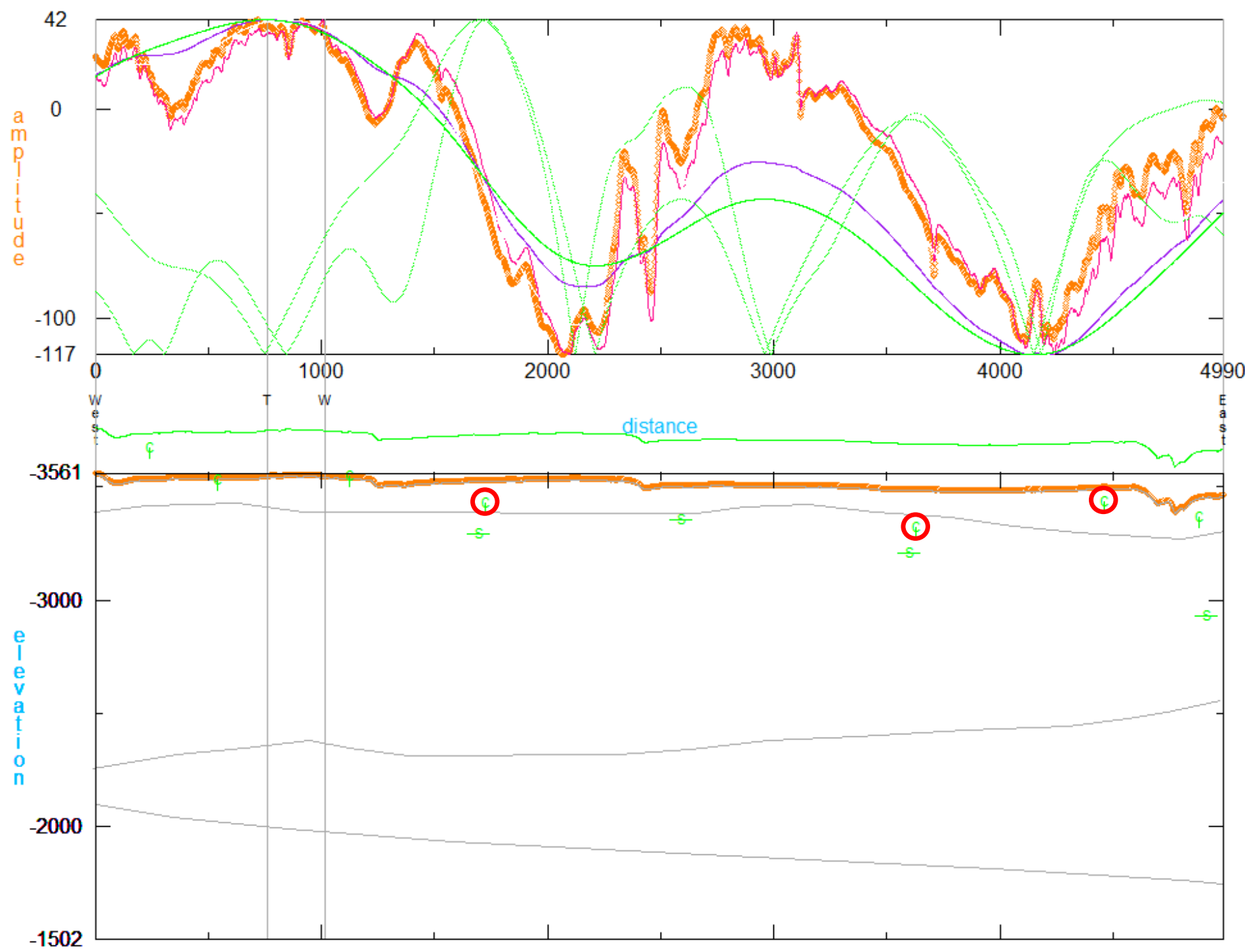

10B. Line E-Horizontal Gradient depth solutions. 


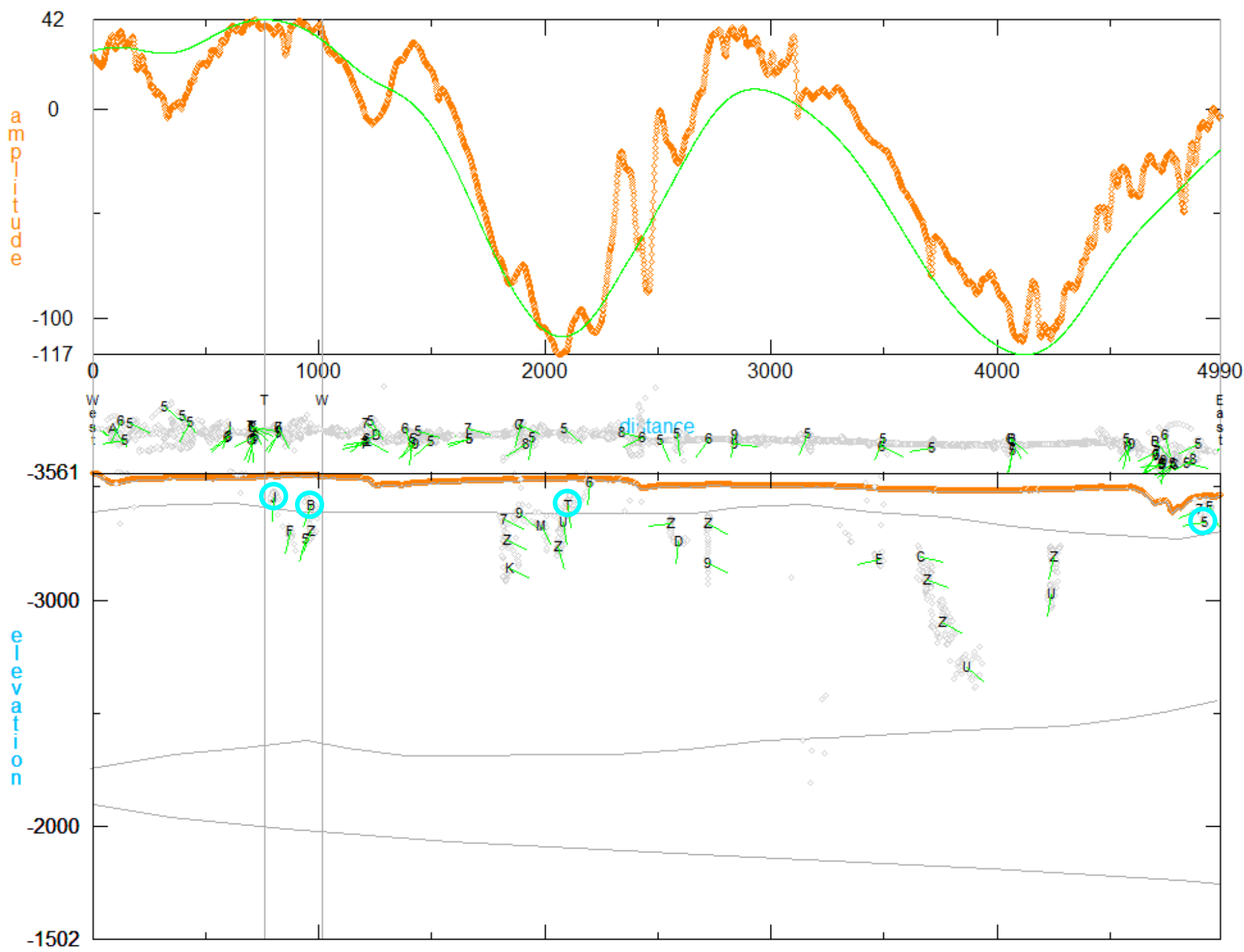

10C. Line E-Multiple-source Werner sheet solutions. 


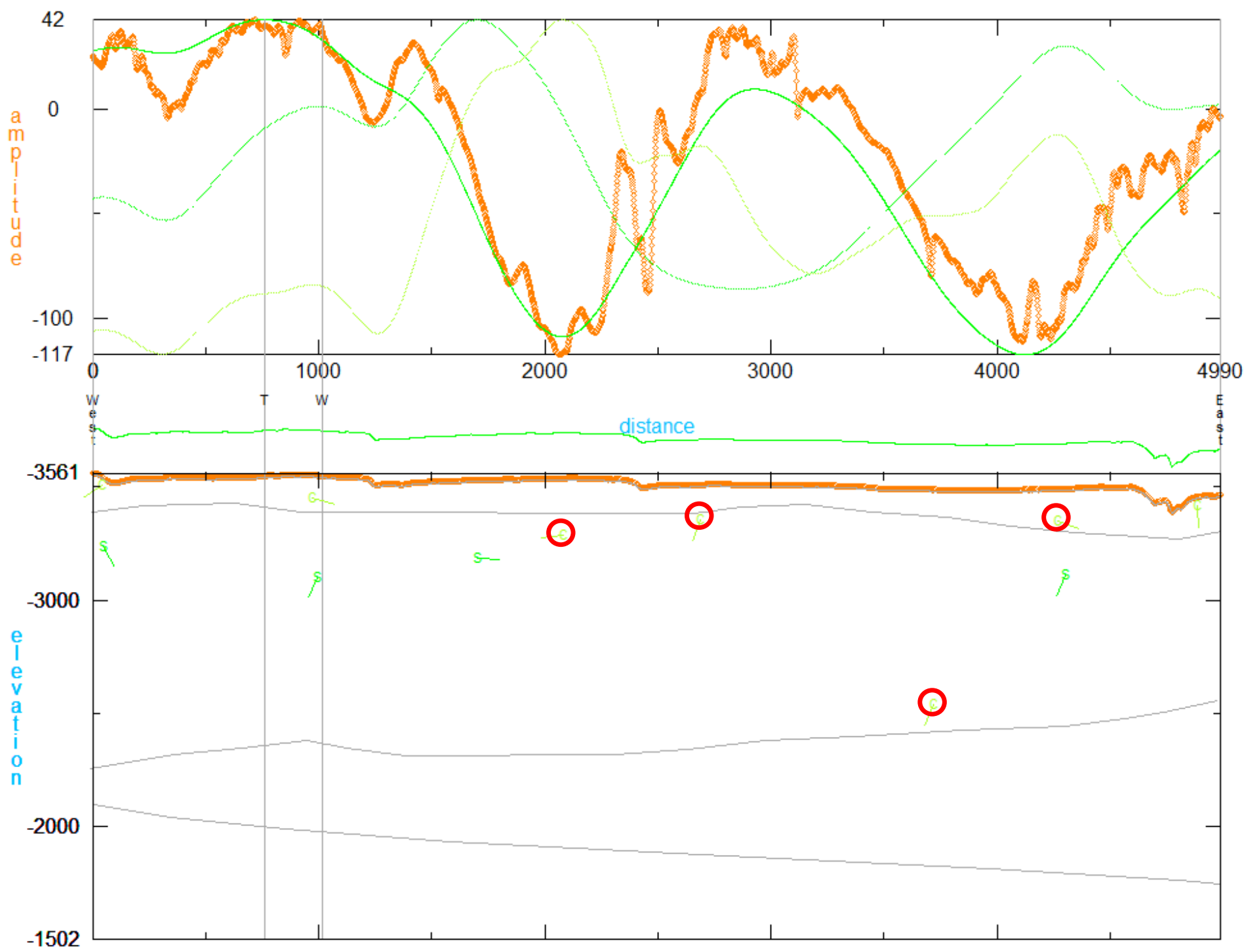

$10 D$. Line $\mathrm{E}-$ Analytic Signal depth solutions.

Figure 10. Line E. See figure 6 for description. 


\section{Line $\mathrm{F}$}

Line F (fig. 11) extends eastward from drill hole UE11a to drill hole UE11c (plate 1). Neither drillhole contains basalt. The EV model shows alluvial thickness increasing to the east, with underlying Timber Mountain Group. Although no basalt is indicated, the stratigraphic horizon containing the basalt in boreholes to the south (the contact between OAA and OAA1) extends across the section. A west-dipping normal fault cuts obliquely through the eastern side of the section. All three HG sheet solutions appear to be at the projected depth of the basalt. The MSW sheet solutions also indicate sources at the projected depth of the basalt as well as shallower sources. A single AS sheet solution is also near the projected depth of the basalt. These results, combined with a broad high in the magnetic profile, suggest that basalt is present under at least the western half of the profile. No significant contact sources were detected. 


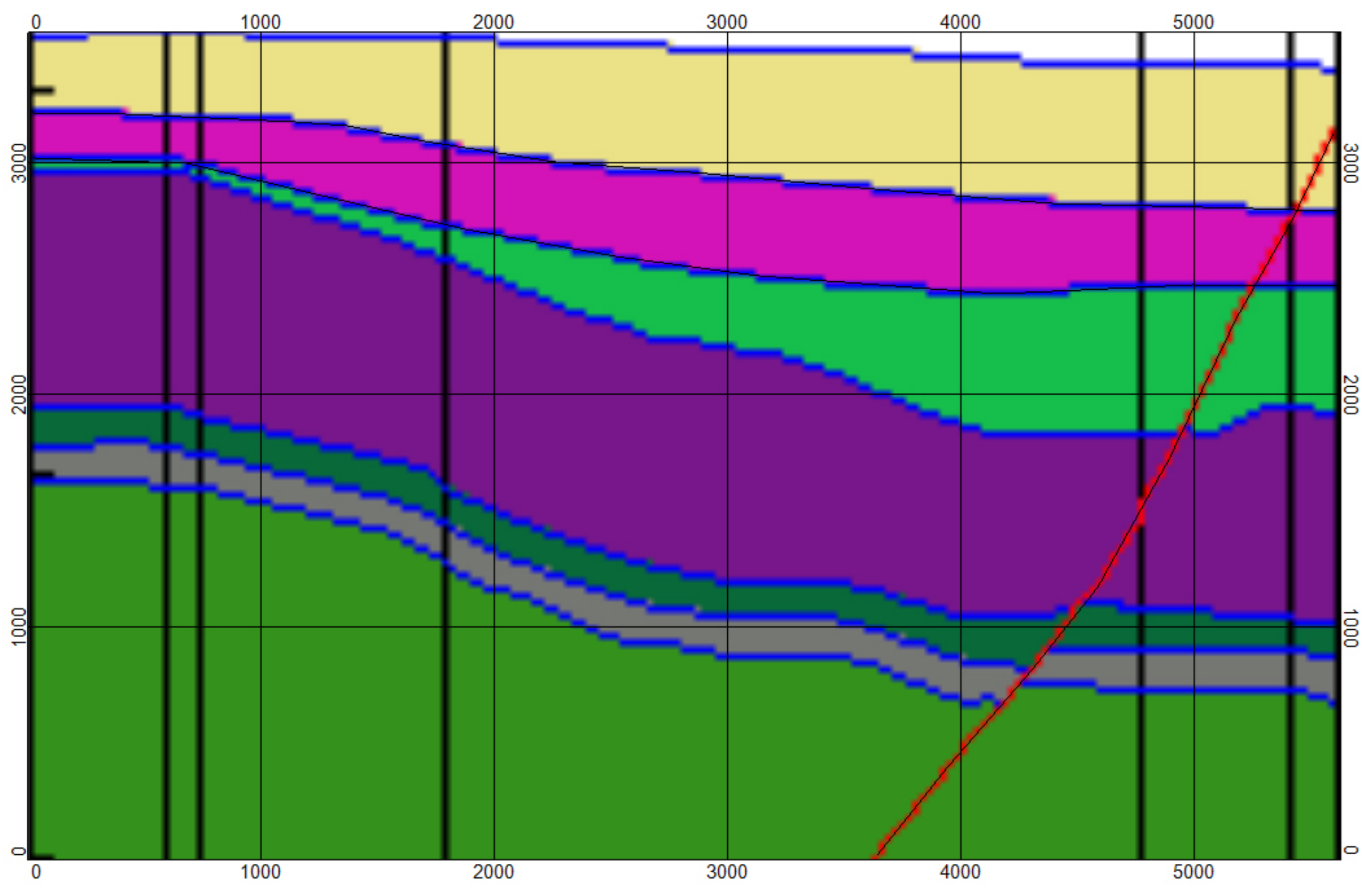

11A. Line F-EarthVision model. 


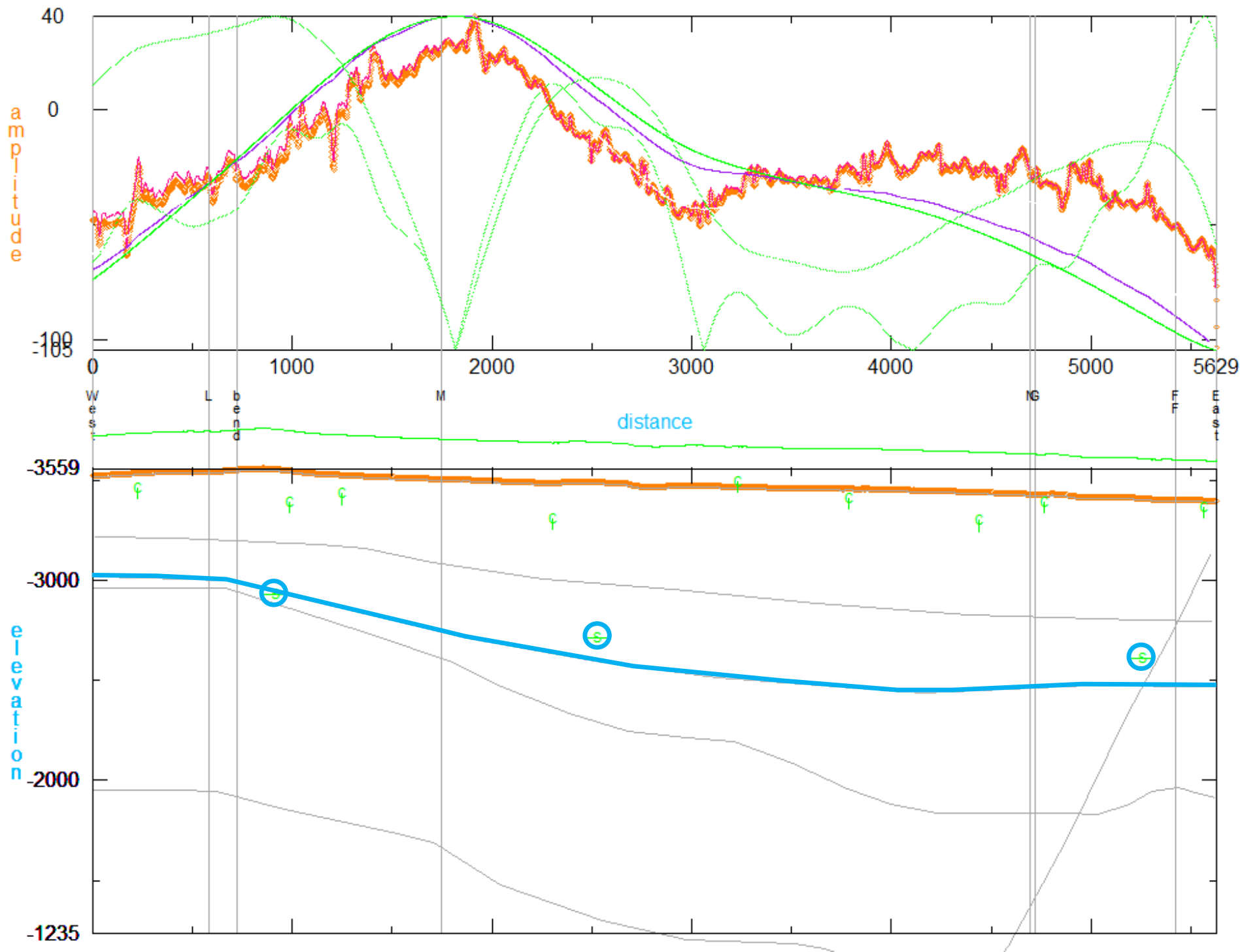

11B. Line F-Horizontal Gradient depth solutions. 


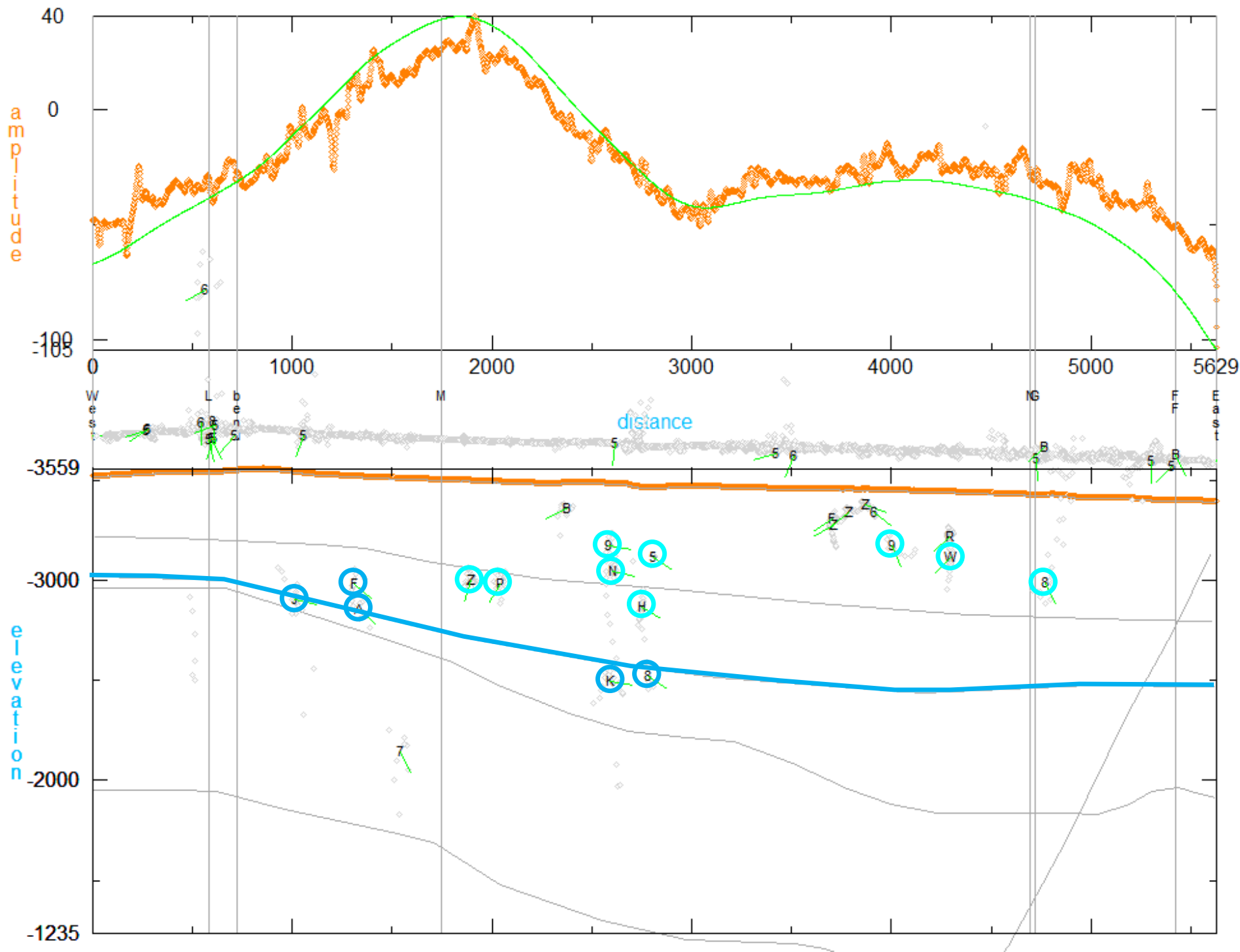

11C. Line F-Multiple-source Werner sheet solutions. 


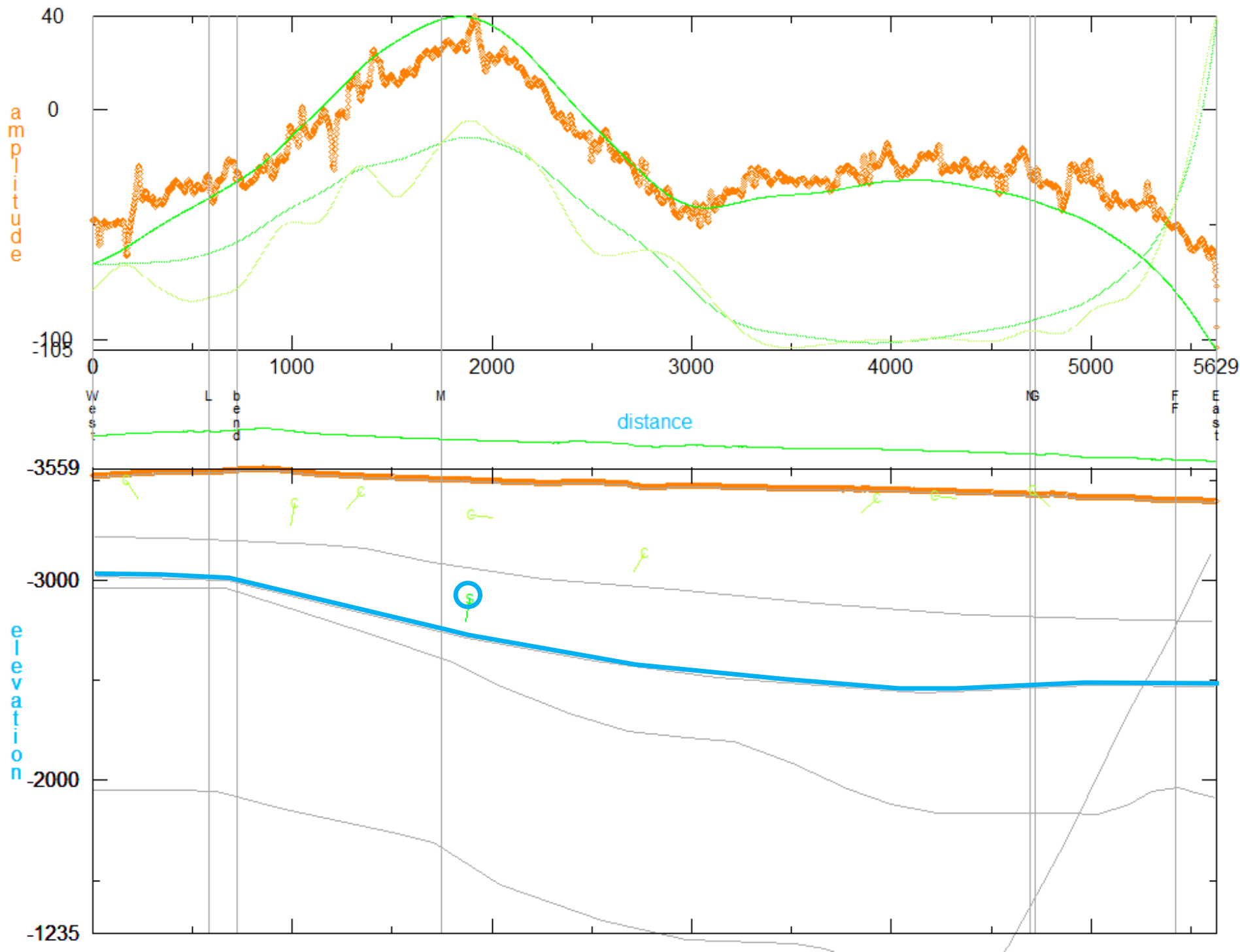

11D. Line F-Analytic Signal depth solutions.

Figure 11. Line F. See figure 6 for description. 


\section{Line $\mathbf{G}$}

Line $\mathrm{G}$ (fig. 12) is a diagonal line extending from the western side of the study area northeast to a point north of drill hole UE11c (plate 1). The EV model shows basalt as being present for a distance of about 2,000 ft near the center of the line. The stratigraphic horizon containing the basalt extends across the entire section. One of three HG sheet solutions falls on this horizon, to the northeast of the modeled basalt. The MSW sheet solutions indicate sources near the basalt horizon in the central part of the section. The AS sheet solutions near the projected depth of the basalt extend to the southwestern end of the section. Thus it seems likely that basalt is present across much of the section. Although no significant contact sources were detected, the noise level in the magnetic profile increases dramatically to the east of distance marker 9,200, indicating an abrupt change in the near-surface magnetic properties. 


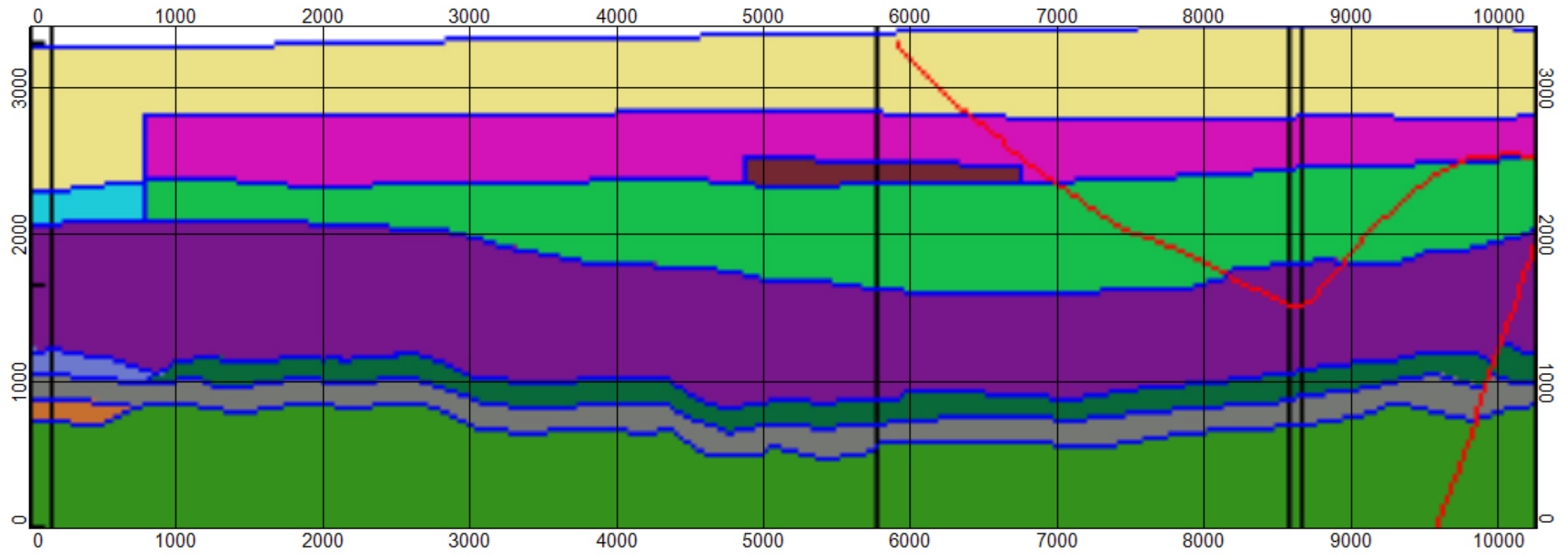

12A. Line G-EarthVision model. 


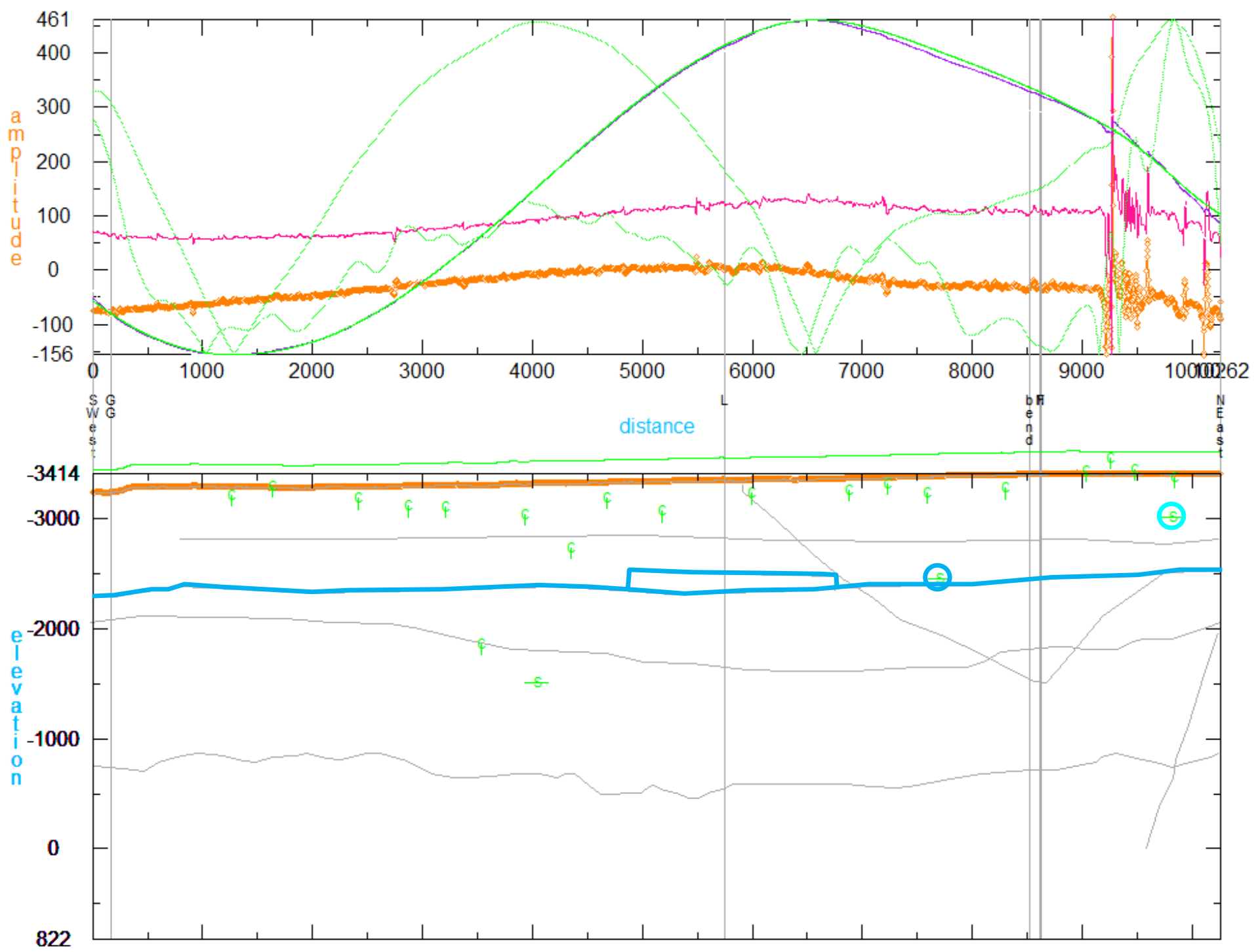

12B. Line G-Horizontal Gradient depth solutions. 


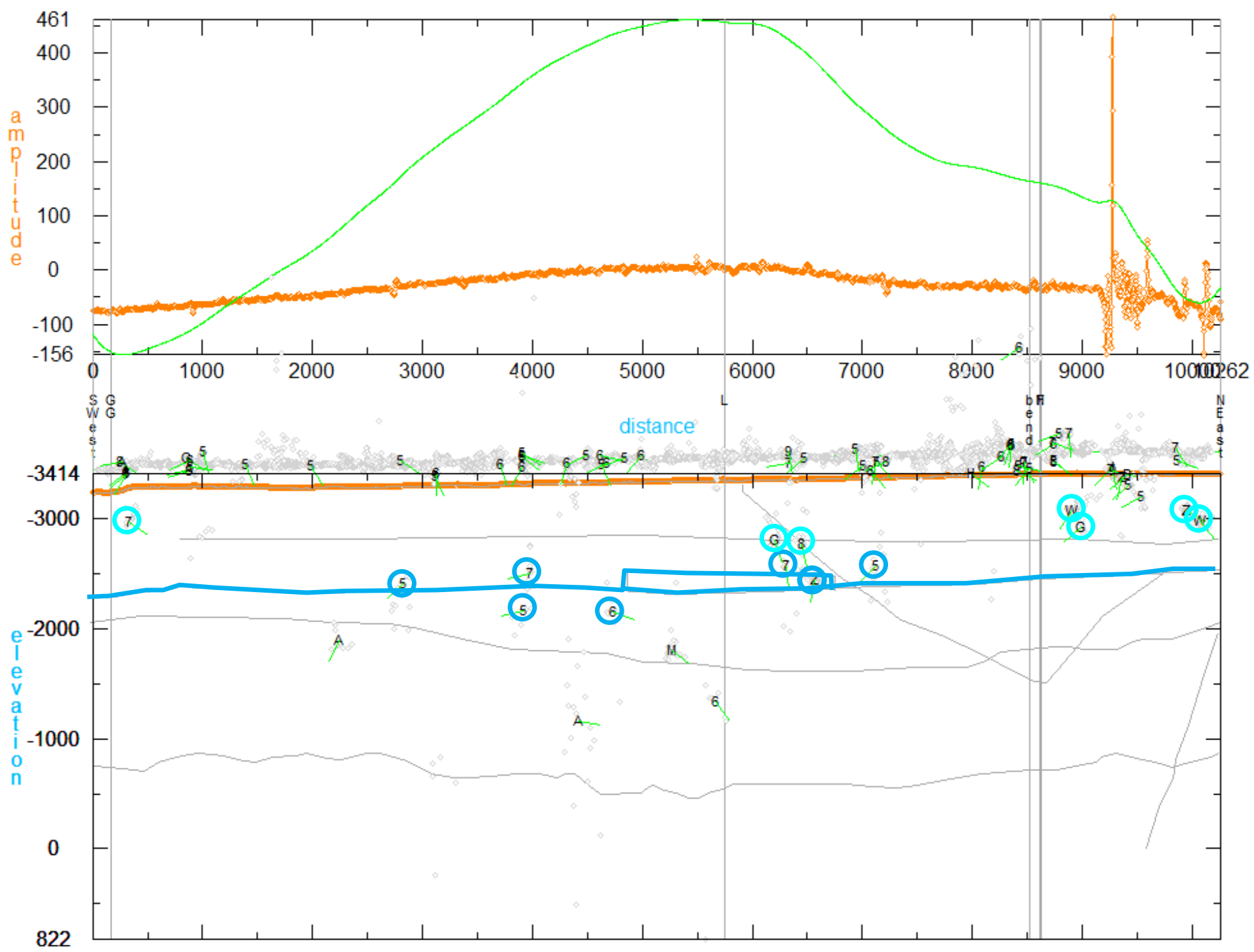

12C. Line G-Multiple-source Werner sheet solutions. 


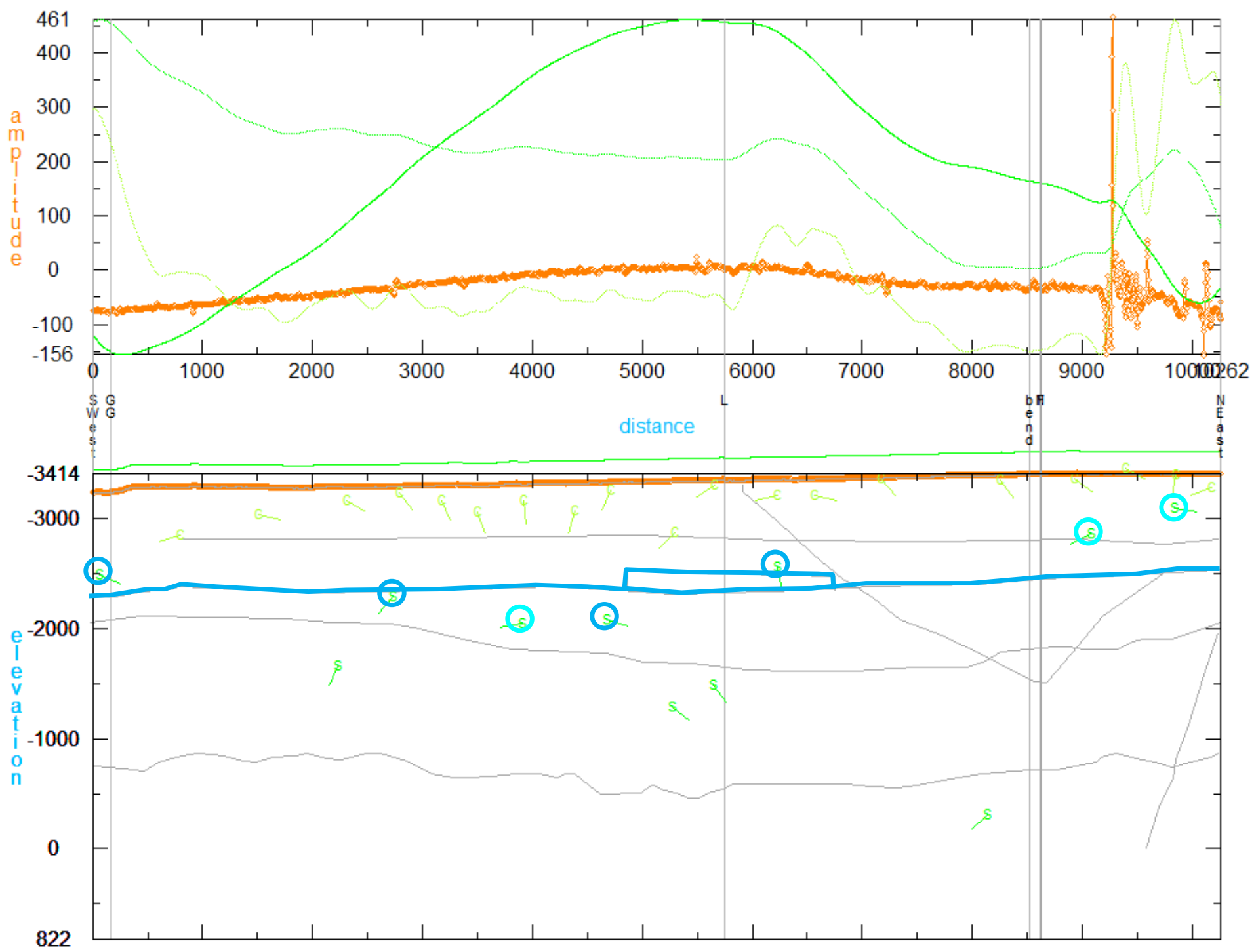

12D. Line G-Analytic Signal depth solutions.

Figure 12. Line G. See figure 6 for description. 


\section{Line $\mathrm{H}$}

Line $\mathrm{H}$ (fig. 13) extends east from Line $\mathrm{N}$ to the southern end of Line $\mathrm{A}$, near drill hole UE5k (plate 1). In the EV model, the basalt flow is present under the eastern two-thirds of the line. The magnetic profile is badly contaminated by a series of spikes produced by unknown sources at very shallow depth. As a result of this contamination, no sheet solutions are seen at the depth of the basalt. The spikes also appear to generate significant but spurious contact solutions. 


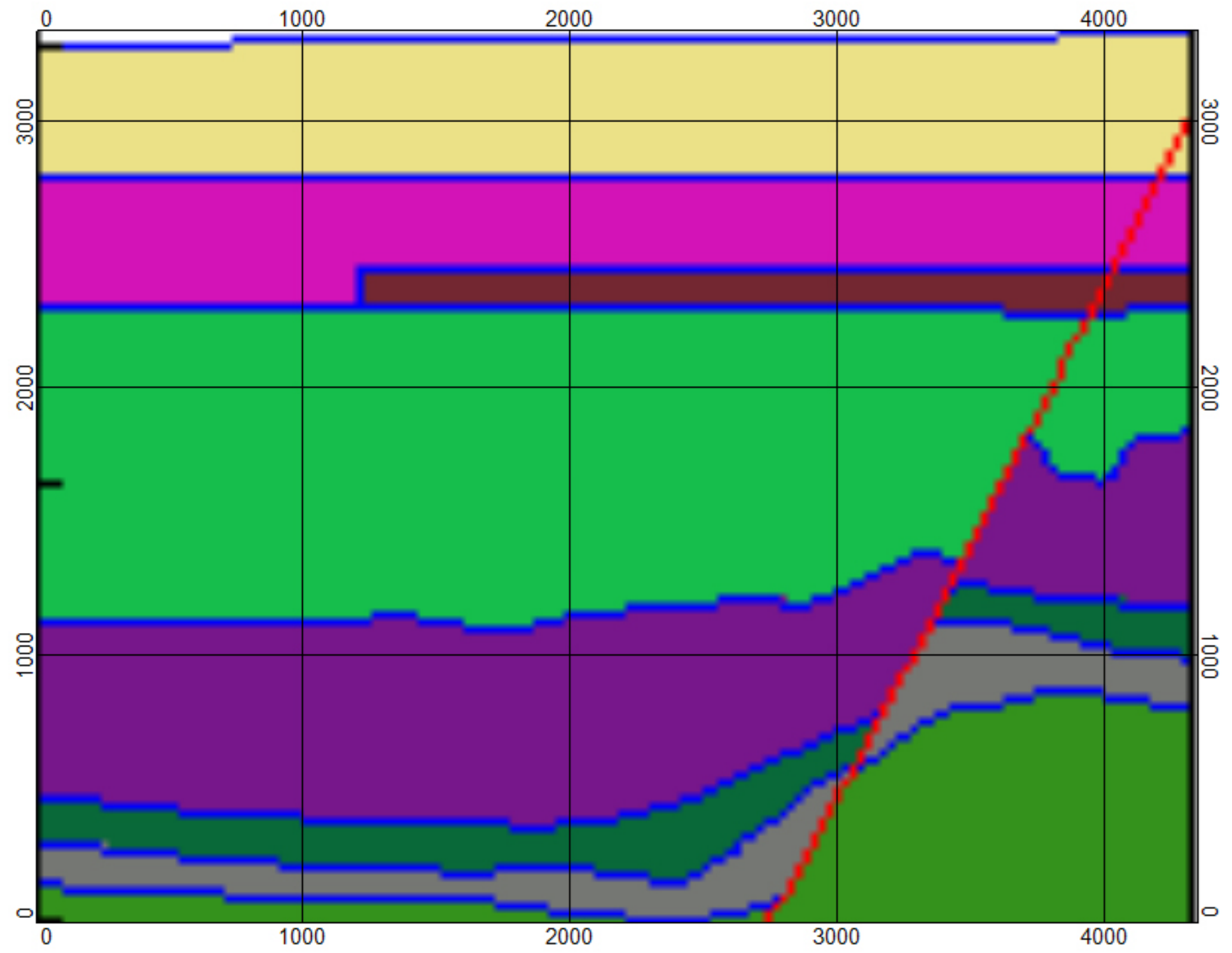

13A. Line $\mathrm{H}-$ EarthVision model. 


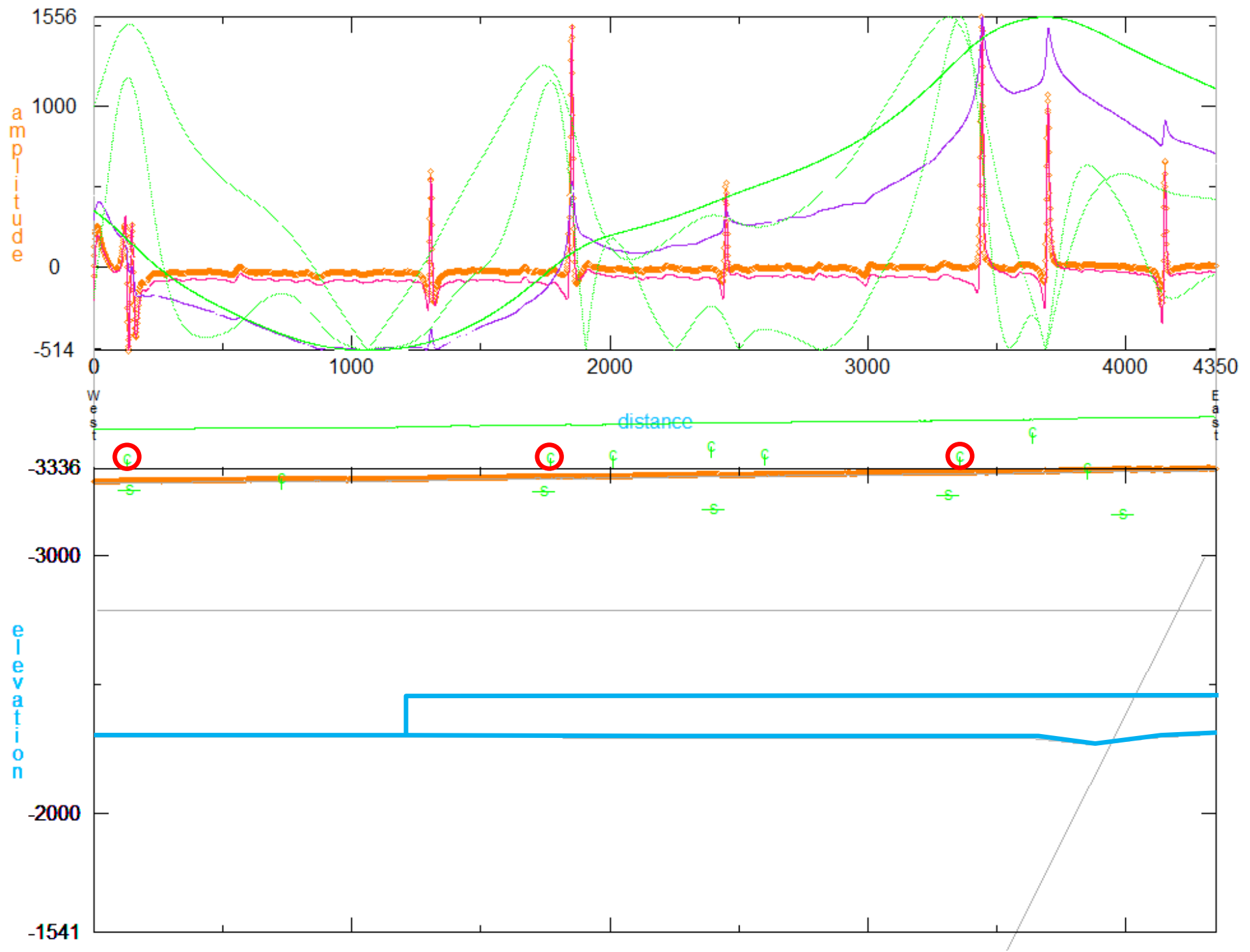

13B. Line $\mathrm{H}-$ Horizontal Gradient depth solutions. 


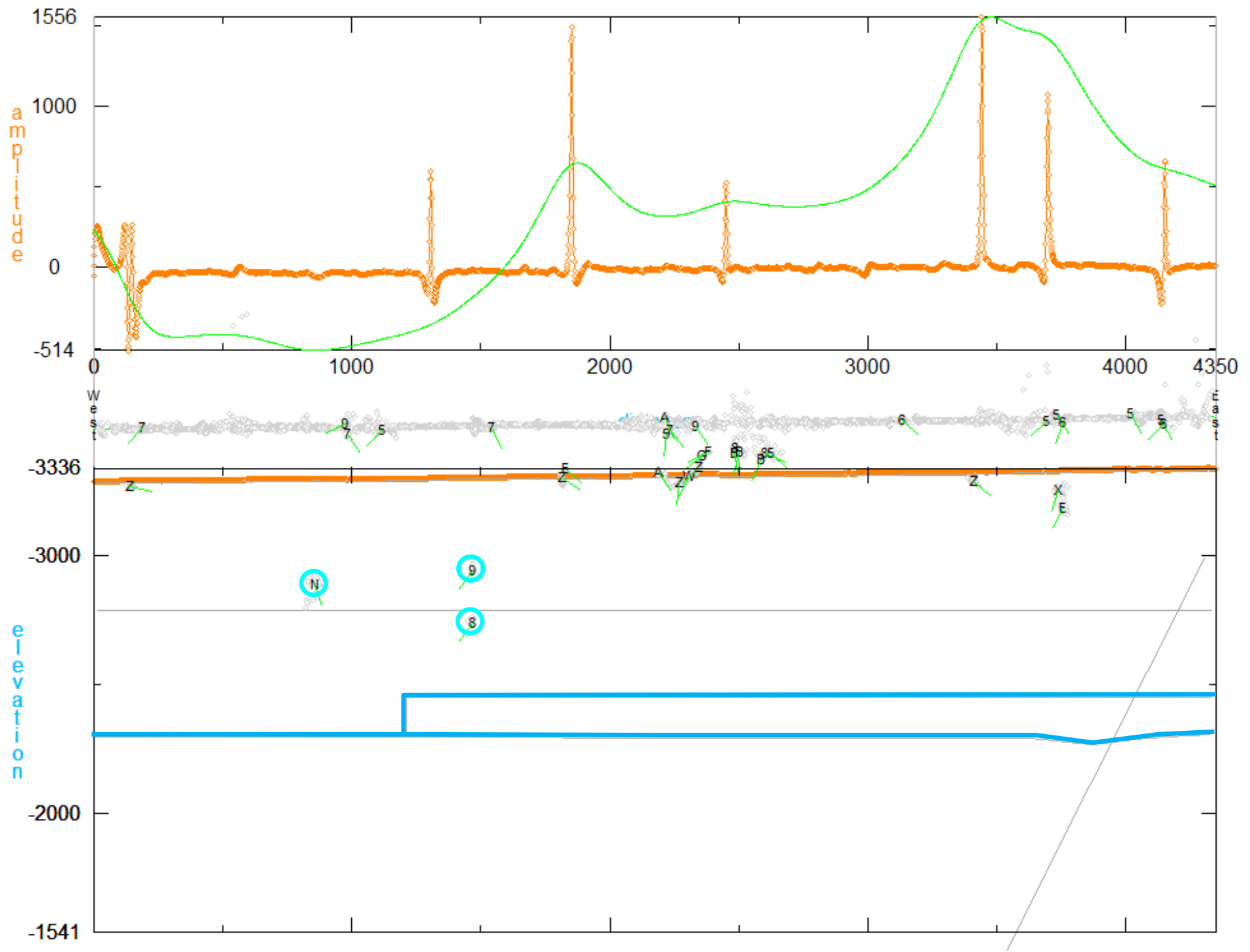

13C. Line H-Multiple-source Werner sheet solutions. 


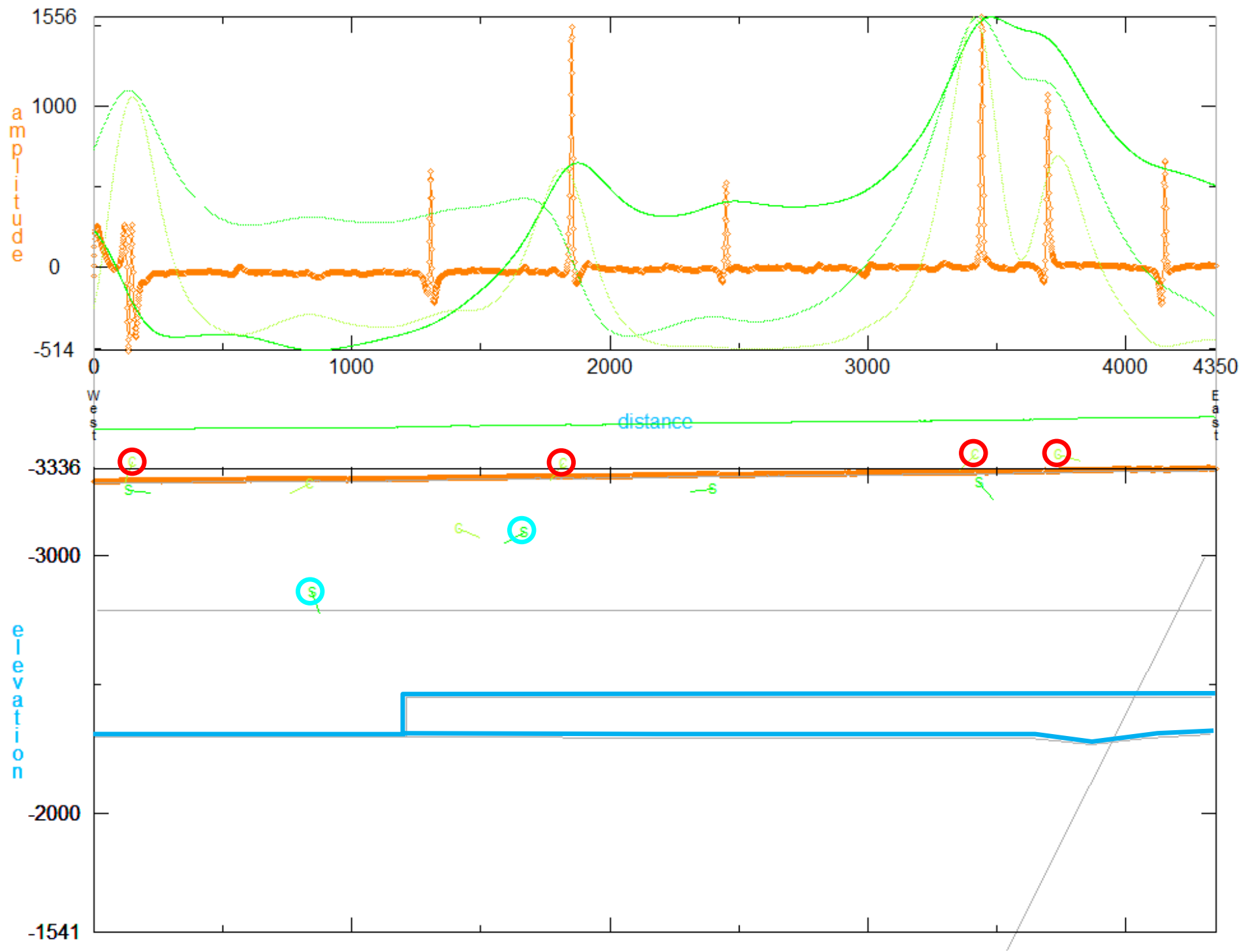

13D. Line $\mathrm{H}-$ Analytic Signal depth solutions.

Figure 13. Line H. See figure 6 for description. 


\section{Line I}

Line I (fig. 14) is a long profile extending eastward from an intersection with Line $\mathrm{N}$ to the eastern side of the study area. The EV model shows three west-dipping normal faults. The basalt is present under the western part of the line, and the horizon containing the basalt extends across most of the line, nearly reaching the easternmost fault. The HG sheet solutions include four sources that are near the projected basalt horizon, with the three best solutions occurring between the two easternmost faults. The MSW and AS sheet solutions also show sources near the depth of the basalt, both where it is modeled and farther to the east. Gaps in the distribution of sheet soultions can be interpreted as possible missing basalt (plate 1). No significant contact sources were detected; however, contact solutions near distance marker 12,000 correspond to a change in the character of the magnetic profile that could indicate a contact or fault. 


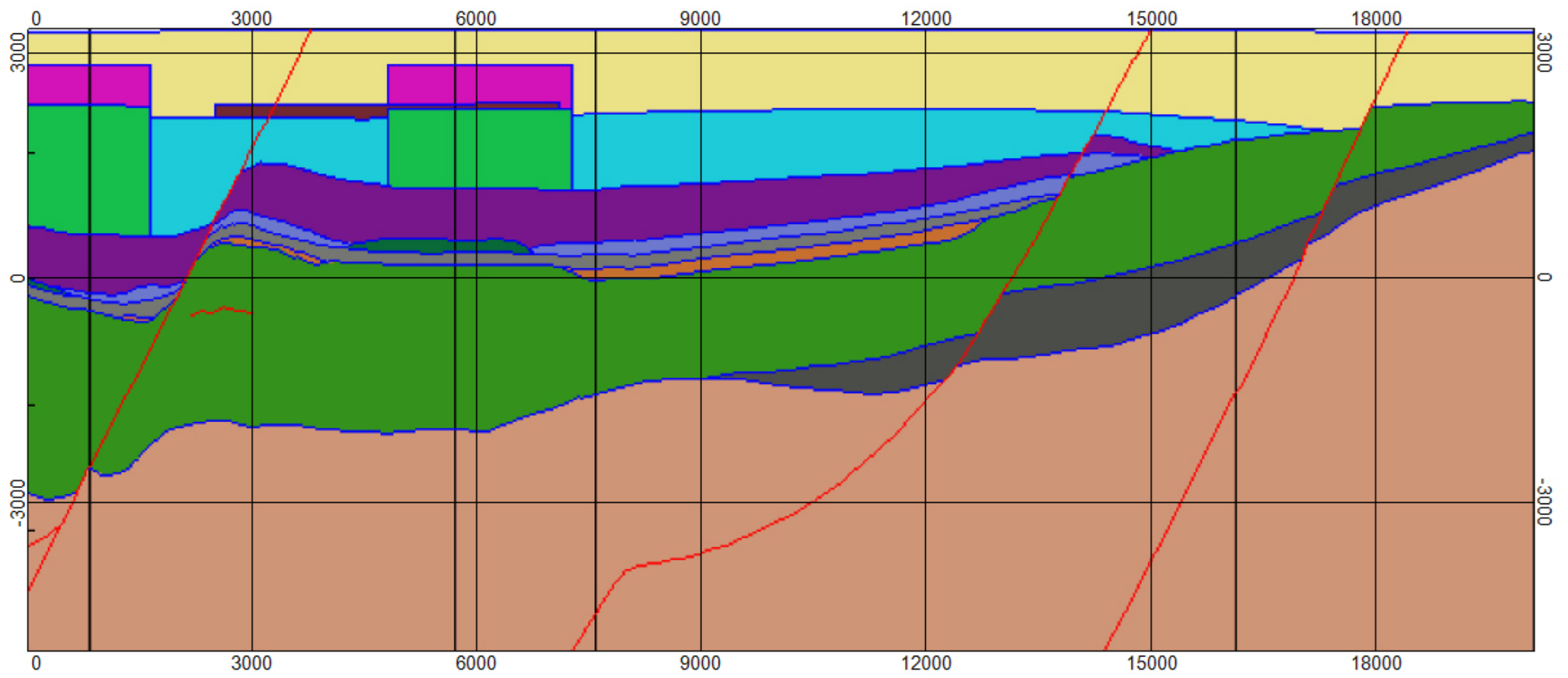

14A. Line I-EarthVision model. 


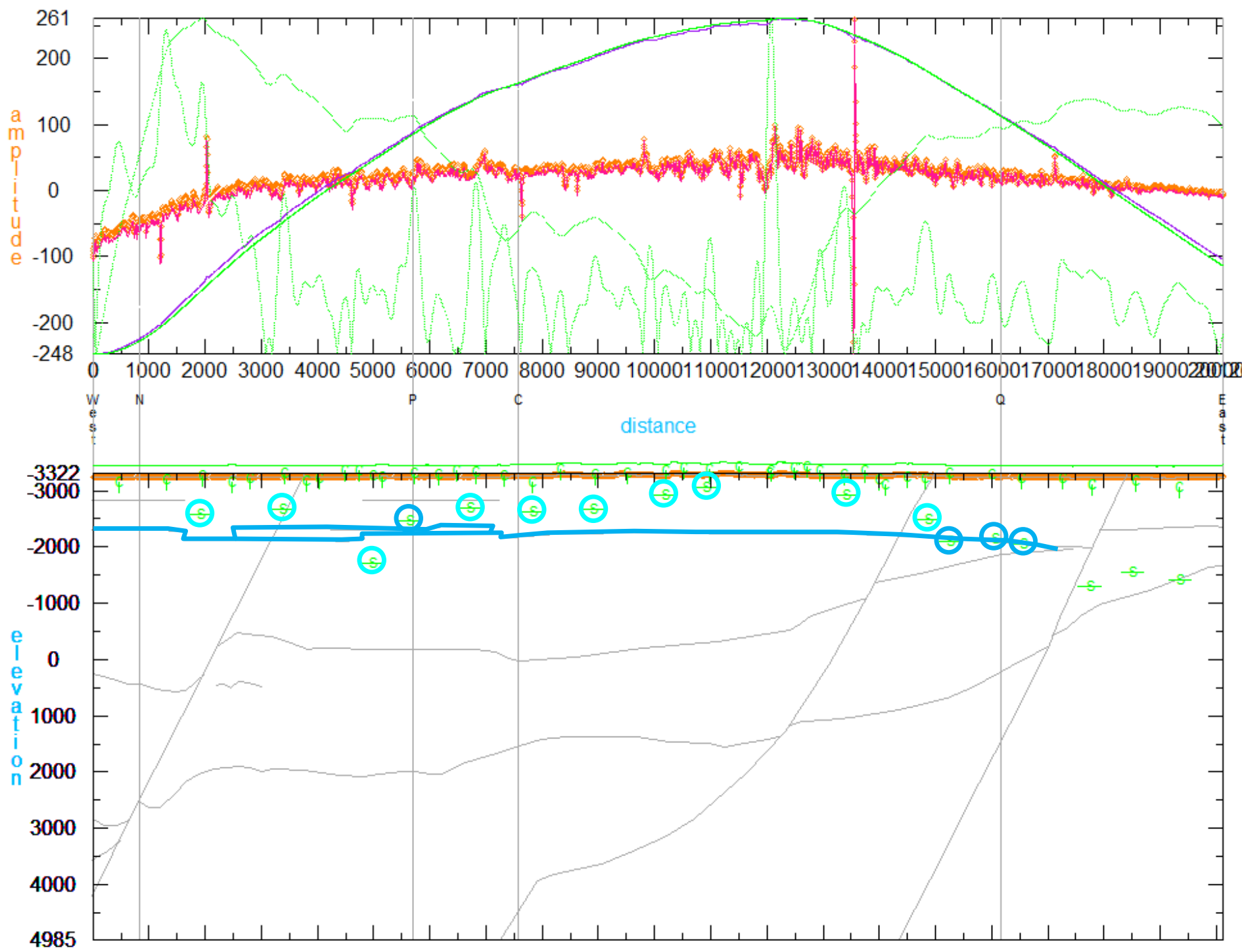

14B. Line I-Horizontal Gradient depth solutions. 

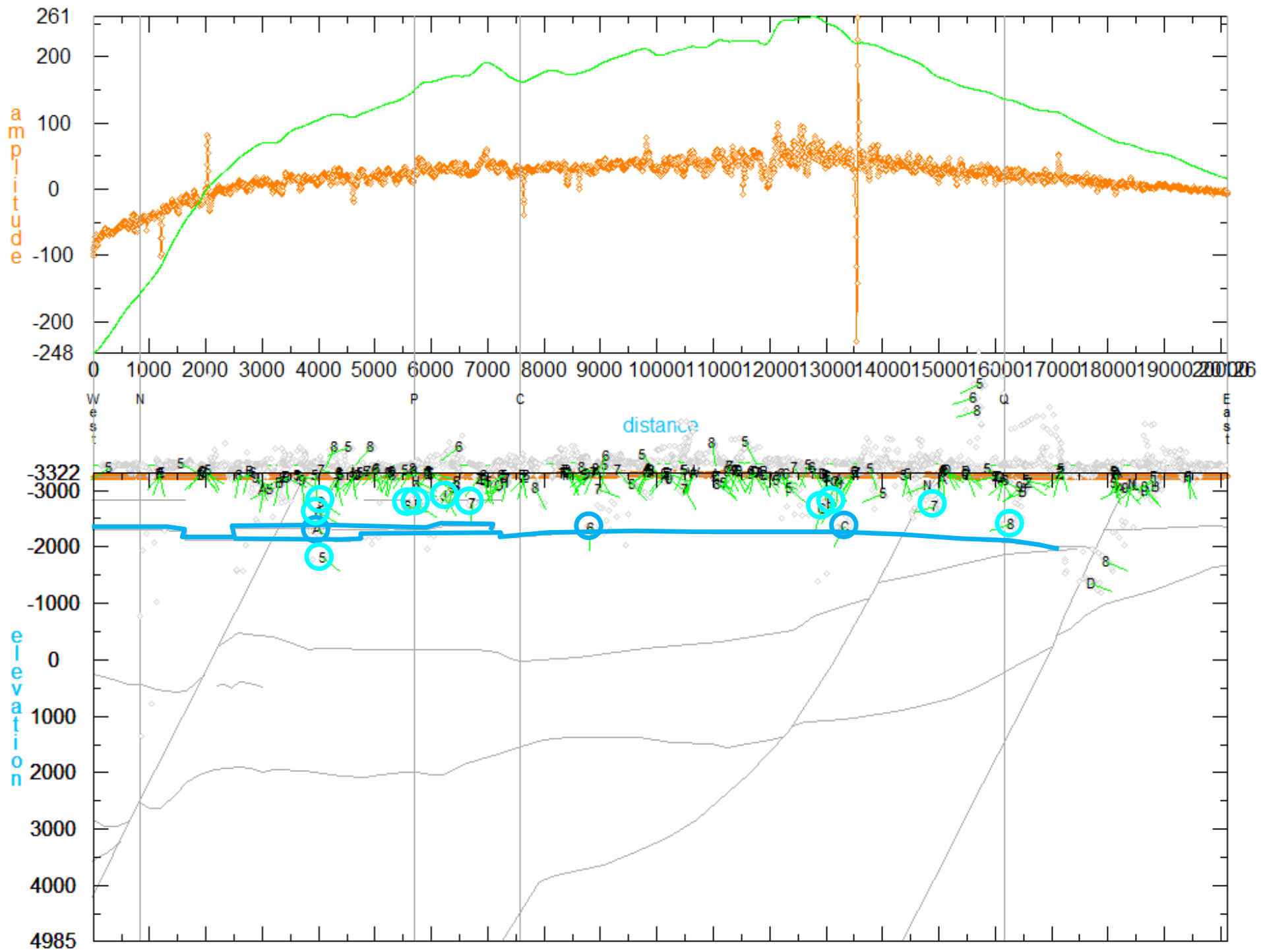

14C. Line I-Multiple-source Werner sheet solutions. 

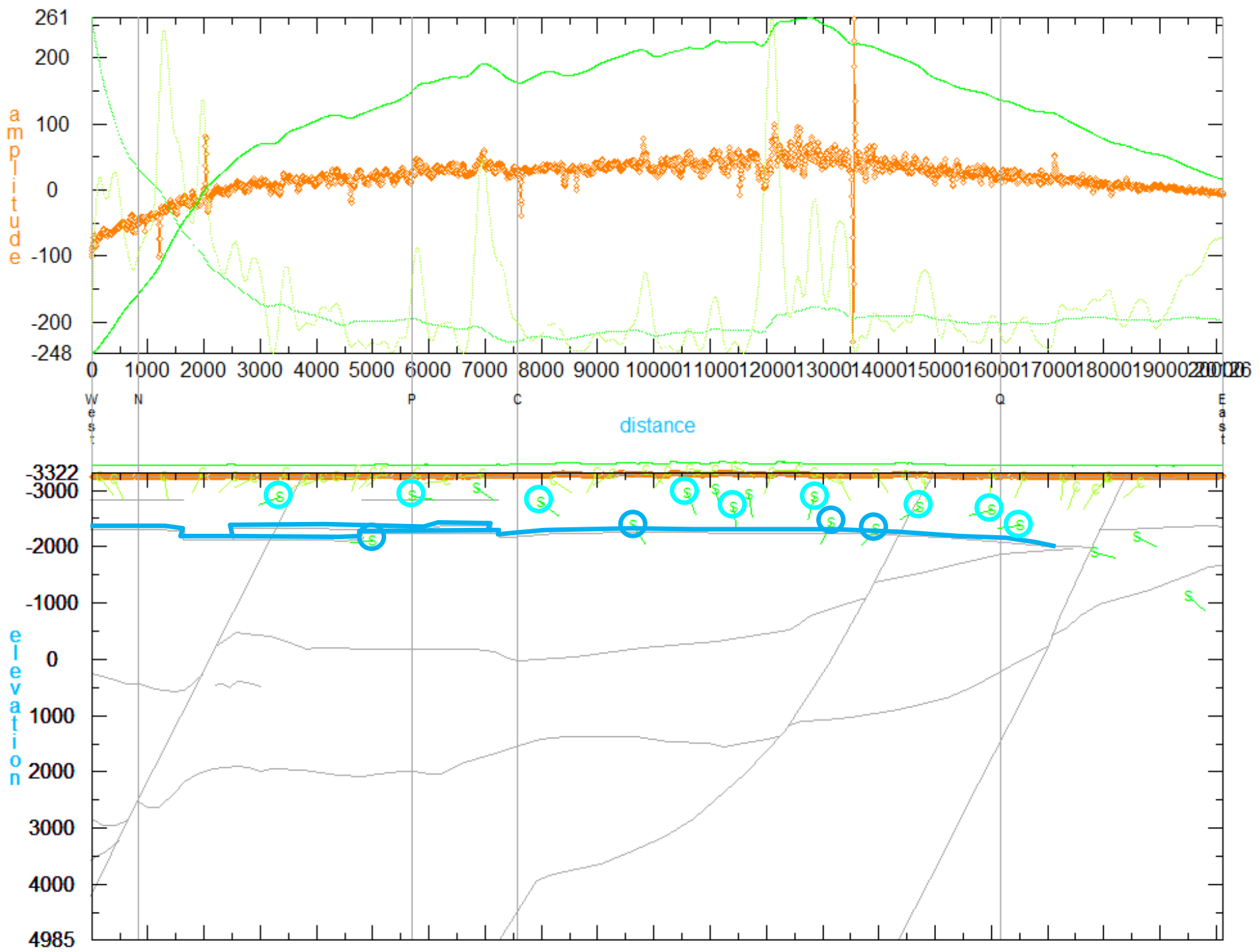

14D. Line I-Analytic Signal depth solutions.

Figure 14. Line I. See figure 6 for description. 


\section{Line $\mathrm{J}$}

Line $\mathrm{J}$ (fig. 15) is a long line just to the north of Line I. It extends east from an intersection with the northern end of Line P to the western edge of the study area. The EV model shows two west-dipping normal faults. These correspond to the two easternmost faults seen in Line I. The basalt is shown as being present only on the western end of the line, and the horizon containing the basalt extends across most of the line to the easternmost fault. The HG sheet solutions include two sources near the depth of the basalt, at opposite ends of its possible range. The MSW sheet solutions include sources near the depth of the basalt both where it is modeled and farther to the east, between the two faults. The AS sheet solutions also include sources near the depth of the basalt horizon between the two faults. It seems likely that the basalt is present both on the western end of the line and between the two faults. The gap in basalt-depth solutions to the west of distance marker 7,000 could be interpreted as evidence for missing basalt (plate 1). However, both the large number of shallower sheet solutions and the noisier character of the magnetic profile within this gap suggest that some sort of magnetic source is present above the level of the basalt. Although no significant contact sources were detected, contact solutions near distance marker 6,750 combined with a change in the character of the magnetic profile at distance marker 7,000 suggest that this is a more likely location for the western fault than its current location at distance marker 7,500. A similar change in the character of the magnetic profile at distance marker 12,400 suggests that this is a better location for the eastern fault than its current location at distance marker 11,600. 


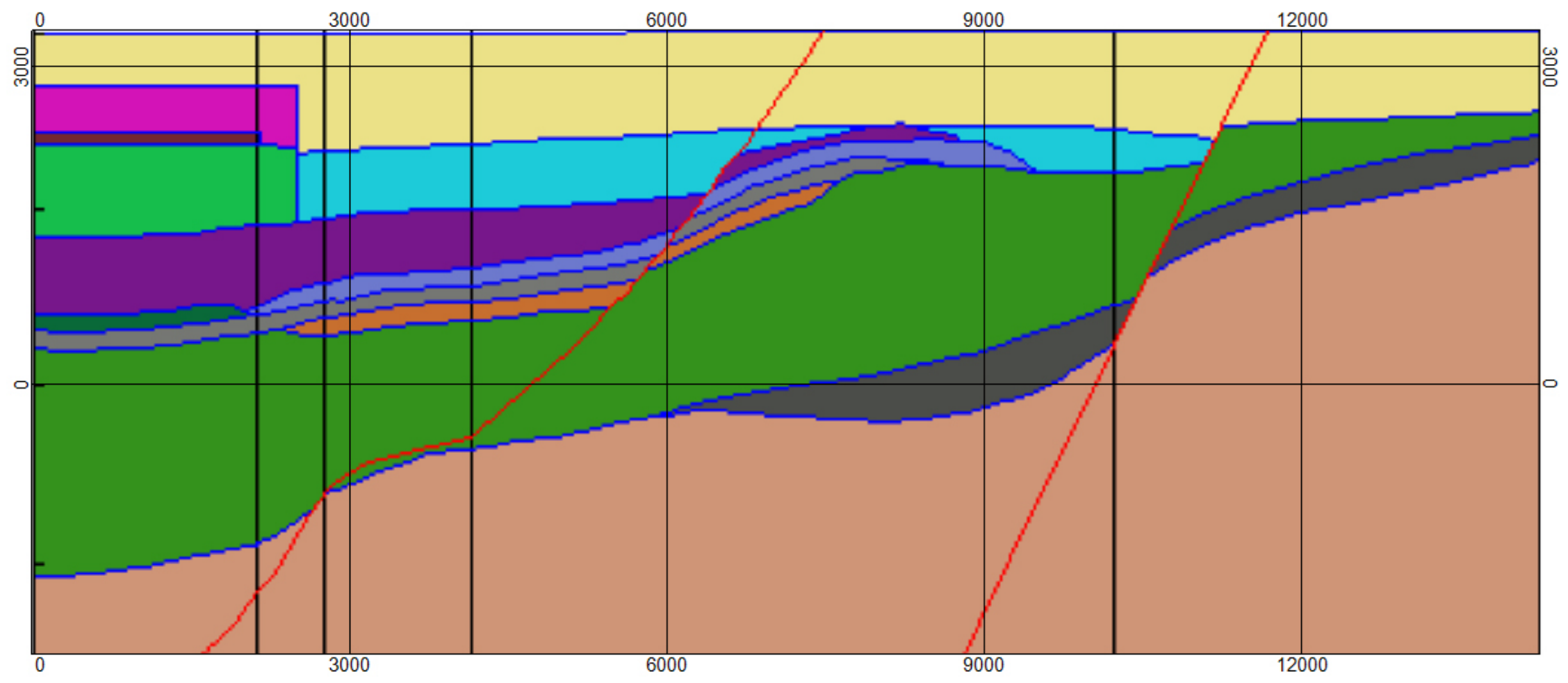

15A. Line J-EarthVision model. 


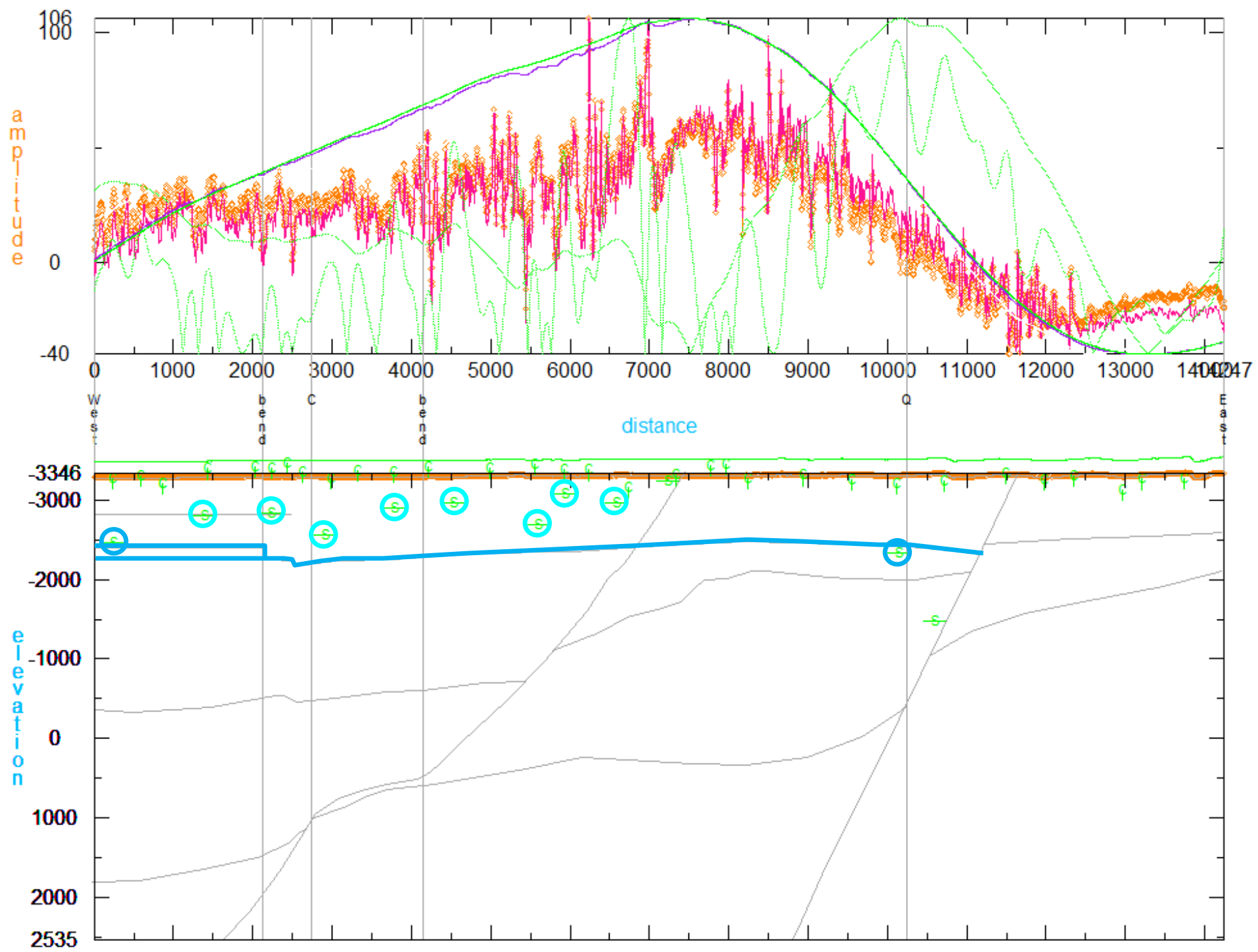

15B. Line J-Horizontal Gradient depth solutions. 


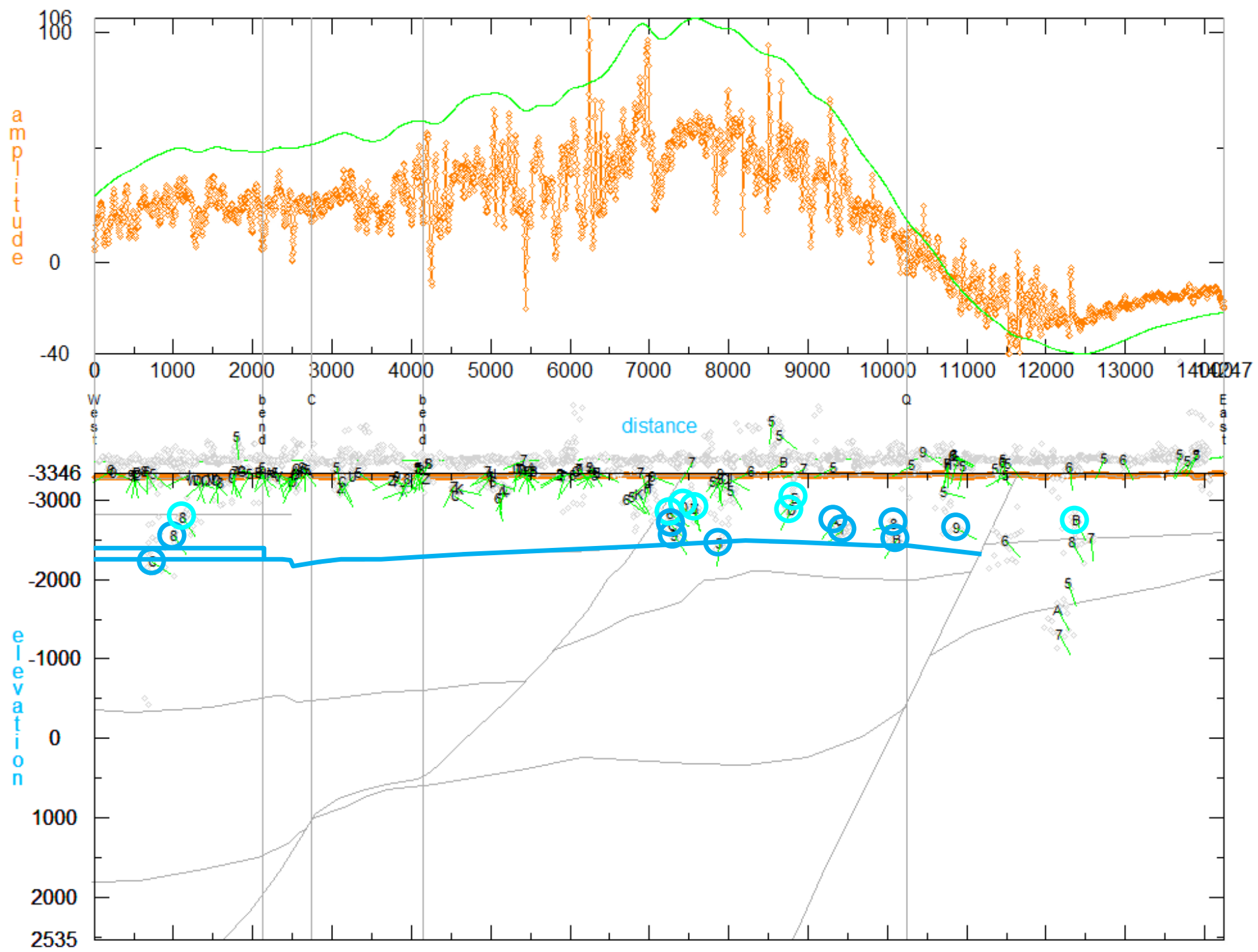

15C. Line J-Multiple-source Werner sheet solutions. 


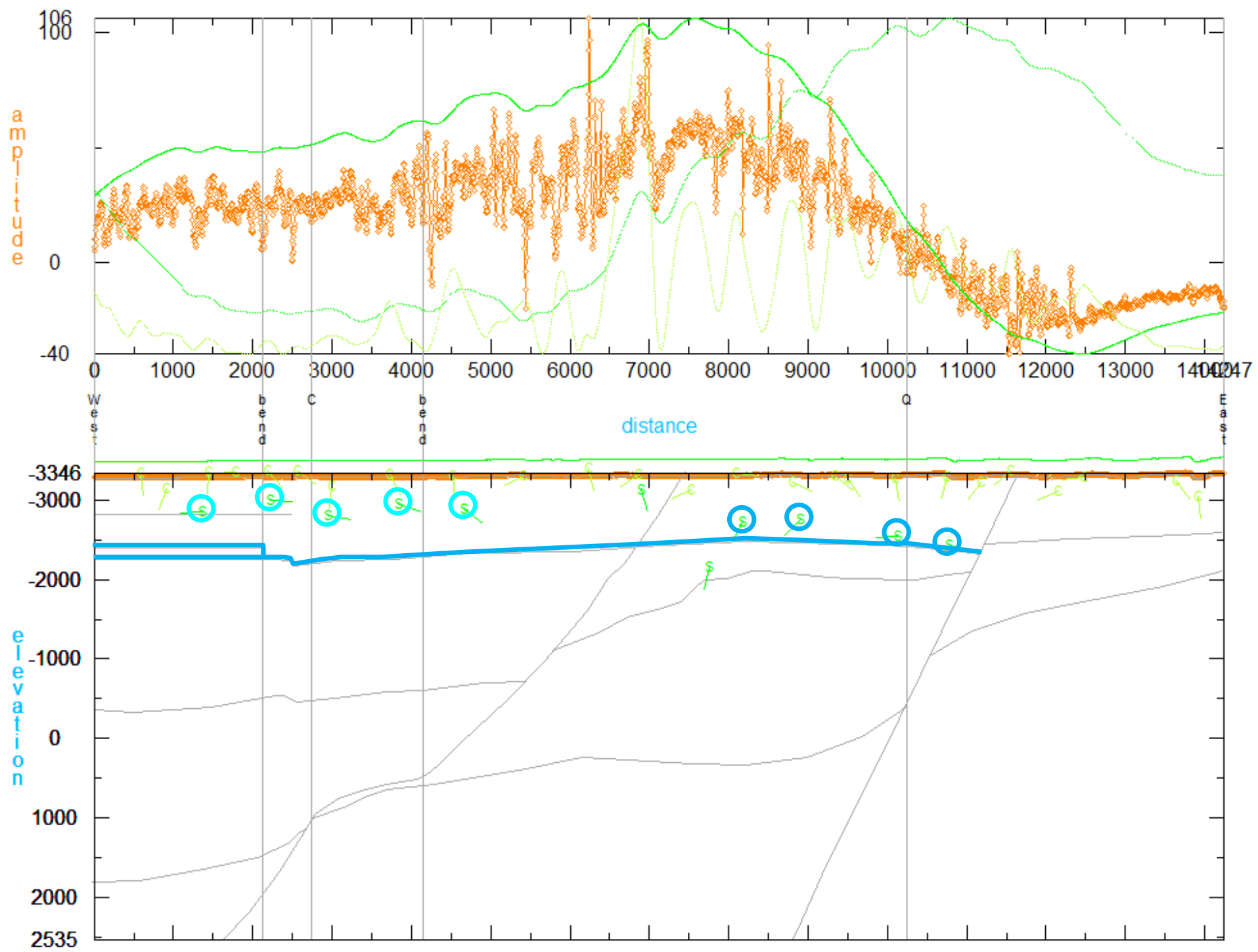

15D. Line J-Analytic Signal depth solutions.

Figure 15. Line J. See figure 6 for description. 


\section{Line $\mathrm{K}$}

Line K (fig. 16) is a long profile along the southern edge of the survey area. It extends from an intersection with Line $\mathrm{C}$ in the west to an intersection with Line $\mathrm{Q}$ and beyond in the east. The EV model shows several west-dipping normal faults with little or no offset at shallow depths. There is no basalt indicated in the EV model, but the stratigraphic horizon corresponding to the basalt extends from the western end of the line almost to the easternmost fault. The HG, MSW, and AS sheet solutions include many sources within the alluvium above the projected basalt horizon, but none are within $250 \mathrm{ft}$ of this horizon. If these sources represent the basalt, then it is shallower than projected; otherwise, the southern limit of the basalt lies to the north of this line. No significant contact sources were detected. An abrupt increase in the noise level of the magnetic profile to the east of distance marker 5,200 may require the westernmost fault to be moved 1,200 ft to the east from its present location. The high noise level continues to distance marker 15,900, near the location of the easternmost fault. 


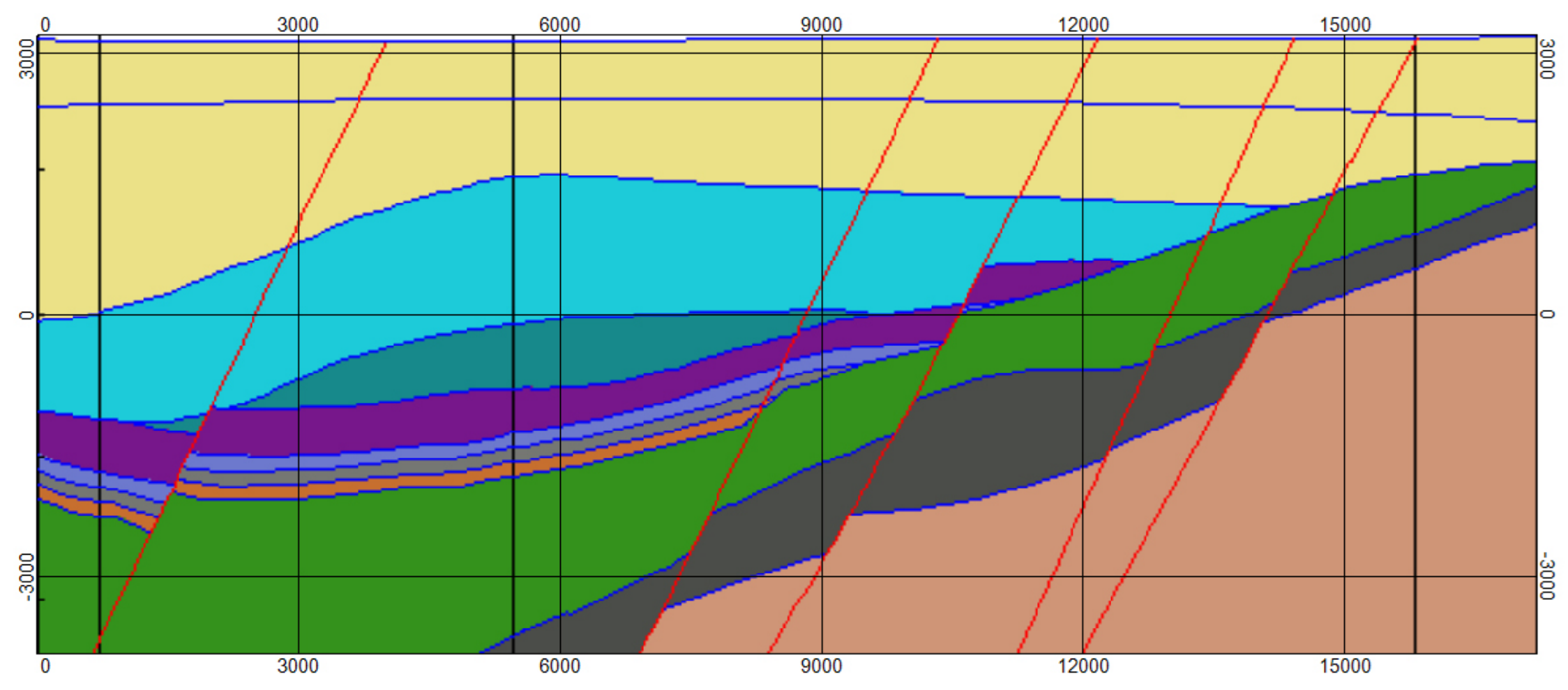

16A. Line K-EarthVision model. 


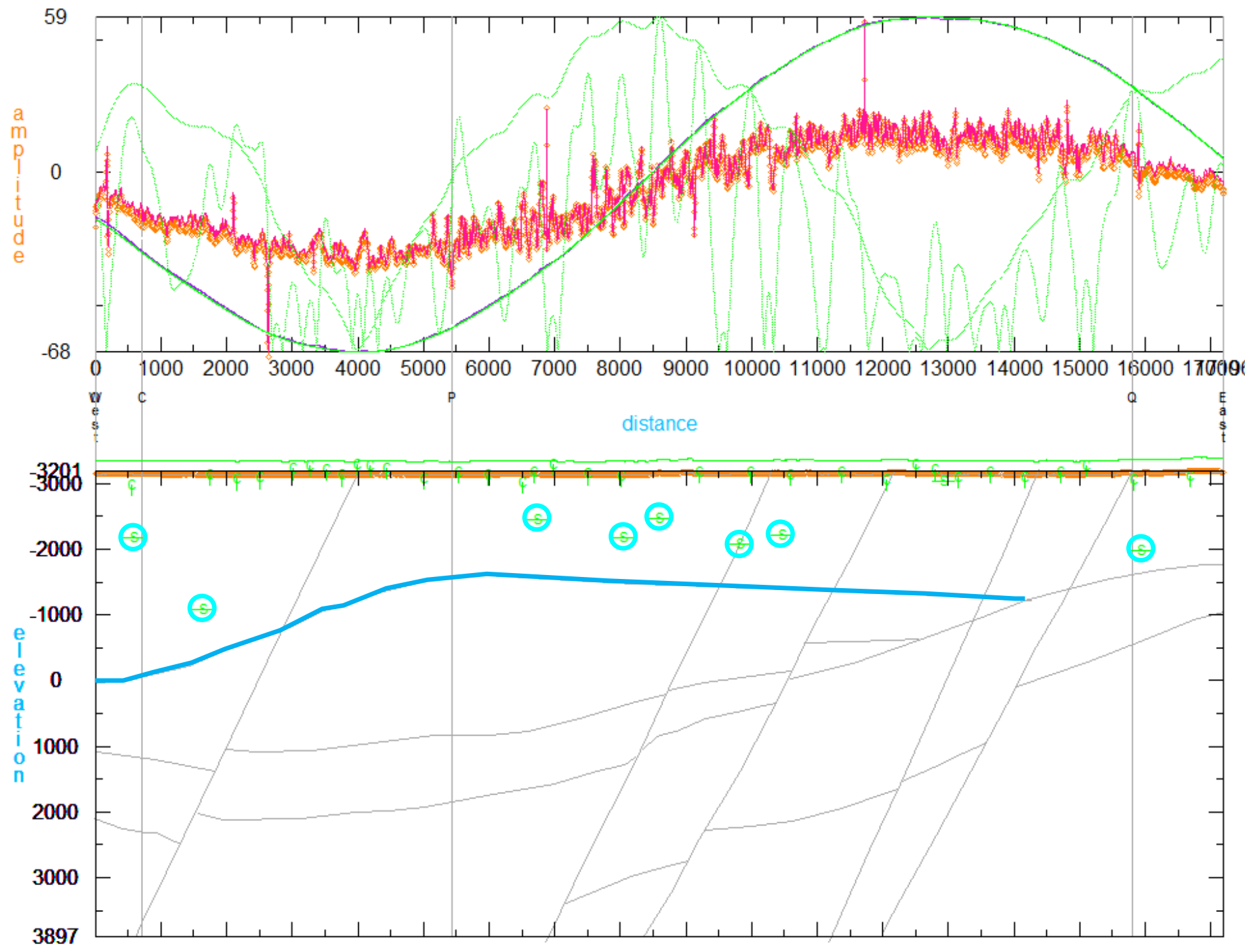

16B. Line K-Horizontal Gradient depth solutions. 


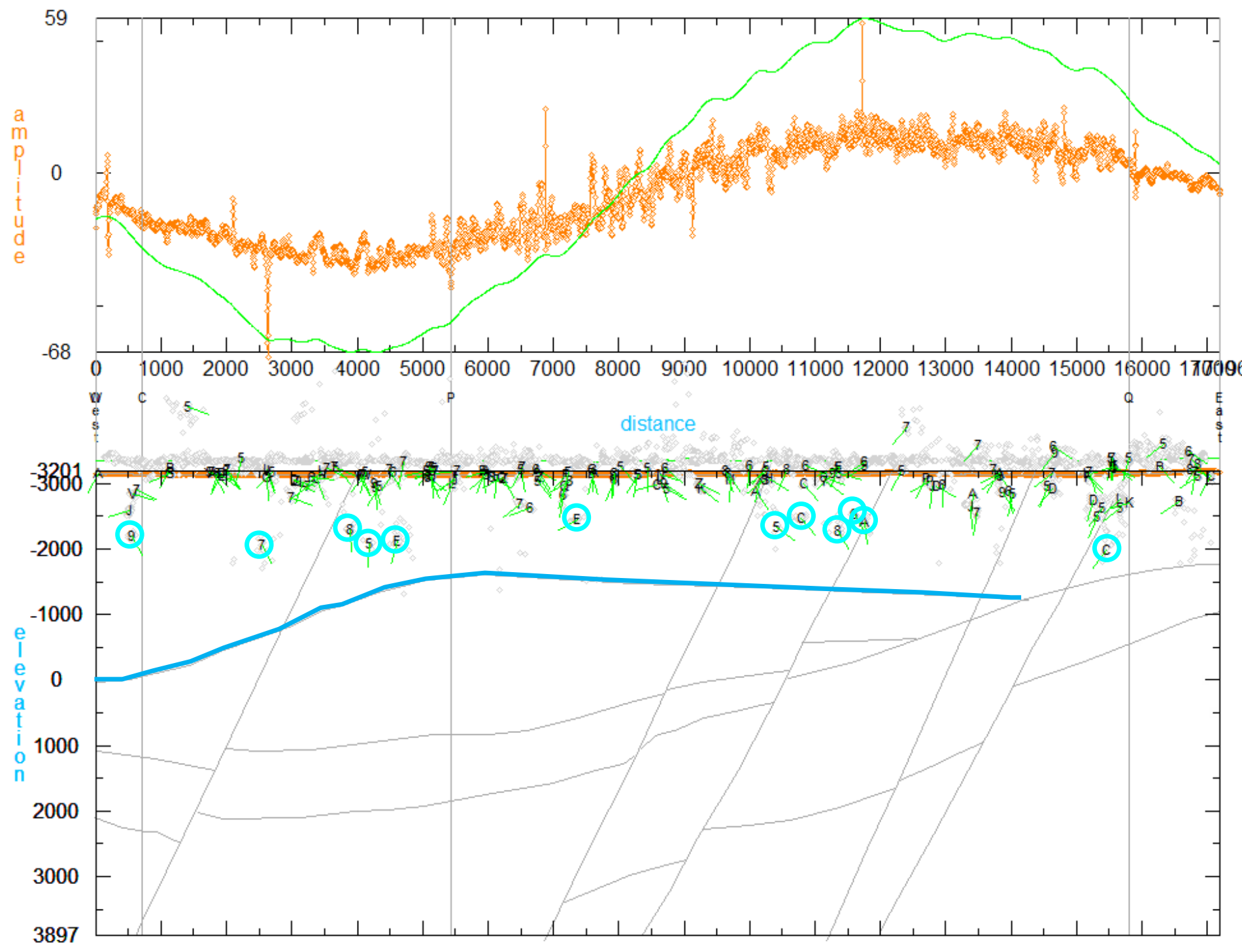

16C. Line K-Multiple-source Werner sheet solutions. 


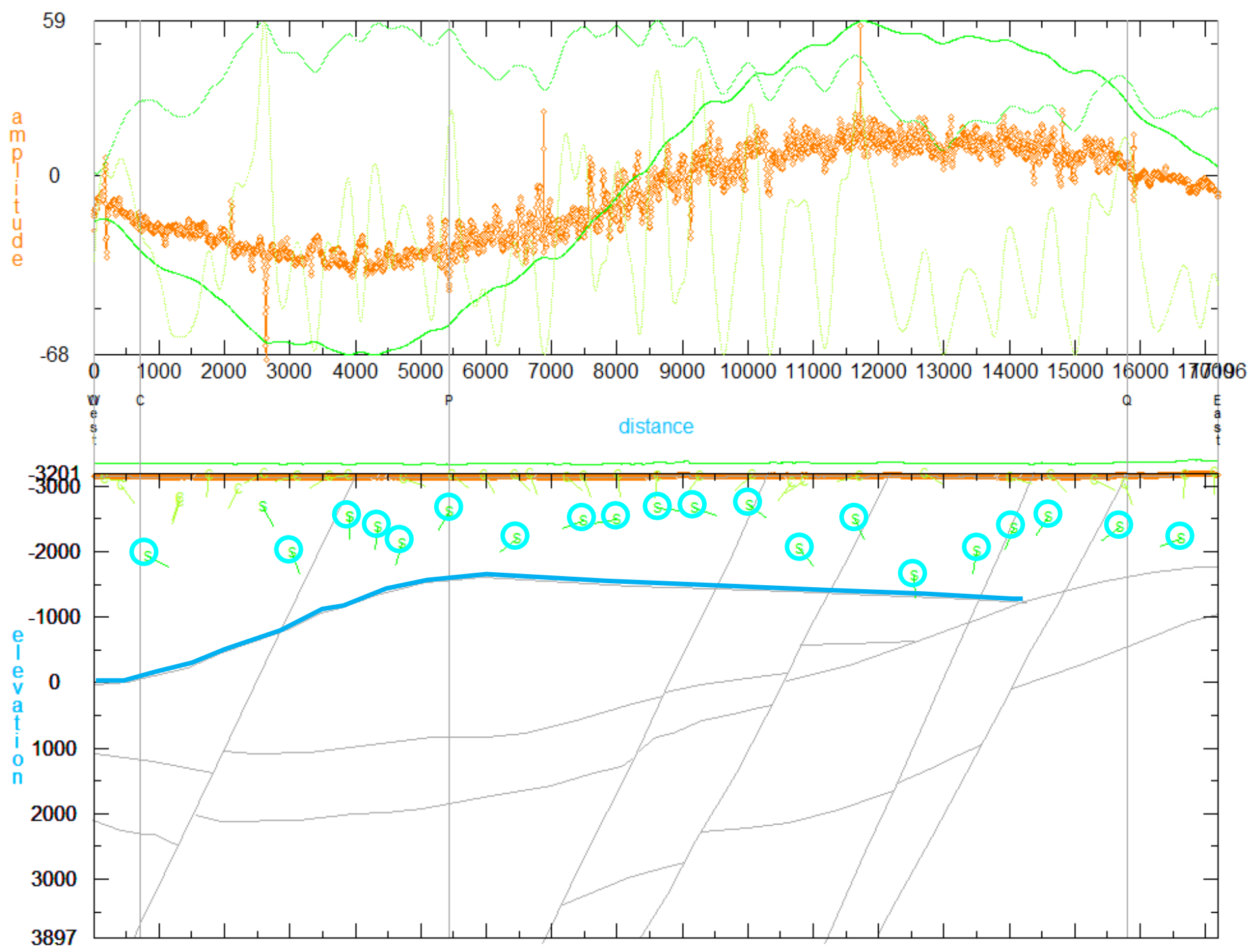

16D. Line K-Analytic Signal depth solutions.

Figure 16. Line K. See figure 6 for description. 


\section{Line L}

Line L (fig. 17) trends northwest from an intersection with Line N, passing drill hole UE5i (near the bend at distance marker 4,400) and ending near drill hole UE1 la after crossing the western end of Line F (plate 1). The EV model shows the basalt encountered in drill hole UE5i as being present in the central two-thirds of the section, with a pronounced southward dip. One north-dipping fault with no offset is seen. The HG sheet solutions include two sources near the modeled basalt, and one at shallower depth. The MSW sheet solutions include three sources near the depth of the basalt, including one at the northern edge of the basalt as modeled. There are no AS sheet solutions at the depth of the basalt. It seems likely that a southward-dipping basalt flow is present along much of the line; it is unlikely that this flow extends to the northern end of the line (where it is missing in the nearby borehole); though there is no evidence here that the flow extends farther to the southeast than the intersection with Line $\mathrm{G}$, it is encountered in two drill holes to the east and interpreted in magnetic solutions to the south. The only significant contact solutions occur at the extreme southern end of the line in the HG solution and at a magnetic noise spike near the southern end of the profile in the AS solution. 


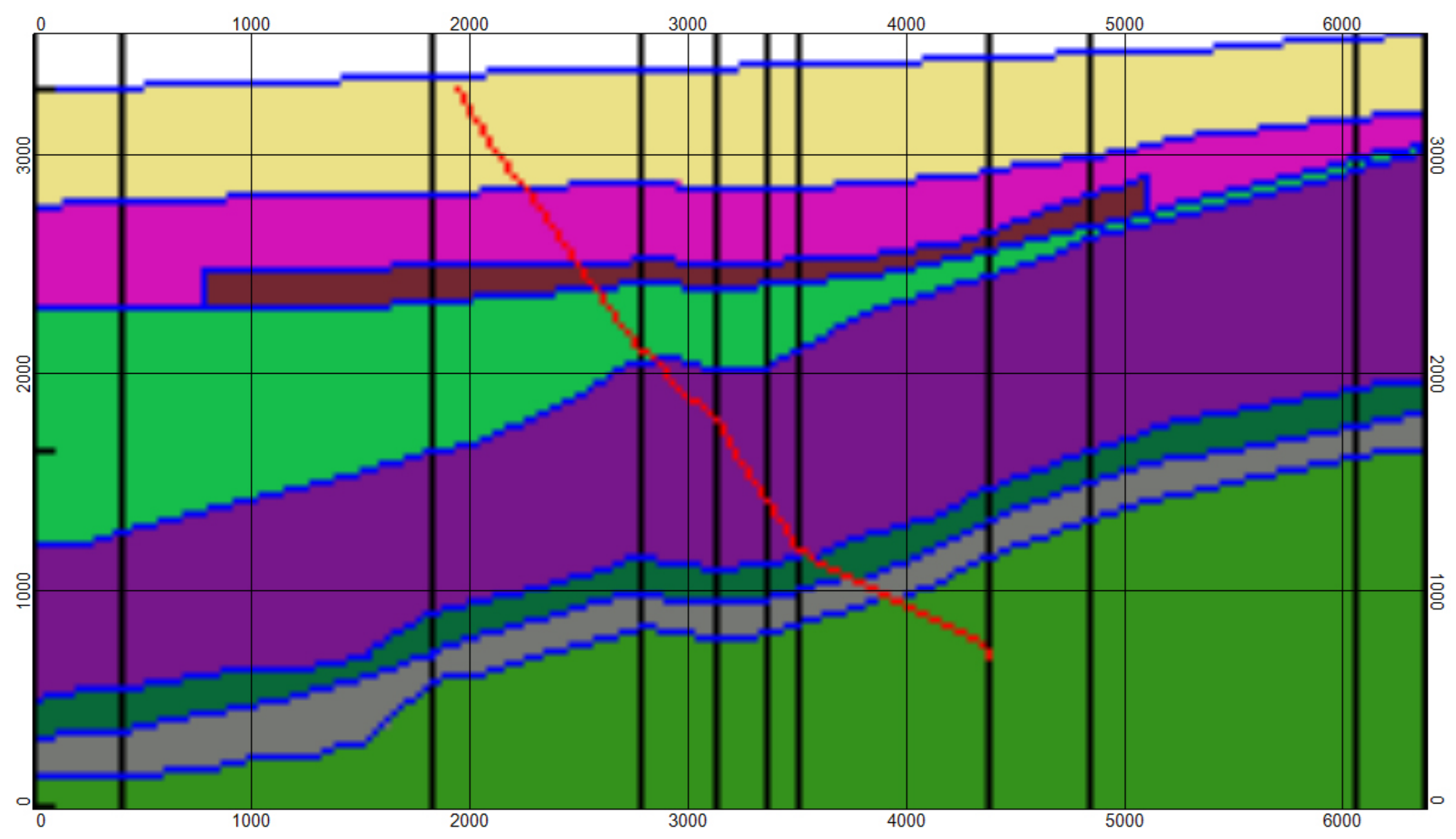

17A. Line L-EarthVision model. 


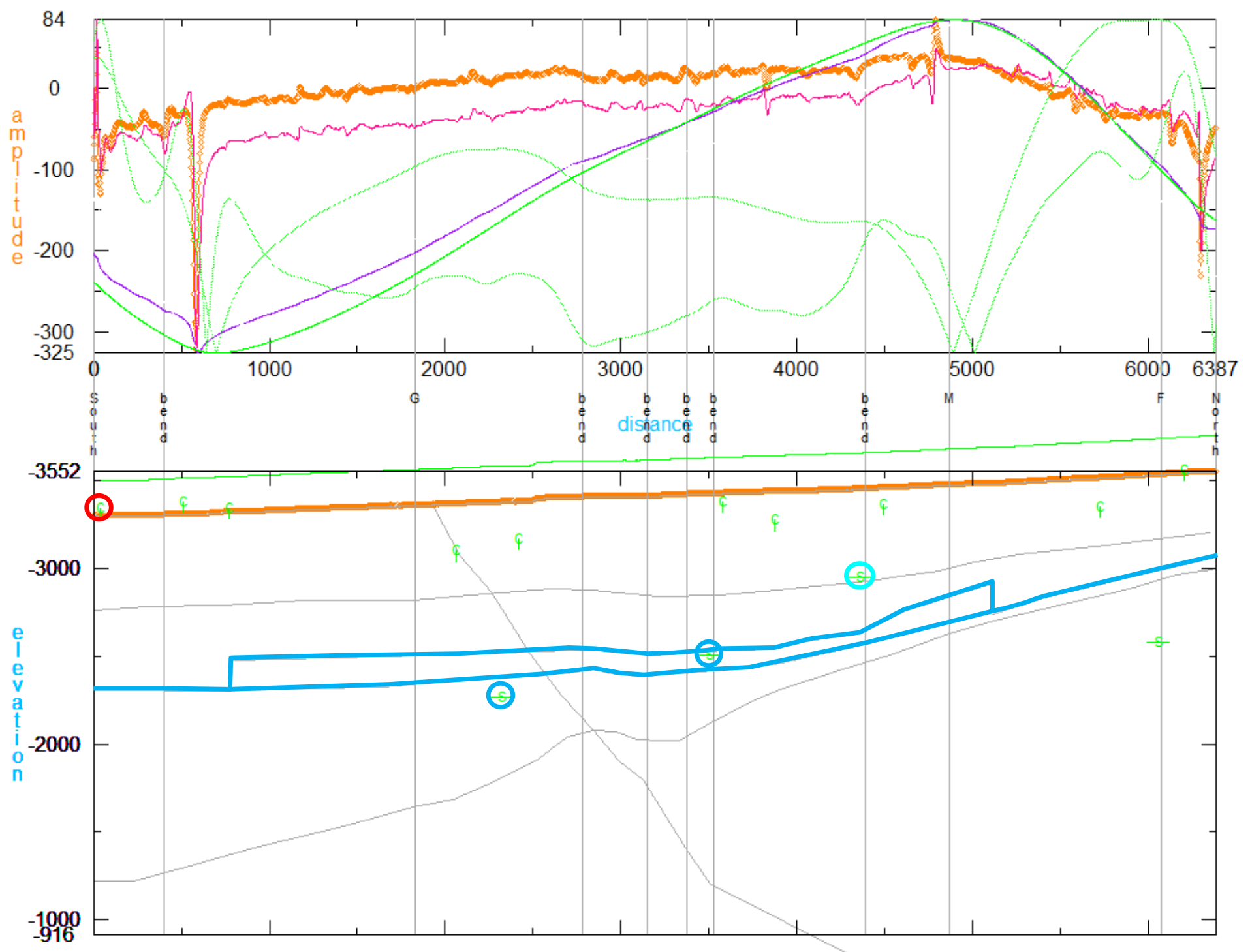

17B. Line L-Horizontal Gradient depth solutions. 


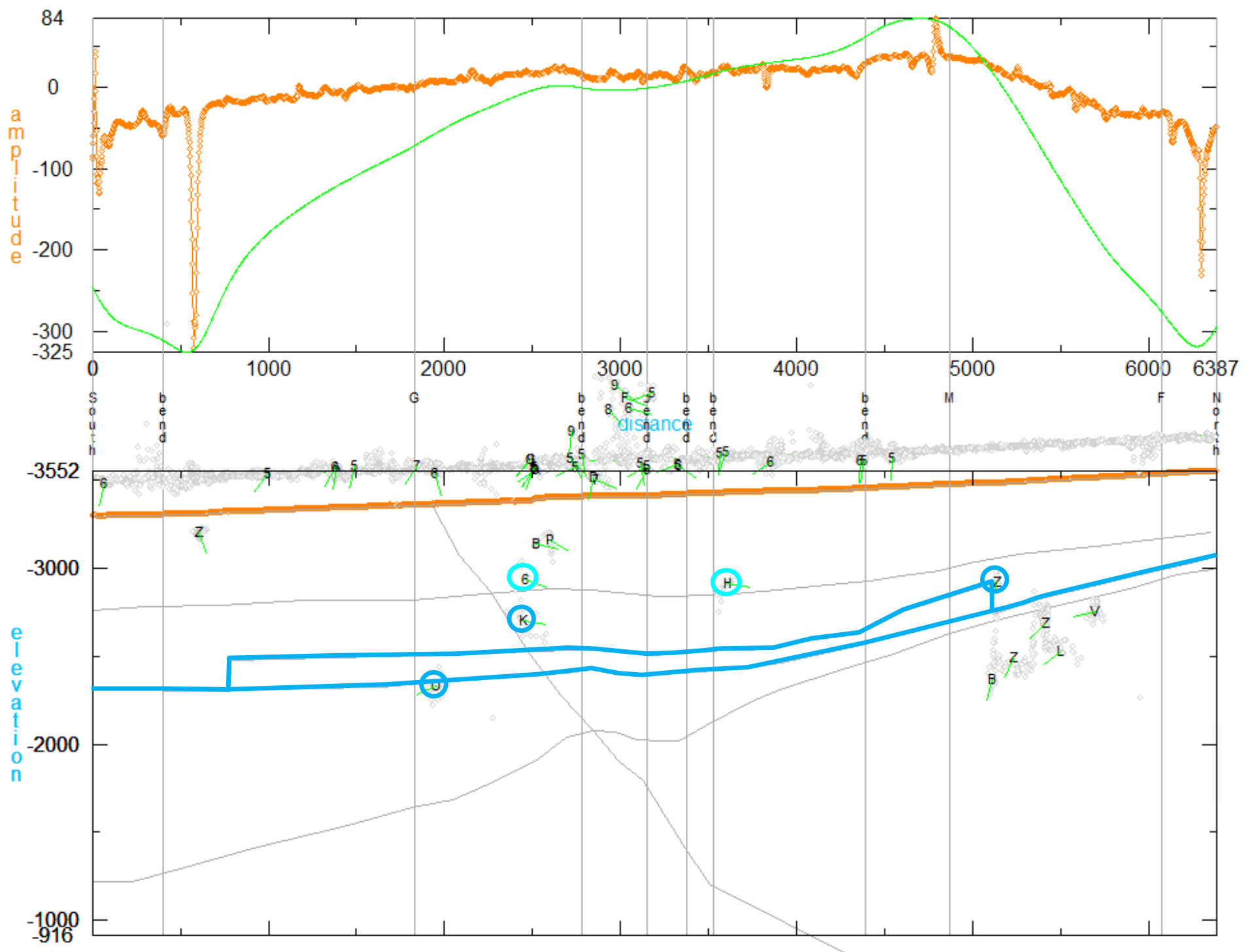

17C. Line L-Multiple-source Werner sheet solutions. 


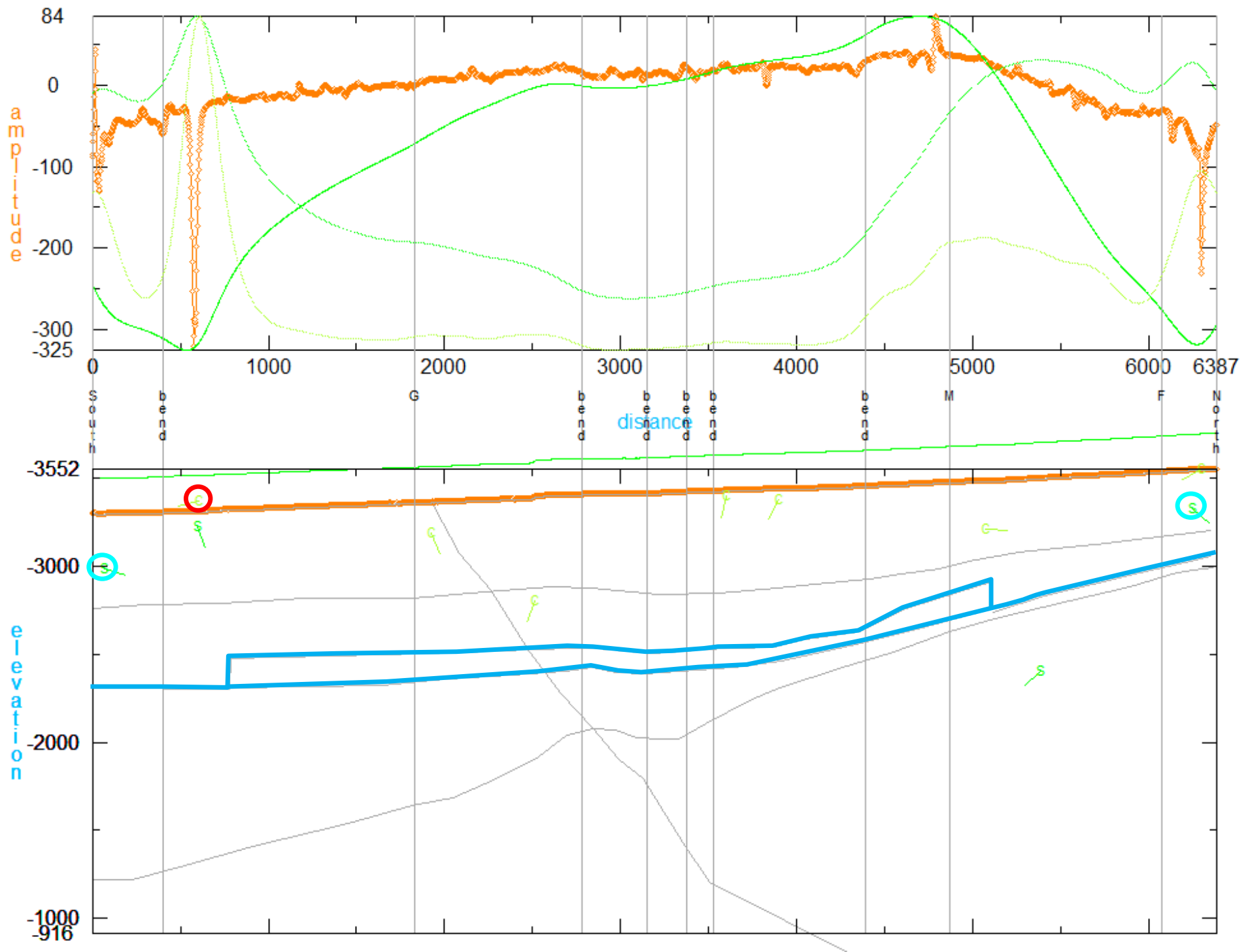

17D. Line L-Analytic Signal depth solutions.

Figure 17. Line L. See figure 6 for description. 


\section{Line M}

Line M (fig. 18) extends from an intersection with Line L north of drill hole UE5i to the northeast toward drill hole UE11b (plate 1). The EV model shows a discontinuous basalt flow, with most of the basalt being concentrated in the southwest near drill hole UE5i. A major southdipping normal fault is seen at depth in the northeast. Basalt was not encountered in drill hole UE11b, located across this fault and off the north end of the profile. The MSW sheet solutions include two sources near the depth of the basalt in the southwestern third of the line. All other sheet solutions occur at shallower depth in the northeastern third of the line. Thus if the basalt flow extends into the northern two-thirds of the section, it may be at shallower depth than predicted by the model. Significant HG and AS contact solutions are seen near the northeastern end of the line. These could be side-lobe artifacts related to the major fault, or an actual ancilliary fault. The early seismic survey detected a fault near this location (plate 1). 


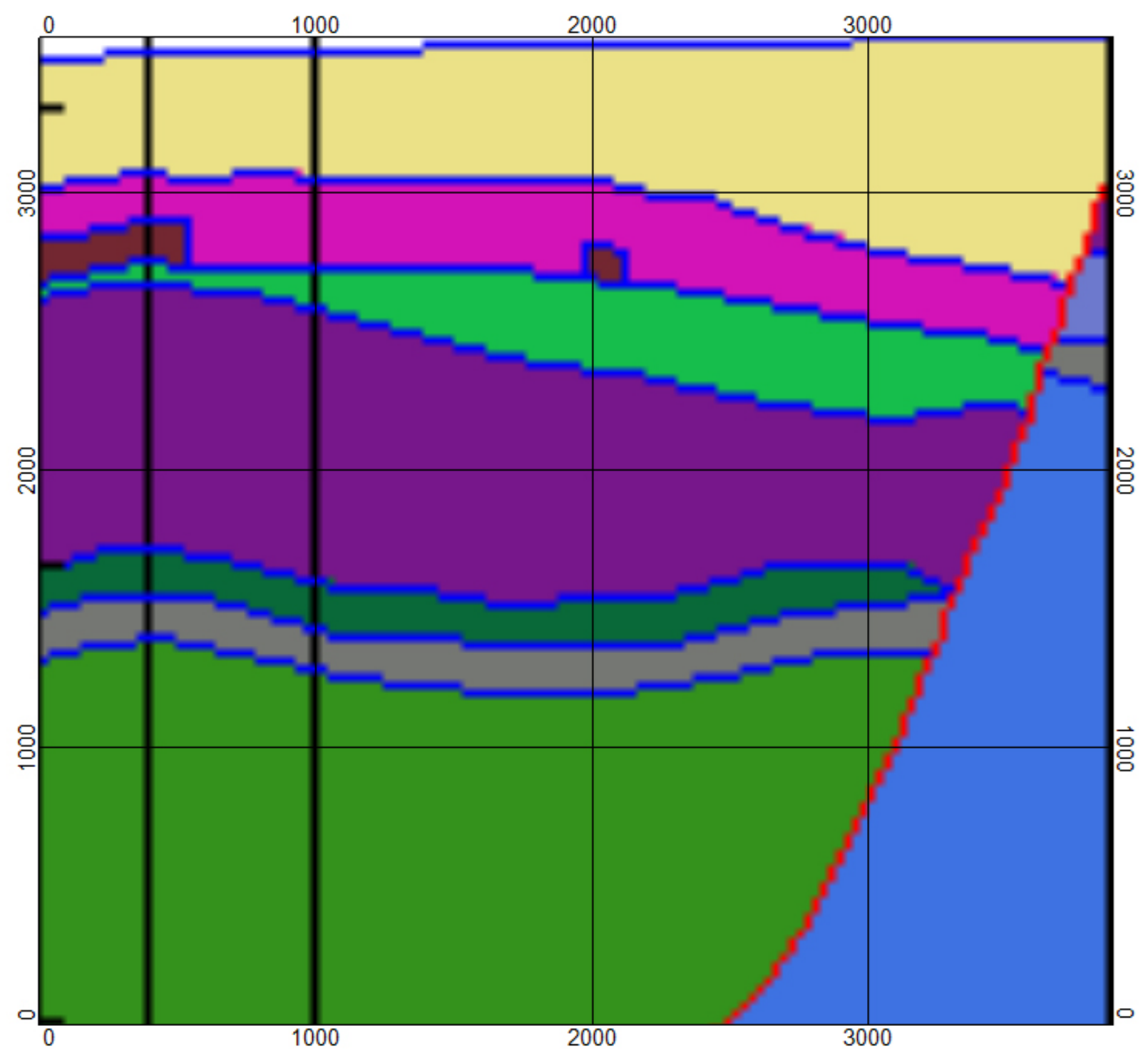

18A. Line M-EarthVision model. 


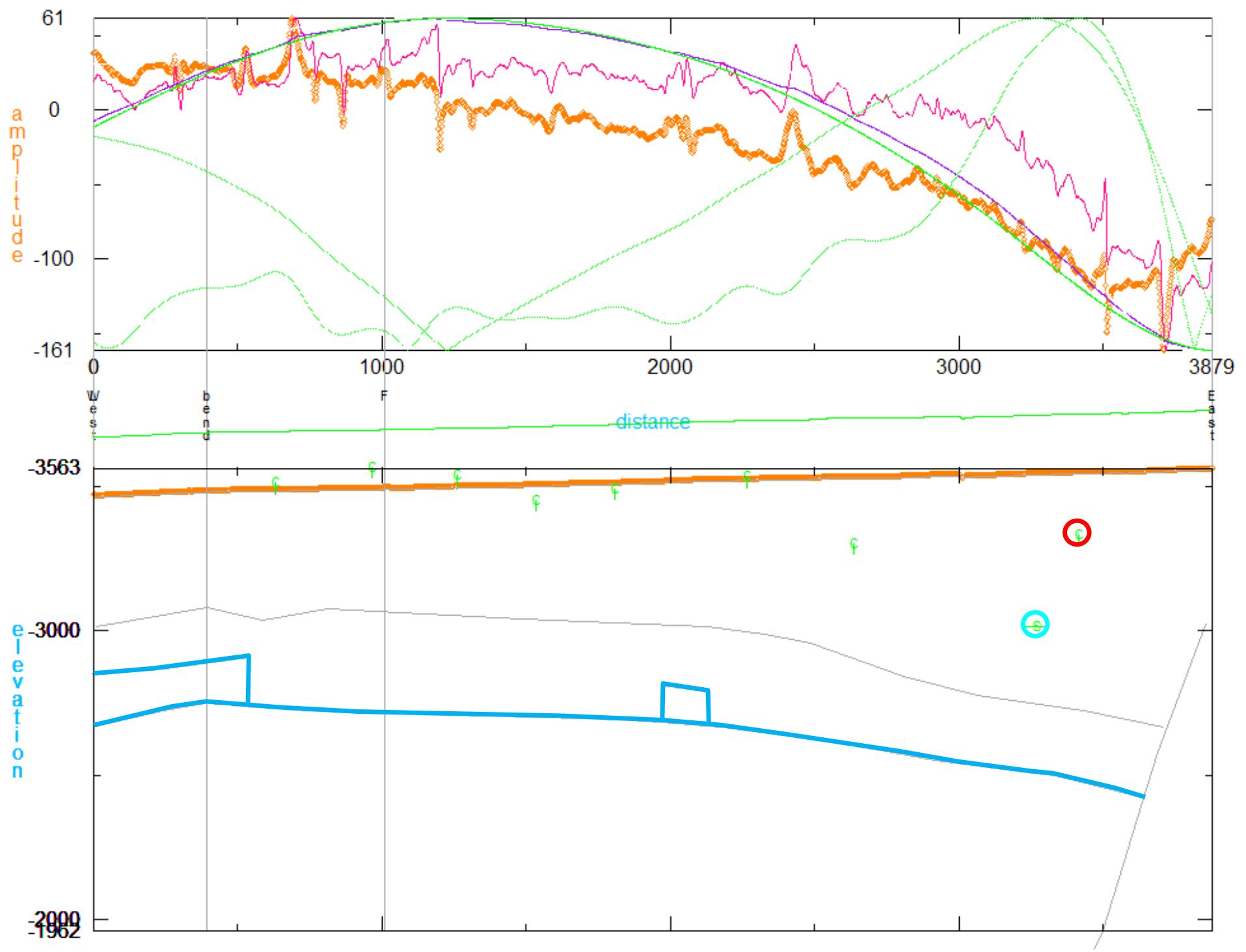

18B. Line M-Horizontal Gradient depth solutions. 


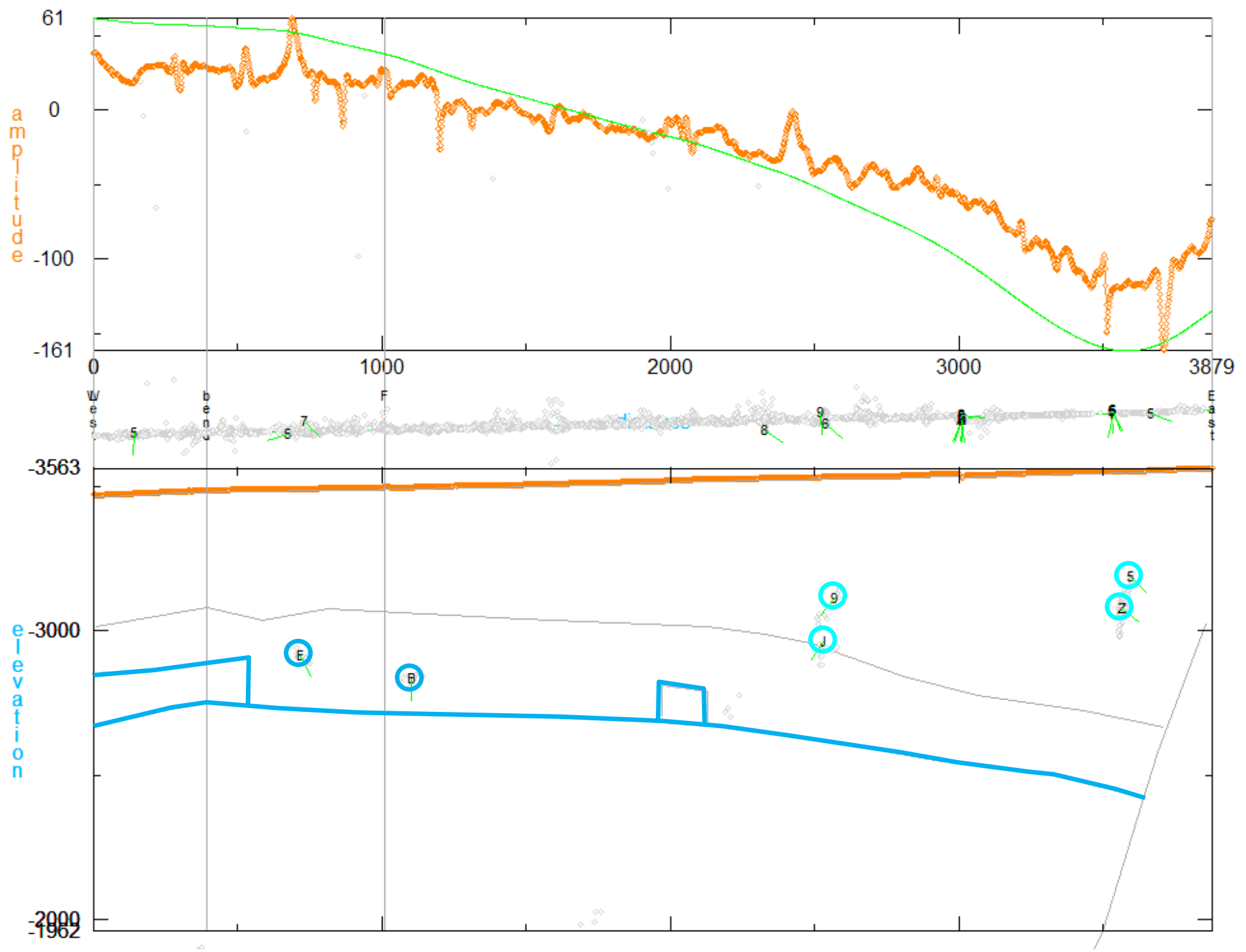

18C. Line M-Multiple-source Werner sheet solutions. 


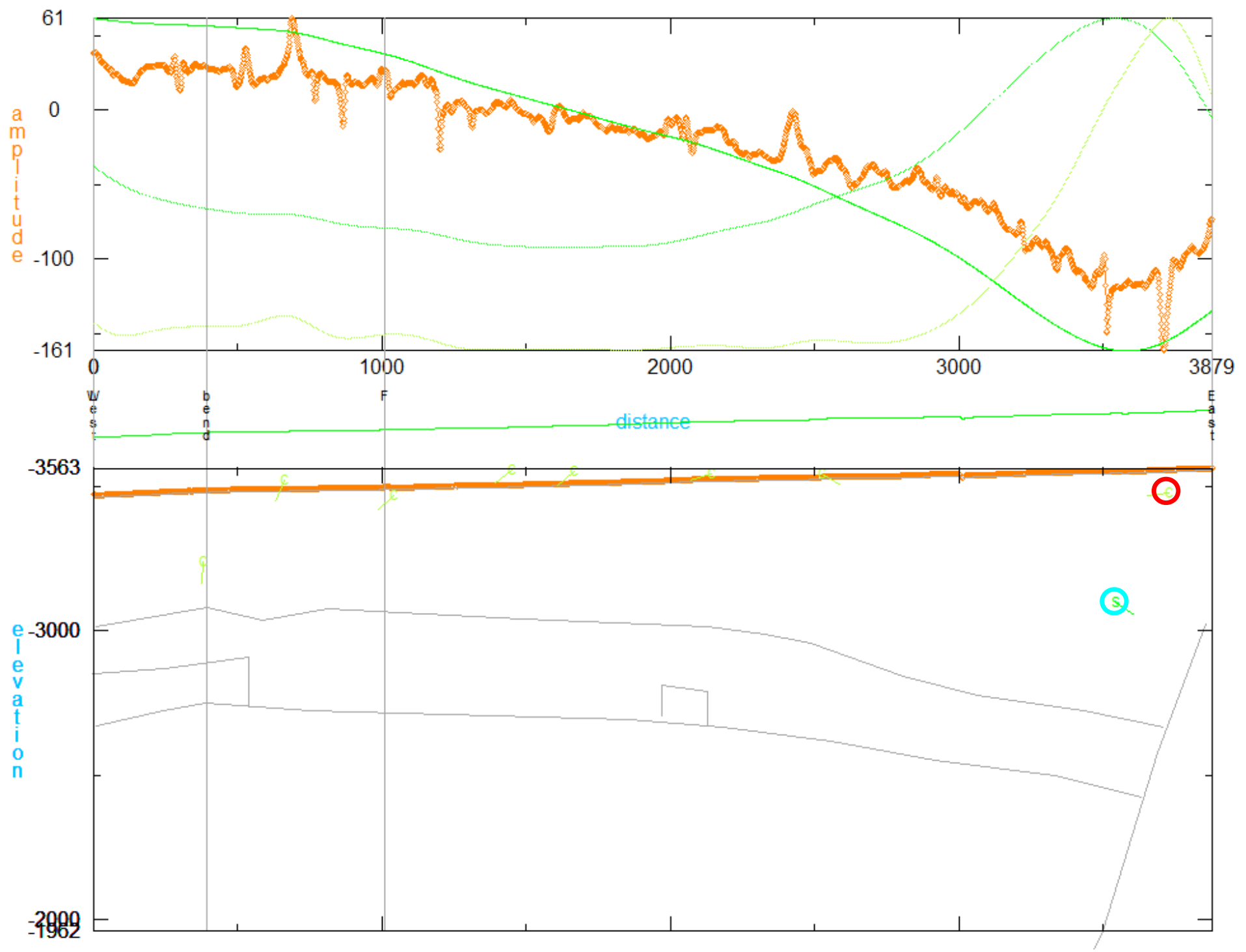

18D. Line M-Analytic Signal depth solutions.

Figure 18. Line M. See figure 6 for description. 


\section{Line $\mathbf{N}$}

Line $\mathrm{N}$ (fig. 19) is a long line trending north from near the northern end of Line $\mathrm{O}$ to an intersection with the eastern end of Line D, just east of drill hole UE11b (plate 1). There is a gap and offset in the line near the western end of Line H. The EV model shows an alluvial section that thins to the north, contains no basalt, and is abruptly truncated in the north by the major south-dipping normal fault seen in Line M. The horizon at which the basalt would be expected extends across all of the section to the south of this fault. There are also two other faults with no shallow offset. The HG sheet solutions include one source at the depth of the basalt where it would be truncated against the northern fault. The MSW sheet solutions include three sources near the expected depth of the basalt, one in the north and two in the south. The AS sheet solutions include one source near the expected depth of the basalt in the south. It seems likely that basalt is present along this line in the north and in the south. It may be missing between the 3,000- and 9,500-ft distance markers, or it may just be flat, unbroken, and of uniform thickness over this range. There is a significant HG contact solution at the location of the major normal fault in the north, suggesting a near-vertical dip for this fault. All other significant contact solutions are artifacts that occur at the edges of the gap in the line. A pair of shallow contact solutions near distance marker 12,000 are interpreted, along with other evidence, as a north dipping fault in plate 1. 


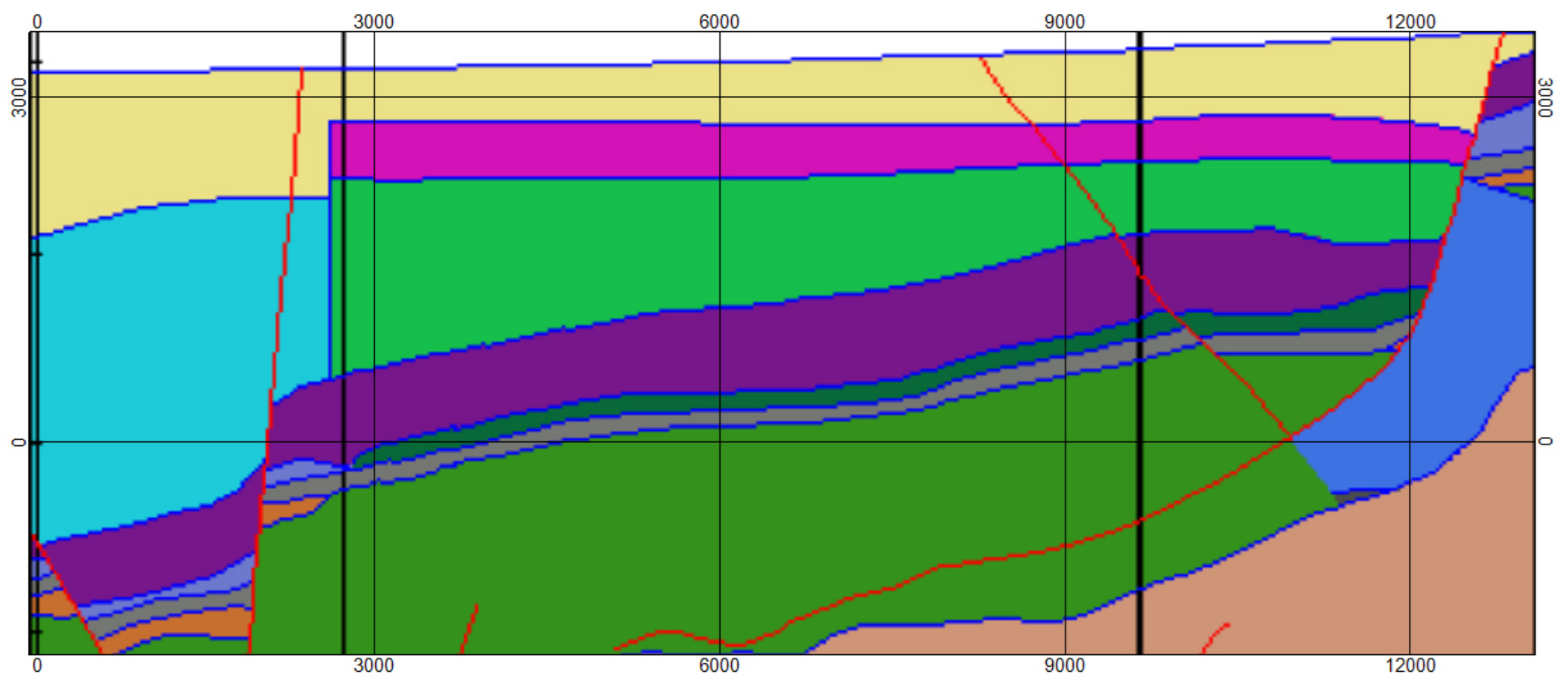

19A. Line N-EarthVision model. 


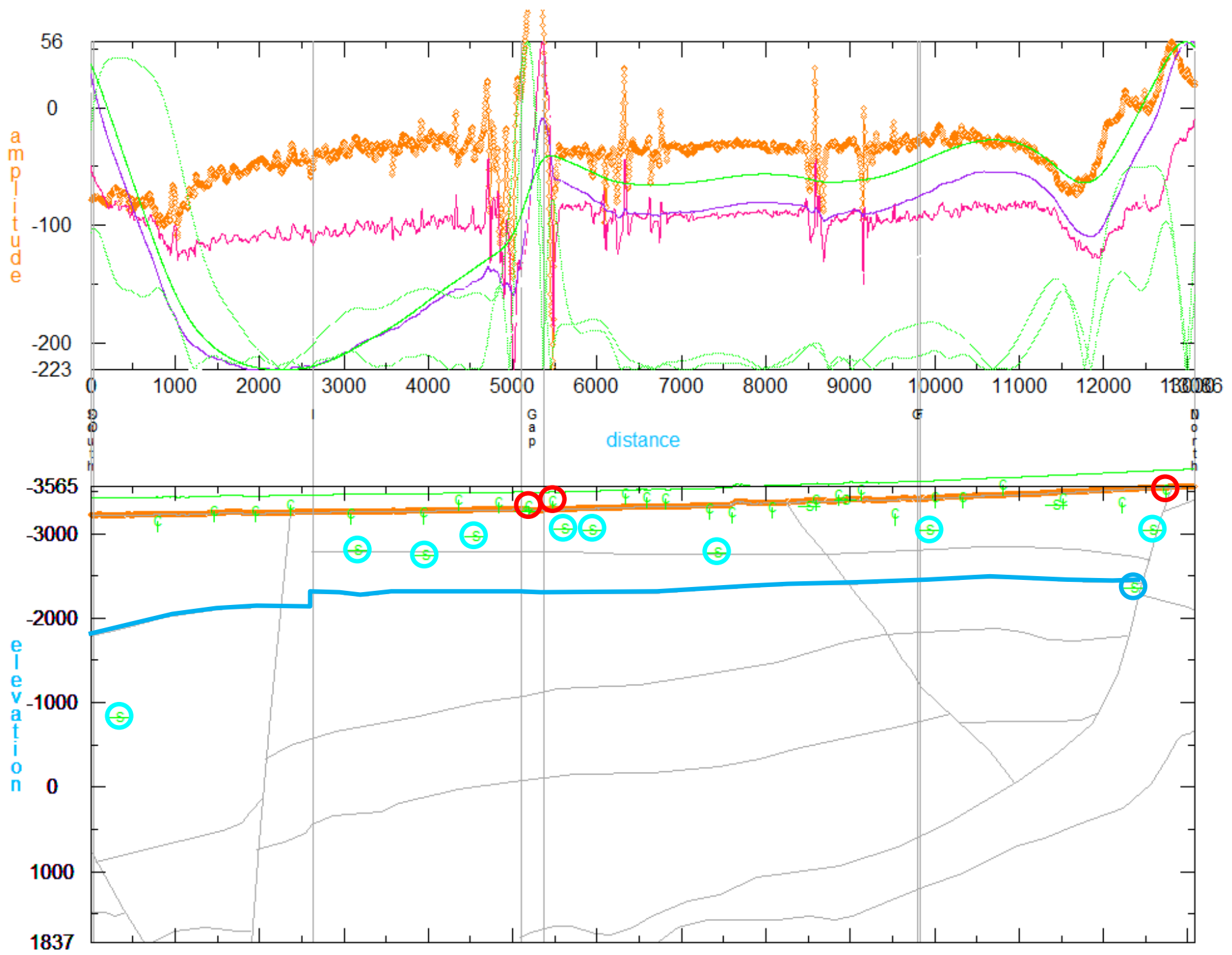

19B. Line N-Horizontal Gradient depth solutions. 


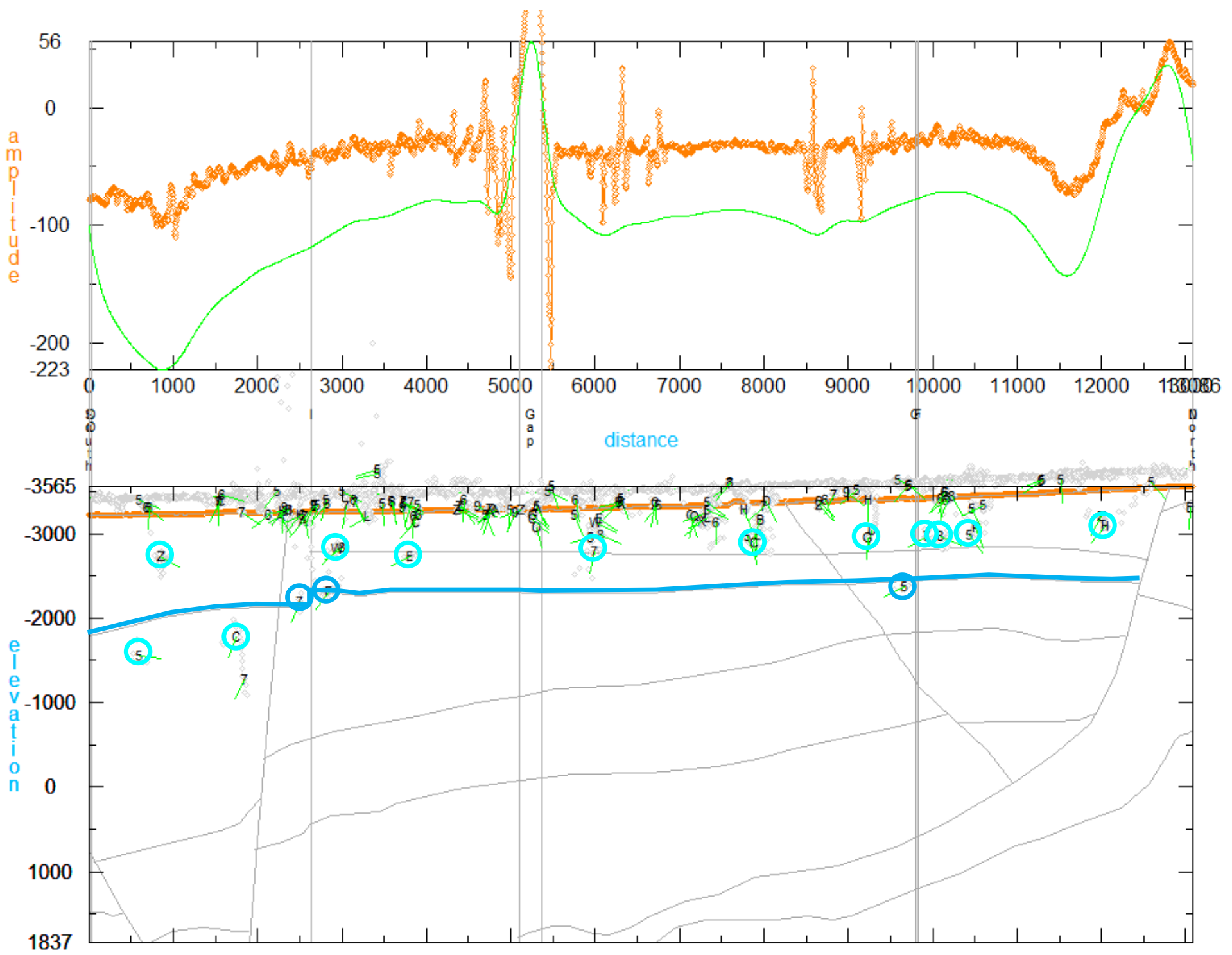

19C. Line N-Multiple-source Werner sheet solutions. 


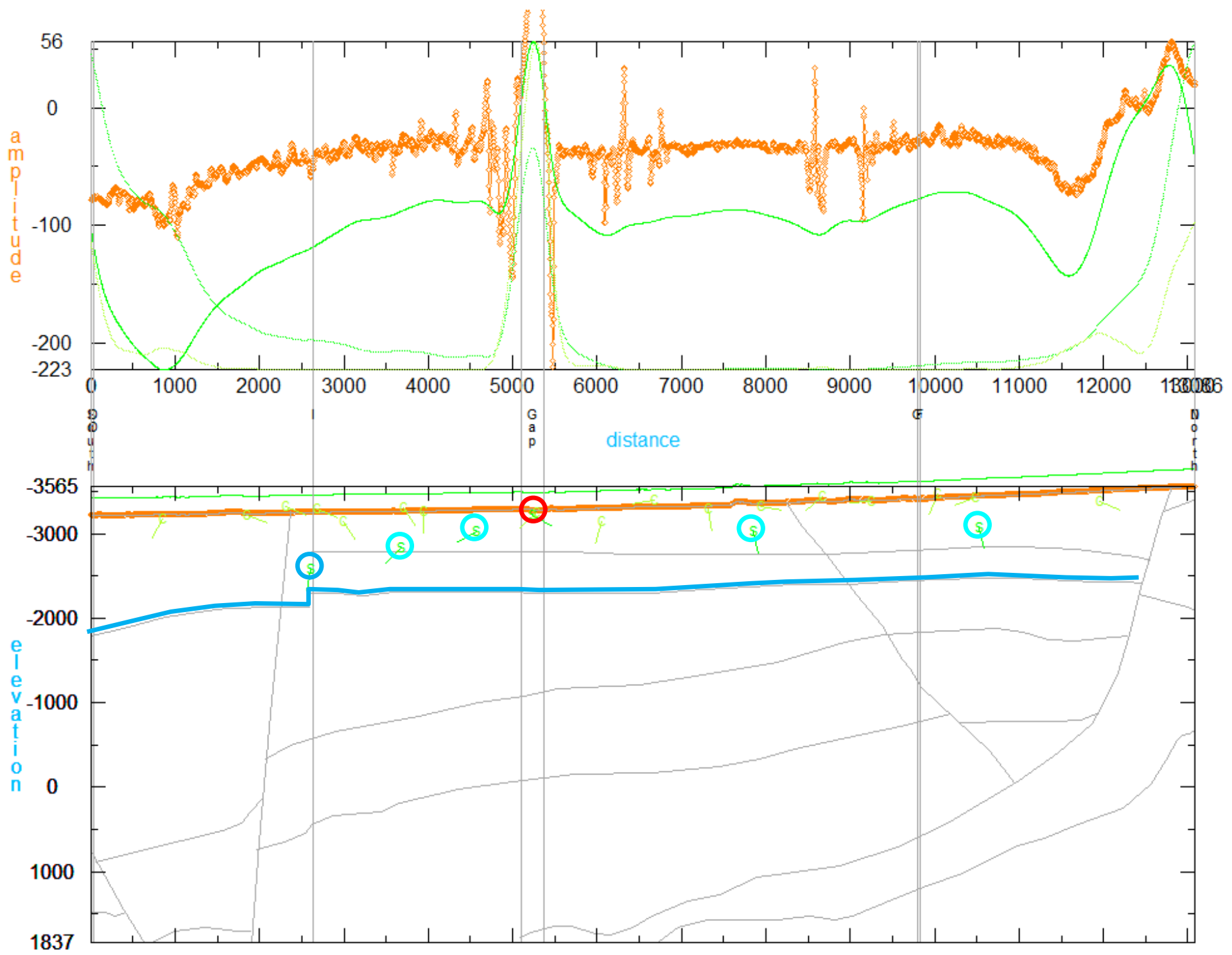

19D. Line N-Analytic Signal depth solutions.

Figure 19. Line N. See figure 6 for description. 


\section{Line 0}

Line $O$ (fig. 20) extends north from the southwest corner of the survey area, where it intersects the southwestern end of Line $\mathrm{C}$, to a point near the southern end of Line N. The EV model shows a thick sequence of alluvium with no basalt and one possible fault. All sheet solutions indicate sources at intermediate depths within the youngest alluvium, suggesting that basalt is either absent or too deep to detect along this line. No significant contact sources were detected. 


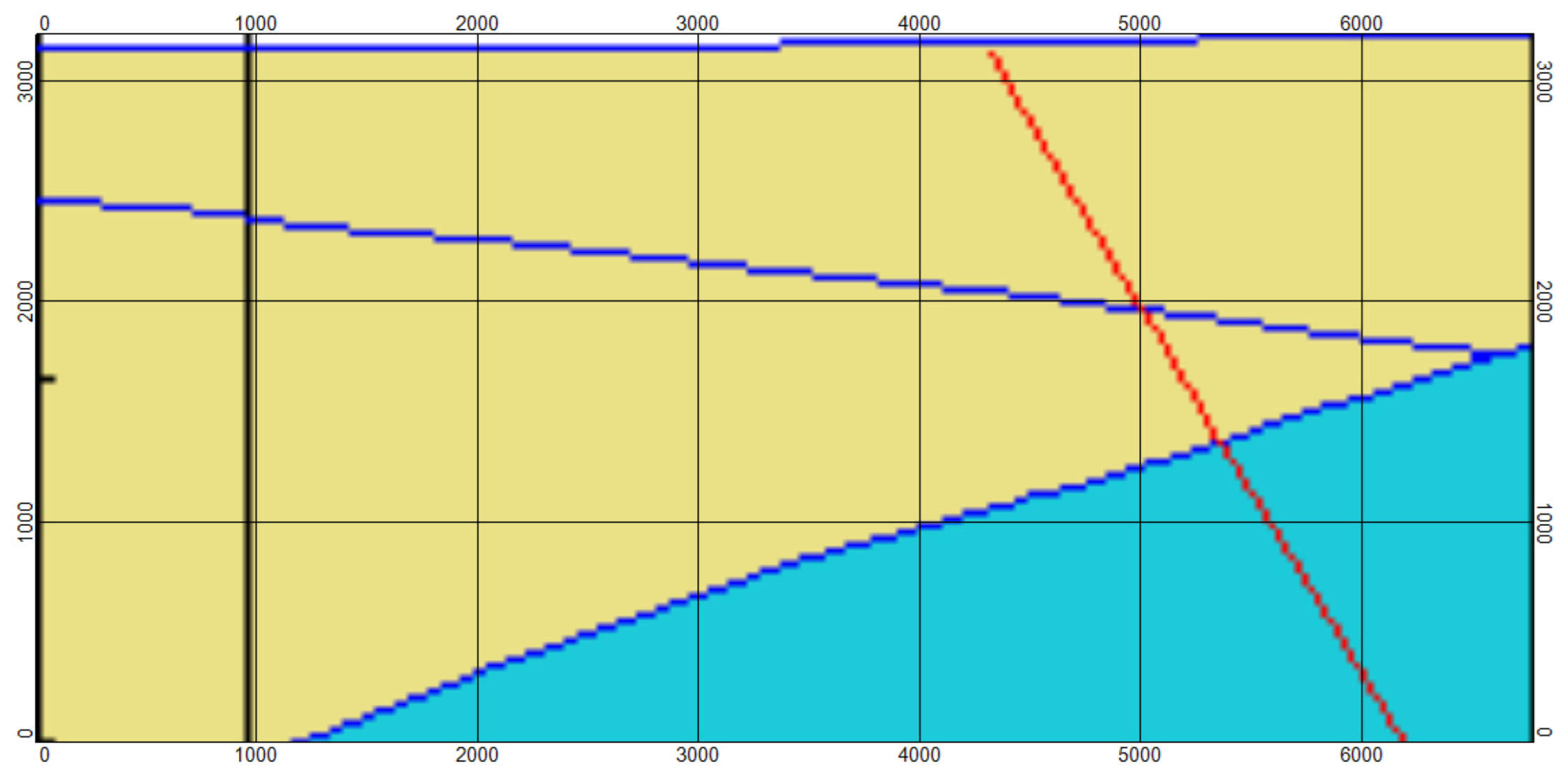

20A. Line O-EarthVision model. 


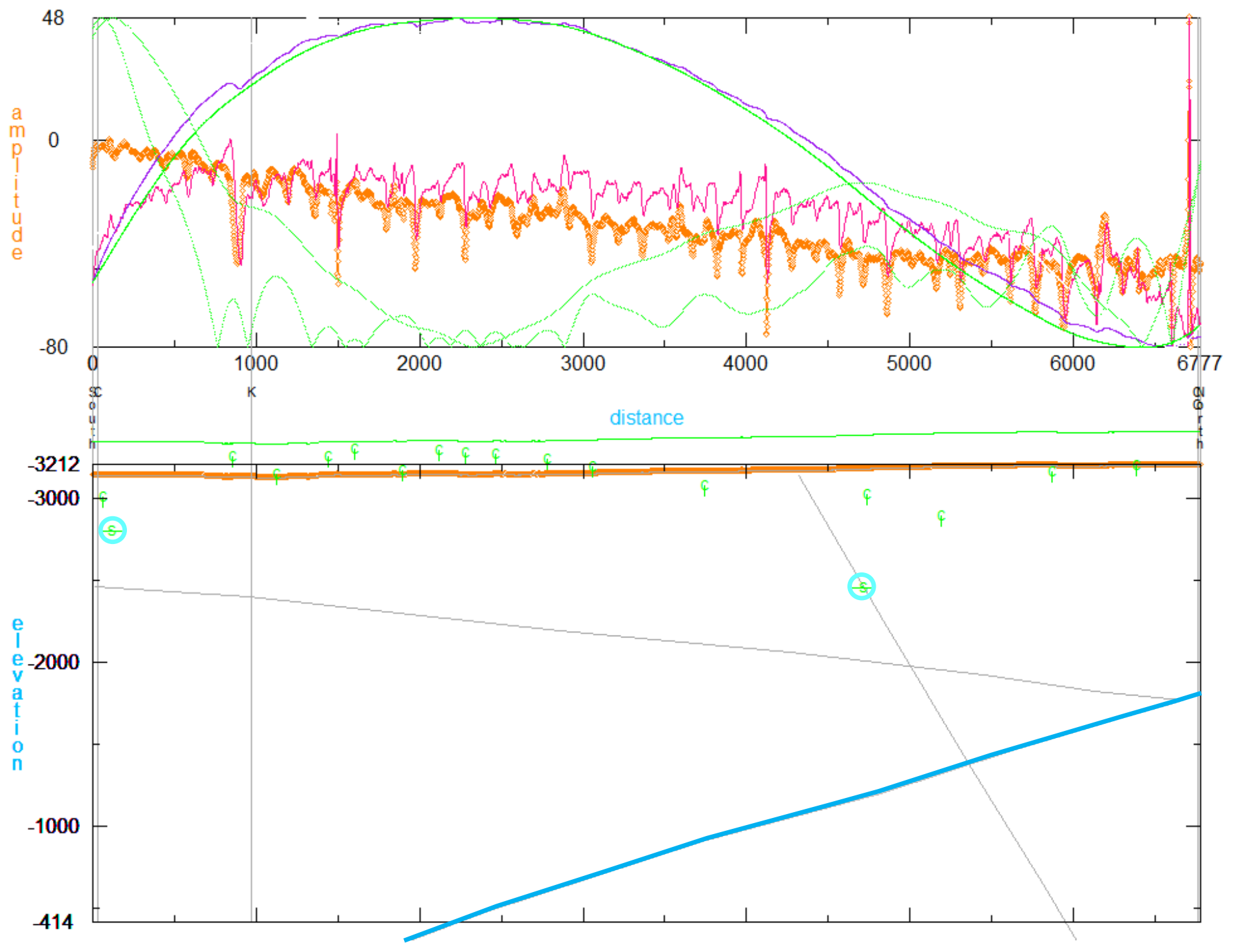

20B. Line O-Horizontal Gradient depth solutions. 


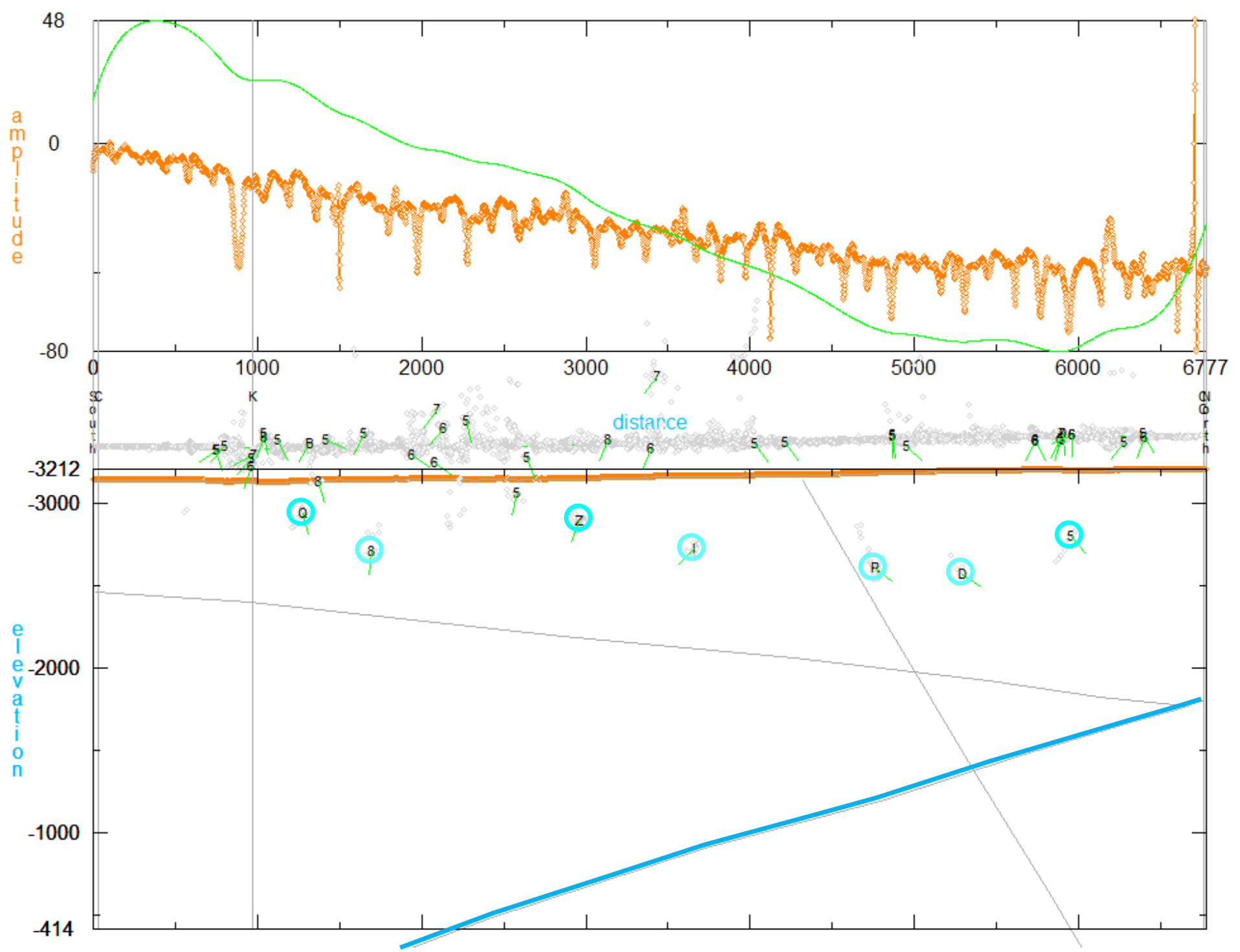

20C. Line O-Multiple-source Werner sheet solutions. 


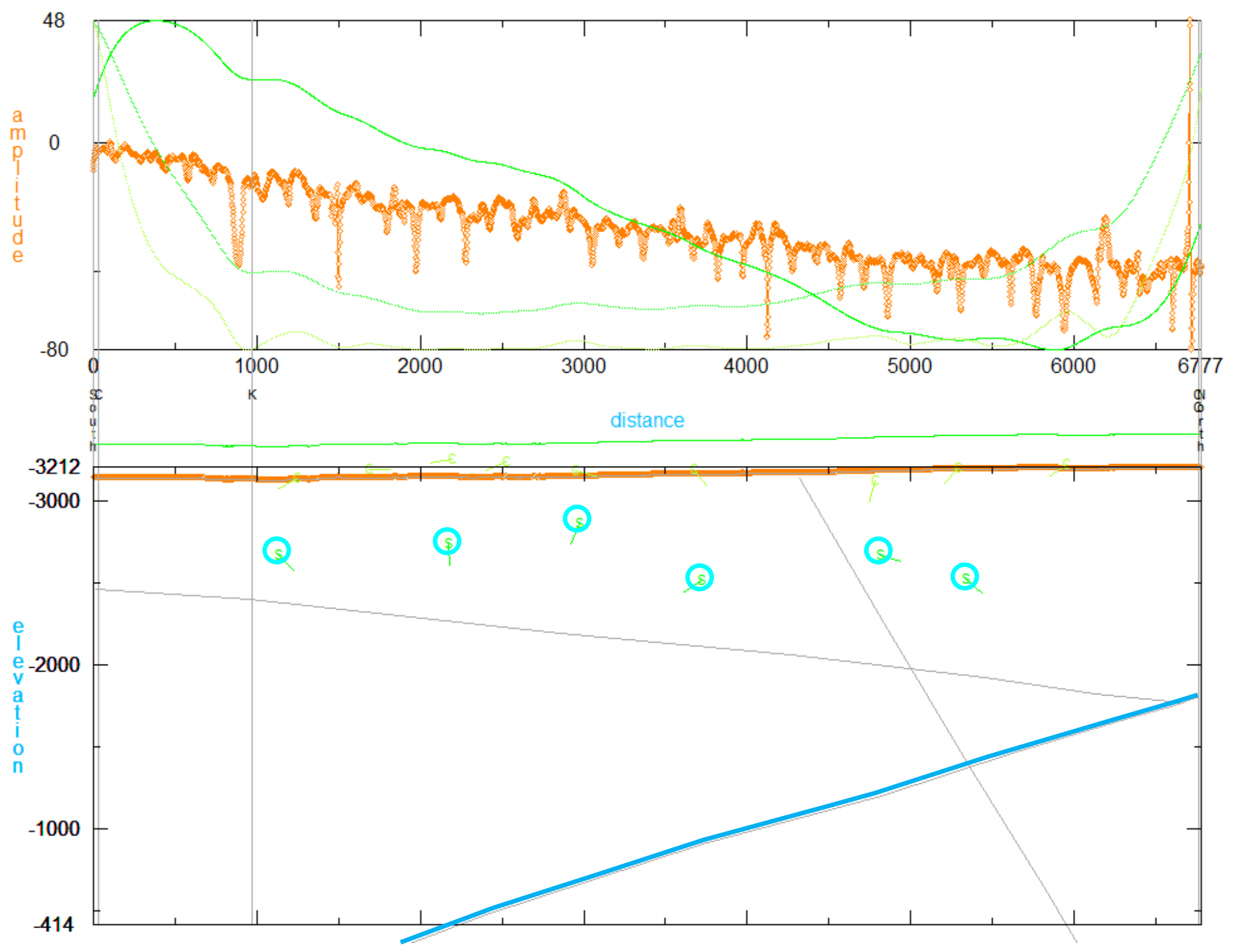

20D. Line O-Analytic Signal depth solutions.

Figure 20. Line O. See figure 6 for description. 


\section{Line $\mathbf{P}$}

Line $\mathrm{P}$ (fig. 21) is east of Line $\mathrm{O}$ and extends north from an intersection with Line $\mathrm{K}$ on the southern boundary of the survey area to an intersection with Line J. The EV model shows a thick alluvial sequence thinning to the north. Basalt is shown to be present in the northern half of the line. The HG sheet solutions include one source at the depth of the basalt. All other sheet solutions are too shallow to represent the basalt. No significant contact sources were detected. 


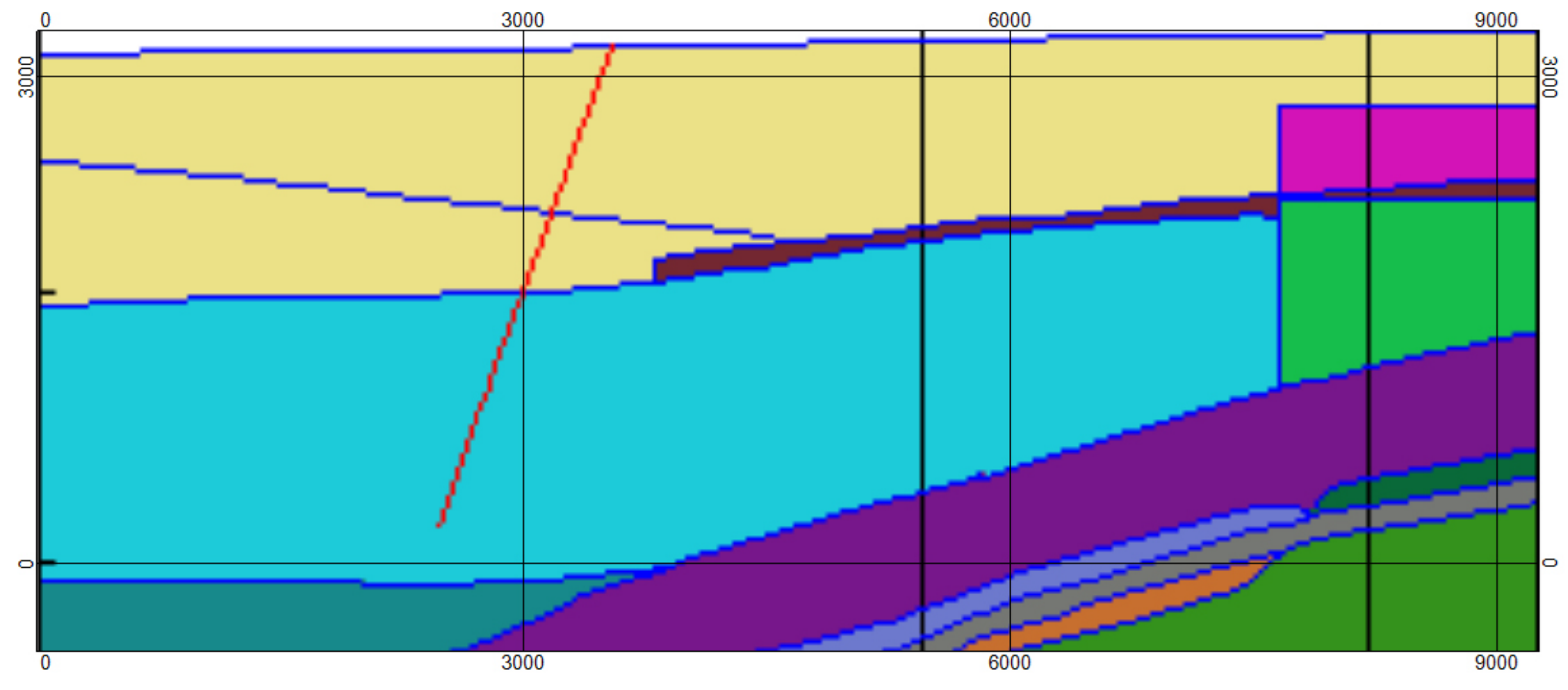

21A. Line P-EarthVision model. 


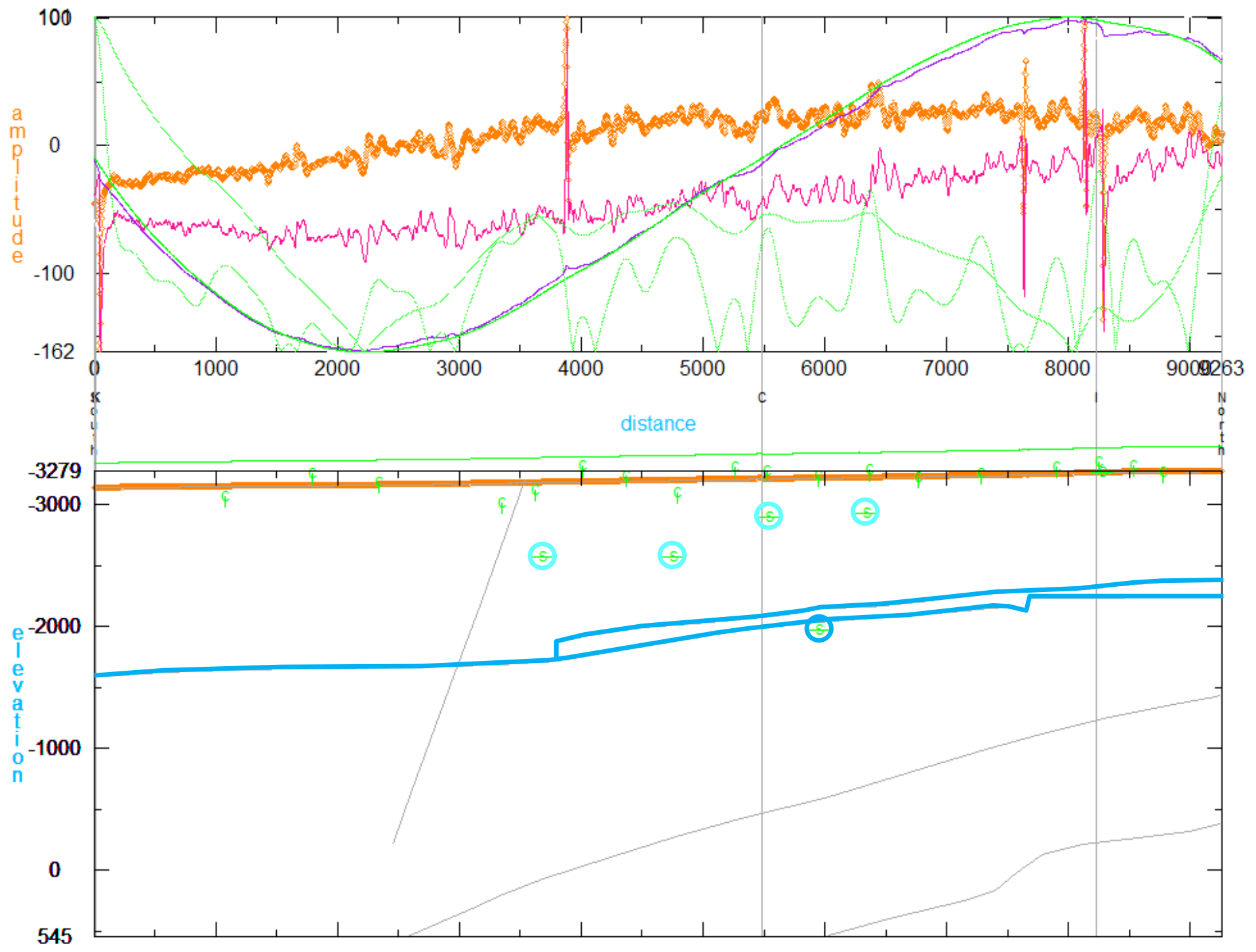

21B. Line P-Horizontal Gradient depth solutions. 


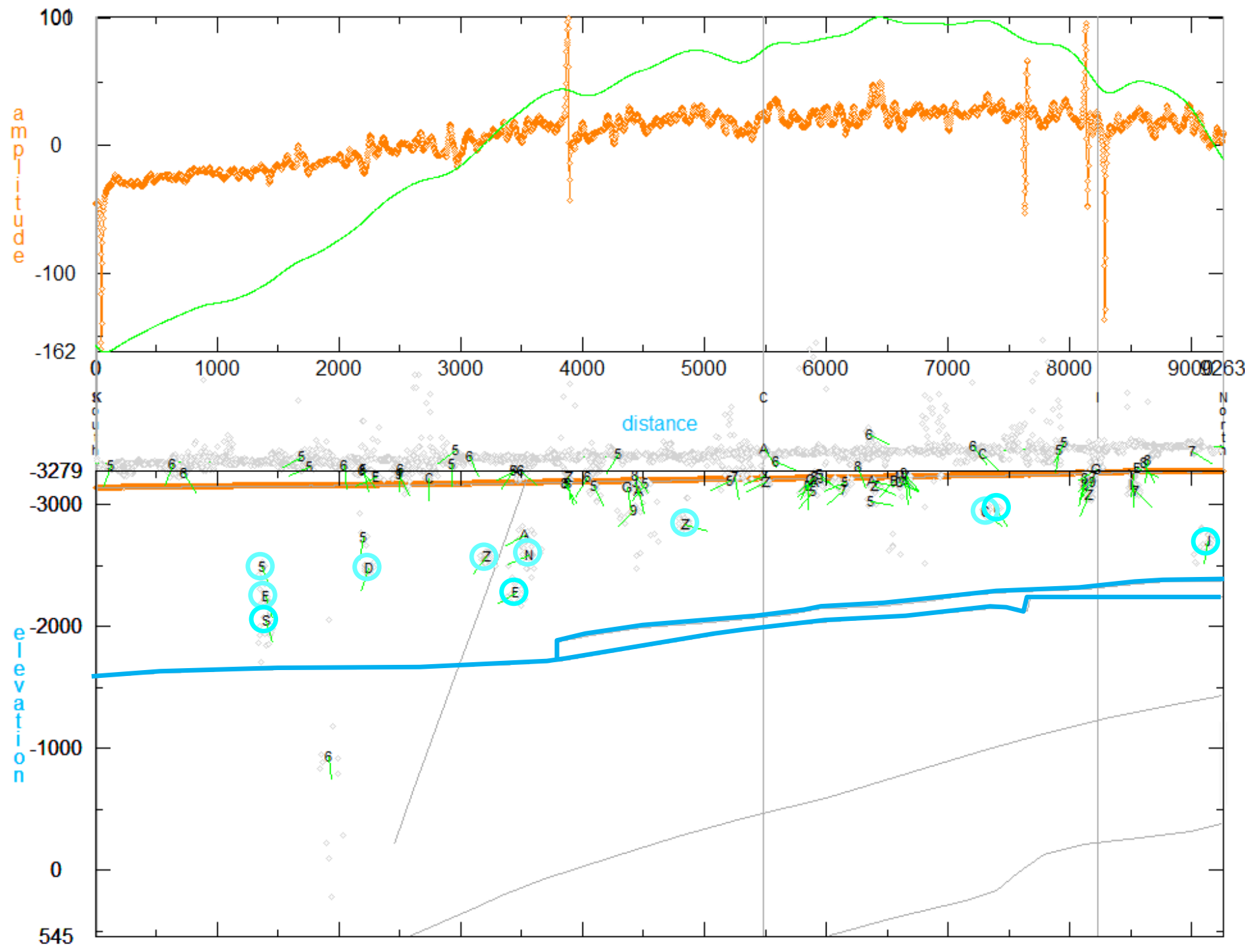

21C. Line P-Multiple-source Werner sheet solutions. 


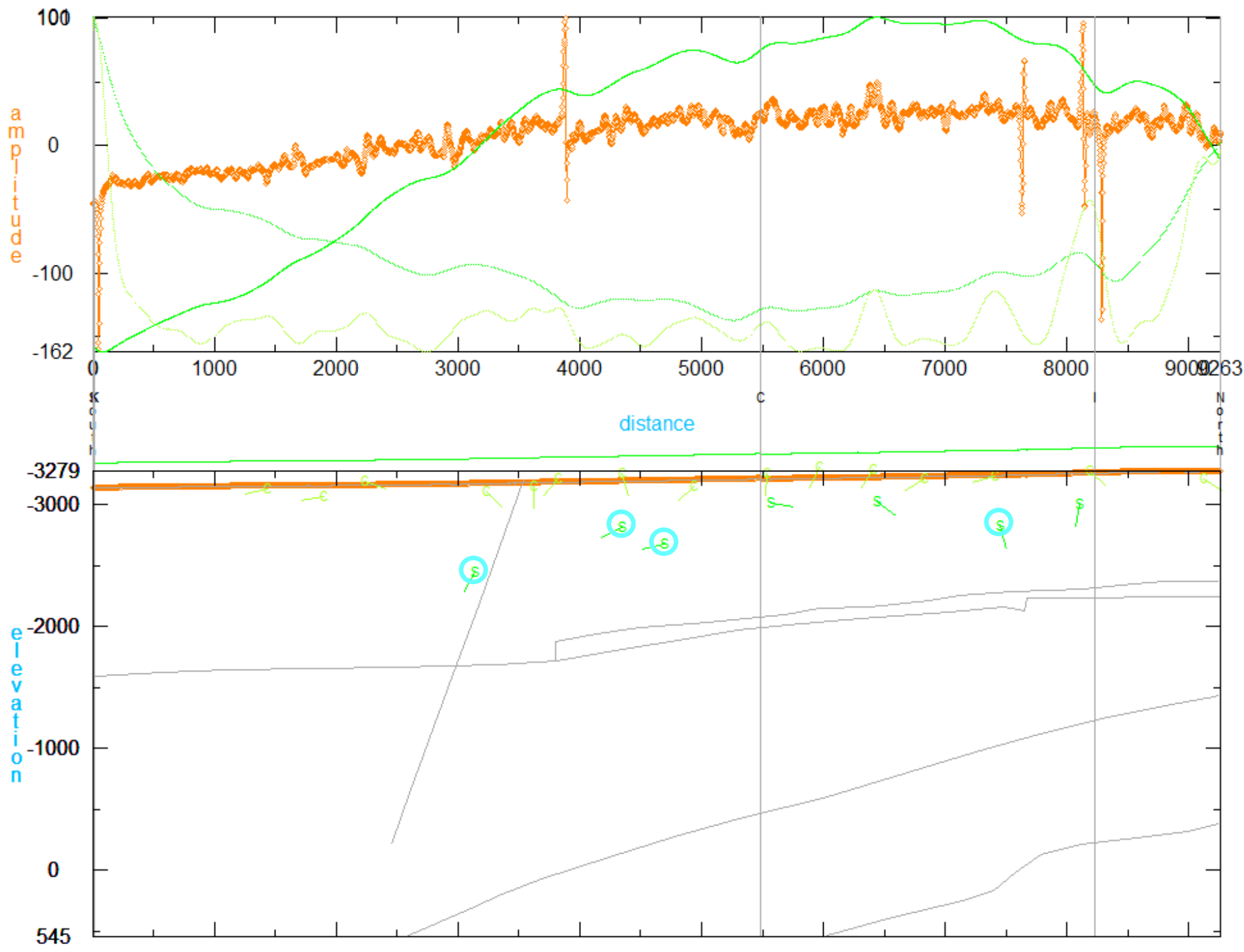

21D. Line $\mathrm{P}-$ Analytic Signal depth solutions.

Figure 21. Line P. See figure 6 for description. 


\section{Line Q}

Line Q (fig. 22) is east of Line P and extends north from the southern boundary of the survey area to an intersection with Line J. The EV base model shows an alluvial basin containing no basalt and underlain by the lower tuff confining unit (LTCU). The stratigraphic horizon corresponding to the basalt is present in the northern two-thirds of the section. A northdipping normal fault is shown in the south, near the intersection with Line K. The MSW sheet solutions include one source near the center of the line that could be at the projected depth of the basalt. All other sheet solutions within the alluvial section are too shallow to represent the basalt. Lines I and J display basalt solutions near their intersections with Line Q; therefore, the northern half of Line Q is interpreted as being underlain by the basalt (plate 1). No significant contact sources were detected. 


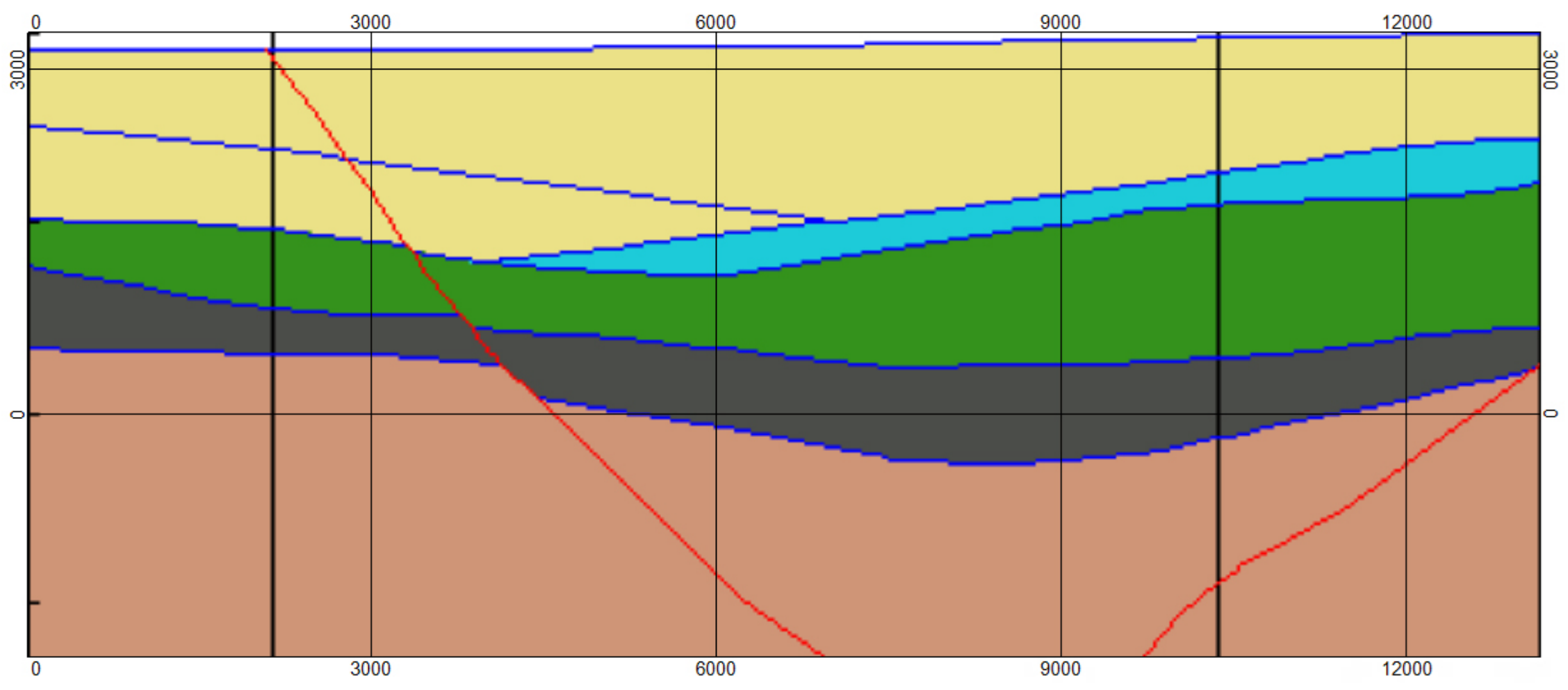

22A. Line Q-EarthVision model. 


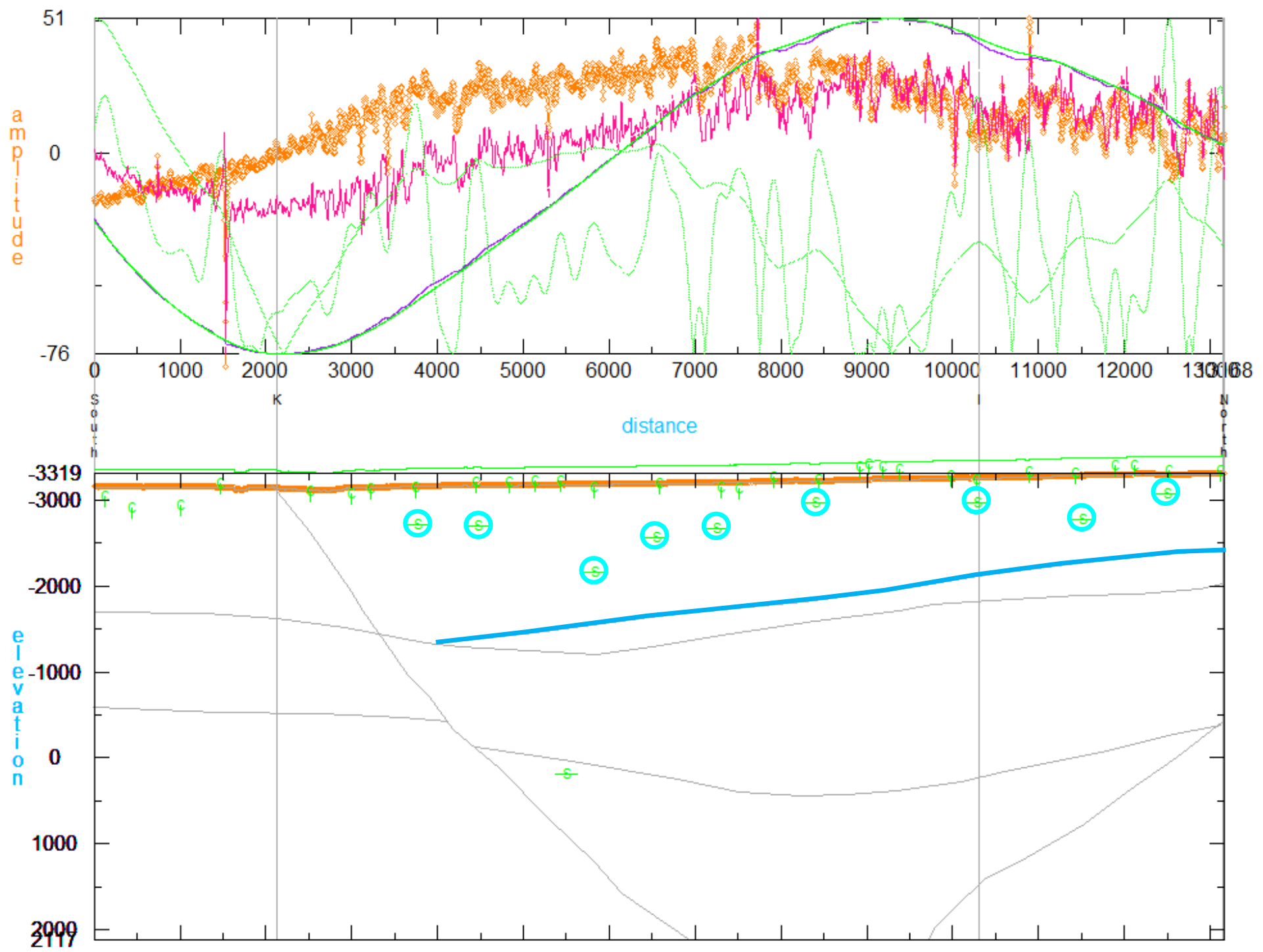

22B. Line Q-Horizontal Gradient depth solutions. 


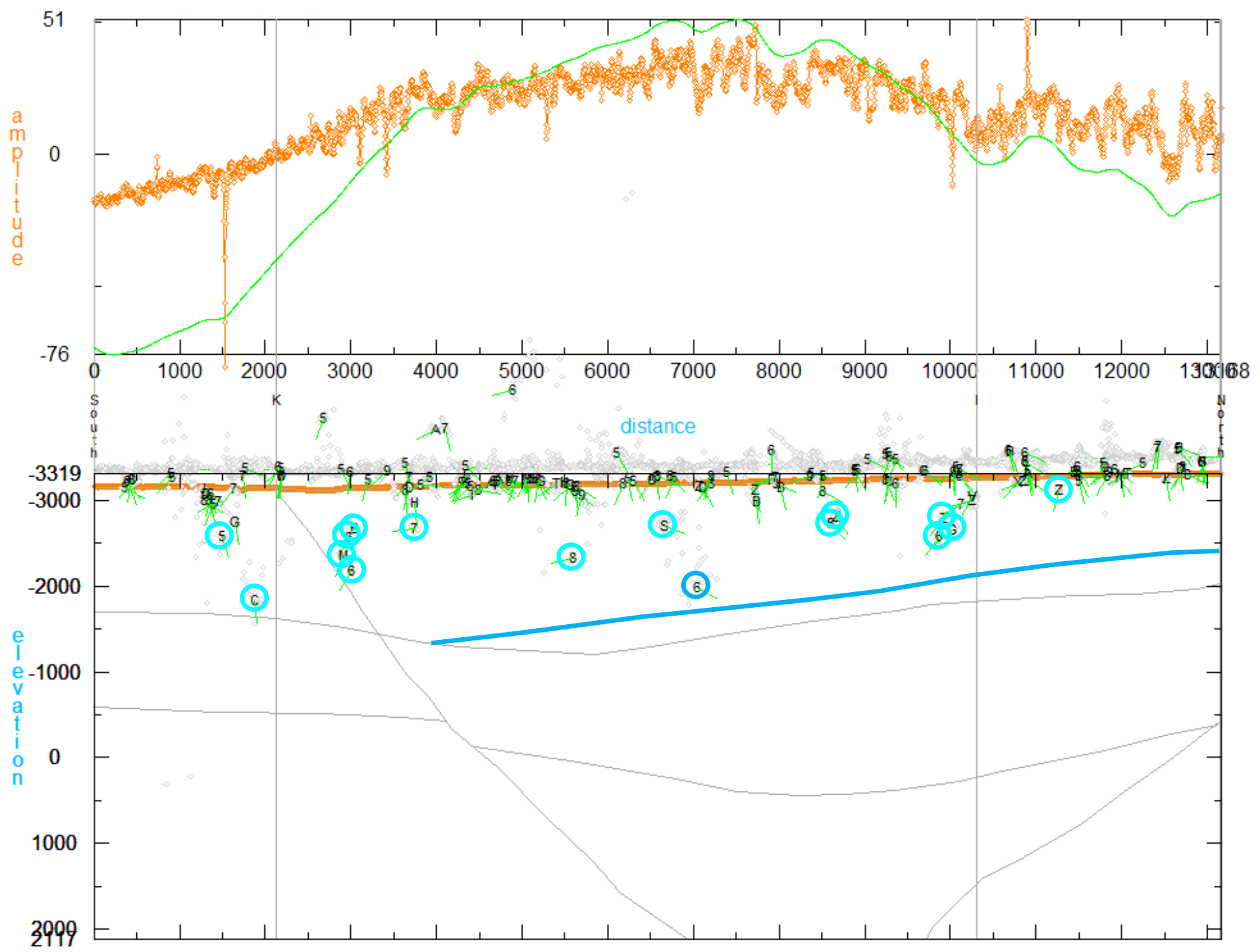

22C. Line Q-Multiple-source Werner sheet solutions. 


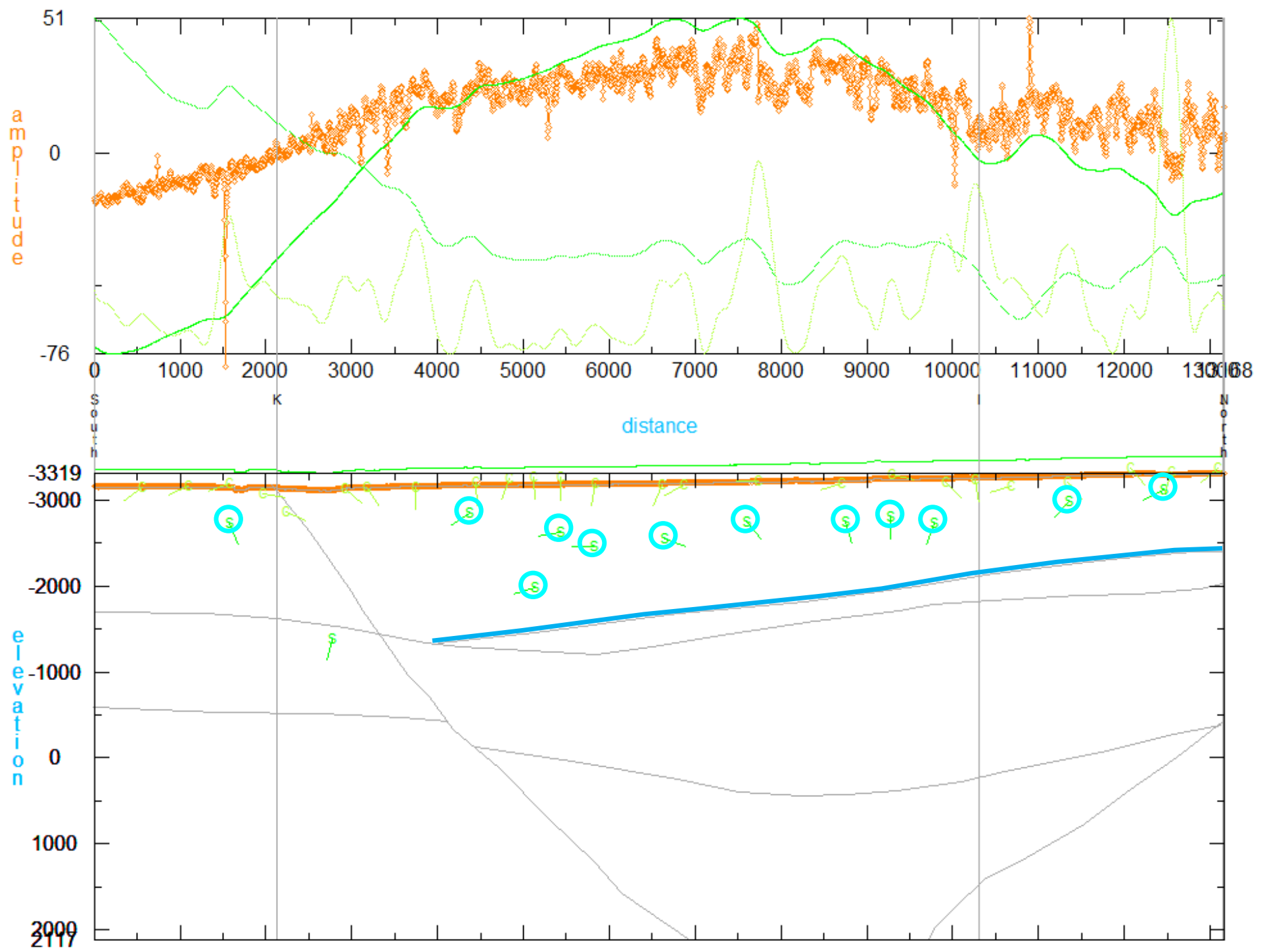

22D. Line $Q-$ Analytic Signal depth solutions.

Figure 22. Line $Q$. See figure 6 for description. 


\section{Line $\mathbf{R}$}

Line R (fig. 23) extends east from the northwest corner of the survey area in the hills north of Frenchman Flat to an intersection with Line A. It crosses two mapped, east-dipping normal faults shown in the EV model. These faults show up as the gray (and blue) faults in plate 1. The alluvial section thickens to the east of the eastern fault, but it does not include the basalt or its equivalent stratigraphic horizon. Both the HG and MSW sheet solutions include sources within the alluvium to the east of the eastern fault. Significant HG contact solutions include one just to the west of the westernmost fault, one just to the west of the easternmost fault, and two just east of the easternmost fault. Four significant AS contact solutions occur between the two faults and just to the east of the eastern fault. Three of these are interpreted as previously unmapped faults in plate 1. 


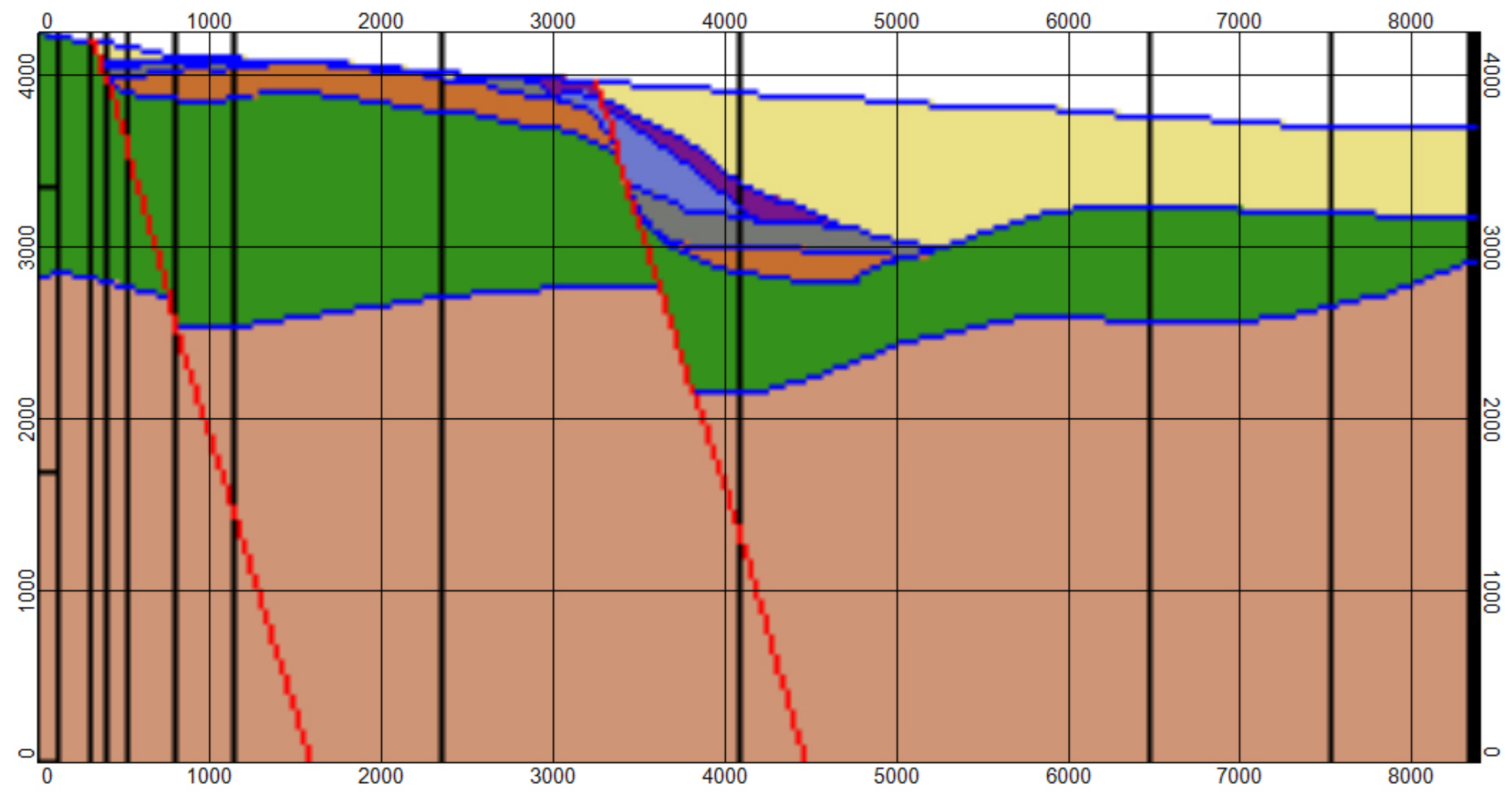

23A. Line R-EarthVision model. 


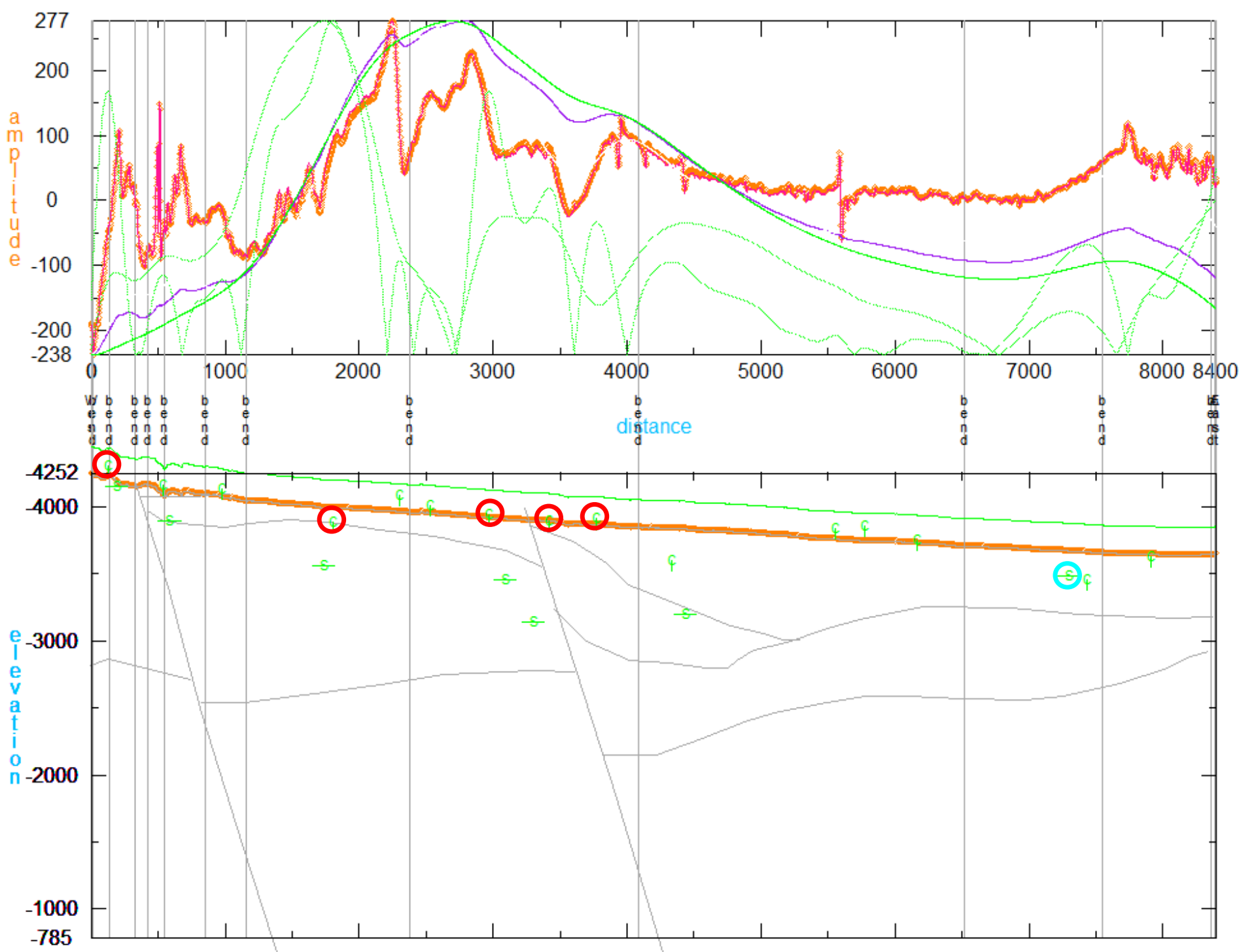

23B. Line R-Horizontal Gradient depth solutions. 


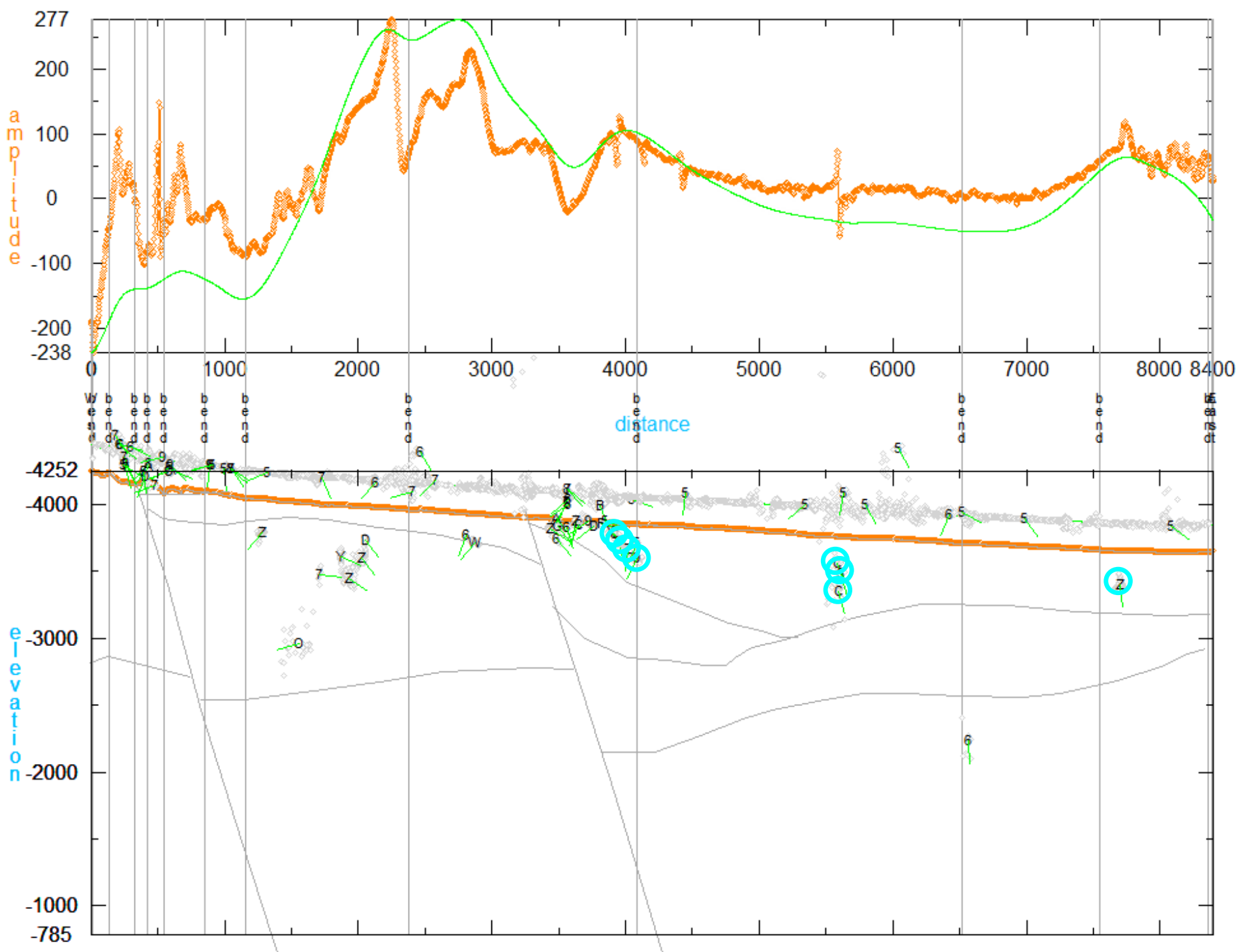

23C. Line R-Multiple-source Werner sheet solutions. 


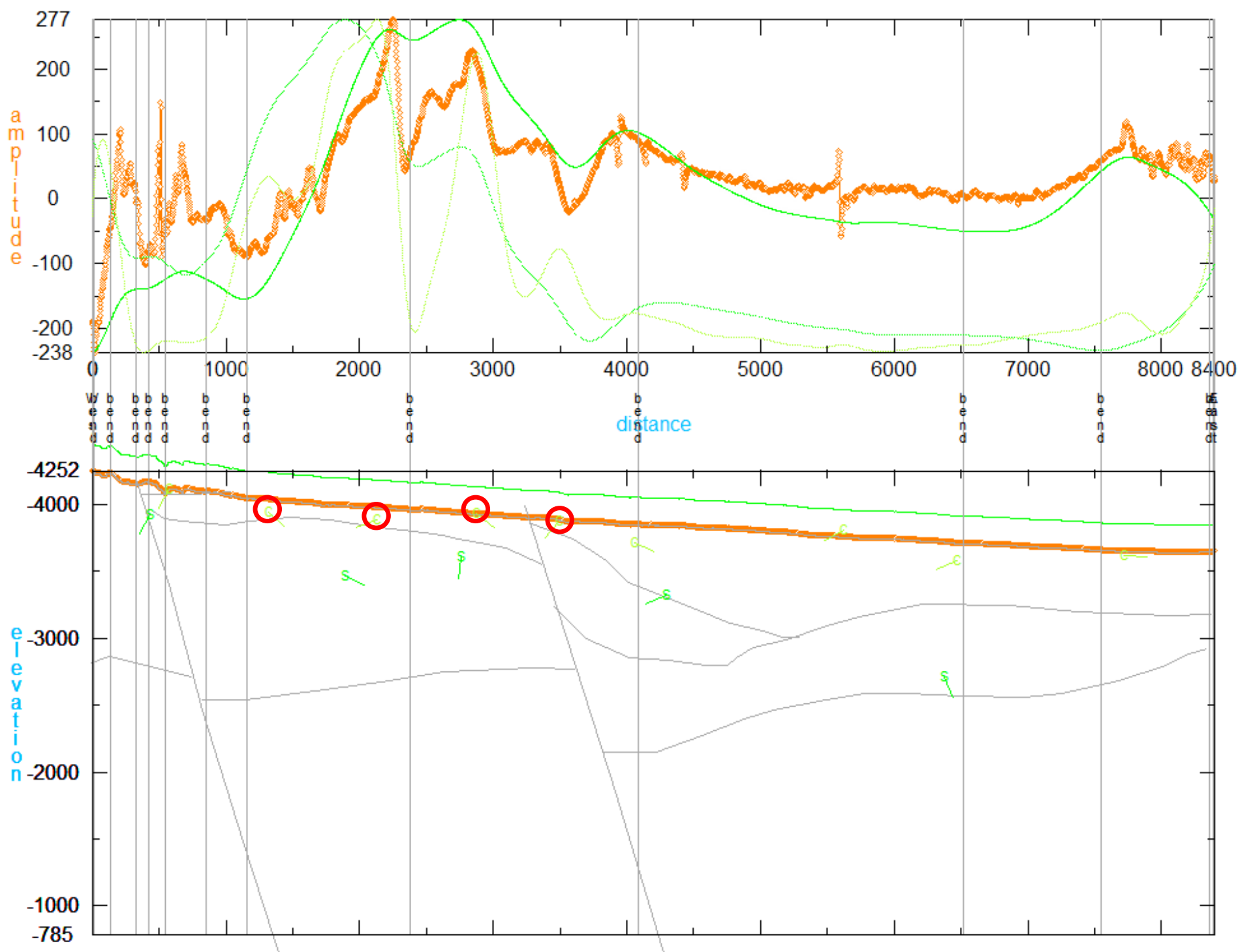

23D. Line R-Analytic Signal depth solutions.

Figure 23. Line R. See figure 6 for description. 


\section{Line S}

Line S (fig. 24) is south of Line R and extends farther to the east. It starts in the hills north of Frenchman Flat, extends east across the eastern fault seen in Line R, and ends at an intersection with Line $\mathrm{C}$. The EV model places the fault within a shallow alluvial basin that does not include the basalt or its equivalent stratigraphic horizon. Carbonate bedrock is exposed on the east end of the line. Sheet solutions from all three methods include sources within the shallow alluvium. Significant HG contact solutions occur at various locations across the section, including one near the modeled normal fault and one on the eastern end of the line near the 10,000 - $\mathrm{ft}$ distance marker that is likely to be a buried contact between non-magnetic limestone on the east and a truncated LTCU magnetic unit on the west. Significant AS contact solutions occur at four locations: the three to the west are interpreted as previously unmapped faults in plate 1; and the one to the east is near the buried limestone contact. 


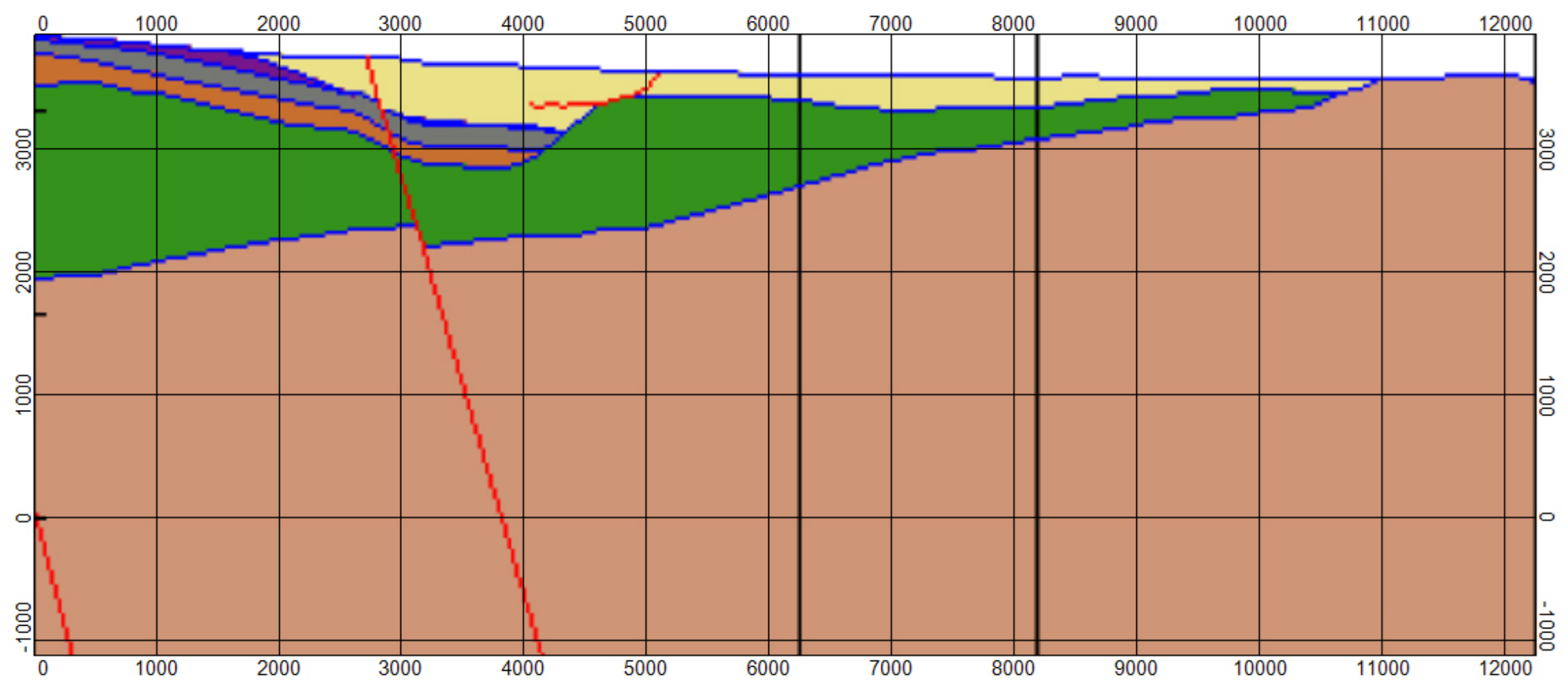

24A. Line S-EarthVision model. 


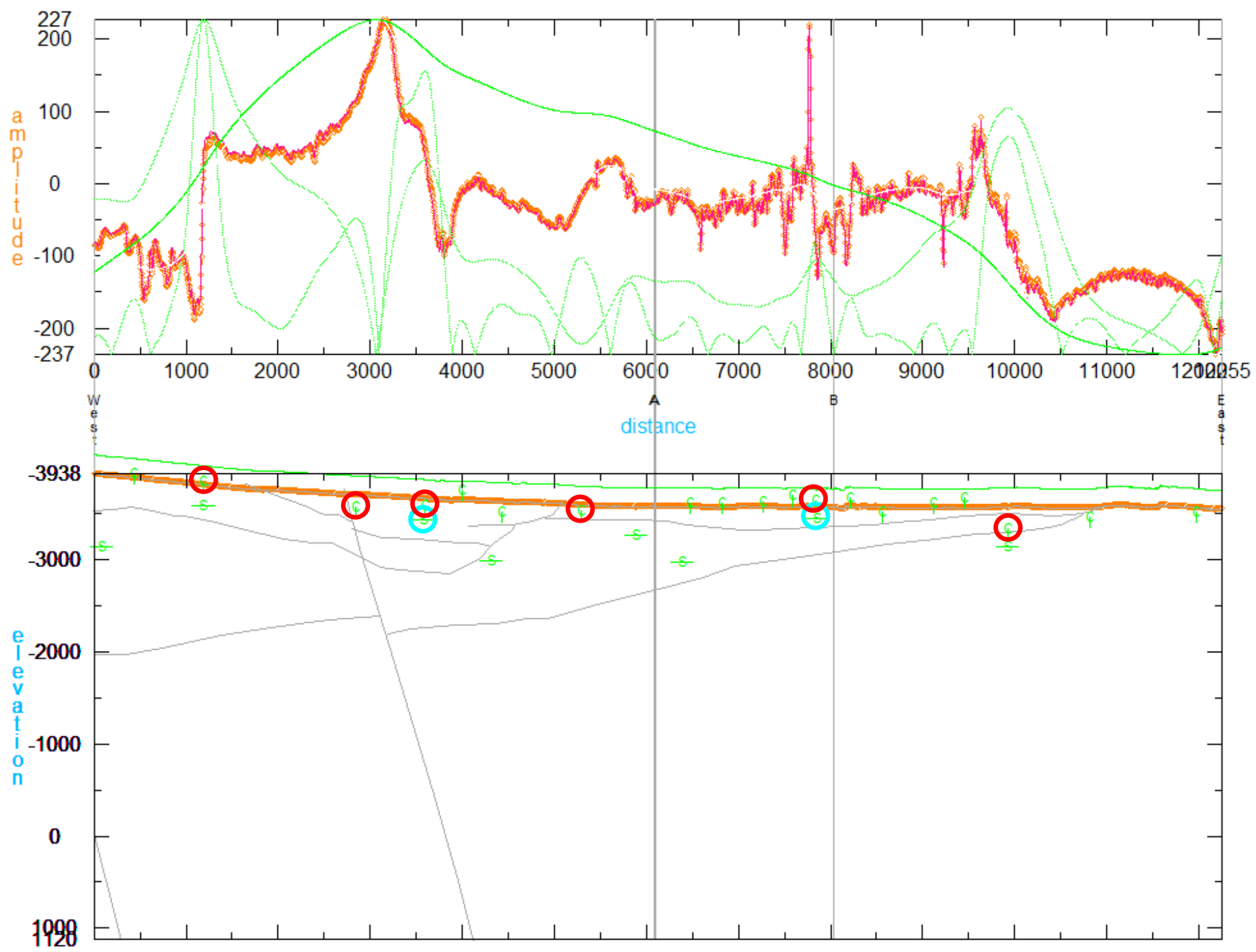

24B. Line S-Horizontal Gradient depth solutions. 


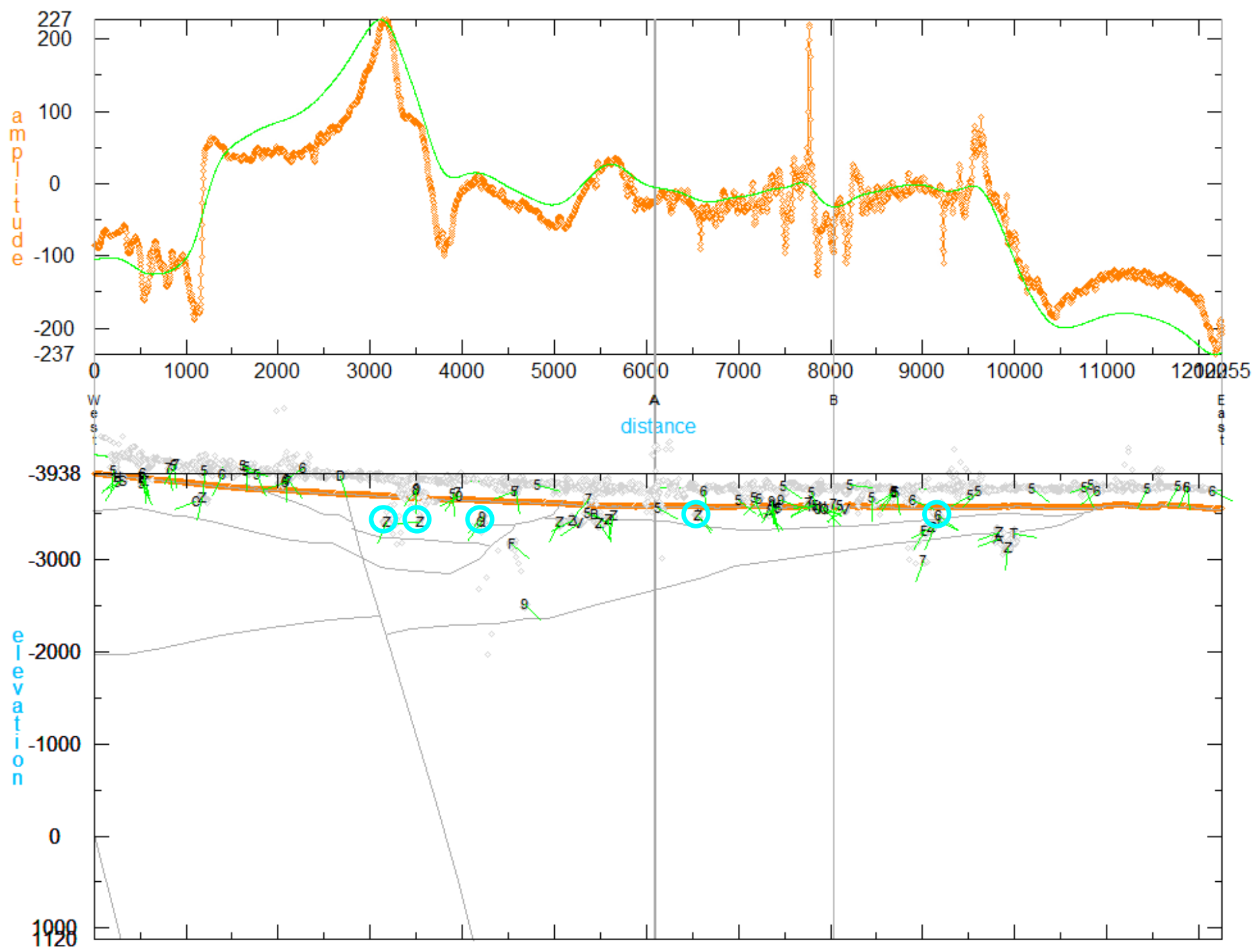

24C. Line S-Multiple-source Werner sheet solutions. 


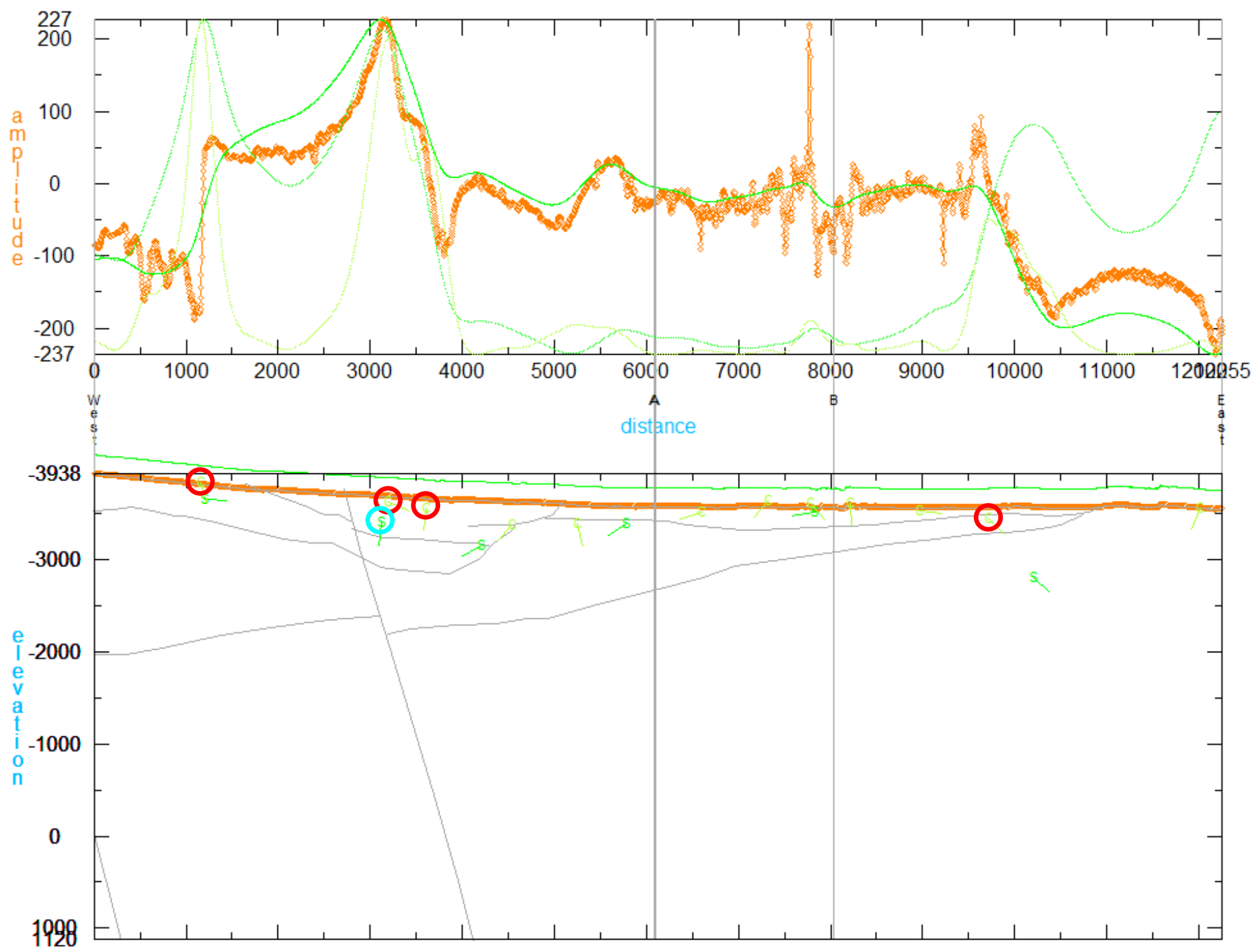

24D. Line S-Analytic Signal depth solutions.

Figure 24. Line S. See figure 6 for description. 


\section{Line T}

Line T (fig. 25) is another line that starts in the hills north of Frenchman Flat and extends east-southeast to an intersection with Line E. It crosses the mapped southern extension of the western fault seen in Line R, but this fault is not shown in the EV model. Instead the model shows exposed and shallowly buried tuff of the Timber Mountain Group along the entire line. Significant HG contact solutions occur at five locations across the section, including one at an obvious magnetic contact near the western end of the line, one just east of the mapped fault near the 2,200-ft distance marker, and three in the vicinity of an 800-nT magnetic high over outcropping tuff of the Timber Mountain Group. A single significant AS contact solution near the southeastern end of the line, which is coincident with one of the significant HG contact solutions, is interpreted as a previously unmapped southeast-dipping normal fault in plate 1 . 


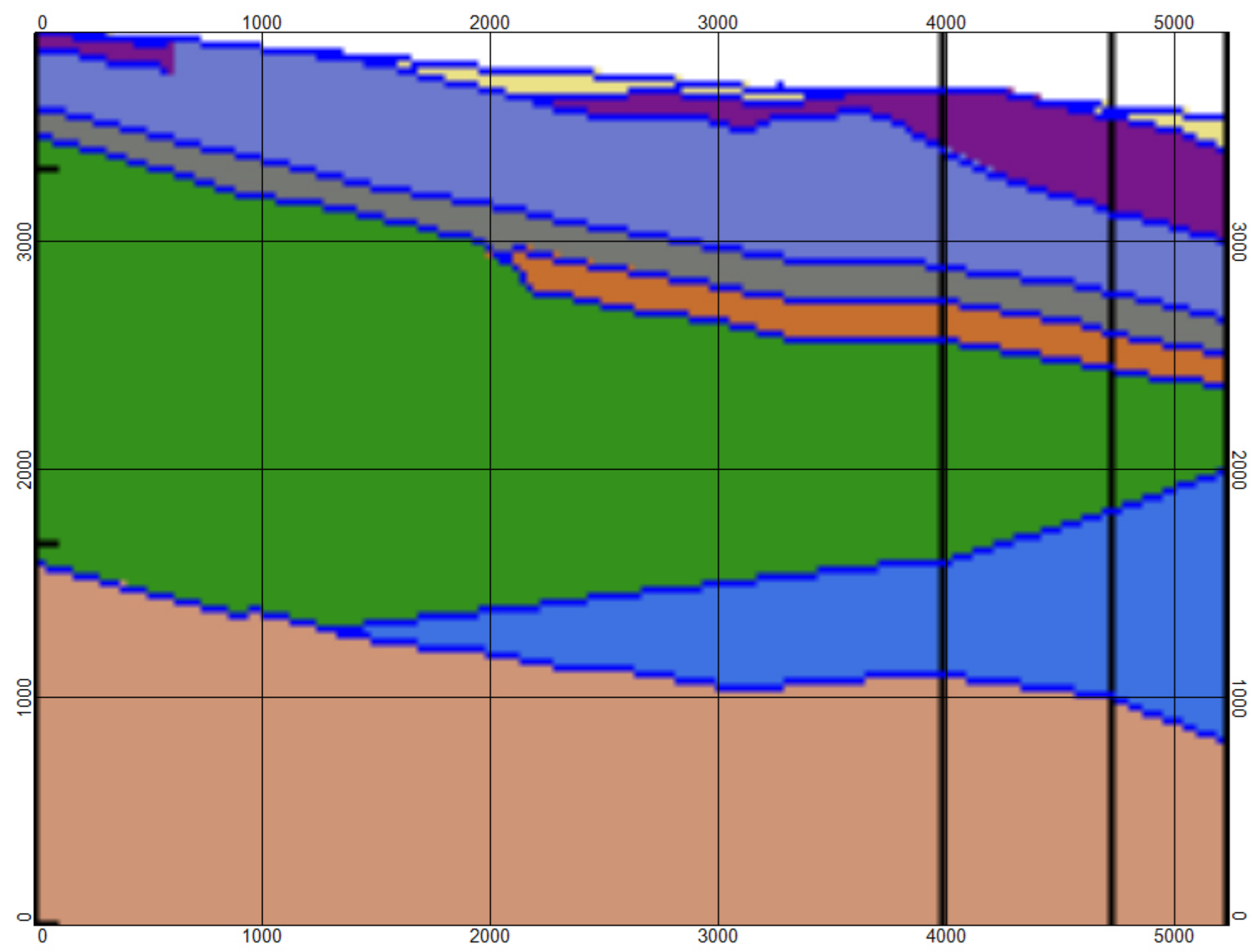

25A. Line T-EarthVision model. 


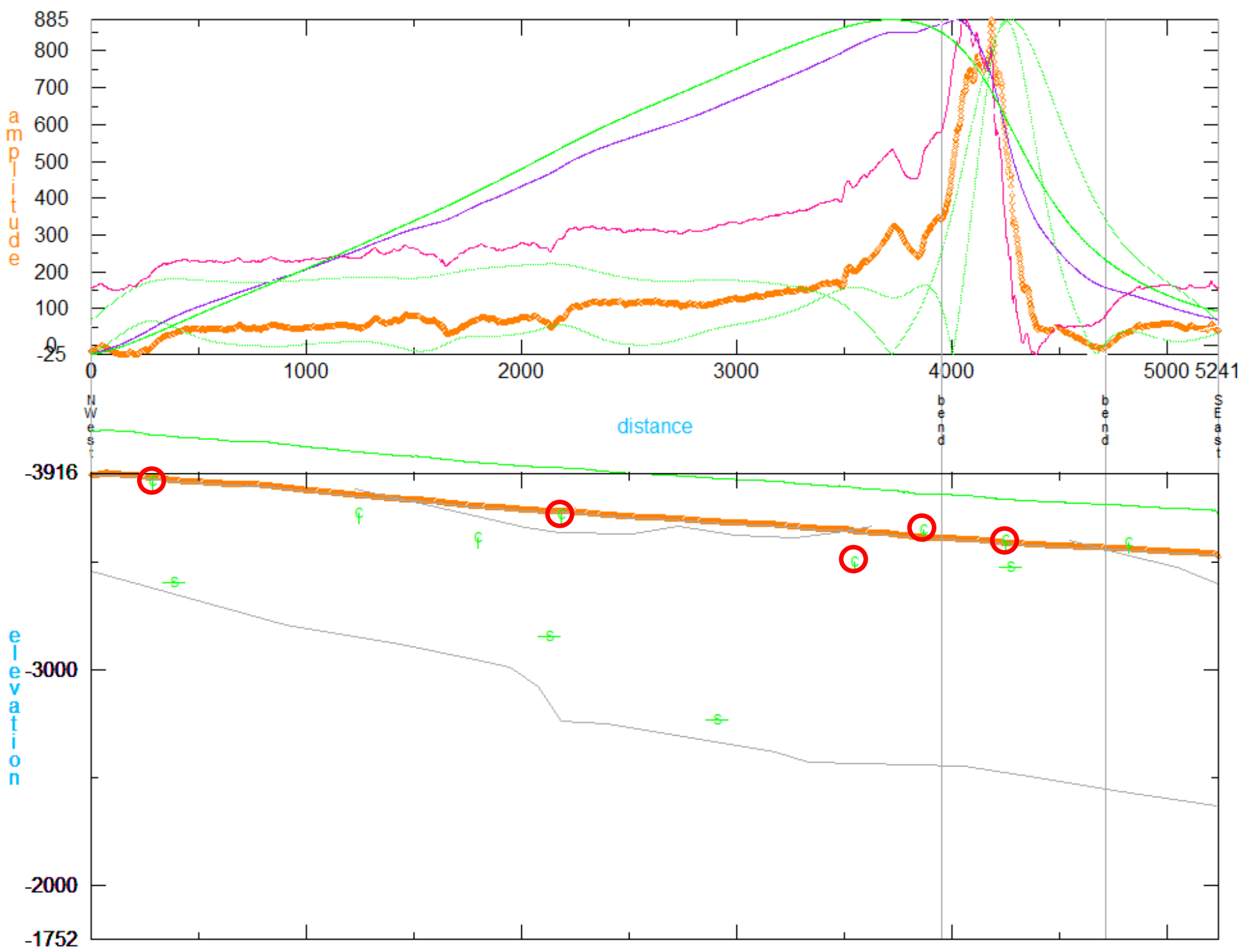

25B. Line T-Horizontal Gradient depth solutions. 


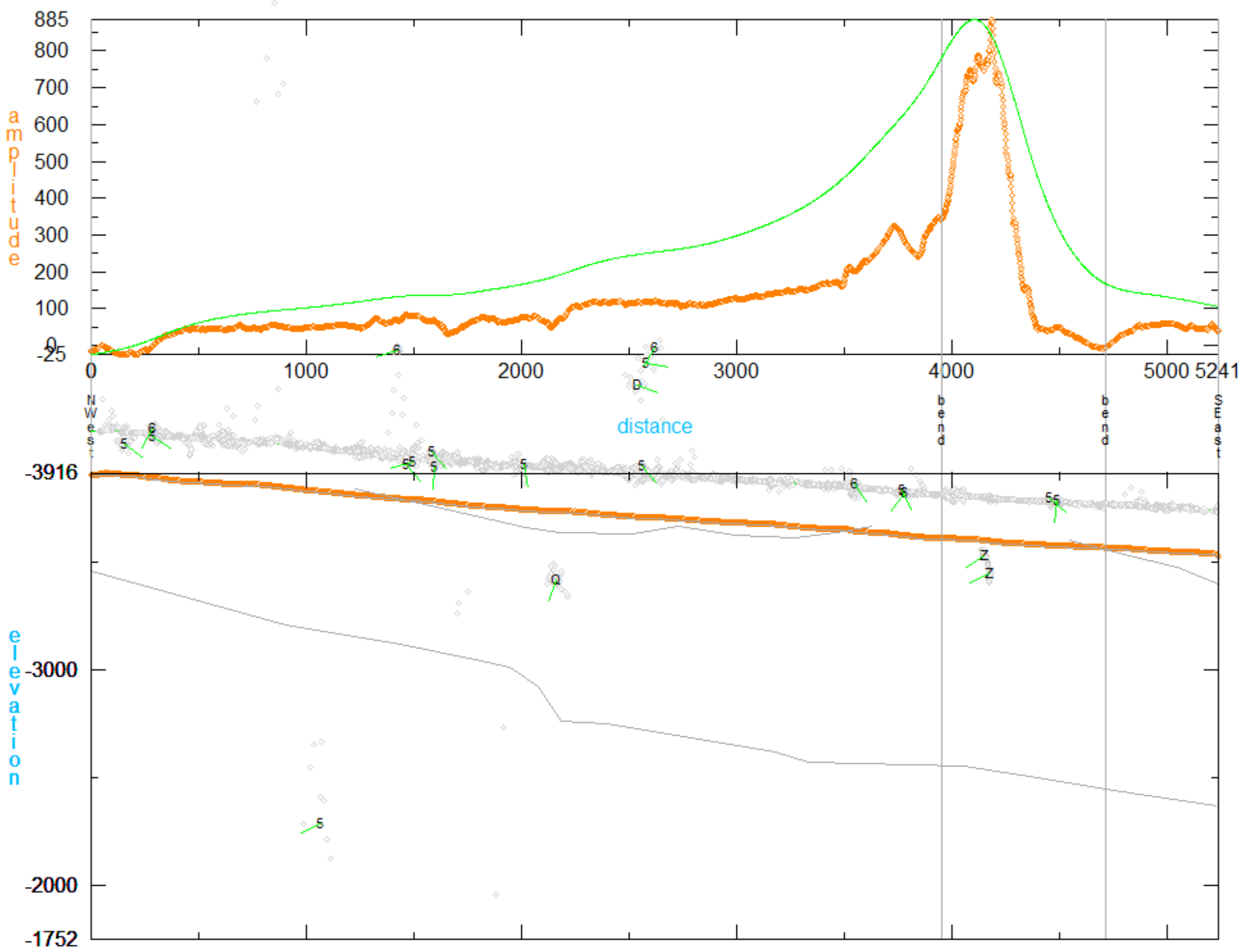

25C. Line T-Multiple-source Werner sheet solutions. 


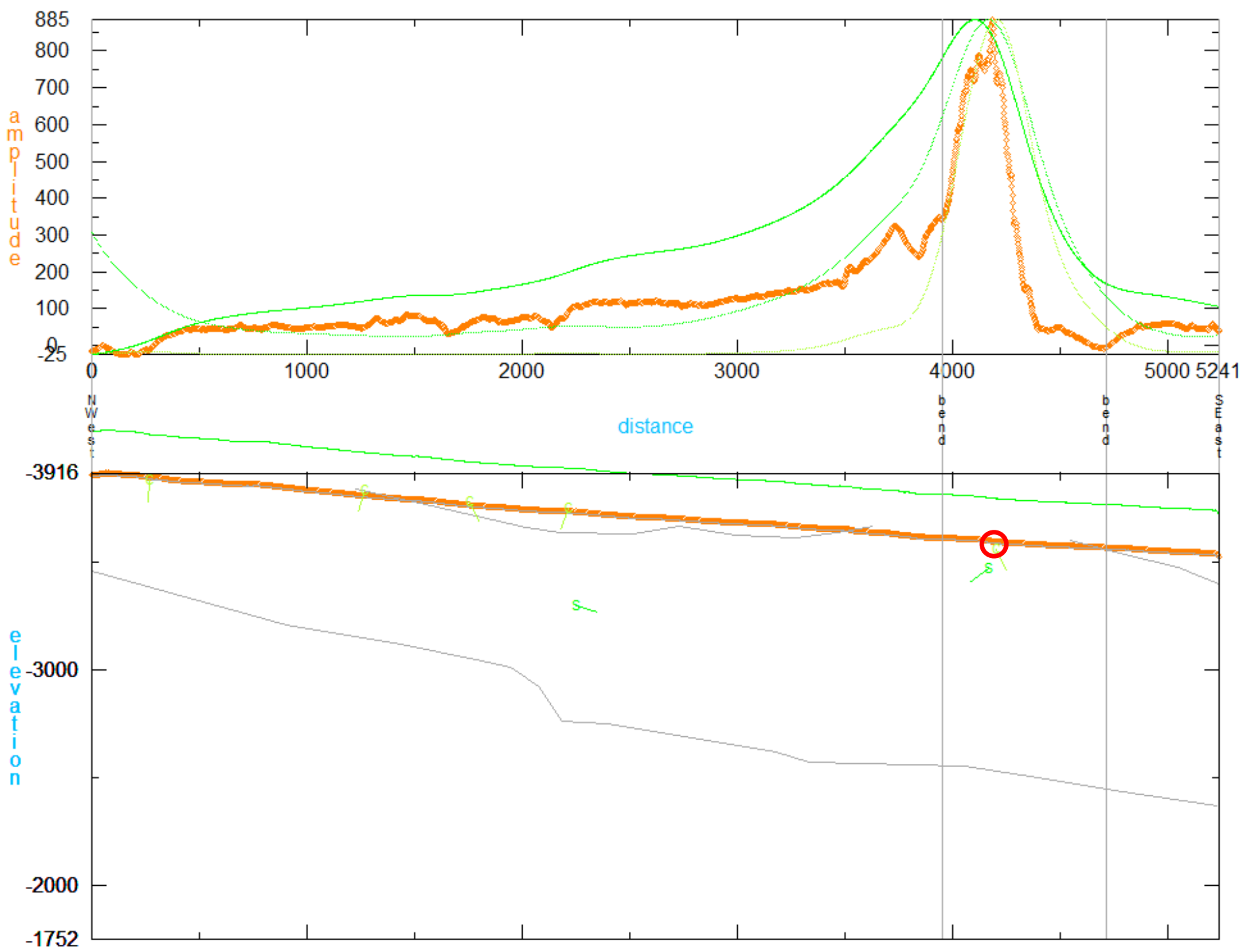

25D. Line T-Analytic Signal depth solutions.

Figure 25. Line T. See figure 6 for description. 


\section{Line U}

Line U (fig. 26) is basically an eastward extension of Line T. It starts on exposed tuff of the Timber Mountain Group at the north end of Line W and trends east-southeast across alluvium to an intersection with Line $\mathrm{C}$. The EV model shows a shallow alluvial basin, with a single west-dipping normal fault truncating the Timber Mountain units at depth. The alluvial section does not include the basalt or its equivalent stratigraphic horizon. The HG and MSW sheet solutions include sources within the deeper alluvium east of the fault; these sources correspond to an increased noise level in the magnetic profile. Four significant HG contact solutions are indicated. The middle two are interpreted as previously unmapped normal faults in plate 1. The westernmost of two significant AS contact solutions is also coincident with the western unmapped normal fault. None of the significant contact solutions coincide with the EV modeled fault, but two coincident solutions lie $600 \mathrm{ft}$ to the east of the fault. This suggests that the fault may be mislocated to the west of its true position. 


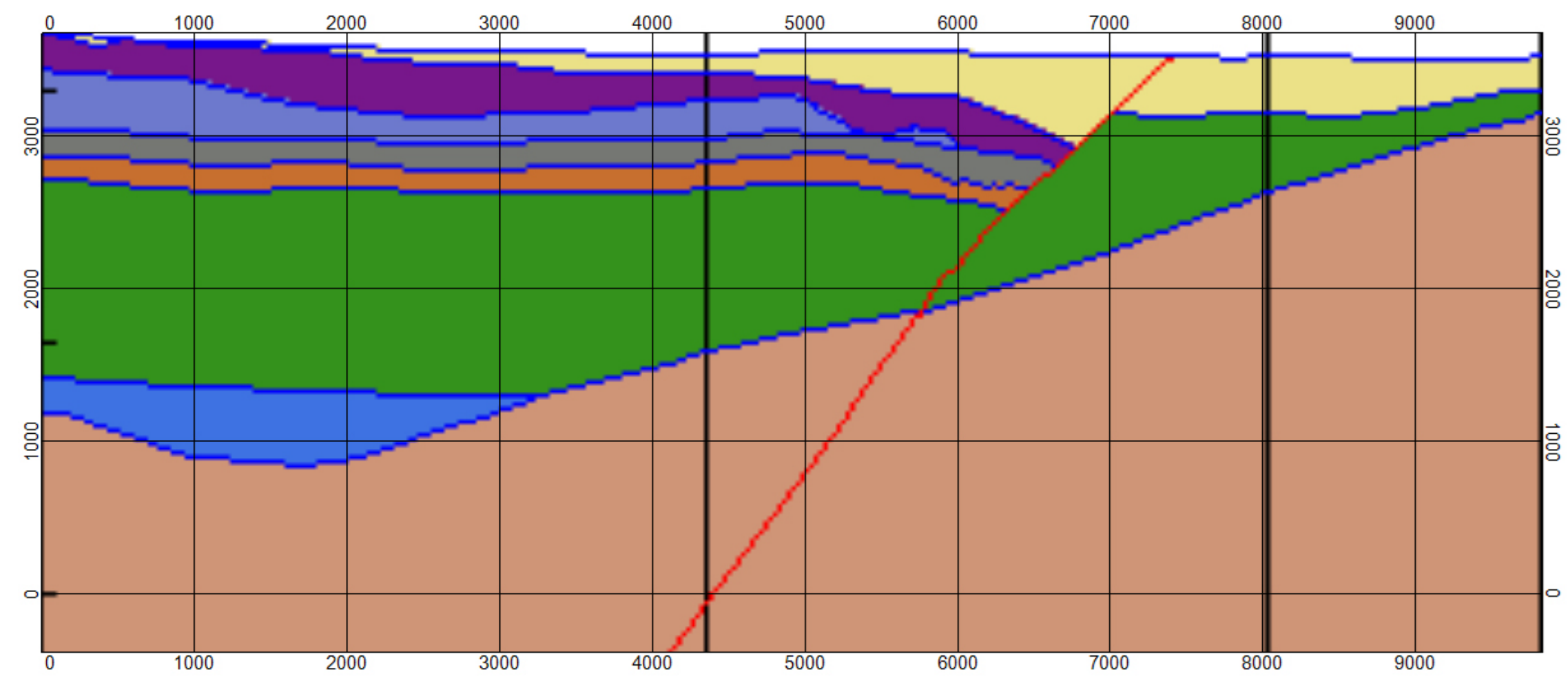

26A. Line U-EarthVision model. 


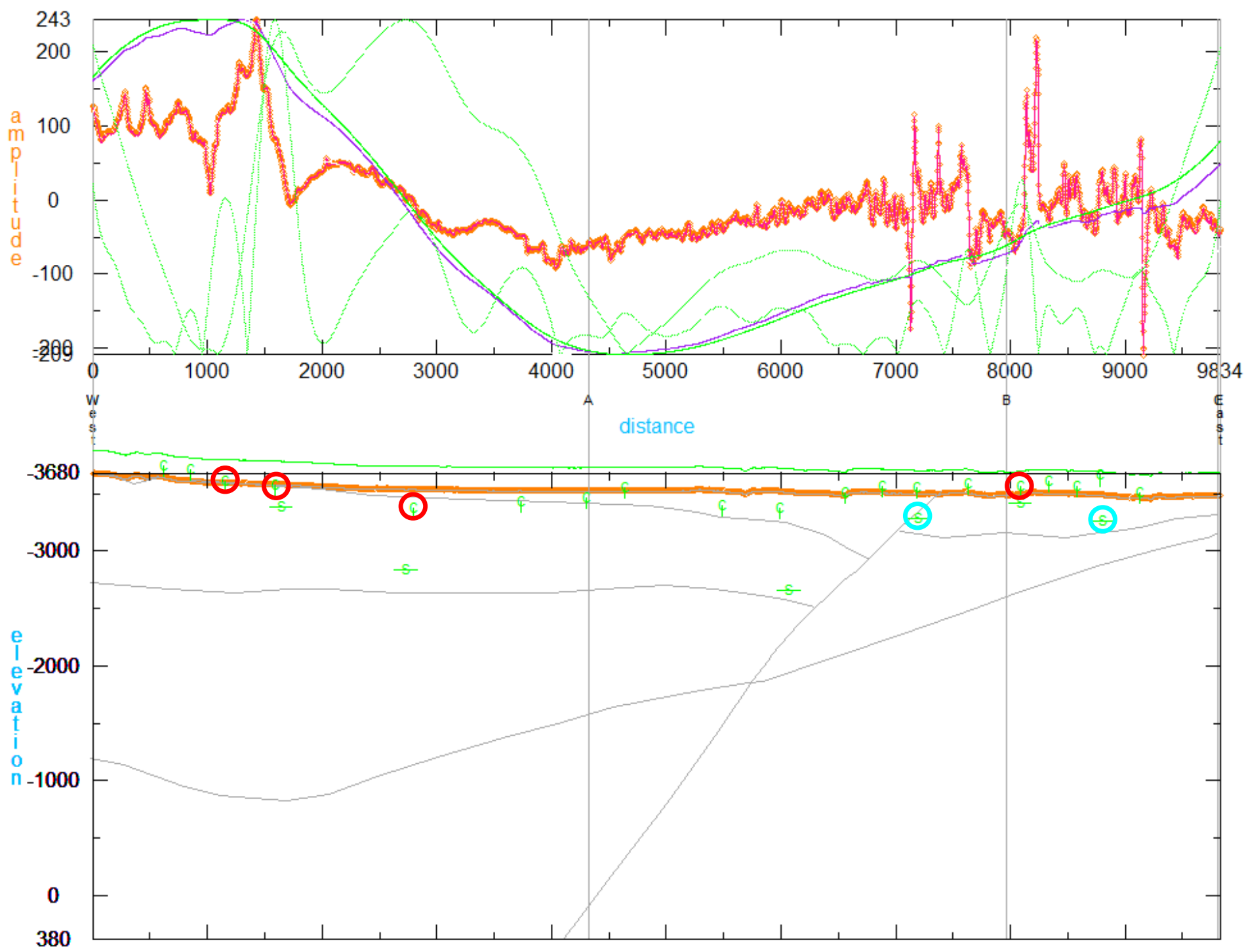

26B. Line U-Horizontal Gradient depth solutions. 


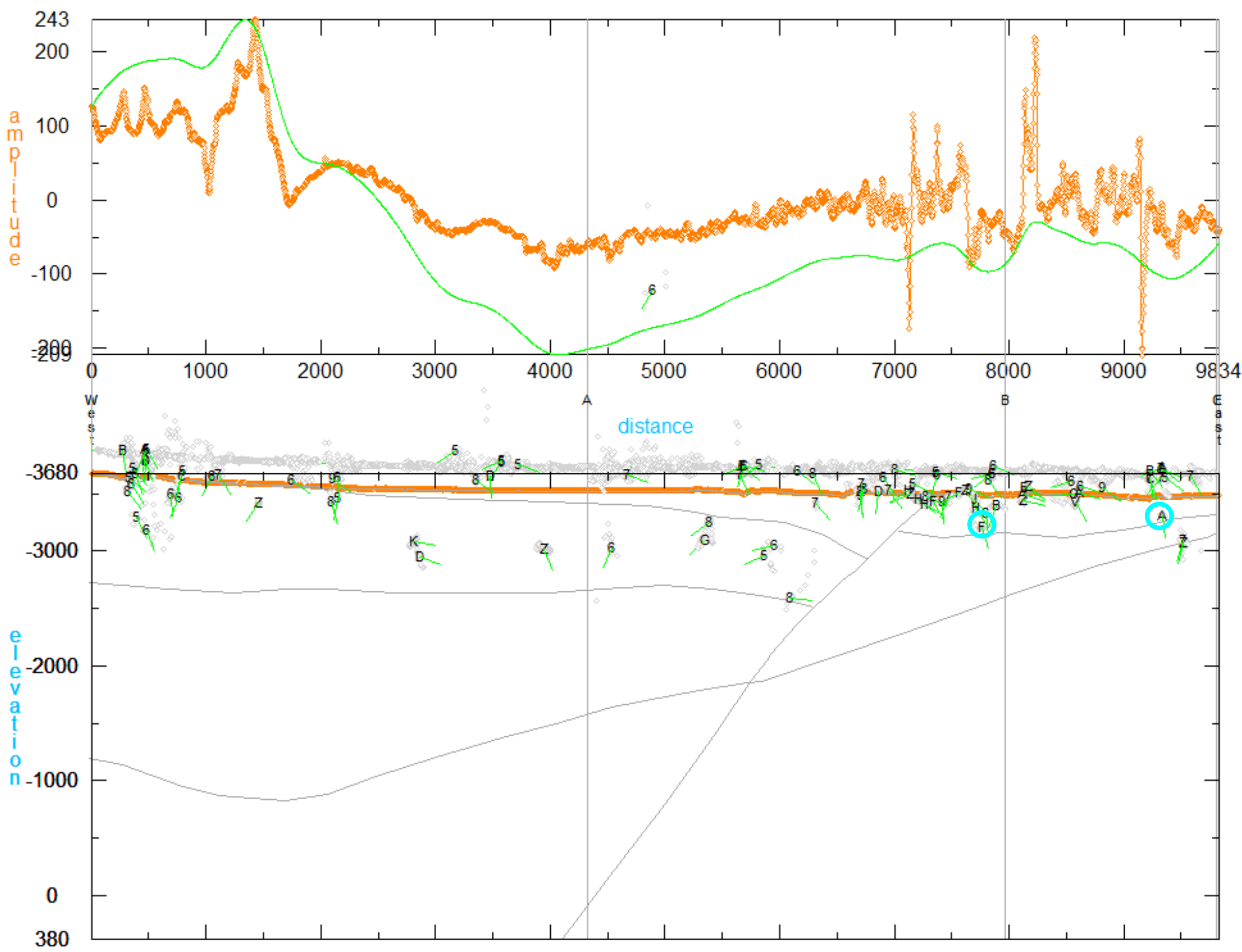

26C. Line U-Multiple-source Werner sheet solutions. 


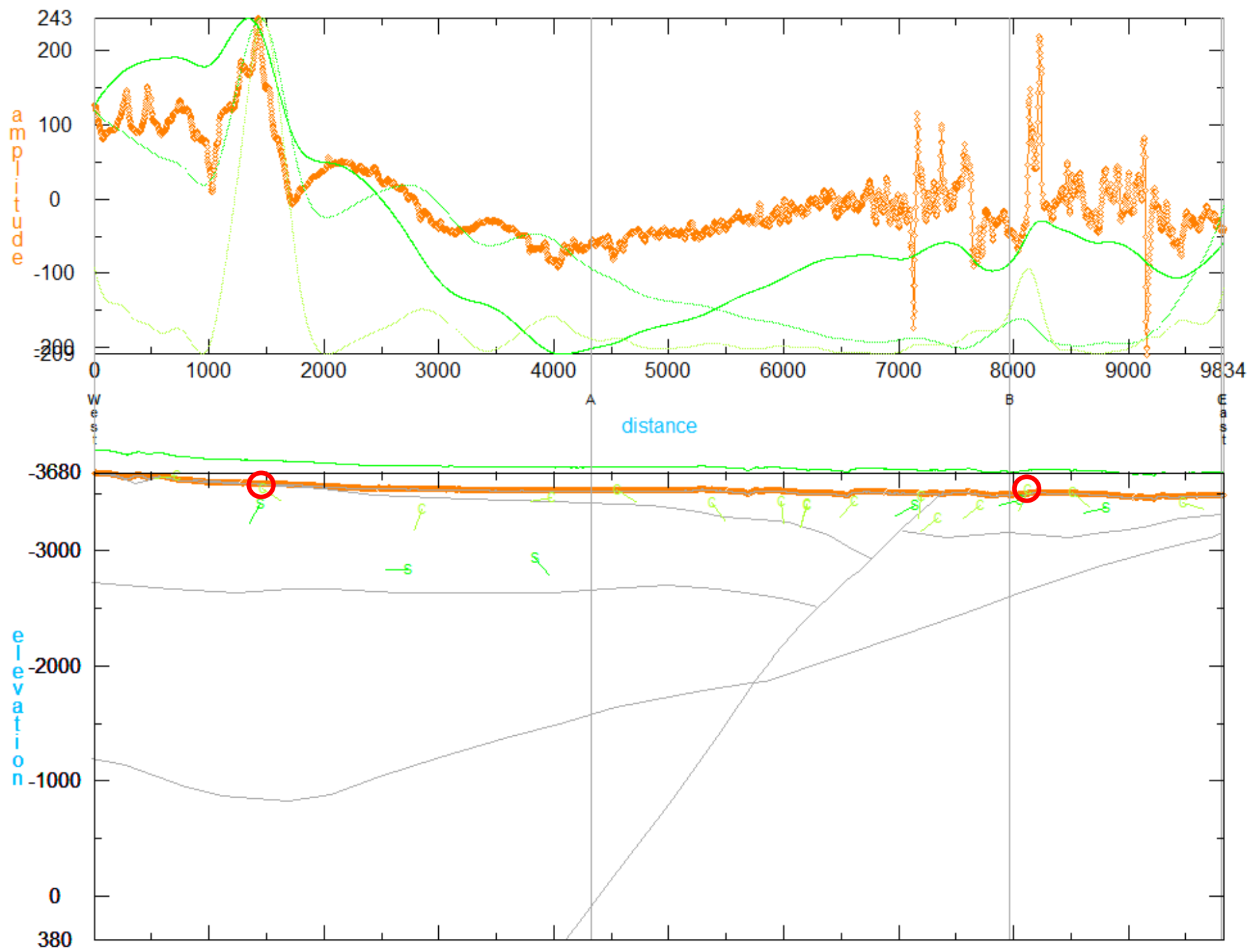

26D. Line U-Analytic Signal depth solutions.

Figure 26. Line U. See figure 6 for description. 


\section{Line V}

Line V (fig. 27) is parallel to, and south of, the western half of Line U. It extends from an intersection with Line $\mathrm{A}$ on the west to an intersection with line $\mathrm{C}$ on the east. The EV model shows an alluvial basin, generally thickening to the east, and underlain by tuff of the Timber Mountain Group. The alluvial section does not include the basalt or its equivalent stratigraphic horizon. A single west-dipping normal fault, which only appears on the section as minor offsets in the bedrock units, is present on the east end of the line. Sheet solutions from all three methods include sources within the alluvium. A single significant HG contact solution (with a corresponding AS contact solution) occurs just west of the normal fault, near some large spikes in the magnetic profile. 


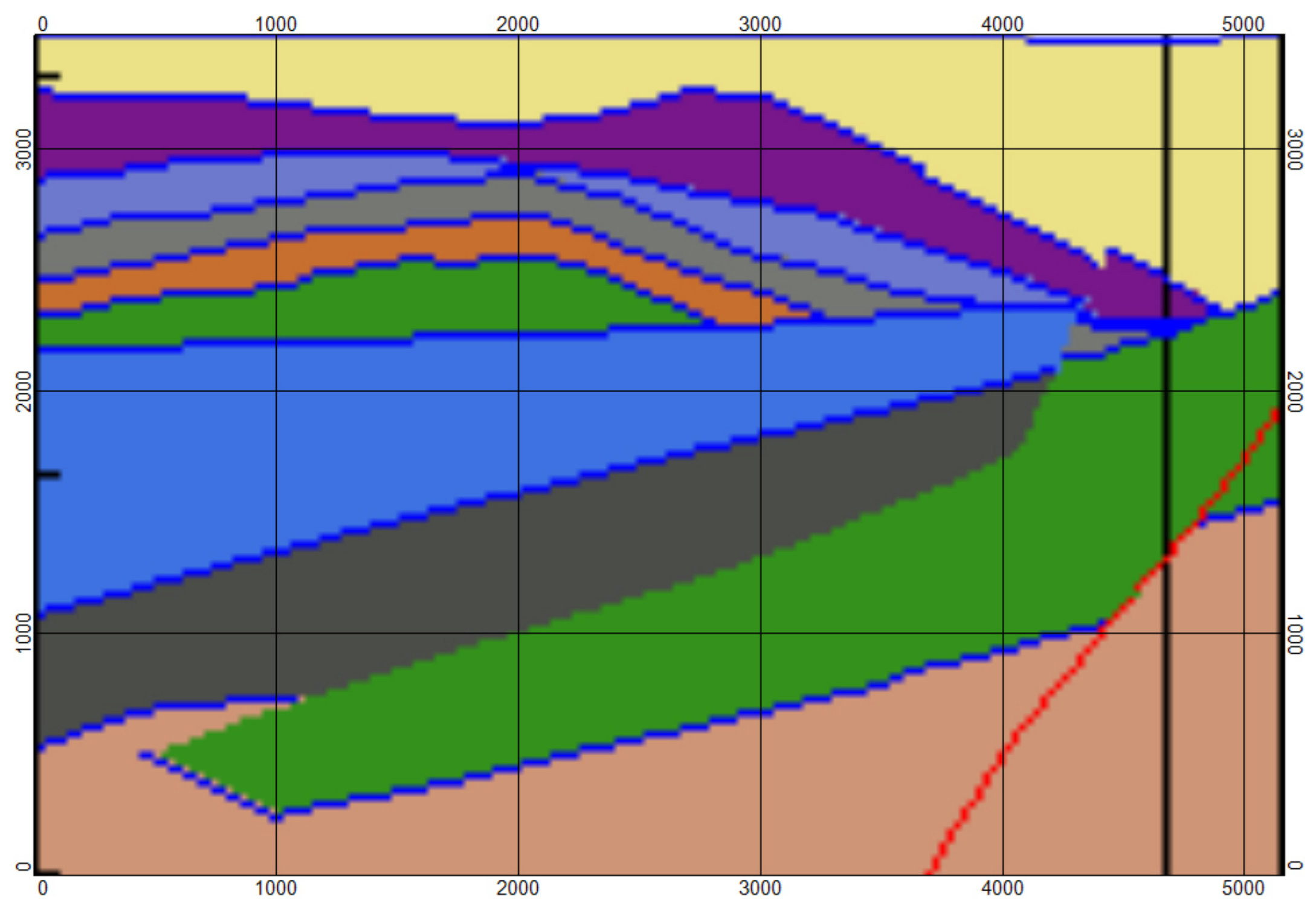

27A. Line V-EarthVision model. 


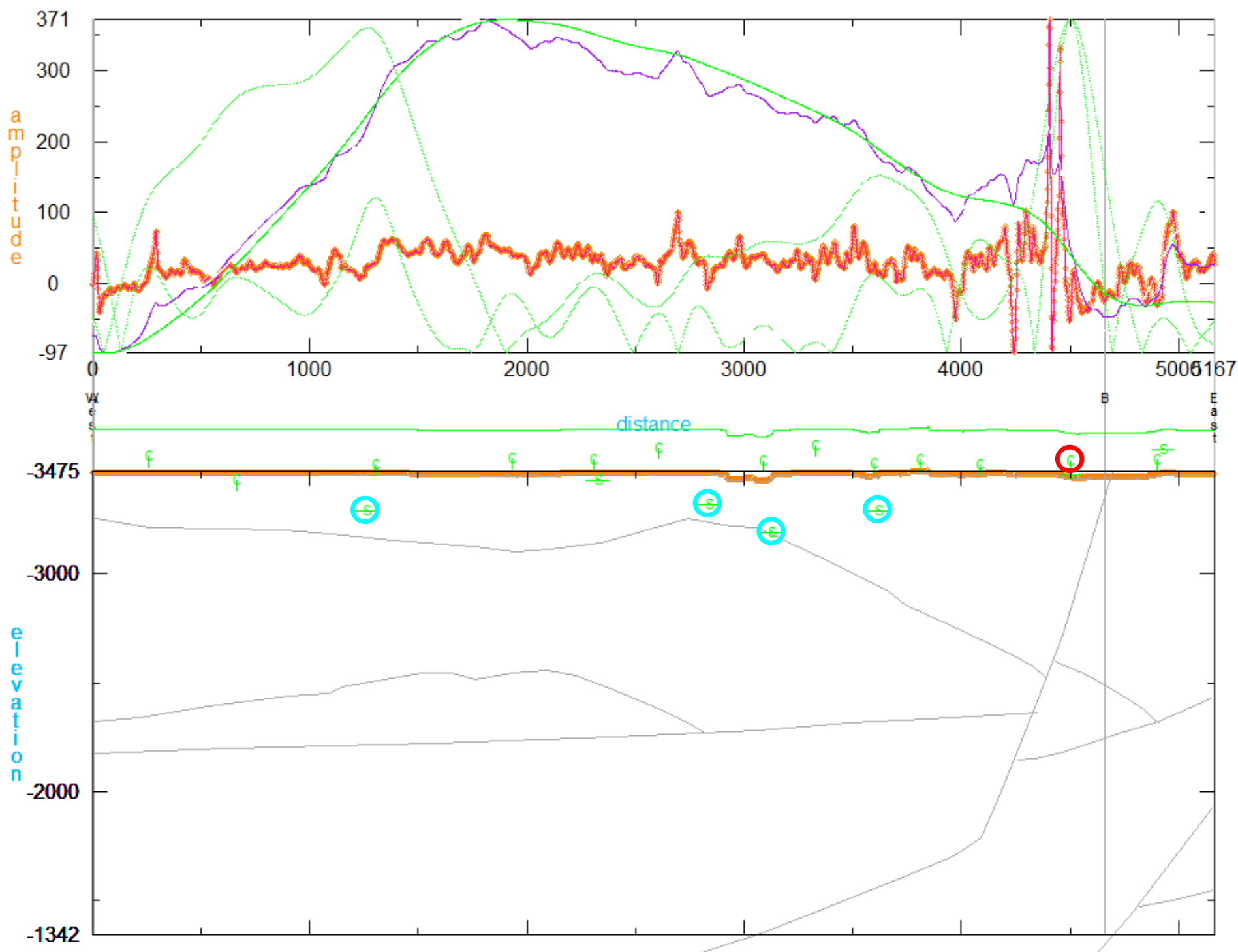

27B. Line V-Horizontal Gradient depth solutions. 


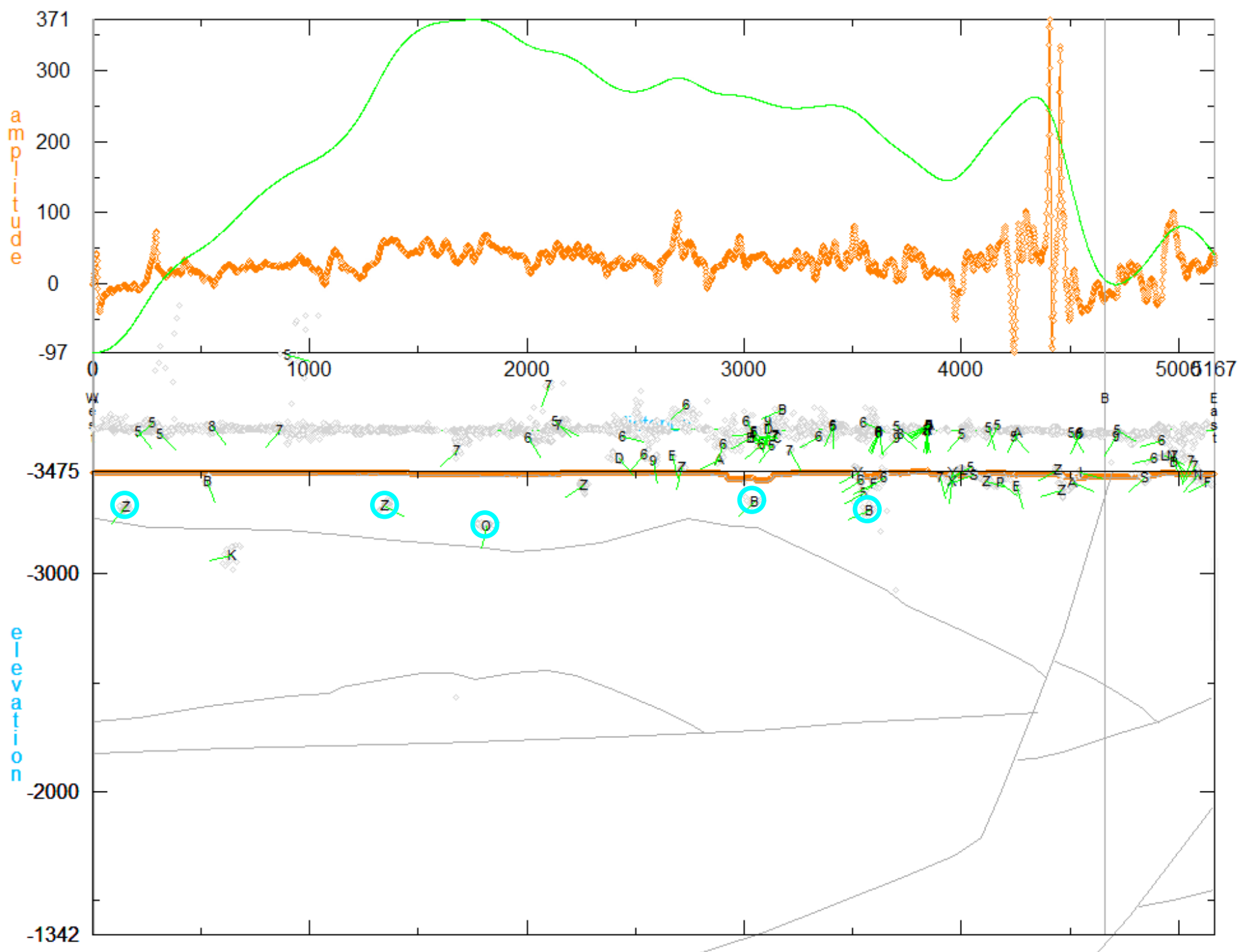

27C. Line V-Multiple-source Werner sheet solutions. 


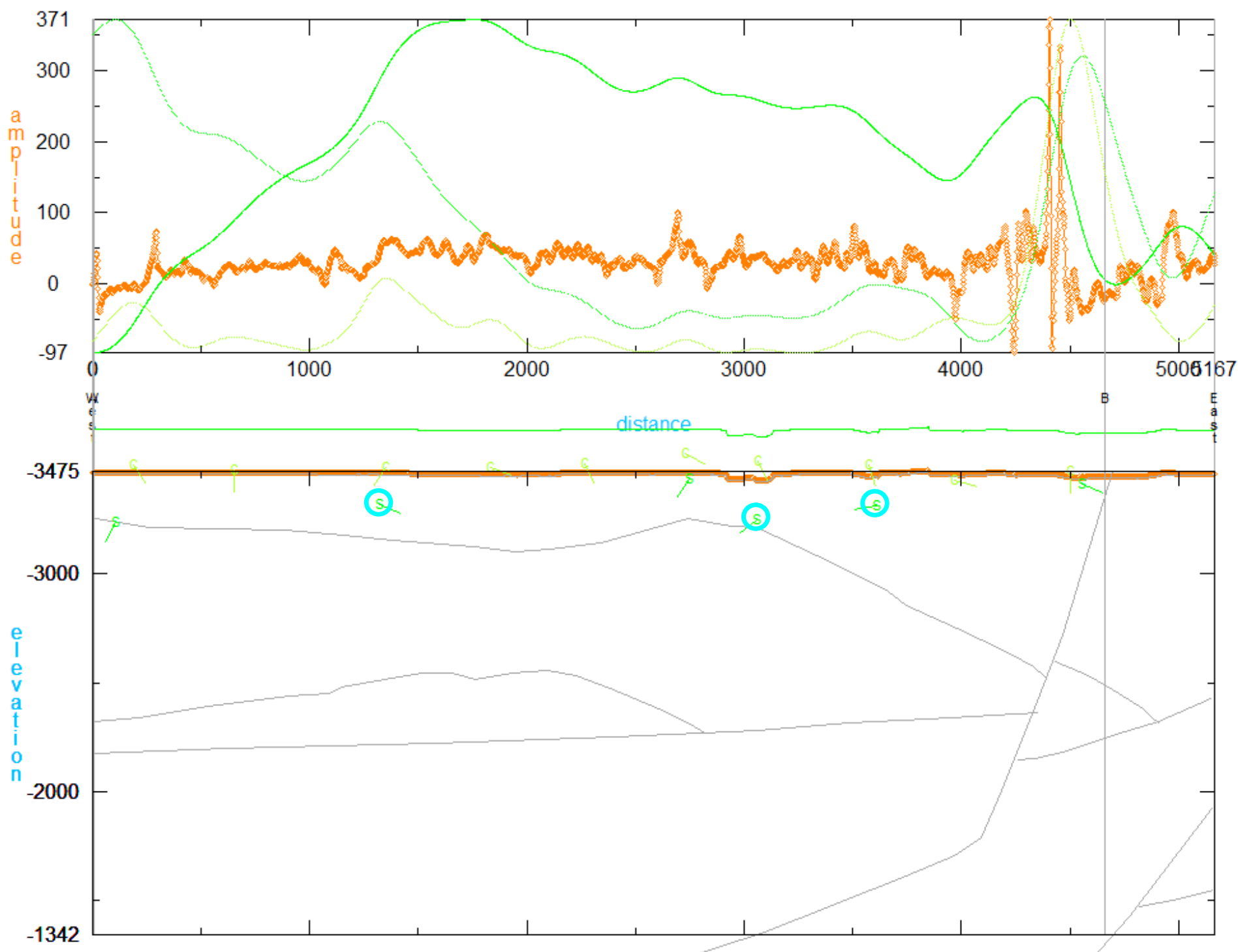

27D. Line V-Analytic Signal depth solutions.

Figure 27. Line V. See figure 6 for description. 


\section{Line W}

Line W (fig. 28) extends from near the eastern end of Line G north to an intersection with Line U. The magnetic profile features a 300-nT anomaly over exposed tuff of the Timber Mountain Group on the northern end of the line. The section crosses the same major southdipping normal fault seen to the west in Lines $\mathrm{M}$ and $\mathrm{N}$, and to the east in Line A.. In the EV model, the stratigraphic horizon corresponding to the basalt is present to the south of this fault. The MSW sheet solutions include three sources near this horizon, one of which is at the fault. This suggests that the basalt is present in the central part of this section. Three significant HG contact solutions are seen; one is within the alluvium near the south end of the line, one is near the normal fault, and one is near the contact between alluvium and exposed tuff of the Timber Mountain Group. Four of five significant AS contact solutions are seen at depth within the alluvial and volcanic units. This is unusual and could imply that the actual sources are shallow but off to the sides of the section. Nonetheless, two of these deep contact solutions (at distance markers 1,900 and 4,300) are interpreted as previously unmapped faults in plate 1. 


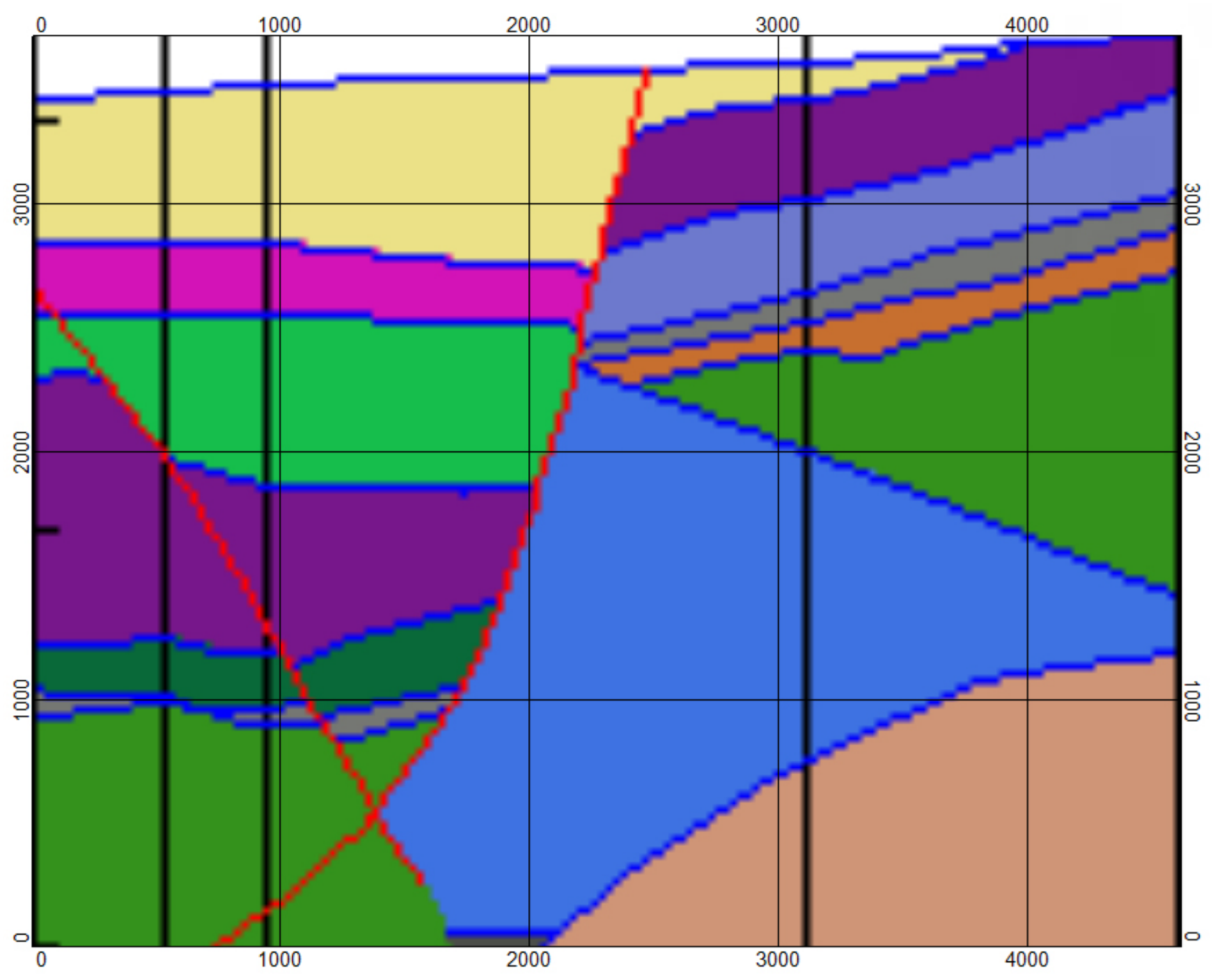

28A. Line W-EarthVision model. 


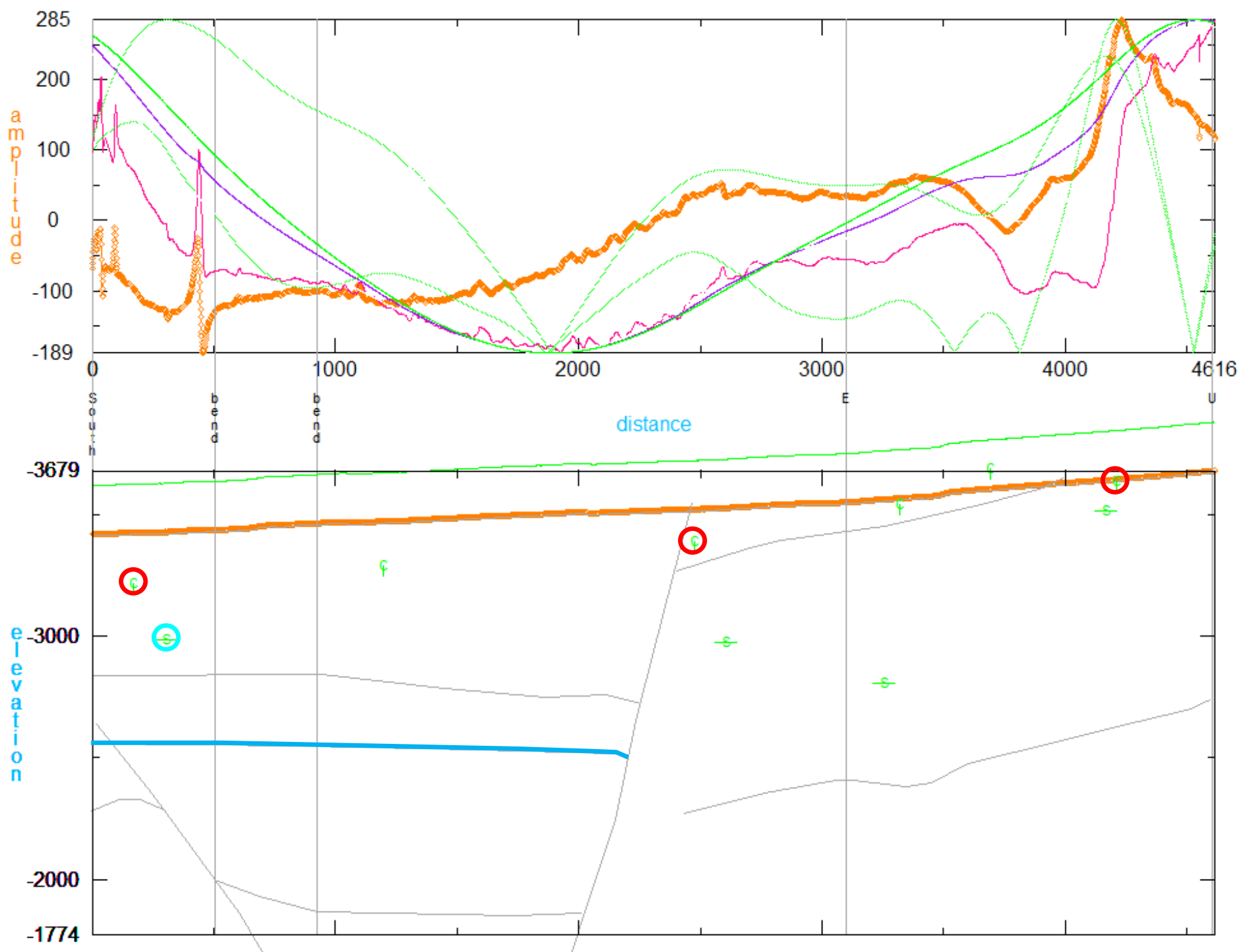

28B. Line W-Horizontal Gradient depth solutions. 


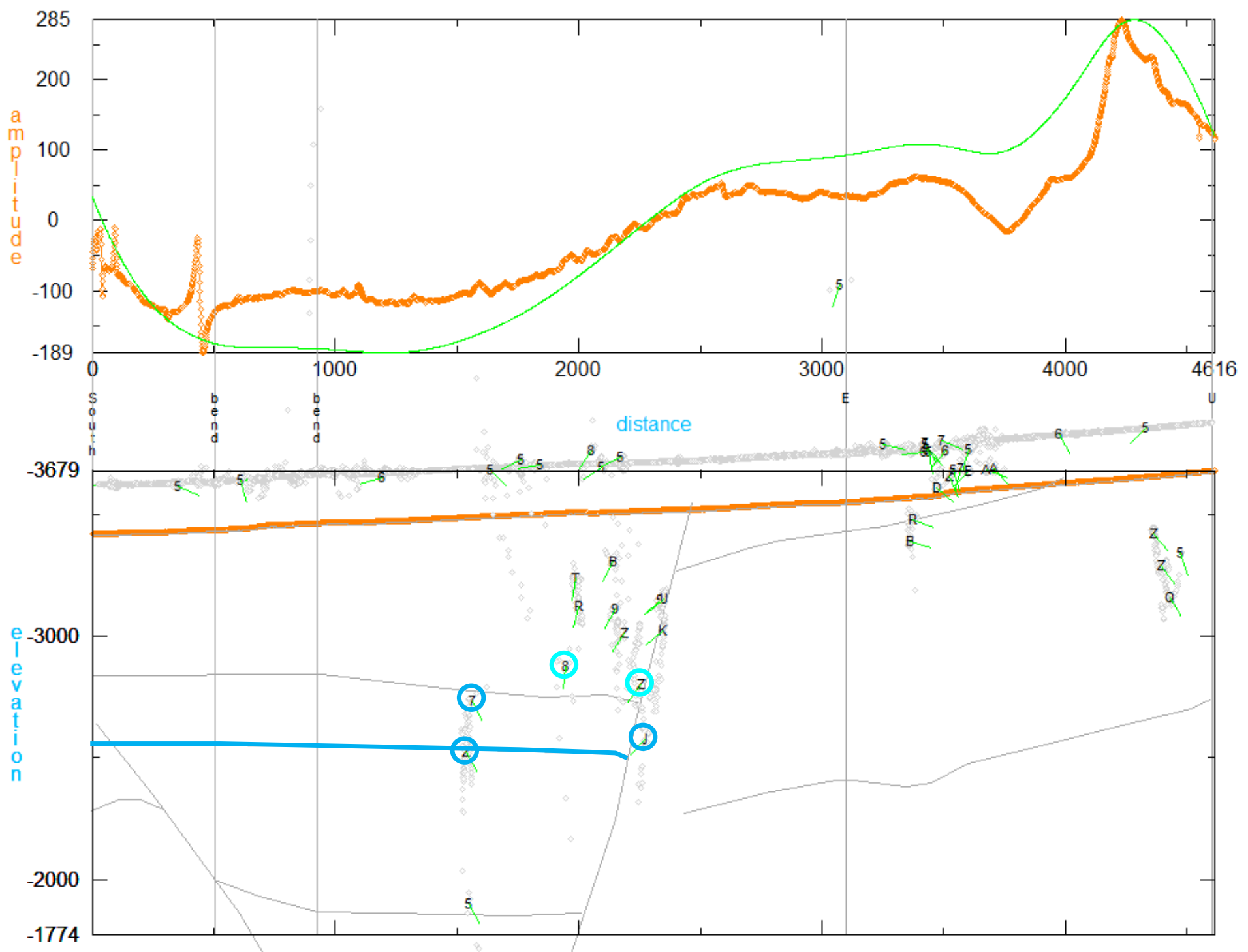

28C. Line W-Multiple-source Werner sheet solutions. 


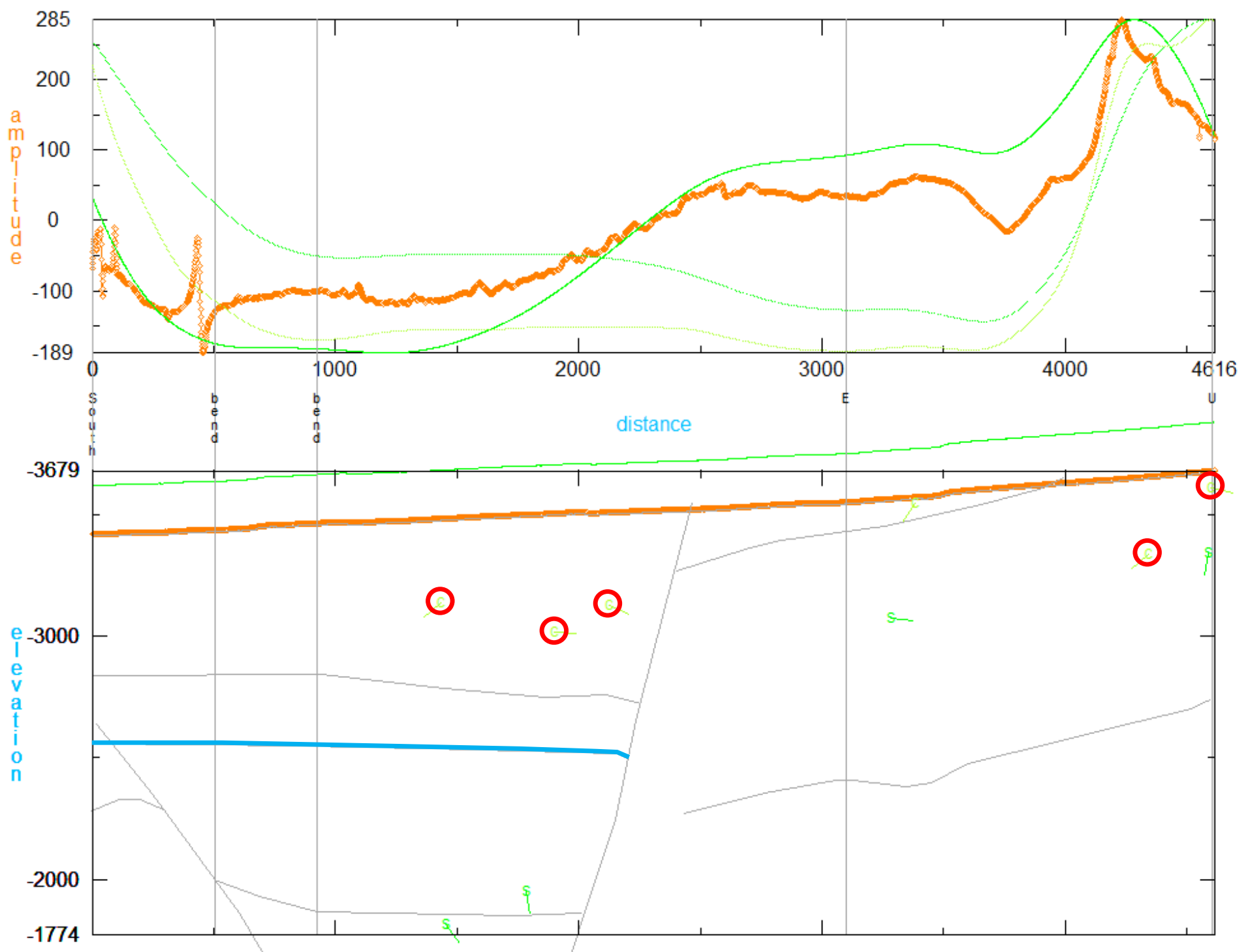

28D. Line $W-$ Analytic Signal depth solutions.

Figure 28. Line W. See figure 6 for description. 


\section{Summary of results in map format}

The data and results are presented in map format on plate 1. Shown on the plate are the locations of the magnetic-profile lines, the magnetic field along the lines in filled-profile format (red for positive anomaly values, blue for negative), generalized geology (Workman and others, 2002), locations of selected wells, and partial results of the previous geophysical survey (Carr and others, 1975).

Estimated depths to the edges of magnetic-sheet sources, such as the buried basalt flow, are plotted along each line using proportionally sized symbols - circles for HG solutions, octagons for MSW solutions, and squares for AS solutions. The symbols for sheet-edge solutions at depths within $250 \mathrm{ft}$ of the projected depth of the basalt or its equivalent stratigraphic horizon are black-edged and filled with colors representing the depth range, whereas the symbols for sheet-edge solutions at other depths within the alluvial section are unfilled and plotted in cyan. Boreholes containing basalt are also represented by colored circles.

The edge of the buried basalt flow as partially mapped by the previous geophysical survey (Carr and others, 1975) is marked by red diamond symbols labeled "basalt" on plate 1. These workers found an isolated basalt-flow unit in the vicinity of well UE5i and a larger basaltflow unit in the vicinity of well UE5k. Both these wells, which penetrated the basalt, occur in areas of positive or mixed-sign magnetic anomalies. Two other wells on plate 1, UE11c (near the eastern end of Line F) and UE11a (near the northwest end of Line L), occur in areas of pronounced negative magnetic anomalies and did not penetrate basalt. This relation suggests that the basalt flow is associated with magnetic anomalies of positive or mixed-sign and is unlikely to occur where the magnetic field is strongly negative. The proportionally sized colored symbols on plate 1, along with the red diamond symbols, provide the basis for reinterpreting the location of the edge of the buried basalt, which is shown as a thick red line on the map. As interpreted, the outer edge of the basalt appears as a large oval, elongated in the northwestsoutheast direction and covering much of the south-central portion of the survey area. Evidence for basalt appears to be missing from an elongated area labeled "No Basalt?" and containing borehole UE11c in the interior of the oval. Due to the widely spaced magnetic-profile lines, and problems with the interpretation along some lines such as Line $\mathrm{H}$, there is ambiguity about the actual extent of the basalt. The area of missing basalt could easily extend to the southwest of borehole UE11c, completely separating the sources on Line G from those on the southern part of Line N. Similarly, the area of missing basalt could easily extend south between the southern part of Line $\mathrm{C}$ and Line Q completely separating the sources on these two lines. A major finding of the present study is that the buried basalt extends to the east and southeast of its previously known location. The eastern edge of the basalt lies just to the west of the easternmost westdipping normal fault defining the Frenchman Flat basin. The southern edge of the basalt is about 4,500 ft north of Line K.

Plotted along the magnetic-profile lines are black strike-and-dip symbols representing estimated contact and fault locations from Analytic Signal analysis of upward continued magnetic profiles. The strikes are plotted perpendicular to the average line direction and do not represent the true strike. At locations of significant magnetic-property contrasts, as indicated by high peak values of the analytic signal amplitude, a green dot is superimposed on the black strike-and-dip symbols. Also plotted along the lines are orange strike symbols representing the locations of vertical contacts having significant magnetic-property contrasts. These locations have been estimated from the horizontal gradient magnitude of the upward-continued, reduced- 
to-pole magnetic field along each profile and will tend to be down-dip of the true contact location (Phillips, 2000; Grauch and others, 2001).

Due to the widely spaced magnetic-profile lines, no unique interpretation of fault locations is possible. However, plate 1 does present some possible fault locations, shown as black lines connecting selected black strike-and-dip symbols, orange strike symbols, and a few red fault symbols from the previous geophysical interpretation. The interpreted faults include a north-dipping normal fault arcing around the southern end of the strong positive magnetic anomalies in northern Frenchman Flat; an east-trending, south-dipping normal fault to the south of the thrust fault, which is aligned with a modeled fault to the east and several north-trending basin-and-range faults, both within Frenchman Flat and east of the hills to the north of Frenchman Flat. The sense of fault motion from the previous seismic interpretation, the dip direction from the current magnetic interpretation, and the magnetic-anomaly pattern were all considered during the interpretation of these faults. The large number of estimated faults or contacts (black and orange symbols) along the magnetic-profile lines suggest that many more faults may be present. A more comprehensive shallow seismic and (or) magnetic survey would be needed to map these faults.

\section{Conclusion}

Surface magnetic-survey data have provided insights into the existence and probable locations of additional faults and the distribution of shallow volcanic units in northern Frenchman Flat. The data suggest that the target basalt (BLFA) is more extensive than depicted in the EV base-hydrostratigraphic model and is similar to that of the BLFA depicted in the EV alternative scenario model, which extends it far to the east and southeast (question 1). Several basin-and-range normal faults similar to those observed in the hills north of Frenchman Flat, extend southward under the alluvial cover far enough to disrupt the volcanic units in the vicinity and to the east of the Pin Stripe UGT. It is likely that the vertical displacement is enough to disrupt the Topopah Spring Tuff (TSA in the EV model) down-gradient of the Pin Stripe UGT (question 2).

\section{References Cited}

Barnes, H., Ekren, E.B., Rodgers, C.L., and Hedlund, D.C. 1982, Geology and tectonic maps of the Mercury quadrangle, Nye and Clark Counties, Nevada: U.S. Geological Survey Miscellaneous Geologic Investigations Series Map I-1197, scale 1:24,000.

Bechtel Nevada, 2005, A hydrostratigraphic framework model and alternatives for the groundwater flow and contaminant transport model of Corrective Action Unit 98-Frenchman Flat, Clark, Lincoln and Nye Counties, Nevada: Bechtel Nevada, Department of Energy contract DOE/NV/11718-1064, Las Vegas, Nev., http://www.osti.gov/bridge/purl.cover.jsp?purl=/859292-Y8IoHG/859292.pdf.

Carr, W.J., Bath, G.D., Healey, D.L., and Hazlewood, R.M., 1975, Geology of northern Frenchman Flat, Nevada Test Site: U.S. Geological Survey Report USGS-474-216, NTS-188, 24 p., 3 plates (reproduced in appendix D of this report).

Ekren, E.B., Rogers, C.L., Anderson, R.E., and Orkild, P.P., 1968, Age of basin and range normal faults in Nevada Test Site and Nellis Air Force Range, Nevada, in Nevada Test Site: The Geological Society of America, Inc., Memoir 110, p. 247-250. 
Grauch, V.J.S., and Hudson, M.R., 2007, Guides to understanding the aeromagnetic expression of faults in sedimentary basins - Lessons learned from the central Rio Grande rift, New Mexico: Geosphere, v. 3, no. 6, p. 596-623, doi:10.1130/ges00128.1.

Grauch, V.J.S., Hudson, M.R., and Minor, S.A., 2001, Aeromagnetic expression of faults that offset basin fill, Albuquerque Basin, New Mexico: Geophysics, v. 66, p. 707-720.

Grauch, V.J.S., Sawyer, D.A., Fridrich, C.J., and Hudson, M.R., 1999, Geophysical framework of the southwestern Nevada volcanic field: U.S. Geological Survey Professional Paper 1608, 39 p.

Hansen, R.O., and Simmonds, Marc, 1993, Multiple-source Werner deconvolution: Geophysics, v. 58, no.12, p. 1792-1800.

IT Corporation, 1996, Groundwater flow model documentation package (phase I data analysis documentation, vol. VI): IT Corporation, prepared for Department of Energy/Nevada, Las Vegas, Nev.

Nabighian, M.N., 1972, The analytic signal of two dimensional magnetic bodies with polygonal cross-section-Its properties and use for automated anomaly interpretation: Geophysics, v. 37 , no. 3, p. 507-517.

National Security Technologies, LLC, 2009, A hydrostratigraphic system for modeling groundwater flow and radionuclide migration at the Corrective Action Unit Scale, Nevada Test Site and surrounding areas, Clark, Lincoln, and Nye Counties: National Security Technologies, LLC, Department of Energy contract DOE/NV/25946-630, Las Vegas, Nev.

Phelps, G.A., and Graham, S.E., 2002, Preliminary gravity inversion model of Frenchman Flat basin, Nevada Test Site, Nevada: U.S. Geological Survey Open-File Report 02-363, 23 p., 1 plate, http://geopubs.wr.usgs.gov/open-file/of02-363/.

Phillips, J.D., 1997, Potential-field geophysical software for the PC, version 2.2: U.S. Geological Survey Open-File Report 97-725, 34 p., http://pubs.usgs.gov/of/1997/ofr-97-0725/pfofr.htm.

Phillips, J.D., 2000, Locating magnetic contacts-A comparison of the horizontal gradient, analytic signal, and local wavenumber methods: Society of Exploration Geophysicists, Expanded Abstracts with Biographies, 2000 Technical Program, v. 1, p. 402-405.

Prothro, L.B., and Drellack, S.L., Jr., 1997, Review and reconnaissance of the hydrogeology of Tertiary sedimentary rocks in the vicinity of Frenchman Flat, Nevada Test Site: Bechtel Nevada, Department of Energy contract DOE/NV/11718-155, Las Vegas, Nev.

Roest, W.R., and Pilkington, Mark, 1993, Identifying remnant magnetization effects in magnetic data: Geophysics, v. 58, no. 5, p. 653-659.

Slate, J.L., Berry, M.E., Rowley, P.D., Fridrich, C.J., Morgan, K.S., Workman, J.B., Young, O.D., Dixon, G.L., Williams, V.S., McKee, E.H., Ponce, D.A., Hilderbrand, T.G., Swadley, W.C., Lundstrom, S.C., Ekren, E.B., Warren, R.G., Cole, J.C., Fleck, R.J., Lanphere, M.A., Sawyer, D.A., Minor, S.A., Grunwald, D.J., Laczniak, R.J., Menges, C.M., Yount, J.C., and Jayko, A.S., 1999, Digital geologic map of the map of the Nevada Test Site and vicinity, Nye, Lincoln, and Clark Counties, Nevada, and Inyo County, California: U.S. Geological Survey Open-File Report 99-554-A, scale 1:120,000.

U.S. Department of Energy, 2000, United States nuclear tests, July 1945 through September 1992: U.S. Department of Energy Nevada Operations Office report DOE/NV-209 Revision 15, Las Vegas, Nev.

Workman, J.B., Menges, C., Page, W.R., Taylor, E., Ekren, E.B., Rowley, P.D., Dixon, G.L., Thompson, R.A., and Wright, L.A., 2002, Geologic map of the Death Valley ground-water model area, Nevada and California: U.S. Geological Survey Miscellaneous Field Studies Map MF-2381-A, scale 1:250,000, http://pubs.usgs.gov/mf/2002/mf-2381/. 


\title{
Appendix A. Ground Magnetic Data as Collected
}

\author{
FF_Mag_858_time.xyz headers: \\ x_NCS27CZ_USft $\quad x$ (east)-coordinate in U.S. survey feet, Nevada CS27 central zone, NAD 27 \\ y_NCS27CZ_USft y(north)-coordinate in U.S. survey feet, Nevada CS27 central zone, NAD 27 \\ NGVD29 USft \\ SensorElev29_ft \\ DATE \\ ground elevation in feet, NGVD29 datum \\ Time_UTC \\ LINE \\ MARK \\ LineName \\ LineName2 \\ Mag_nT \\ BaseMag_nT \\ Diurnal_nT \\ AcqDir \\ Operator \\ SensorHt_m \\ TopConsoleHt_m \\ Zorig_USft \\ HDOP \\ PDOP \\ magnetometer elevation in feet, NGVD29 datum \\ date of acquisition (UTC) \\ universal time at aquisition \\ original line number \\ operator doc marks \\ final line name \\ interim line name \\ observed total magnetic field (nanotesla) \\ base station total magnetic field (nanotesla) \\ total magnetic-field anomaly (observed minus base in nanotesla) \\ the aquisition direction \\ operator's initials \\ the height of the magnetometer above ground (meters) \\ the height of the instrument console above ground (meters) \\ GPS elevation (feet) \\ GPS horizontal error \\ GPS position error \\ GPS vertical error \\ NAVD88_USft \\ ground elevation in feet, NAVD88 datum
}

\section{Appendix B. Ground Magnetic Data Reordered into Lines}

FF_Mag_858_lines.xyz headers:

x_NCS27CZ_USft $\quad x$ (east)-coordinate in U.S. survey feet, Nevada CS27 central zone, NAD 27

y_NCS27CZ_USft y(north)-coordinate in U.S. survey feet, Nevada CS27 central zone, NAD 27

NGVD29_USft

SensorElev29_ft

Diurnal_nT

Mag_nT

BaseMag_nT

Dist

Dist1

Operator

ground elevation in feet, NGVD29 datum

magnetometer elevation in feet, NGVD29 datum

total magnetic-field anomaly (observed minus base in nanotesla)

observed total magnetic field (nanotesla)

base station total magnetic field (nanotesla)

distance along line in feet from the original start location

distance along line in feet from the south or west end of line

operator's initials

SensorHt_m

TopConsoleHt_m

AcqDir

Time_UTC

x_UTMmNAD27

y_UTMmNAD27

the height of the magnetometer above ground (meters)

the height of the instrument console above ground (meters)

the aquisition direction

universal time at aquisition

$\mathrm{x}$ (east)-coordinate in meters, UTM zone 11N, NAD 27

$\mathrm{y}$ (north)-coordinate in meters, UTM zone 11N, NAD 27 
NAVD88_USft ground elevation in feet, NAVD88 datum

DATE date of acquisition (UTC)

Notes line crossings and bends in line

\section{Local Geomagnetic-Field Parameters:}

inclination: $\quad 61.9$ degrees down from horizontal

declination: 12.7 degrees east of north

intensity: $\quad 49,638$ nanotesla 


\section{Appendix C. U.S. Geological Survey Procedure for Ground- Based Magnetic Data Collection}

U. S. Geological Survey

Procedure for

Ground-Based Magnetic Data Collection

for the

U.S. Department of Energy, National Nuclear Security Administration

Prepared by

Date

Jeffrey Phillips

USGS/NNSA Program Manager

Date

Bonnie Thompson 


\section{TABLE OF CONTENTS}

Page

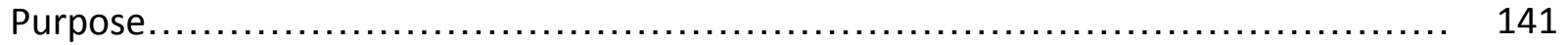

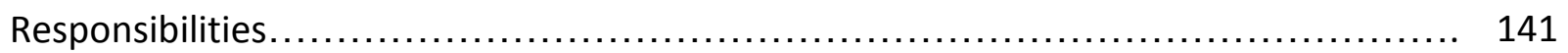

General Field Activities........................................................ 141 


\section{PURPOSE}

This document describes the procedure used by the U.S. Geological Survey (USGS) for groundbased magnetic data collection (indirectly measuring depth below land surface to subsurface geological units by measuring the Earth's magnetic field, which is related to the magnetic properties of those geological units), for the U.S. Department of Energy, National Nuclear Security Administration, Nevada Operations Office (NNSA/NV).

This procedure applies to USGS personnel in the Crustal Geophysics and Geochemistry Science Center working group, working on or off of the Nevada Test Site (NTS) who will be involved with ground magnetic data collection activities conducted for NNSA/NV.

\section{RESPONSIBILITIES}

Project Chiefs and Unit Supervisors - Project Chiefs and Unit Supervisors are responsible for assuring that correct field methods and safety practices are used for all ground-based magnetic data collection activities. Assurance of correct ground-based magnetic data collection methods may be achieved by training in the field or reviewing correct procedures in the office.

\section{GENERAL FIELD ACTIVITIES}

The order of field activities for ground-based magnetic data collection will be to:

1. Prior to going into the field, confirm that Subpart B "NTS Operations Schedule" of the Real Estate / Operations Permit has been sent to and received by the Site Operation Center.

2. If applicable, confirm that all field personnel have a copy of the "Field Activity Work Package" (FAWP). 
3. Travel to site selected for base station magnetometer and park field vehicle(s) nearby and complete walk around of the site identifying any hazardous conditions. Following walk around, complete "Pre-Task Hazard Review" contained in the FAWP. Following this, unload equipment necessary for establishing the magnetic base station from the vehicle(s). Insure that all safety procedures discussed in the FAWP have been followed. Choose best local site for measuring the time-varying magnetic field (typically a flat surface away from drop-offs and metal objects). Assemble the base station and start recording the magnetic base station data. Record GPS location of base station.

4. Travel to start of ground-based magnetic data collection traverse and, if possible, drive the length of the traverse, identifying any hazardous conditions along the way. Park field vehicle(s) at one end of the traverse, and complete "Pre-Task Hazard Review" contained in the FAWP. Following this, unload and assemble equipment necessary for complete ground-based magnetic data collection from the vehicle(s). Insure that all safety procedures discussed in the FAWP have been followed. Remove all magnetic materials from the person conducting the traverse and place in vehicle. Remove vehicle(s) and other magnetic objects from the area around the start of the magnetic traverse. Start recording GPS and magnetic field data. Walk the traverse, avoiding any hazardous conditions noted earlier. Keep vehicles away from the magnetometer during data collection. At the end of the traverse, turn off data recording. Return equipment to vehicle and continue to the start of the next data collection traverse.

5. At the end of the day, travel to the site of base station magnetometer and park field vehicle(s) nearby. Download the base-station magnetometer data to safe storage media. Turn off the base-station magnetometer. If the ground-based magnetic survey is complete, return all base-station equipment to the vehicle. Otherwise leave the base station tripod in place, and return all other equipment to the vehicle.

6. Assumptions for ground-based magnetic data collection traverses include:

a. The terrain along the traverse is stable and accessible. 
b. All locations along the traverse are considered to be radiologically clean sites.

c. Measuring instruments are working properly and the operator performs no errors in observing and recording the data.

7. All data collected must be recorded in the field on digital media or in non-volatile memory, with supplementary information recorded as standard field notes. 


\section{Appendix D. Previous Geophysical Work}

Geology of Northern Frenchman Flat, Nevada Test Site-USGS Report474-216/NTS-188

See file USGS-474-216.pdf. 